\title{
Variations in Teachers' Work, Lives and Effectiveness
}

Christopher Day [1], Gordon Stobart [2], Pam Sammons [1], Alison Kington [1], Qing Gu [1],

Rebecca Smees [2] and Tamjid Mujtaba [2]

[1] School of Education, University of Nottingham

[2] London Institute of Education 


\title{
Research Report
}

No 743

\section{Variations in Teachers' Work, Lives and Effectiveness}

\author{
Christopher Day [1], Gordon Stobart [2], Pam Sammons [1], \\ Alison Kington [1], Qing Gu [1], \\ Rebecca Smees [2] and Tamjid Mujtaba [2]
}

[1] School of Education, University of Nottingham [2] London Institute of Education 


\section{Table of Contents}

\begin{tabular}{|c|c|c|}
\hline & & Page \\
\hline \multicolumn{2}{|c|}{ Index of Figures and Tables } & iii \\
\hline \multirow{2}{*}{\multicolumn{2}{|c|}{ Executive Summary }} & \\
\hline & & $v i$ \\
\hline \multicolumn{2}{|c|}{ PART ONE: Chapter 1} & 1 \\
\hline & & \\
\hline 1.0 & Introduction & 1 \\
\hline 2.0 & Design of the study & 11 \\
\hline 3.0 & Conclusion & 34 \\
\hline \multicolumn{2}{|c|}{ PART TWO: Chapter 2 The Teachers and The Pupils } & 35 \\
\hline & & \\
\hline 1.0 & Introduction & 35 \\
\hline 2.0 & Conclusion & 46 \\
\hline \multicolumn{2}{|c|}{ Chapter 3 Hypotheses and Definitions } & 47 \\
\hline 1.0 & Introduction & 47 \\
\hline 2.0 & Hypotheses & 47 \\
\hline 3.0 & Definition of terms & 48 \\
\hline 4.0 & Conclusion & 52 \\
\hline \multicolumn{2}{|c|}{$\begin{array}{l}\text { PART THREE: Variations in Effectiveness } \\
\text { Chapter } 4 \text { Relative Effectiveness: Using value added approaches to } \\
\text { explore pupil attainment and progress }\end{array}$} & 53 \\
\hline 1.0 & Introduction & 54 \\
\hline 2.0 & $\begin{array}{l}\text { Multilevel Modelling, Contextualised Value Added } \\
\text { Attainment Results }\end{array}$ & 62 \\
\hline 3.0 & Summary of key findings & 78 \\
\hline \multicolumn{2}{|c|}{ Chapter 5 Professional Life Phases } & 82 \\
\hline 1.0 & Introduction & 82 \\
\hline 2.0 & Findings & 86 \\
\hline 3.0 & The dynamic nature of professional life phases & 118 \\
\hline 4.0 & Conclusion & 120 \\
\hline \multicolumn{2}{|c|}{ Chapter 6 Continuing Professional Development (CPD) } & 123 \\
\hline 1.0 & Introduction & 123 \\
\hline 2.0 & Findings & 124 \\
\hline 3.0 & Conclusion & 140 \\
\hline \multicolumn{2}{|c|}{ Chapter 7 The Emotional Contexts of Teaching: Teacher identities } & 142 \\
\hline 1.0 & Introduction & 142 \\
\hline
\end{tabular}




\begin{tabular}{|c|c|c|}
\hline 2.0 & Findings & 154 \\
\hline 3.0 & The interactive nature of identity Scenarios & 182 \\
\hline 4.0 & Conclusion & 185 \\
\hline \multicolumn{2}{|c|}{$\begin{array}{l}\text { PART FOUR: Chapter } 8 \text { Commitment and Resilience: How teachers } \\
\text { sustain their effectiveness }\end{array}$} & 188 \\
\hline 1.0 & Introduction & 188 \\
\hline 2.0 & $\begin{array}{l}\text { Commitment and Resilience: Variations in VITAE } \\
\text { teachers' effectiveness }\end{array}$ & 221 \\
\hline 3.0 & $\begin{array}{l}\text { Conclusions: How teachers sustain their commitment, } \\
\text { resilience and effectiveness }\end{array}$ & 236 \\
\hline \multicolumn{2}{|c|}{$\begin{array}{l}\text { PART FIVE: Chapter } 9 \text { Associations Between Variations in Teachers' } \\
\text { Work, Lives and Effectiveness: Summary of Key Messages and Core } \\
\text { Messages }\end{array}$} & 242 \\
\hline 10 & Introduction & 242 \\
\hline 2.0 & Variations in Effectiveness & 243 \\
\hline 3.0 & $\begin{array}{l}\text { Moderating Factors in Teachers' Work, Lives and } \\
\text { Effectiveness }\end{array}$ & 244 \\
\hline 4.0 & Teacher Identities and Effectiveness & 248 \\
\hline 5.0 & $\begin{array}{l}\text { Mediating Influences on Teachers' Work, Lives and } \\
\text { Effectiveness }\end{array}$ & 251 \\
\hline 6.0 & The Influence of Pupils & 253 \\
\hline 7.0 & School Leaders, Colleagues and Effectiveness & 254 \\
\hline 8.0 & Work and Life Interaction (Well-Being) and Effectiveness & 255 \\
\hline 9.0 & Continuing Professional Development and Effectiveness & 256 \\
\hline 10.0 & Commitment, Resilience and Effectiveness & 257 \\
\hline 11.0 & Conclusions & 259 \\
\hline 12.0 & Core Messages & 261 \\
\hline \multicolumn{2}{|l|}{ References } & 264 \\
\hline \multirow{2}{*}{\multicolumn{2}{|c|}{ Appendices }} & \\
\hline & & I \\
\hline Appendix 1 & Summary of Working Papers & $I$ \\
\hline Appendix 2 & $\begin{array}{l}\text { Technical Report on Value Added Analysis of Pupil Key } \\
\text { Stage Outcomes Across Three Cohorts }\end{array}$ & $I V$ \\
\hline Appendix 3 & Examples of Transition Teachers (Professional Life Phase) & $X V I$ \\
\hline Appendix 4 & \multirow{2}{*}{ Professional Life Phase Illustrations } & $X V I I I$ \\
\hline & & \\
\hline
\end{tabular}




\section{Index of Figures and Tables}

\section{Chapter 1}

\section{Figures}

Figure 1.1: Relational and Relative Effectiveness

Figure 1.2: Hypothesised initial model of factors contributing to variations in teacher effectiveness

Figure 1.3: Teachers' selves as factors moderating effectiveness

Figure 1.4: $\quad$ Data sources and types

Figure 1.5: $\quad$ Summary of sampling design

Figure 1.6: Case Study Primary Teachers Compared to National Profile Numbers of Years in Service

Figure 1.7: Case Study Secondary Teachers Compared to National Profile Numbers of Years in Service

Figure 1.8: Case Study Primary Schools Compared to National Profile Numbers of Pupils on Roll

Figure 1.9: $\quad$ Case Study Secondary Schools Compared to National Profile Numbers of Pupils on Roll

Tables

Table 1.1: $\quad$ Primary schools case study matrix (75 schools) - Banded performance at KS 2 (level 2 and above)

Table 1.2: $\quad$ Secondary schools case study matrix (25 schools) - Banded performance at KS 3 (level 5 and above)

Table 1.3: $\quad$ Timetable of data collection methods

Table 1.4: $\quad$ Size of primary schools in case study sample compared to national figures

Table 1.5: $\quad$ Size of secondary schools in case study sample compared to national figures

Table 1.6: $\quad$ Primary school pupils' eligibility for free school meals compared to national figures

Table 1.7: Secondary school pupils' eligibility for free school meals compared to national figures

\section{Chapter 4}

Tables

Table 4.1:

Table 4.2:

Table 4.3:

Table 4.4:

Categorisation of contexualised residuals

The numbers of pupils, classes and school in the multilevel analysis

Child and school factors significantly related to attainment (Year 2)

Child and school factors significantly related to progress after control for prior attainment (Years 6 and 9)

Table 4.5: $\quad$ Intra school correlations - Maths and English value-added results for Year 6 and Year 9 teachers

Table 4.6: $\quad$ Distribution of Value Added results for Year 6 and 9 outcomes

Table 4.7: Relationships between teachers' relative effectiveness (value-added) across cohorts 1 and 2 for the Year 6 sample

Table 4.8: Relationships between teachers' relative effectiveness (value-added) across cohorts 1 and 2 for the Year 9 sample (controlling for class ability level)

Table 4.9: $\quad$ Comparison of relative effectiveness in English and maths - Year 6 teachers (cohort 1)

Table 4.10: $\quad$ Comparison of relative effectiveness in English and maths - Year 6 teachers (cohort 2)

Table 4.11: $\quad$ Number and Gender of Teachers with Value Added Results for at least one of the first two cohorts 
Table 4.12: $\quad$ Percentage of Teachers with Value Added Results for both Year Cohorts

Table 4.13: Numbers of Broadly More Effective and Less Effective Teachers in Cohorts 1 and 2 by Year group

\section{Chapter 5}

\section{Figures}

Figure 5.1:

Figure 5.2:

Figure 5.3:

Figure 5.4:

Figure 5.5:

Figure 5.6:

Figure 5.7:

Figure 5.8:

Figure 5.9:

Figure 5.10:

Figure 5.11:

Figure 5.12:

Figure 5.13:

Figure 5.14:

Figure 5.15:

Figure 5.17:

Figure 5.16:

Figure 5.17:

Figure 5.18:
Developing Efficacy (0-3) (N=15)

Reduced Efficacy (0-3) N=10)

Variations in levels of commitment (4-7) $(\mathrm{N}=75)$

Key influences on teachers with growing identity, increased efficacy (4-7) $(\mathrm{N}=36)$

Key influences on teachers who had sustained a moderate level of efficacy (4-7) $(\mathrm{N}=23)$

Key influences on teachers whose identity and efficacy are at risk (4-7) $(\mathrm{N}=15)$

Variations in levels of commitment (8-15) $(\mathrm{N}=86)$

Key influences on teachers with sustained engagement (8-15) (N=62)

Key influences on teachers with decreased motivation (8-15) $(\mathrm{N}=20)$

Key influences on teachers with sustained

Motivation (16-23) $(\mathrm{N}=23)$

Key influences on teachers with decreased motivation (16-23) (N=6)

Variations in levels of commitment (16-23) $(\mathrm{N}=46)$

Variations in levels of commitment (24-30) $(\mathrm{N}=52)$

Key influences on teachers with sustaining motivation (24-30) (N=28)

Key influences on teachers who are holding on but losing motivation (24-30) $(\mathrm{N}=24)$

Key influences on teachers who felt tired and trapped (31+) $(\mathrm{N}=8)$

Key influences on teachers who sustained commitment $(31+)(\mathrm{N}=14)$

Key influences on teachers who felt tired and trapped $(31+)(\mathrm{N}=8)$

Variations in levels of motivation $(31+)(\mathrm{N}=22)$

\section{Chapter 6}

Figures

Figure 6.1:

Figure 6.2:

Figure 6.3:

Figure 6.4:

Figure 6.5:

Figure 6.6:

Figure 6.7:

Figure 6.8:

Figure 6.9:

Figure 6.10:

Figure 6.11:

Figure 6.12:

Figure 6.13:

Figure 6.14:
Summary of Teachers' Positive Experiences of CPD

Q17. How satisfied are you with the extent you get time to reflect on your teaching? (By professional life phase)

Q18. How satisfied are you with the time and opportunity to learn with and from colleagues? (By professional life phase)

CPD Dimensions and Professional life phase 0-3

CPD Dimensions and Professional life phase 4-7

CPD Dimensions and Professional life phase 8-15

CPD Dimensions and Professional life phase 16-23

CPD Dimensions and Professional life phase 24-30

CPD Dimensions and Professional life phase 31+

Q14. How satisfied are you with your overall current CPD opportunities (by

FSM band)?

Q19. How satisfied are you with the balance of professional development opportunities your school has supported to meet your needs and those the school?

Q17. How satisfied are you with the extent to which you get time to reflect on your teaching?

CPD Dimensions and FSM (0-3)

CPD Dimensions and FSM (4-7) 
Figure 6.15: $\quad$ CPD Dimensions and FSM (8-15)

Figure 6.16: CPD Dimensions and FSM (16-23)

Figure 6.17: $\quad$ CPD Dimensions and FSM (24-30)

Figure 6.18: $\quad$ CPD Dimensions and FSM (31+)

Tables

Table 6.1: Teachers' Views of CPD by gender

\section{Chapter 7}

Figures

Figure 7.1

Figure 7.2:

Figure 7.3:

Figure 7.4:

Figure 7.5:

\section{Tables}

Table 7.1:

Table 7.2:

Table 7.3:

Table 7.4:

Table 7.5:

Chapter 8

Figures

Figure 8.1:

Figure 8.2:

Figure 8.3:

Figure 8.4:

Figure 8.5:

Figure 8.6:

Figure 8.7:

15)

Figure 8.8: $\quad$ School Contexts by Teacher Scenarios

Figure 8.9: Teacher Professional Life Phase and Value Added Pupil Attainment (Cohort1)

Figure 8.10: Teacher Professional Life Phase and Value Added Pupil Attainment (Cohort2)

Tables

Table 8.1: A summary of the negative and positive factors affecting teachers' motivation and commitment

Table 8.2: $\quad$ Crosstabulation of professional life phase trajectories and pupil attainment (Cohort 1)

Table 8.3: $\quad$ Crosstabulation of professional life phase trajectories and pupil attainment (Cohort 2)

\section{Chapter 9}

Tables

Table 9.1: Teachers' Professional Life Phases

Table 9.2: $\quad$ Teacher Identity Scenarios 


\title{
EXECUTIVE SUMMARY
}

\section{Variations in Teachers' Work, Lives and Effectiveness (VITAE)}

\begin{abstract}
Aims
The VITAE project was commissioned by DfES to investigate factors contributing to variations in teachers' effectiveness at different phases of their careers, working in a range of schools in different contexts. The aim was to identify those factors which contributed to these variations and why teachers do, or do not, become more effective over time. The scope of this research is internationally unique. It involved both primary and secondary teachers of different age and experience, working in a range of schools, over a three year period. It examined influences upon and between their professional and personal lives and relations between these and their effectiveness in terms of pupil attainment. The research took place between 2001-5, a time of continuing educational policy changes in England which affected teachers' work. Among these major changes were the introduction of the National Key Stage 3 Strategies in English and maths, National primary strategies through Excellence and Enjoyment (DfES, 2003a) and the National Agreement on Raising Standards and Tackling Workload (DfES, 2003b). These and other changes were designed not only to raise standards of teaching, learning and achievement in schools but also ensure that bureaucratic demands upon teachers were minimised. The research was jointly conducted by the University of Nottingham and the University of London, Institute of Education.
\end{abstract}

\section{Core Messages}

1. There are significant variations in both teachers' perceived and relative effectiveness across year groups and sectors. Teachers' capacities to be effective are influenced by variations in their work, lives and identities and their capacities to manage these.

2. Teachers' effectiveness is not simply a consequence of age or experience.

3. Teachers' professional life phases are core moderating influences on teachers' effectiveness. 
4. Teachers' capacities to sustain their effectiveness in different phases of their professional lives are affected positively and negatively by their sense of professional identity.

5. Teachers' sense of identity is a major contributing factor to teachers' commitment and resilience. It is neither intrinsically stable nor unstable, but can be affected positively or negatively by different degrees of tension experienced between their own educational ideals and aspirations, personal life experiences, the leadership and cultures in their schools, pupils' behaviour and relationships and the impact of external policies on their work.

6. Commitment and resilience are found to be crucial to teachers' abilities to sustain effectiveness. Positive relationships with school leaders and colleagues' support and sustain teachers' commitment, resilience and effectiveness.

7. CPD has a consistently positive influence on teachers across all professional life phases, though needs and concerns vary in relation to these.

8. The extent to which teachers sustain their commitment (i.e. are resilient) is dependent upon their capacities to manage interactions between personal, work and professional factors which mediate their professional lives and identities positively or negatively.

9. The quality of leadership, both at school and department level, relationships with colleagues and personal support are key influencing factors on teachers' motivation, commitment and quality retention.

10. Teachers who work in primary schools are more likely to sustain their commitment over a career than secondary teachers.

11. Teachers who work in schools in more challenging socio-economic contexts are more likely to experience greater challenges to their health, well-being, and thus resilience, than those who work in relatively more advantaged schools.

12. There is a statistically significant association between the levels of pupils' progress and attainment at KS1, 2 and 3 (English and maths) and the extent to which teachers sustain their commitment. 


\section{Research Design}

The key questions addressed were:

1. Does teacher effectiveness vary from one year to another and in terms of different pupil outcomes and do teachers necessarily become more effective over time? If so, how and why?

2. What are the roles of biography and identity?

3. How do school and/or department leadership influence teachers' practice and their effectiveness? What particular kinds of influence does CPD have on teachers' effectiveness?

4. Are teachers equally effective for different pupil groups or is there differential effectiveness relating (for example) to gender or socio-economic status? If so, how and why?

5. Do the factors which influence effectiveness vary for teachers working in different school cultures contexts, or for different kinds of outcomes? If so, how and why?

6. Do factors influencing teachers' effectiveness vary across different sectors (primary and secondary) and different age groups (Key Stage 1, 2 and 3)? If so, how and why?

The research conceptualised effectiveness as involving both teachers' perceptions of their own effectiveness and their impact on pupils' educational outcomes. Central to the research design were: i) twice-yearly recorded interviews of the 300 teachers in the research. These monitored their perceptions of effectiveness and the positive and negative influences upon these; and ii) the extent to which these related to pupil progress and attainment. Value-added analyses of pupils' progress and attainment and an annual pupil attitude survey were used to measure pupil outcomes and explore differences between classes and teaching groups. This mixed methodology also enabled the identification of teachers who appeared to be more, or less, successful with their pupils over a three-year period and why this was so.

\section{The teachers and the schools}

The sample for this research was drawn from seven local authorities (LAs) which were nationally, and geographically, representative and included both large shire counties and authorities in deprived inner cities. An initial teacher survey in these LAs 
assisted in the selection of samples of 100 schools and 300 case study teachers for the study. Half of the sample were primary teachers (Years 2 and 6) from 75 primary schools. The secondary teachers taught English or mathematics to Year 9 pupils in 25 schools. These teachers were broadly representative of the national profile in terms of age and gender. The schools themselves were selected to be representative in terms of Free School Meal (FSM) and overall attainment levels. Schools operating in more disadvantaged circumstances were slightly over-represented in the sample on the assumption of higher mobility and drop-out. The choice of teachers in Years 2, 6 and 9 for the sample was so that the key stage national curriculum test results could be used as pupil outcome measures.

\section{Methods of data collection}

The main data concerning perceived effectiveness were collected through semistructured, face-to-face interviews with teachers. These were supplemented at various stages of the research by document analysis, interviews with school leaders and groups of pupils. The evidence was gathered in an iterative and evolving process consistent with the use of grounded theory methods. Guided by a critical examination of the literature, an initial questionnaire for teachers was developed. The analysis of data collected from this questionnaire led to the development of interview schedules and further follow-up interviews. Group interviews with pupils $(10 \%$ of the classes of the participating teachers) were used to extend findings from a pupil attitudinal questionnaire.

Measures of teachers' effectiveness as expressed through improvements in pupils' attainment were created using baseline test results at the beginning of the year and matched with pupils' national curriculum results at the end. This enabled progress over the school year to be analysed and differences in the relative 'value added' identified using multilevel statistical techniques. These were adjusted for individual background factors such as gender and FSM eligibility as well as pupils' prior attainment. The results identified those teachers of similar experience and working in schools in similar contexts whose pupils had made relatively more, or less, progress than would have been predicted given their pupil intake. Using both qualitative and quantitative data, profiles of teachers were then constructed to see if patterns emerged in terms of perceived and relative (value-added) effectiveness. 


\section{Key Findings}

The project's general findings are summarized in ten sections, which focus upon knowledge generated by VITAE. These findings link to the main sections of the report.

\subsection{Teacher Development and Effectiveness}

1.1 Teacher development is not a linear process. Experience and expertise do not fully account for differences in teachers' perceived and relative effectiveness. Effectiveness does not necessarily grow in relation to time in teaching (experience).

1.2 Six professional life phases, relating to experience, rather than age or responsibilities, were identified.

Key characteristics of the six professional life phases were:

0-3 years - Commitment: Support and challenge. The focus here was a developing sense of efficacy in the classroom. This was a phase of high commitment. A crucial factor in a successful negotiation of this period was the support of school/department leaders. Poor pupil behaviour was seen as having a negative impact. Teachers in this professional life phase had either a developing sense of efficacy $(60 \%)$ or a reduced sense of efficacy $(40 \%)$.

4-7 years - Identity and efficacy in the classroom. The key characteristic was the increased confidence about being effective teachers. Seventy eight per cent of teachers in this phase had taken on additional responsibilities, which further strengthened their emerging identities. The management of heavy workloads had a negative impact on some teachers. Teachers in this professional life phase were grouped as a) sustaining a strong sense of identity, self-efficacy and effectiveness (49\%); b) sustaining identity, efficacy and effectiveness (31\%); or c) identity, efficacy and effectiveness at risk $(20 \%)$. 
8-15 years - Managing changes in role and identity: Growing tensions and transitions. This phase was seen as a watershed in teachers' professional development. Eighty per cent had posts of responsibility and for many there were decisions to make about progression in their career. Of the teachers in this professional life phase, 76 per cent were judged to have sustained engagement, with 24 per cent showing detachment/ loss of motivation.

\section{6-23 years - Work-life tensions: Challenges to motivation and commitment.}

As well as managing heavy workloads, many were facing additional demands outside school (health issues or from partners, children or as carers) as well as additional responsibilities in school, making work-life balance a key concern. The struggle for balance was often reported as a negative impact. The risk at this stage was a feeling of career stagnation linked to a lack of support in school and negative perceptions of pupil behaviour. The three sub-groups in this phase were: a) further career advancement and good results leading to increased motivation/commitment (52\%); b) sustained motivation, commitment and effectiveness (34\%); or c) workload/managing competing tensions/career stagnation leading to decreased motivation, commitment and effectiveness (14\%).

24-30 years - Challenges to sustaining motivation. Maintaining motivation in the face of external policies and initiatives, which were viewed negatively, and declining pupil behaviour was the core struggle for teachers in this phase. While 60 per cent of primary teachers in this phase were judged to have retained a strong sense of motivation, over half the secondary teachers were rated as losing motivation. Teachers in this phase were categorised as either sustaining a strong sense of motivation and commitment (54\%); or holding on but losing motivation (46\%).

$31+$ years - Sustaining/declining motivation, coping with change, looking to retire. For the majority of teachers this was a phase of high commitment. Of the small group of teachers in this phase (22), almost two thirds were judged to have high motivation and commitment. Positive teacher-pupil relationships and pupil progress were the basis of this. Government policy, health issues and pupil behaviour were often perceived as the most negative factors for this group. Teachers in this phase were seen as either maintaining commitment (64\%); or 'tired and trapped' (36\%). 
1.3 The capacity of teachers to manage work-life tensions in different professional life phases and in different school contexts is key to their effectiveness. Within each professional life phase the majority of teachers reported increasing effectiveness, though there were different concerns and challenges in each

phase. For example, the 8-15 years phase of teachers' professional lives is a 'watershed'. It is where teachers face growing tensions in managing their professional and personal lives.

1.4 Across all professional life phases a supportive school culture was a key factor in sustaining motivation and a sense of effectiveness. These were also affected by school phase and SES contexts as measured by the percentage of pupils eligible for free school meals (FSM).

1.5 The majority (74\%) of teachers in all phases were either sustaining or increasing their commitment. However, this proportion varied by professional life phase.

\subsection{Professional Identities: the emotional contexts of teaching}

Effective teaching requires emotional and intellectual investments from teachers which draw upon personal and professional capacities and experience, knowledge and skills. Teachers' well-being and perceived effectiveness at work were affected by life experiences and events both positively and negatively. The majority of teachers (67\%) had a positive sense of identity. They identified a close association between their sense of positive, stable identity and their self-efficacy and agency - their belief that they could 'make a difference' in the learning and achievement of their pupils. However, one in three teachers did not. Teacher identity comprises the interactions between professional, situated and personal dimensions. The professional dimension reflects social and policy expectations of what a good teacher is and the educational ideals of the teacher. The situated dimension is located in a specific school and context and is affected by local conditions (i.e. pupil behaviour, level of disadvantage), leadership, support and feedback. The personal dimension is located in life outside school and is linked to family and social roles. 
2.1 We identified four Scenarios in which teachers managed the interplay of the three dimensions which constituted their identity. The first was holding the three in balance. Over a third of teachers were in this group, with over half coming from primary schools and the majority coming from more advantaged schools. The second Scenario was the largest group (131 teachers), predominantly from the 4-15 years phases. This Scenario involved one dimension being dominant e.g. immediate school demands dominating and impacting on personal and professional life which affected 44 per cent of this Scenario group $(\mathrm{N}=57)$. Most were highly committed and saw themselves as effective. In the third Scenario two dimensions dominated and impacted on the third e.g. teachers might be experiencing health problems (personal) in conjunction with difficult collegial relationships (situated). Over half this smaller group (44) were secondary teachers. While their motivation levels generally remained high, they were more negative about their well-being and work-life balance. The fourth Scenario represents a state of extreme fluctuation in which each dimension is unstable e.g. teachers might be experiencing adverse family circumstances (personal), challenging pupil behaviour (situated) and negative impact of external policy (professional). Of the small group of teachers (18) who experienced this Scenario, the majority (14) worked in FSM 3/4 schools ${ }^{1}$.

2.2 Teacher identity comprises the interactions between professional, situated and personal dimensions. There is a close association between teachers' sense of positive, stable professional identity and their perceived effectiveness.

2.3 Teacher identities are neither intrinsically positively or negatively stable, nor intrinsically fragmented. They are subject to varying degrees of fluctuation and will display characteristics of stability and/or fragmentation at different times during a career, depending on the management of personal, professional and situated factors.

2.4 In developing positive, resilient identities, key mediating factors are supportive school/department leadership, colleagues and family.

\footnotetext{
${ }^{1}$ Pupils' free school meal (FSM) eligibility is divided into four categories. FSM 1 describes schools with $0-8 \%$ of pupils eligible for free school meals. This percentage rises to 9-20\% for FSM 2 schools, $21-35 \%$ for FSM 3 schools, and over 35\% for FSM 4 schools.
} 
2.5 Significant negative factors are pupil behaviour and workload.

2.6 Schools which were concerned with the effectiveness of their teachers were alert to their socio-emotional needs.

\subsection{Leadership, School Cultures and Effectiveness}

3.1 Eighty per cent of teachers in all professional life phases, scenarios, school phase and contexts found leadership, colleagues and culture to be key influences, positive or negative, upon their capacity to be effective. The quality of leadership, both at school and departmental level, relationships with colleagues and personal support were major factors that influenced their sustained commitment and their motivation to remain in or leave a school.

3.2 Positive relationships with school leaders and colleagues were found to support and sustain teachers' commitment and effectiveness.

3.3 Professional care by school leaders was a core component of supportive school cultures.

3.4 Teachers in all primary schools are more likely to sustain their commitment and perceived effectiveness than their secondary school colleagues.

\subsection{The Influence of CPD on Effectiveness}

4.1 CPD has a consistently positive influence on teachers across all professional life phases. Eighty per cent of primary teachers were satisfied with their CPD opportunities, though satisfaction dropped to 66 per cent for secondary teachers. Seventy-five per cent of primary teachers and 60 per cent of secondary teachers were satisfied with the quality of their CPD.

4.2 The main dissatisfaction for over $75 \%$ of the teachers was with the time available to reflect on their teaching and to learn from colleagues. Seventy per cent of teachers across all professional life phases felt that heavy workload, a lack of time and financial constraints were important inhibitors in their pursuit of professional development.

4.3 Teachers in phases 0-3 and 31+ were primarily drawn to CPD that addressed classroom knowledge. At 4-7 personal development became the most frequently mentioned. Middle career teachers (8-30) reported an increasing proportion of role effectiveness activities, though personal development remained important. 
4.4 Teachers in more disadvantaged schools generally placed more emphasis on classroom knowledge related CPD and CPD which related to their socioemotional professional needs than those in more advantaged schools, where the demands were more evenly spread.

4.5 Collaborative learning with colleagues within and across schools was rated as a highly important form of CPD.

4.6 Schools did not appear to offer a range of CPD experiences which related to the needs and concerns specific to teachers' professional life phases. The experiences which teachers described overwhelmingly concerned in-service courses and events which focused on classroom knowledge and skill updating, the implementation of policy ad other organisation related matters.

4.7 CPD activities which focused upon role effectiveness were regarded as important by teachers in middle and later professional life phases, particularly those with 8-15 and 16-23 years of experience in which 76.5 per cent and 91.3 per cent respectively held additional out-of-classroom responsibilities.

\subsection{Pupil Progress and Attainment}

5.1 Differences in the characteristics of pupils do not fully account for the differences in levels of pupil attainment or progress between classes and teaching groups. Variations between teachers in terms of promoting pupil progress in Years 6 and 9 were highly significant and accounted for between $15 \%$ and $30 \%$ of the variance in pupil progress.

5.2 The majority of teachers were sustaining or building their commitment. Pupils of teachers in each professional life phase who were sustaining or continuing to build their commitment (74\%) were more likely to attain results at or above the level expected, regardless of school context. Pupils of teachers who were not sustaining their commitment $(26 \%)$ were more likely to attain results below the level expected, regardless of school context.

5.3 The qualitative data revealed no systematic links of relative effectiveness with age, professional life phase or gender. How well teachers were managing their work-life balance did appear to relate to effectiveness. Relatively less effective teachers were also more likely to report negative personal factors, pupil behaviours or policy initiatives which were impacting on their work. 
5.4 While teachers varied in their effectiveness from year to year, the tendency was for relatively more effective teachers to remain effective and less effective teachers remain less effective. Few moved from effective to ineffective or vice versa across one year to another.

5.5 Pupils in Year 9 made more progress if taught in higher attaining teaching groups that had a higher average level of attainment and less progress when taught in lower attaining groups, even taking into account their own prior attainment levels.

\subsection{The Influence of Pupil Relationships and Behaviour on Effectiveness}

6.1 Positive relationships with pupils are central to teachers' self-efficacy and ability to teach well. Ninety per cent of teachers reported positive relationships, irrespective of their levels of motivation and commitment.

6.2 Nonetheless, $50 \%$ of the teachers rated pupil behaviour as having a negative impact. Nearly two-thirds (65\%) of secondary and over half (51\%) of primary teachers identified poor behaviour as an issue that, at times, hindered their teaching. Primary teachers $(49 \%)$ were more positive than secondary teachers $(35 \%)$. Teachers in the $8-15$ years professional life phase were the most positive $(66 \%)$.

6.3 Teachers in the first three years of their careers were particularly concerned about their ability to manage disruptive pupils.

6.4 There is evidence that pupils' attitudes to school and their teachers tend to be less positive in Year 9 than in Years 2 and 6. The different pupils in each of the three years of the survey showed similar attitudes towards their school and their teachers.

6.5 FSM pupils were consistently more negative about safety and bullying in school than non-FSM pupils. However, most FSM pupils were more strongly positive about their schools and teachers than others.

6.6 Teachers across the sample reported the disruptive behaviour of a minority of pupils which impeded their ability to be effective. Teachers who worked in schools in challenging socio-economic contexts experienced a relatively greater range of negative pupil behaviour influences than those who did not. 


\subsection{The Influence of School Context and School Phase on Effectiveness}

7.1 There are different cultures in primary and secondary schools which impacted upon teachers' capacities to sustain commitment. A total of 87 per cent ( $\mathrm{N}=136)$ of primary teachers spoke positively regarding situated factors such as leaders and colleagues, as compared to 68 per cent $(\mathrm{N}=94)$ of secondary teachers. Moreover, 29 per cent $(\mathrm{N}=45)$ of primary teachers spoke negatively about pupil behaviour, as compared to 53 per cent $(\mathrm{N}=73)$ of secondary teachers. School phase appears to have a significant positive influence on teachers' commitment and resilience, particularly in their mid-career professional life phases. Whereas 85 per cent of primary teachers in the 8-15 professional life phase were sustaining their engagement, only 63 per cent of secondary teachers were doing so. Conversely, 37 per cent of secondary school teachers had a sense of detached engagement, as against 15 per cent of primary teachers in this professional life phase.

7.2 Teachers who work in challenging socio-economic contexts are not necessarily less effective than others.

7.3 Teachers who work in challenging socio-economic contexts are more likely to experience greater challenges to their commitment, resilience and effectiveness than those who work in relatively more advantaged school contexts. Whereas $61 \%$ of teachers in FSM 1 and 2 schools experienced relatively stable Scenarios, $74 \%$ of teachers in FSM 3 and 4 schools experienced relatively unstable Scenarios. However, the majority (84\%) of teachers working in FSM 4 schools in the sample, were resilient. It is the extent to which the experiences of these challenges are ameliorated by the support received which determines whether teachers are able to maintain their commitment and effectiveness.

\subsection{Teachers' Initial Motivation and Sustained Commitment}

8.1 Sustaining initial commitment is a key factor in teachers' long term capacities to be effective (perceived and relative).

What motivates teachers and sustains their level of commitment can impact on their effectiveness. Of the 1143 respondents to the initial survey, 68 per cent of teachers stated that their motivation for becoming a teacher was either 'working with children' 
(51\%) or 'wanting to make a difference' $(17 \%)$. Thirty two per cent of secondary teachers gave interest in a particular subject as their reason, a motivation hardly found in primary teachers. When motivation was followed up in interviews, 71 per cent reported that the original motivation still held. Whether or not there had been a shift in motivation, the vast majority $(89 \%)$ of the project teachers intended to remain in teaching.

\subsection{Commitment, Resilience and Effectiveness}

9.1 There are significant relationships between teachers' commitment and their perceived (relational) and relative effectiveness (see 1.0).

- Commitment (motivation, belief, aspiration) is a necessary but insufficient condition for both perceived and relative effectiveness.

- Resilience, the ability of an individual to withstand or recover quickly from difficult conditions, is a necessary condition for sustaining commitment.

- Commitment and resilience influence, and are influenced by, professional life phase and identity which, in turn, are affected by personal, situated and professional influences.

9.2 Teachers' capacities to manage their professional lives and identities are mediated positively or negatively by personal factors (life events and circumstances), situational factors (leadership, colleagues, pupil relationships and behaviour) and professional factors (policy, educational ideals). The ways these are managed can affect teachers' commitment and resilience.

9.3 The majority of teachers $(74 \%)$ reported a sustained commitment to their work and were positive about contextual factors. Primary teachers were more likely to have sustained their commitment $(81 \%)$ than their secondary colleagues. Pupils of teachers who were on an upward trajectory in each professional life phase were more likely to attain results at or above the level expected, regardless of school context. Pupils of the 26 per cent of teachers who were on a downward commitment trajectory were more likely to attain results below the level expected, regardless of school context. 
9.4 Teachers in FSM 3/4 schools were more likely to experience more complex Scenarios with a greater intensity and persistence of challenges than those in socio-economically advantaged FSM 1/2 schools. These challenges were principally concerned with negative pupil behaviour and lack of parental support.

9.5 The commitment of 26 per cent of the sample was declining. The most frequently cited causes for this were workload (68\%), pupil behaviour (64\%) and poor leadership (58\%).

9.6 Of the personal factors investigated, personal health issues were more pronounced for teachers in less socio-economically advantaged schools (FSM 3 and 4). Thirty-seven per cent of primary teachers and 63 per cent of secondary teachers who cited personal influences reported that health issues were impacting on motivation and commitment. This compared with 25 per cent of primary teachers and 42 per cent of secondary teachers in FSM 1and2 schools.

\section{Summary}

This research has shown that knowledge of the variations in teachers' work, lives, and identities in the process of managing work-life tensions over the course of a career in different contexts is key to understanding variations in teacher effectiveness. There were a number of factors which affected all teachers, but there were noticeable differences observed in the way that these factors impacted upon teachers in different professional life phases and in different Scenarios. These factors challenged their capacities to sustain commitment in different school contexts (as defined by FSM). Their capacity to sustain effectiveness was related to the ways they managed and were supported in managing the interactions between their i) beliefs, values, life experiences and events (personal dimension); ii) professional life phases, professional beliefs and values, and external policies (professional dimension); iii) socio-economic context of their schools, composition of the pupil population, school leadership and colleagues (situated dimension). 
These three sets of influences contributed positively or negatively to the teachers' capacities to manage the different work and life Scenarios which sometimes threatened to de-stabilise their positive professional identities, commitment and capacity to be effective, pursue their original call to teach and sustain commitment in the profession. Most of the teachers in VITAE were continuing to do so, even when facing adverse circumstances and complex Scenarios. Many, but not all, exercised a strong sense of resilience in managing negative influences and rebounding from adversity.

Thus, resilience - the ability of an individual to withstand or recover quickly from difficult conditions - may be said to be a necessary quality for all, and especially those who experience changing or challenging circumstances. This research was shown that teachers' commitment, underpinned by their sense of vocation, plays an essential role in their endeavours to sustain effectiveness throughout their professional lives, in both favourable and unfavourable circumstances.. Research on teacher retention tends to focus on factors affecting teachers' decisions to leave the teaching profession. This research provides a new perspective, focussing upon teacher retention in terms of teacher effectiveness. It has found that what is required is a better understanding of the moderating and mediating factors which enable teachers, not simply to remain in teaching but, more importantly, to sustain their commitment and, therefore, effectiveness over the whole of their careers. 


\section{PART ONE CHAPTER ONE}

\subsection{Introduction}

The VITAE project aimed to identify factors that affect teachers' work and lives and how these impact upon the teachers and their work with pupils over time. It is the first large scale study to explore how teachers' work and lives vary as a result of these factors and possible connections between these variations and their effects on pupils. The study has identified professional life phases and teachers' identities as key moderating influences in their effectiveness. It has found that these are directly affected by three mediating factors: personal (life), situated (leadership, colleagues, pupils), and professional (policies, roles). The ways in which these are managed affect the extent to which teachers are able to sustain their commitment and capacities for resilience. The findings from the study shed new light upon the meanings of effectiveness, the complex nature and trajectories of teachers' work and lives, the interaction between these, and the influences of different school contexts, phases and identity Scenarios upon their capacities to be effective. A key finding is that there are significant relationships between teachers' commitment, resilience and pupil progress and attainment.

VITAE adopted a multi-method design which combined a range of quantitative and qualitative methods of data collection and analysis. The study was carried out over a three year period and was intended to involve 300 primary and secondary teachers in 100 schools located in different geographical and socio-economic contexts ${ }^{2}$. The teachers were representative of the national teacher profile in terms of age, experience and gender. The schools were also representative of the national profile of phase, SES, size. They were sampled from seven local authorities (LAs) in England. These varied from large shire to small city LAs.

\footnotetext{
${ }^{2}$ In all, 309 teachers in 96 schools were recruited to the study.
} 
This report presents the findings from this project. It comprises nine chapters contained within five main Parts. Part One explains the context within which the project was commissioned, in addition to providing a synthesis of previous research in the fields of teachers' lives and work and school effectiveness, the research design (including the conceptual framework for the research and methods of data collection and analysis), and the sample. Part Two provides a brief discussion of the characteristics of the teachers and pupils involved in the research, the primary hypotheses generated from the data analyses, and definitions of key terms used throughout the report. Part Three reports the main findings relating to variations in pupil attainment and progress, teachers' professional life phases, an analysis of the reported experiences of CPD by the teachers who participated in VITAE, and teacher identities. Part Four examines the relationships between these, teachers' capacities to sustain their commitment and resilience and the associations between these and effectiveness. Finally, Part Five summarizes the key issues and messages arising from the research. As part of a deliberate developmental strategy, the VITAE project team has, individually and collectively, written and presented to the project Steering Group and, with its agreement, at selected conferences, a number of working papers. These can be accessed on the VITAE website: www.nottingham.ac.uk/education/crtsd/vitae.

\subsection{Project Specification}

The VITAE Project was designed against a set of specifications in a competitive DfES tender which defined its overarching aim as:

... to assess variations over time in teacher effectiveness, between different teachers and for particular teachers, and to identify factors that contribute to variations. The Department wants to understand how teachers become more effective over time. (DfES Tender No: 4/RP/173/99)

The specified methodology demanded that, 'teacher effectiveness should be assessed in relation to outcomes,' and that, 'robust and reliable quantitative data, and in-depth qualitative data from a representative sample of LAs/maintained schools' should be collected. This document also specified that the study should involve '...teachers at different stages in their career' (ibid.). 
To our knowledge, no large scale project has previously attempted to combine qualitative and quantitative measures to provide a means of establishing, over time, whether there are associations between the lives and work of so many teachers and their perceived effectiveness and effectiveness as measured by value added pupil attainment scores. Whilst we were able to draw upon previous research which had investigated aspects of these, VITAE provided the opportunity for a more detailed and holistic map to be constructed. Our objectives, as outlined in the bid, were that by the end of the research period, we would have:

- provided an authoritative view of the literature on the development over time of teacher effectiveness

- conducted and analysed the results of a mapping exercise with the a sample of approximately 1500 teachers in seven LAs in England

- collected in-depth quantitative and qualitative data from 300 teachers in early, middle and late career stages in Years 2, 6, and 9 (English and maths), in a range of high, medium and low socio-economic status (SES) primary and secondary school classrooms

- tracked this representative sample of 300 teachers over a three year period

- evaluated the impact of training and development, conditions of service, school, department and personal level factors, taking into account those factors identified by OFSTED (1999), Hay McBer (2000), Reynolds (2000) and others which indicate effective teaching for raising pupil attainment

- triangulated teachers' perceptions with robust outcome data and other information, both qualitative and quantitative, focusing on years 6 and 9, using value-added measures of pupil progress, and on year 2, using existing data

- synthesised the multiple strands of evidence into an account of the factors affecting teacher effectiveness and changes in teacher effectiveness over time

- provided accessible outcomes which would be of value to teachers and other educational professionals.

The rationale of the study was that, 
Expertise, capacity, personal and professional biography, situational and psychological factors as well as the complexity of the pupils whom they teach and changes over time and circumstances affect teachers' effectiveness. Thus, any attempts to sustain initiatives aimed at raising standards in schools and classrooms and to retain high quality teaching are unlikely to succeed without a more comprehensive understanding of teacher effectiveness, its complex configuration and its antecedents. (ibid. p6-7).

\subsection{Previous research}

Until now, research on a) teacher (and school) effectiveness and b) teachers' work and lives has been, and largely remains, two distinct fields. Prior to VITAE, there had been no major research study which had examined the relationship between teacher effectiveness and the interplay of factors which impacts on teachers' work and personal lives. The purpose of providing a synthesis of previous research in each these two areas was to highlight the importance of a study which would go some way towards bridging that gap. For details of working papers produced from VITAE, including a review of the literature, see Appendix 1.

\subsubsection{Teacher Effectiveness and Pupil Attainment}

There are a number of syntheses of research on effective teaching (e.g. Brophy and Good, 1986; Walberg, 1986 and Wittrock, 1986) and, in addition to research on teaching behaviour, much has been written about effective teaching skills (e.g. Wragg, 1984; Kyriacou, 1986; Clark and Peterson, 1986). Similarly, some research studies identify generic features of effective teaching (e.g. Walberg, 1990; Bennett and Carre, 1993, Muijs and Reynolds, 2005). In England, Mortimore and Watkins (1999) stressed the need for greater awareness of pedagogical issues and for developing better links between the perspectives of practitioners, policy makers and educational researchers, and Desforges (2000) argued the case for research to build an evidence base in critical areas of teaching and learning. It is increasingly recognised that teaching is a complex and challenging task; that in the practice of teaching various knowledge components interact with affective and interpersonal elements; and that teacher experience, work contexts and identities (Day et al, forthcoming) play important parts in this process (Hegarty, 2000). Many studies also have explored differences between school and classes in pupils' progress using value-added methodologies (see Teddlie and Reynolds, 2000). 
Reynolds (1995) commented that the 'touchstone' criteria for evaluating different educational policies or practices should be their impact on pupil learning outcomes. The choice of these outcomes (or outputs as they may be termed in models of effectiveness) is of particular importance since these become the criteria for judging teacher and school effectiveness. However, a focus on a narrow range of outputs which take no account of pupil and teacher background, motivation, individual/collective efficacy, or social, cultural, economic and organisational contexts can provide only partial indicators of effectiveness. Sammons' (1996) work goes some way towards a more holistic approach. She argues that, in addition to cognitive measures, social and affective outcomes should be studied and particular attention be given to the equity implications, for example gender, ethnicity or socioeconomic status (SES) (Sammons, 1999). However, even this does not take account of the qualitative factors which may influence pupil outcomes.

Although links between school reform and changes in teacher effectiveness have been discussed (Ross et al, 2003), little research has been conducted that combines factors which affect teaching effectiveness with factors which affect variations in teacher effectiveness or how teacher effectiveness changes over time. Few studies have explored whether teachers are equally effective in different school contexts and in terms of different types of outcomes (cognitive and social/affective). Research by Sammons and Smees (1998) suggests that individual primary school teachers can vary in their success in teaching different curriculum areas. In short, little empirically based knowledge exists concerning the ways in which teacher effectiveness in the classroom grows and/or diminishes over the course of a career and in different contexts. Indeed, until now the nature of 'effectiveness' itself has not been analysed in depth. Further discussion of the school effectiveness literature is given in Chapter Four. It should be noted that due to resource constraints, the VITAE study did not include a classroom observation component; therefore, the study was not able to test the relationship between particular features of classroom practice and pupil progress and social and affective outcomes. 


\subsubsection{The Meanings of Effectiveness}

The project set out to examine two dimensions of effectiveness. Whilst each was important in its own right, it was thought possible that there might be a relationship between the two.

Perceived effectiveness - Effectiveness in this sense was defined as the extent to which teachers believed that they were able to do the job to the best of their ability. Effectiveness was perceived in both cognitive and emotional ways. It included teachers' perceptions of the effectiveness of their classroom relationships and pupil progress and achievement, and how their ability to be effective related to their selfefficacy, motivation and commitment. Effectiveness for each individual varied in different organizational contexts and professional and life phases; and this was influenced - positively and/or negatively - by pupils (attitudes and behaviour), colleagues, departmental and school leadership, external policy and personal circumstances. The investigation of teachers' perceptions of effectiveness caused us to examine more closely the effects of these on teachers' professional life phases and identities and the relationship of these to their commitment and resilience.

Effectiveness in terms of pupil attainment - Effectiveness in this sense was measured by 'value added' pupil attainment data as defined by national tests at Key Stages 1, 2 and 3. In addition to these results, an independent baseline test was administered at the beginning of the year to pupils at Key Stage 2 (Year 6) and 3 (Year 9), thus allowing progress over the academic year to be measured. Multilevel models were used to separate teacher level variation from that at the pupil level to obtain valueadded estimates of effectiveness. (see Goldstein, 1997). The administration of the baseline tests was undertaken voluntarily by teachers over the three years of the project fieldwork. The cognitive results enabled us to look for relationships with i) pupil attitudes collected (again voluntarily) through annually administered surveys and ii) teachers' perceptions of effectiveness.

These definitions of effectiveness led us to develop notions of 'relative' and 'relational' effectiveness as analytical tools (Fig. 1.1). By 'relative', we mean that teachers in similar schools and of similar age and experience might be compared in relation to their effectiveness - both perceived and in terms of 'value added' pupil 
attainment scores. By 'relational', we mean that teachers might perceive themselves to be more or less effective in the classroom in relation to their past performance and according to perceived variations in effectiveness (how one teacher perceives the present and how (s)he performs in relation to his/her past history).

Figure 1.1: Relational and Relative Effectiveness

\section{RELATIONAL AND RELATIVE EFFECTIVENESS}

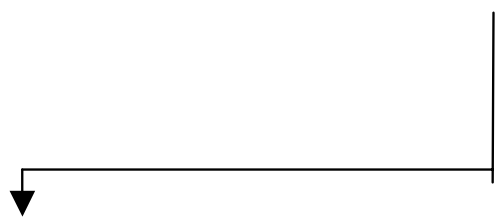

RELATIONAL EFFECTIVENESS (CASE STUDY DATA AND NARRATIVES)

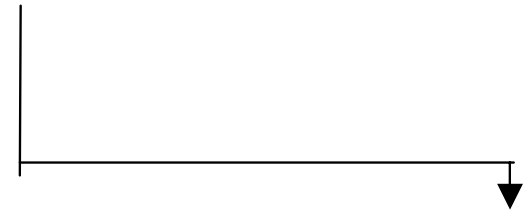

\section{RELATIVE EFFECTIVENESS (CASE STUDY DATA AND MULTI-LEVEL MODELLING)}
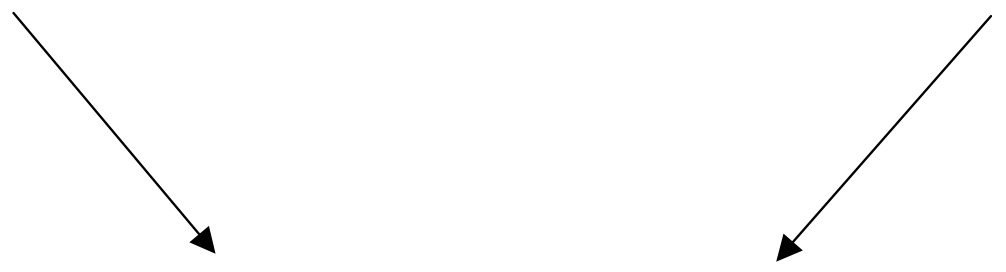

\section{VARIATIONS IN TEACHERS' WORK, LIVES AND THEIR EFFECTS ON}

\subsubsection{Influences on Teachers' Work and Lives}

There is a developing awareness of connections between teachers' private lives, the personal and biographical aspects of their careers, and how these intersect with and shape professional thoughts and actions (e.g. Day, 1999; Goodson, 2003). Woods (2001, see also Woods et al, 1997), for example, describes how teachers have made adaptations to restructuring in curriculum, pedagogy and assessment; to the "new public management'; forms of accountability; to new forms of school organization; to changes in teacher culture and to the intensification of their work. He categorises influencing factors as arising at three levels: structural (macro), organizational (meso) and personal (micro) and argues that these are interrelated (see also Helsby, 1999). As Hargreaves (1998) has also observed, these levels are not 'tightly insulated from one another' and 'structure and agency are relationally connected' (p. 422). 
It is becoming increasingly clear from the literature on teachers' work, professional lives and development that not only expertise, but also personal and professional biography, situational, emotional and psychological factors, as well as the complexity of the schools in which they work and the pupils whom they teach, alongside changes over time and circumstance, may affect their effectiveness as teachers (Van Den Berg, 2002; A. Hargreaves, 1999).

\begin{abstract}
We are beginning to recognize that, for teachers, what goes on inside the classroom is closely related to what goes on outside it. The quality, range and flexibility of teachers' classroom work are closely tied up with their professional growth - with the way in which they develop as people and as professionals. Teachers teach in the way they do not just because of the skills they have or have not learned. The ways they teach are also rooted in their backgrounds, their biographies, and so in the kinds of teachers they have become. Their careers - their hopes and dreams, their opportunities and aspirations, or the frustrations of these things - are also important for teachers' commitment, enthusiasm and morale. So too are relationships with their colleagues - either as supportive communities who work together in pursuit of common goals and continuous improvement, or as individuals working in isolation, with the insecurities that sometimes brings
\end{abstract}

(A. Hargreaves, 1999, p.vii).

Influencing factors on teachers' work can exert a positive or negative impact on their effectiveness and, therefore, on pupil learning. Understanding how the interrelationships among these influences work and how they exert their effects is, however, not easy. Ancess (1997), like Askew et al (1997), acknowledges the crucial importance of teachers in the school effectiveness and improvement relationship and concludes that there is "a reciprocal influence among restructuring, teacher learning and practice, and student outcomes'. From her research she deduces, that 'chicken and egg analyses may be erroneous in that the set of variables under examination-teacher learning and practice, restructuring, and student outcomes - are inter-connected in an interdependent constellation ... their relationship varies in detail, is context specific, unpatterned, reciprocal, and dynamic rather than linear and static' (p. 34).

It is also increasingly evident from the literature, that events and experiences in the personal lives of teachers are intimately linked to perceptions of performance in their professional role (Ball and Goodson, 1985; Goodson and Hargreaves, 1996). In her research on the 'realities of teachers' work', Acker (1999) describes the considerable pressures on teaching staff, not just arising in their work but also from their personal 
lives. Complications in personal lives can become bound up with problems at work (Woods et al., 1997). Commenting on Huberman's (1993) classic text on the personal and professional career trajectories, Hargreaves (1993) argues that:

Teachers don't just have jobs. They have professional and personal lives as well. Although it seems trite to say this, many failed efforts in in-service training, teacher development and educational change more widely are precisely attributable to this neglect of the teacher as a person - to abstracting the teacher's skills from the teacher's self, the technical aspects of the teacher's work from the commitments embedded in the teacher's life. Understanding the teacher means understanding the person the teacher is.

(A Hargreaves, 1993, p. viii).

In a study of primary teacher morale and job satisfaction, Evans (1992) found that the situation-specific variables of headteacher behaviour and staff relationships were key factors which influenced teachers' satisfaction/dissatisfaction with teaching. Her study of teachers' working lives found their job satisfaction, motivation and morale to be strongly related to their professional identities. Another key area of work in teacher development and its relationship to pupil achievement is the mediating factor of teacher self-efficacy (Ashton and Webb, 1986; Rosenholtz, 1989), the self-belief of teachers that they can exert a positive effect on their students' success.

In a more recent study, Rudow (1999) notes that teachers need to feel wanted and important, and require affirmation of this by those with whom they live and work. Bandura (1989) suggests that, among the mechanisms of personal agency, none is more central and pervasive than people's beliefs about their capabilities to exercise control over events that affect their lives. Self-efficacy beliefs function as an important set of proximal determinants of human motivation, affect, and action.

The research literature leaves little doubt that commitment (or lack of it) can be a key influencing factor in the performance effectiveness levels of teachers (Bryk et al, 1993; Kushman, 1992). For example, research in the USA indicates that teachers with low commitment are less likely to develop plans to improve the quality of their teaching (Firestone and Pennell, 1993; LeCompte and Dworkin, 1991). Commitment is also associated with their identification with the goals and values of the school (Reyes, 1990). For these reasons, commitment is considered to be one of the most prominent factors influencing the performance levels of teachers and their students 
(e.g. Bryk et al, 1993; Kushman, 1992). It has been found to be a predictor of teachers' performance, burnout, and attrition, as well as having an important influence on pupils' cognitive, social, behavioural and affective outcomes (Firestone, 1996; Day et al, 2005).

Teachers who are committed to their work have an enduring belief that they can make a difference to the learning lives and achievements of students (efficacy and agency) through who they are (their identity), what they (knowledge, strategies, skills) and how they teach (their beliefs, attitudes, personal and professional values embedded in and expressed through their behaviour in practice settings). Commitment is the expression over a career of a desire to be the best possible teacher and provide the best possible teaching for all students at all times through care and competence. Commitment occurs, then, in both real time and is an enduring aspiration. At its best is both a cognitive (intellectual) and affective (emotional) endeavour. To sustain commitment involves personal and professional investments of intellectual energy, emotional understanding (Denzin, 1984: 137) and 'emotional labour' (Hochschild, 1983). Sustaining commitment requires resilience.

According to Oswald et al. (2003: 50), resilience in children is 'that capacity to successfully overcome personal vulnerabilities and environmental stressors, to be able to 'bounce back' in the face of potential risks, and to maintain well-being.' Luthar et al. (2000:543) emphasise the heterogeneous nature of resilience 'heterogeneity in risks experienced and competence achieved by individuals viewed as resilient' - and define it as 'a dynamic process encompassing positive adaptation within the context of significant adversity.' The particular value of their definition is that it clearly articulates the relative dynamism (as opposed to fixedness) of resilient qualities. These qualities are essential for 'a developmental progression' (Luthar et al., 2000: 544; see also Werner and Smith, 1982; Masten and Garmezy, 1985; Richardson et al., 1990; Higgins, 1994; Benard, 1995), in which individuals take a series of purposeful actions over time, 'often accompanied with emotional difficulties' and tremendous stress (Gordon et al., 2000), in order to manage and successfully develop and grow in the face of adverse circumstances. These qualities do not merely serve the developmental progression; indeed, at the heart of the process, they interact with negative influences and develop in strength as a result. In other words, adversity 
may also promote the development of resilient qualities (Rutter et al., 1979, Benard, 1991; Wang et al., 1993; Pence, 1998; Henderson and Milstein, 2003; Oswald et al., 2003). Influencing factors in teachers' professional life phases and identities may affect their commitment and resilience and in doing so, contribute to their effectiveness.

\subsection{Design of the study}

A major criticism of 'effectiveness' research in the field of teachers and schools is that it indicates a particular understanding of causality and correlation. The Input-ProcessOutput model on which it is based has been rejected by those who research the nature of teaching and learning and teachers' workplaces, careers and lives as inadequate in explaining how and why internal and external conditions influence and the relative extent of their impact upon teachers' work and lives. Other approaches have, therefore, been developed through, for example, case study, narrative and action research, which take account of social and policy analyses of the wider contexts in which teaching, learning and achievement occur. These have sought to understand rather than reduce complexity. In their turn, these have been criticised either for being ideologically driven or too fine-grained and small-scale to provide any generalisable or transferable conclusions. Yet, collectively, they present a recognisably powerful and vivid mosaic of the complexity of teachers' work and lives.

In pursuit of the main research focus, a set of guiding questions was derived from a review of relevant literature which provided an initial framework for the development of a research design which would be appropriate to purposes. However, the concepts were kept sufficiently broad to allow an iterative process of progressive focusing as the research advanced (Hammersley and Atkinson, 1983; Strauss and Corbin, 1998). The guiding questions the study sought to address were:

- Does teacher effectiveness vary from one year to another and in terms of different pupil outcomes and do teachers necessarily become more effective over time?

- What are the roles of biography, culture and professional development?

- How do schools and/or departments influence teachers' practice and their effectiveness? 
- Are teachers equally effective for different pupil groups or is there differential effectiveness relating (for example) to gender or socio-economic status?

- Do the factors which influence effectiveness vary for teachers working in different contexts, or for different kinds of outcomes?

- Do factors influencing teachers' effectiveness vary across different sectors (primary and secondary) and different age groups (key stage 1,2 and 3)?

In designing a methodology appropriate to these questions, three key challenges were addressed:

i) How to measure the effectiveness of teachers working within different school phases, contexts and at different points in their careers in terms of pupil attainment and progress.

ii) How to identify and assess variations in effectiveness between teachers at different career points over time.

iii) How to differentiate between, and assess the significance of, the key factors associated with variations in teachers' effectiveness.

Each of these challenges influenced the overall design of the study, from the selection of teachers to the nature of the methods used.

\subsection{Methodological synergy}

The complexity of this research led the VITAE project to adopt a multi-method approach involving a range of research techniques, including approaches traditionally associated with both 'positivist' / 'quantitative' and 'interpretive' / 'qualitative' paradigms, in order to gather the range of information needed to address all of these complex and potentially interrelated issues and concerns. Shulman (1986) maintains that research programmes growing out of a particular perspective tend to '...illuminate some part of the field ... while ignoring the rest'. A combination of approaches would allow triangulation of evidence sources and would be likely to prove more fruitful than reliance on a single paradigm or approach (whether 'quantitative' or 'qualitative') (see Tashakorri and Teddlie, 2003). 
The team, therefore, chose a methodology less constrained by limiting theoretical perspectives and more focused on the practical problems of addressing particular research questions (see Bryman, 1988: 183). Research methods were selected on the basis of fitness for purpose. To the extent that the distinction between 'qualitative' and 'quantitative' methods can plausibly be maintained, it has thus been argued that 'certain questions cannot be answered by quantitative methods, while others cannot be answered by qualitative ones' (Walker, 1985). Hammersley (1996) describes such an approach as methodological eclecticism.

The use of quantitative and qualitative data for this study enabled the tracking of individual teachers, departments and schools in terms of their relative efficacy in promoting pupils' academic progress and positive affective outcomes over a threeyear period. In addition, variations in the trajectories between individual teachers, departments, and schools over time allowed for the identification of a range of possible contributory factors.

The different areas of strength and expertise of the research team facilitated a mixed method approach. Regular team meetings to discuss the emerging data allowed the dialogue necessary to generate hypotheses for further analysis.

\subsection{Integrating the data}

An important and innovative part of VITAE was the continuous integration or 'synergy' of data collected and analysed by different means. This approach was considered vital in the development of an holistic picture of variation in teachers' work and lives, which would illuminate and explain how these affected teacher effectiveness.

The research design needed to make a series of comparisons over time within each teacher's individual work, life and effectiveness and between teachers in different professional life phases working in the same department, or key stage, within the school as a whole, and across groups of different schools. 
The design also needed to be sufficiently focused to explore shorter-term variations, as well as longer term patterns of effectiveness, and be able to locate teacher effectiveness in past as well as current performance.

Two main approaches were used to achieve this synergy of data:

1) the construction of individual teacher profiles illustrating the variations and changes in their work and lives throughout the three-year period; and,

2) multi-level modelling of school, teacher and pupil level characteristics in each of three years of the study to enable classification of teachers in terms of relative (value-added) effectiveness and the inclusion of these classifications in the teacher profiles.

\subsection{Conceptual Framework}

The preliminary thinking, based upon our own experiences and review of the literature on teachers' lives, work and effectiveness, led to the creation of an initial conceptual map which included the main ideas, issues and debates which seemed to relate to teacher effectiveness. At this time, the relationships between the issues themselves remained unconnected, partly because the kind of holistic research which would enable this process had not been carried out previously, and partly because any associations would be more powerful if based on empirical data.

The initial conceptual framework was based on a model (Fig. 1.2) where teacher effectiveness was considered central and was understood to relate to pupil attitudes, achievements and attainments and to be affected by policy, pupils, personal and practice factors (including school leadership and culture). 
Figure 1.2: Hypothesised initial model of factors contributing to variations in teacher effectiveness

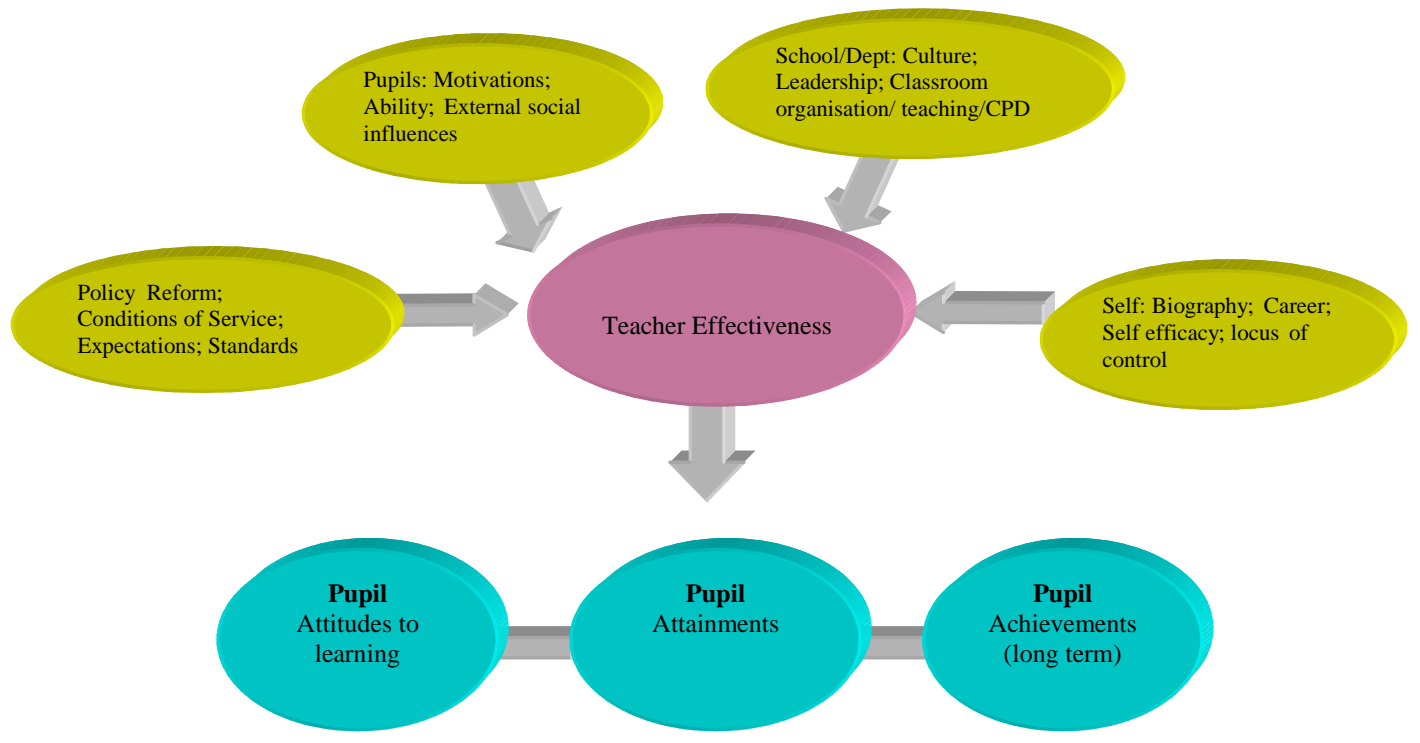

Following the analysis of the initial survey and the first round of interviews, it became clear, also, that teachers' selves were central to a consideration of variation and effectiveness. In Wenger's (1998) words, 'one can design roles, but one cannot design the identities that will be constructed through these roles' ( $\mathrm{p}$ 229). A second conceptual framework grounded in the empirical data was, therefore, developed, with teachers' identities and professional life phases as key factors which might moderate their commitment and effectiveness (Fig. 1.3).

The two key interlocking components of variation: professional life phase and identity became key strands of the research. They were found to be closely associated with agency, commitment and resilience. 
Figure 1.3: Teachers' selves as factors moderating effectiveness

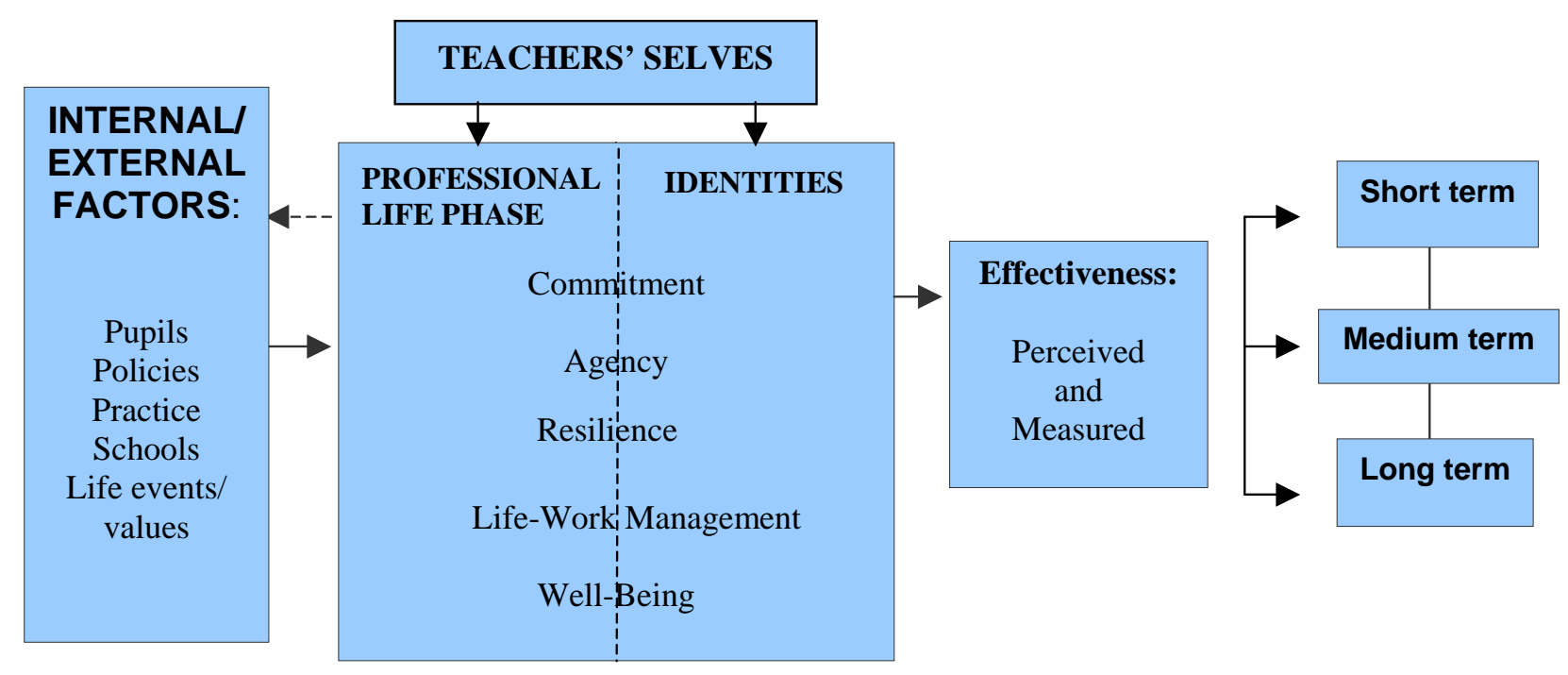

\subsection{Overview of the study}

The project was conducted over two main phases:

Phase 1 (2001-2002) involved an audit of LAs in order to identify a group which, between them, could offer a range of representative schools. Seven LAs were selected to cover a range of areas (inner city, suburban metropolitan and rural), and a range of ethnic diversity and socio-economic disadvantage. School and teacher effectiveness research recognises that there are a number of factors that contribute to pupil attainment and progress that are not under the direct control of schools or teachers. In order to make valid comparisons in terms of impact on pupil attainment, it was, therefore, important to collect detailed information about prior attainments and other individual pupil level characteristics such as age, gender, ethnicity, fluency in English and (where applicable) SEN classification, and data relating to socioeconomic status (SES), for all children in Year 2 and 6 classes taught by primary teachers, and all pupils in Year $9^{3}$ group taught by English and maths secondary teachers in the study. This was achieved through the collection of both secondary data from national DfES databases (i.e. LA, school and pupil level data) and primary data via pupil prior attainment/baseline assessments.

\footnotetext{
${ }^{3}$ These year groups were chosen because they provide national pupil outcome measures in the form of key stage 1,2 and 3 national tests results.
} 
As part of Phase 1 of the project, the study used existing quantitative pupil data already collected by LAs, schools and teachers, and available on DfES national databases.

In addition, contextual factors such as level of disadvantage in the schools' pupil intake and pupil mobility were likely to be relevant (Sammons, 1999). The pupils' national assessment results ${ }^{4}$ were collected as cognitive outcome data and, in addition, PLASC (Pupil Level Annual School Census) data relating to ethnicity, terms in school, SEN and FSM (Free School Meals) status, and fluency in English, were collected to further enhance the value added analyses.

The modelling controlled for different pupil and school level influences in addition to pupils' prior attainments in the analyses of progress. Such factors were also explored in relation to pupils' affective outcomes. Also, particular care was taken to ensure that mobile pupils were not included in the analyses of teacher effects. To be included pupils needed to be present for both assessments, at the beginning and end of the academic year. Data for each LA were:

- matched pupil level data files available linking KS1-KS3 national assessment data and KS2-KS3 national assessment data, with relevant pupil and school level data such as pupil gender, age, free school meal (FSM) entitlement, percentage of pupils with English as a second language, special educational needs (SEN) status, to enable analyses of effectiveness patterns for schools across KS2 and KS3 from 1999-2001;

- data which covered a range of high, medium and low SES schools in urban, suburban and rural areas; and,

- demonstrated a representative sample of teachers' age and experience profiles.

All Year 2 and Year 6 teachers in primary schools and all Year 9 maths and English teachers in secondary schools within each of the seven LAs were asked to complete a short questionnaire ${ }^{5}$.

\footnotetext{
${ }^{4}$ This did not include data collected via statutory teacher assessment.

${ }^{5}$ Details of the initial teacher questionnaire can be found later in the section (2.7.1).
} 
Phase 2 (2002-2005) involved the selection of case study schools and teachers and the collection of data via teacher, school leader and pupil interviews. The study employed a number of different approaches to interviewing the various participants involved in the research. Over the course of the project, the 300 participating teachers were involved in a total of six interviews (including semi-structured interviews, hierarchically focused interviews, and telephone interviews).

Data collected via these methods, together with school level data, pupil focus group and questionnaire data, and the contextual (Year 2) and value added analyses of pupil attainment progress across Year 6 (primary) and Year 9 (secondary), provided estimates of teacher effectiveness for particular pupil outcomes (English, mathematics) and enabled the combination of context and cohort specific factors (Fig. $1.4)$.

Figure 1.4: Data sources and types

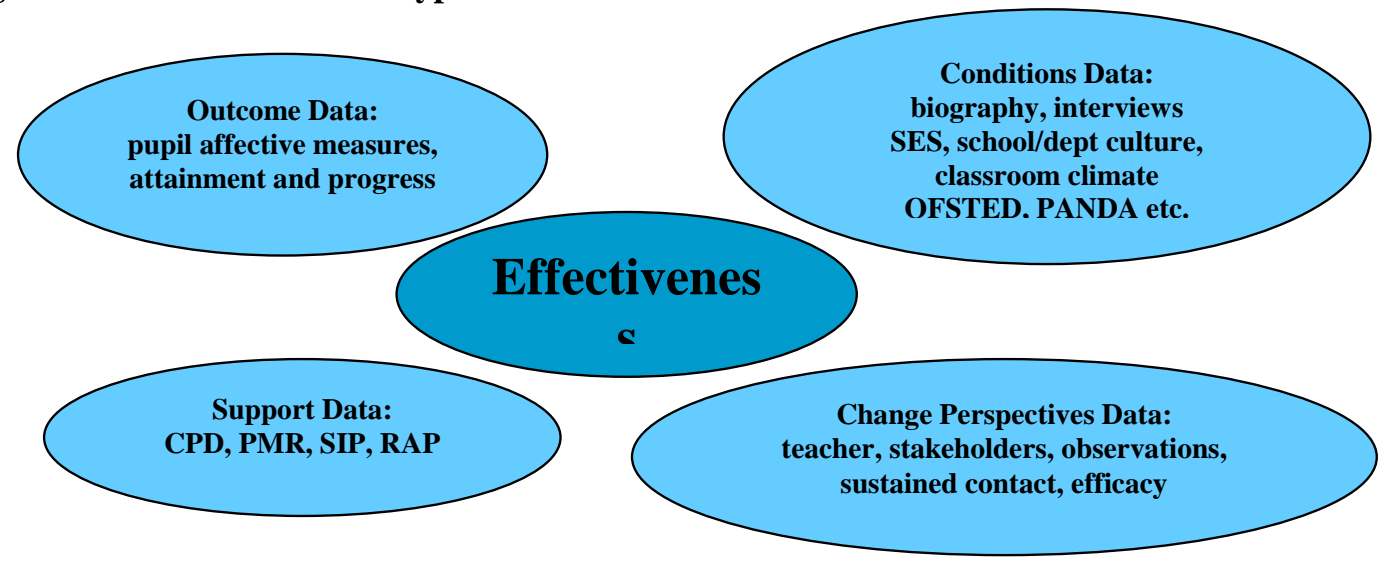

\subsection{Sampling}

\subsubsection{Initial sample (Phase 1)}

The project was designed to include a cross-section of LAs in England (Unitary, Metropolitan, County, etc) which comprised schools of high, medium and low socioeconomic status (SES) in rural, suburban and city areas. By clustering teachers in schools (2 in each primary, 6 in each secondary) it was possible to analyse for potential school and departmental level effects, as well as possible variations in teacher level effects. Figure 1.5 provides a summary of the sampling design. 
The teachers were selected from each of the year groups identified as the initial focus for the research (Years 2, 6 and 9). These groups were chosen because they provided national pupil outcome measures in the form of key stage 1,2 and 3 national tests results. The number of teachers sampled was determined partly by the need to include a balanced distribution of experience, age, career stage, specialism and gender and partly in order to have sufficient numbers in a particular group to allow for the use of multilevel modelling techniques, given the likelihood of teacher attrition.

Figure 1.5: Summary of sampling design

$$
\text { Initial sample (Phase 1) Case study sample }
$$

(Phase 2)

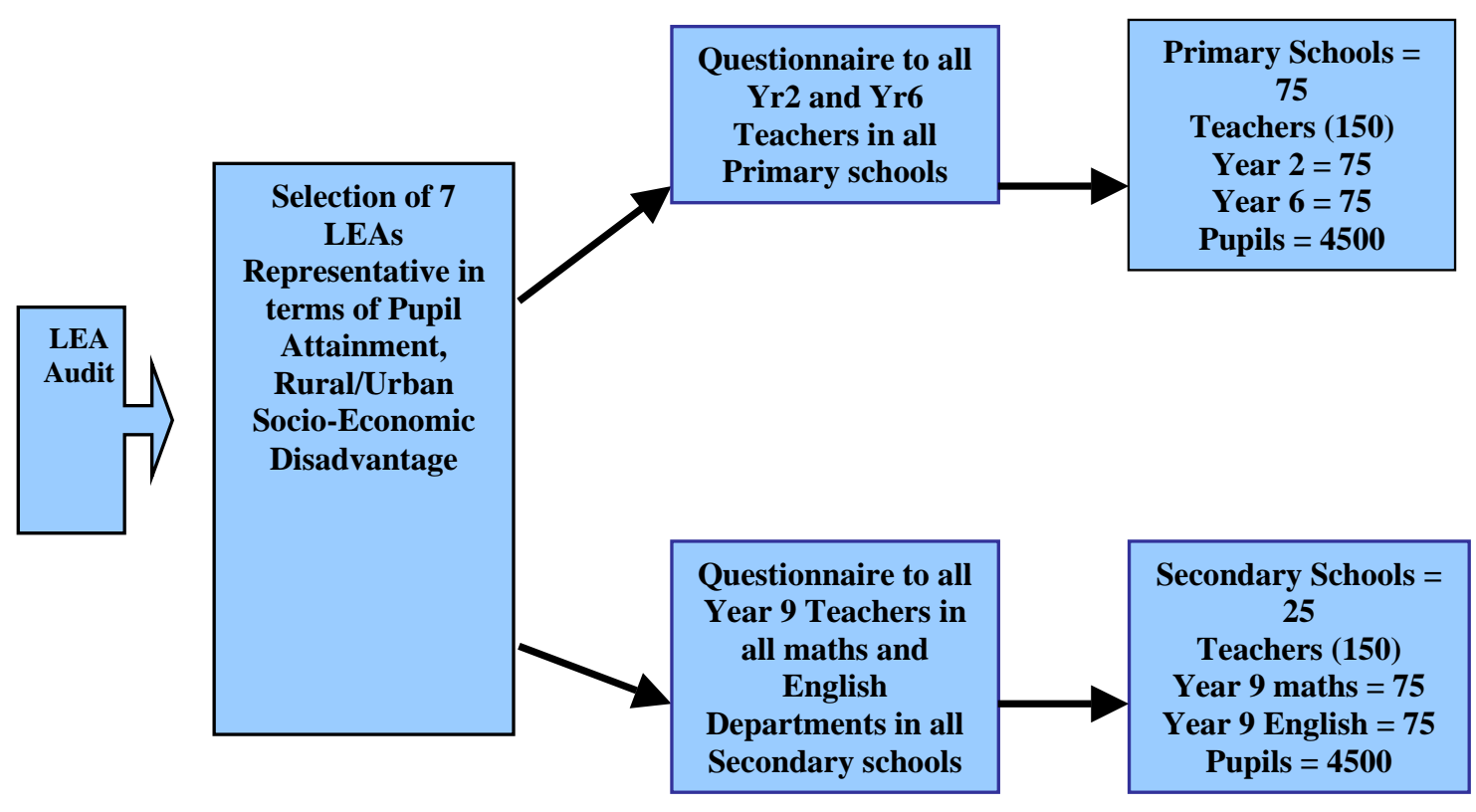

Tables 1.1 and 1.2 illustrate the representativeness of the achieved sample of primary and secondary schools by comparing pupil performance at KS 2 or 3 respectively in these schools (by free school meal entitlement) with the national averages. The achieved sample of case study secondary schools was slightly over-represented in those schools with low attainment results and with low SES (as indicated by FSM entitlement) in the country as a whole. This was deliberately stratified in order to allow better generalisation and to anticipate the possibility of greater attrition in more disadvantaged schools. 
Table 1.1: Primary schools case study matrix (75 schools) - Banded performance at KS 2 (level 2 and above)

\begin{tabular}{|lllllllll|}
\hline \multicolumn{7}{|c|}{ Attainment quartile } \\
\hline \% Free School Meals & Top & Second & Third & Bottom & Total & $\begin{array}{l}\text { Actual } \\
\text { Sample }\end{array}$ & National \\
Up to 8\% & 8 & 13 & 2 & 0 & 23 & $31 \%$ & $33 \%$ \\
more than 8\% up to 20\% & 2 & 14 & 4 & 0 & 20 & $27 \%$ & $29 \%$ \\
more than 20\% up to 35\% & 0 & 3 & 6 & 6 & 15 & $20 \%$ & $19 \%$ \\
more than 35\% & 0 & 1 & 8 & 8 & 17 & $23 \%$ & $19 \%$ \\
Total & & & & & 75 & & \\
\hline
\end{tabular}

Table 1.2: Secondary schools case study matrix ( 25 schools) - Banded performance at KS 3 (level 5 and above)

\begin{tabular}{|llllllllll|}
\hline \multicolumn{7}{|c|}{ Attainment quartile } & & & \\
\hline \% Free School Meals & Top & Second & Third & Bottom & Total & $\begin{array}{l}\text { Actual } \\
\text { Sample }\end{array}$ & National \\
Up to 13\% & 3 & 5 & 3 & 0 & 11 & $40 \%$ & $45 \%$ \\
$\begin{array}{l}\text { More Than 13\% and up } \\
\text { to 35\% }\end{array}$ & 0 & 3 & 4 & 1 & 8 & $36 \%$ & $36 \%$ \\
More than 35\% & 0 & 0 & 1 & 3 & 4 & $20 \%$ & $14 \%$ \\
Grammar Schools & 1 & 0 & 0 & 0 & 1 & $4 \%$ & $5 \%$ \\
Total & & & & & 25 & & \\
\hline
\end{tabular}

The study recruited teachers, on a voluntary basis, who possessed a range of teaching experience, from newly qualified teachers (NQTs) to more 'veteran' teachers. Against the national profile, our sample included a higher number of experienced teachers (see Fig. 1.6 and 1.7). This may be partly due to a tendency for schools to prefer to place experienced teachers in those year groups that undertake national assessment. 
Figure 1.6: Case Study Primary Teachers Compared to National Profile Numbers of Years in Service

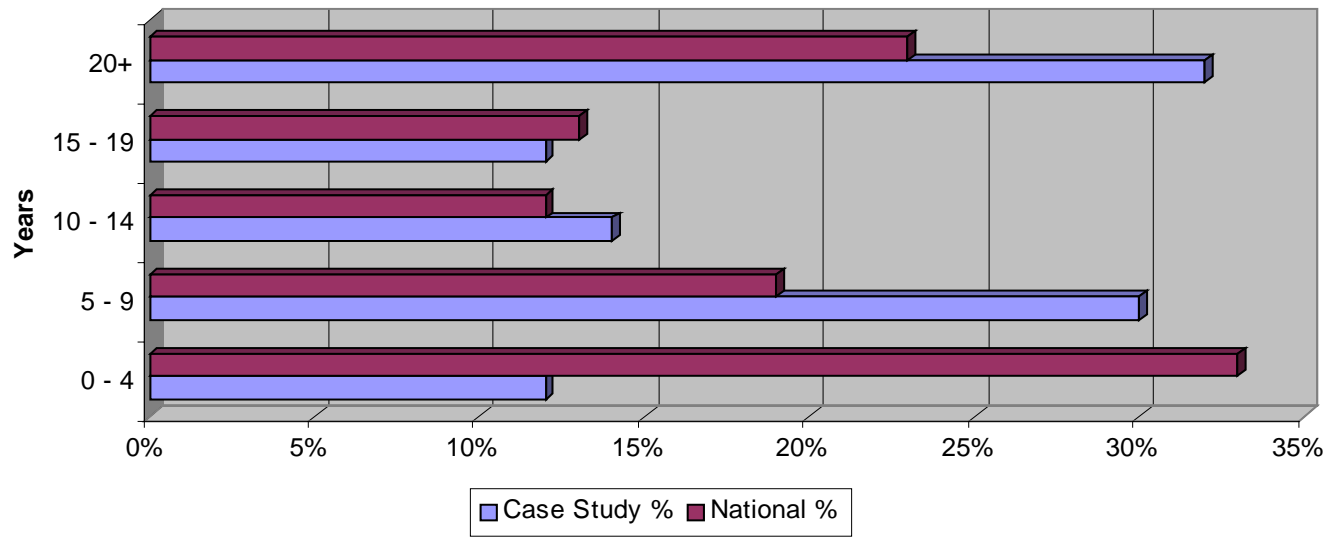

Figure 1.7: Case Study Secondary Teachers Compared to National Profile Numbers of Years in Service

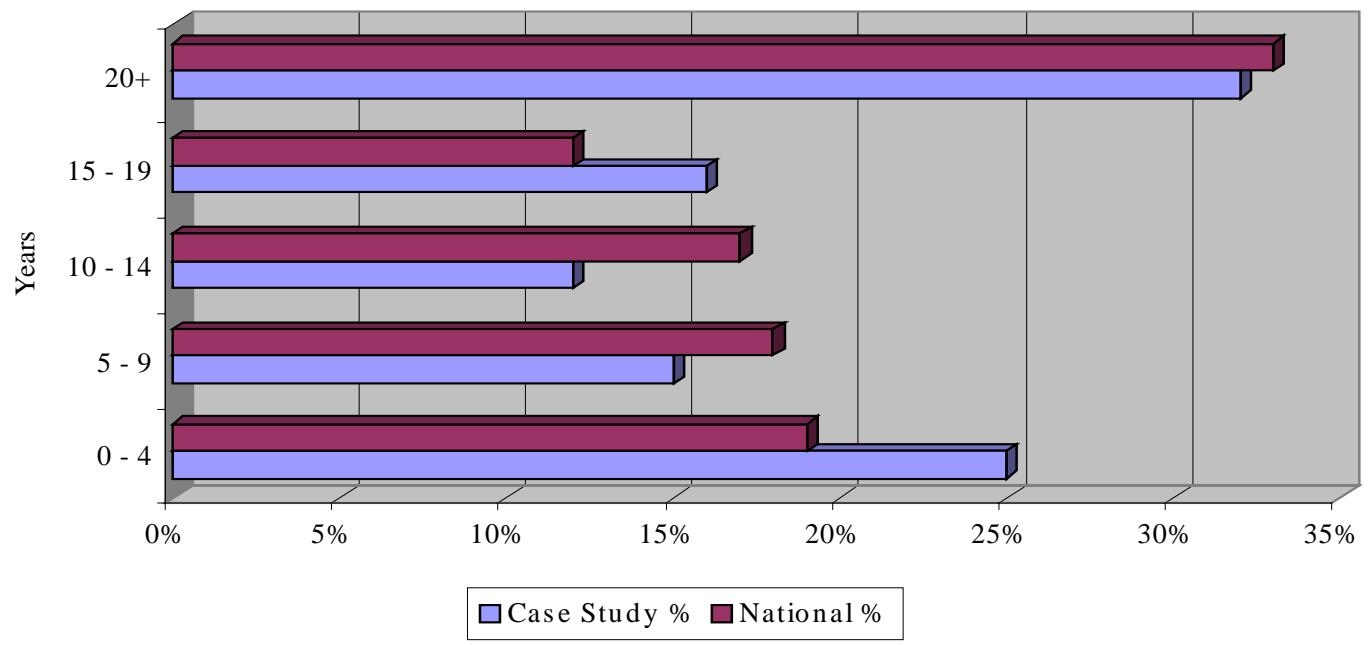

Our achieved gender balance for primary school teachers (10\% male, 90\% female) generally mirrored that of the national profile (12\% male, $88 \%$ female). However, our sample of secondary school teachers (28\% male, $62 \%$ female) over-represented women compared with the national profile ( $45 \%$ male, $55 \%$ female). This was due to there being higher numbers of women teaching English, one of our two selected subjects. 
As part of the school selection criteria, consideration was taken of the numbers of pupils on the school roll, in order to provide, as far as possible, a representative number of small, medium and large schools. Figures 1.8 and 1.9 show that, on these criteria, our achieved sample matched fairly closely the national profile. However, we included a higher proportion of small and very large schools in our sample, in order to facilitate meaningful analysis in this area.

Figure 1.8: Case Study Primary Schools Compared to National Profile Numbers of Pupils on Roll

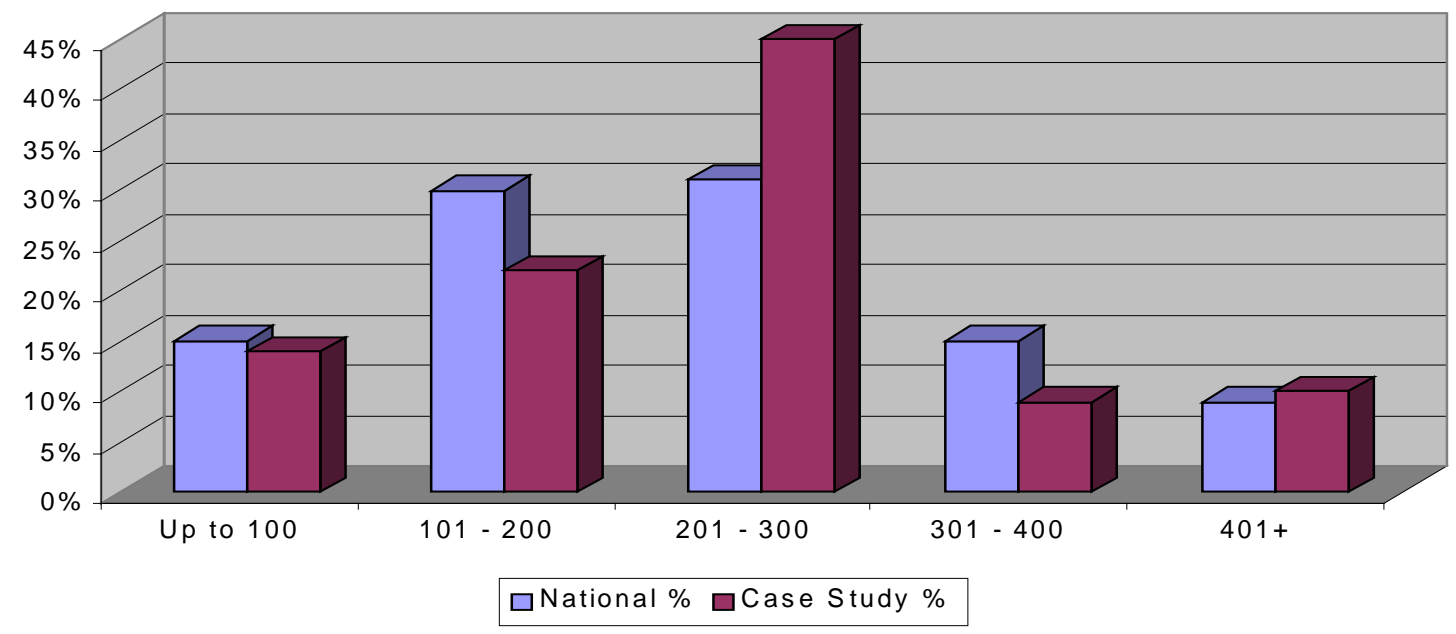

Figure 1.9: Case Study Secondary Schools Compared to National Profile Numbers of Pupils on Roll

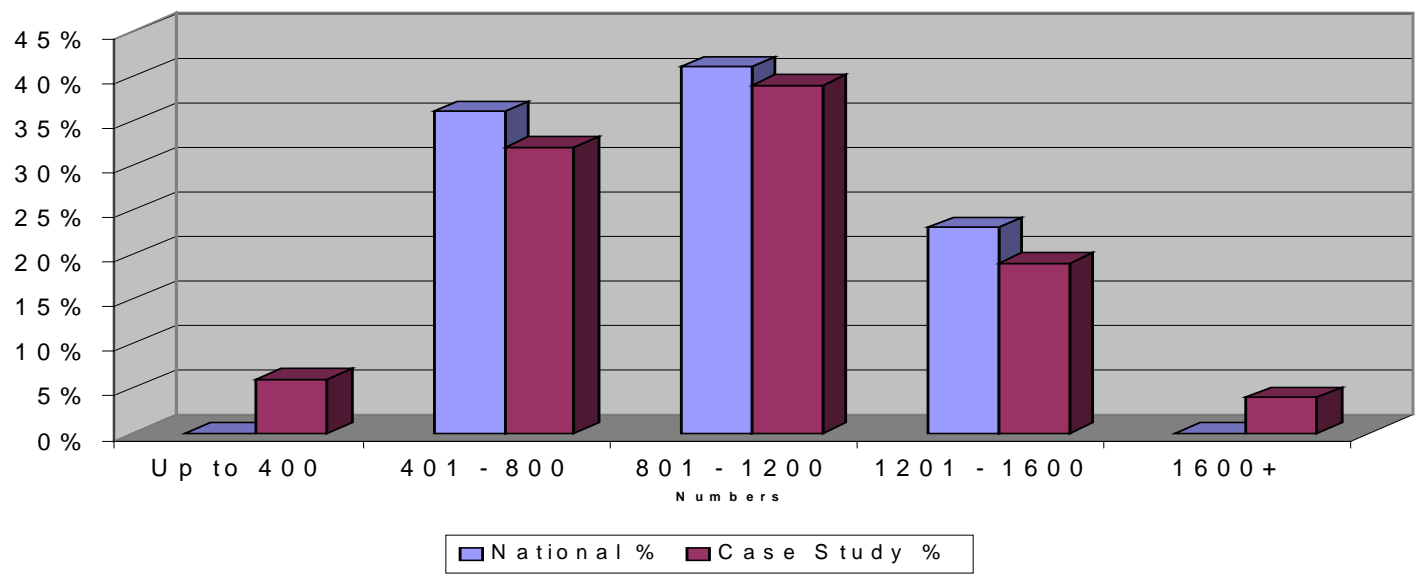




\subsubsection{Case study sample (Phase 2)}

The aim had been to recruit a total of 150 teachers from 75 primary schools, and 150 maths and English teachers from 25 secondary schools for the Phase 2 case studies. In reality schools were identified in which some teachers had responded but others were then invited to join the project. This was particularly the case with secondary schools from which we wished to recruit three Year 9 mathematics teachers and three Year 9 English teachers. Nevertheless, the spread of 300 teachers was broadly in line with the national age/experience teacher profile. The sample was selected in order to ensure representation in the following categories:

- age

- experience

- gender

- phase

- subject specialism

- length of service

- career phase.

The teachers were located in schools which represented a range of:

- geographical locations (urban, suburban, rural)

- SES (high to low disadvantage)

- schools in terms of pupil key stage attainment

- mobility of pupils.

\subsection{Strategy for inquiry}

According to Tashakkori and Teddlie (1998) and Cresswell (2003) mixed method studies can follow one of two strategies: sequential or parallel/simultaneous. Sequential strategies use one method first and based on the results, a second method extends or clarifies the findings from the first. Parallel strategies use several research methods simultaneously to understand a single phenomenon. VITAE contains elements of both strategies. 
Firstly, the project adopted a sequential strategy, in which the findings from one method were elaborated and expanded with another method. In the case of VITAE, this began with a qualitative, literature-based conceptualisation of the field. This was used to inform the development of a questionnaire. The themes emerging from this were investigated further during the first interview with teachers. However, the design was multi-layered, whereby data collected by one method fed into more than one subsequent research instrument, each examining the focus of the study from different perspectives. For example, data collected via the first round of teacher interviews fed into the design of the second round of teacher interviews with school leaders and the pupil focus group interviews.

Secondly, different methods of data collection (e.g. teacher interviews and pupil attitudinal questionnaires) were used during the same time period. Furthermore, data collected via different methods were analysed concurrently and iteratively, with emergent findings from the analysis of each dataset informing the analysis of the other. Thus the overall strategy also involved a simultaneous element.

The approach is centred on a conceptual framework which is more important in guiding the study than the use of methods alone. It is the purpose of the chosen strategy to employ the methods that will best serve the framework. Other advantages to this strategy focus upon:

1 instrument development - themes were obtained from participants in an initial data collection phase. In the next phase, these statements were used as specific items on interview schedules that were grounded in the views of the participants;

2 data transformation - this involved creating codes and themes qualitatively, then counting the number of times they occurred in the text data. This quantification of qualitative data then enabled the team to compare quantitative results with the qualitative data. The team also qualified quantitative data. For example, in a factor analysis of data from a scale on an instrument, themes were created then compared with themes from the qualitative database;

3 exploration of outliers - this involved an analysis of quantitative data which yielded extreme or outlier cases. These cases were followed-up with 
qualitative interviews in order to provide further insights.

\subsection{Data-collection and analysis}

The main evidence collection method was semi-structured, face-to-face interviews with teachers. These were supplemented at various stages of the research by document analysis, interviews with leaders and groups of pupils, amongst others. The evidence was gathered in an iterative and evolving process consistent with the use of grounded theory methods. Thus, guided by a critical examination of the literature, an initial questionnaire for teachers was developed. The analysis of data collected from this questionnaire led to the development of interview schedules and further follow-up interviews. Group interviews with pupils (from the classes of $30(10 \%)$ of the participating teachers) were used to follow-up on findings from in the pupil attitudinal questionnaire.

Table 1.3: Timetable of data collection methods

\begin{tabular}{|c|c|c|c|}
\hline Focus & Method & Participants & Time \\
\hline \multirow[t]{5}{*}{ Teachers } & Questionnaire survey & $\begin{array}{l}\text { Year 2, } 6 \text { and } 9 \text { (maths and English) } \\
\text { teachers in all schools in sample LAs }\end{array}$ & Spring 2002 \\
\hline & Semi-structured interview & 300 case study teachers & $\begin{array}{l}\text { Autumn 2002; } \\
\text { 2003; Summer } \\
2005\end{array}$ \\
\hline & $\begin{array}{l}\text { Hierarchically-focused } \\
\text { interview }\end{array}$ & 300 case study teachers & Summer 2003 \\
\hline & $\begin{array}{l}\text { Narrative approach } \\
\text { interview and teacher } \\
\text { worklines }\end{array}$ & 300 case study teachers & Summer 2004 \\
\hline & Telephone interview & 300 case study teachers & Spring 2005 \\
\hline $\begin{array}{l}\text { School } \\
\text { leaders }\end{array}$ & Semi-structured interview & $\begin{array}{l}\text { Headteachers, Heads of department, } \\
\text { key stage leaders }\end{array}$ & Summer 2003 \\
\hline \multirow[t]{4}{*}{ Pupils } & $\begin{array}{l}\text { Baseline and outcome } \\
\text { measures: } \\
\text { - NFER tests in English and } \\
\text { mathematics }\end{array}$ & $\begin{array}{l}\text { Year } 6 \text { and } 9 \text { (maths and English) } \\
\text { pupils in classes or sets (Yr9) taught by } \\
\text { case study teachers }\end{array}$ & $\begin{array}{l}\text { Autumn 2002; } \\
2003 ; 2004\end{array}$ \\
\hline & - National test data & $\begin{array}{l}\text { Year 2, } 6 \text { and } 9 \text { (maths and English) } \\
\text { pupils }\end{array}$ & $\begin{array}{l}\text { Summer 2003; } \\
2004 ; 2005\end{array}$ \\
\hline & Attitudinal survey & $\begin{array}{l}\text { Year 2, } 6 \text { and } 9 \text { (maths and English) } \\
\text { pupils in classes or sets (Yr9) taught by } \\
\text { case study teachers }\end{array}$ & $\begin{array}{l}\text { Spring 2003; } \\
2004 ; 2005\end{array}$ \\
\hline & Focus group interview & $\begin{array}{l}\text { Sub-sample of Year 2, } 6 \text { and } 9 \text { (maths } \\
\text { and English) pupils }\end{array}$ & $\begin{array}{l}\text { Summer 2003; } \\
2004 ; 2005\end{array}$ \\
\hline
\end{tabular}


A significant limitation of the research design was that classroom observational data was not included. Although the study had been designed to accommodate this (e.g. employing focus group interviews with pupils as means of eliciting further perspectives on classroom activity), classroom observations would have been of value in studying in detail variations in teaching approaches, classroom organisation and behaviour, particular interactions between the teacher and the pupils, and how, if at all, these affected and were affected by professional and/or personal factors and related to pupil outcomes. This research, therefore, focuses upon variations in teachers work and lives, but not on the specific features of their approaches to teaching.

Throughout, the analysis of school documentation was used to provide important contextual information. Thus, a rich and detailed picture of aspects of 300 teachers' lives and work in 100 schools during the period 2001-2005 was recorded. The preservation of this evidence in detail serves to enhance the verifiability of the findings (audit trail, etc). Table 1.3 shows the timetable of data collection.

There follows an overview of the methods of data collection chosen for the study.

\subsubsection{Methods used for data collection with teachers}

Questionnaire survey

During phase one of the study (Spring term 2002), a questionnaire was sent to all Year 2 and 6 teachers in all primary schools and Year 9 maths and English teachers in all secondary schools in the 7 LAs selected, with the aim of providing a representative cross-section of schools and pupils in terms of social economic status and pupil attainment.

This survey was carried out for three main reasons:

1. To identify groups of teachers within a range of schools who were prepared in principle to take part in the main body of the research, that would eventually involve a representative sample of some 300 teachers in 100 schools across 7 LAs. 
2. To establish, in conjunction with the literature review, a 'baseline' of key conditions and factors which teachers perceived currently to affect their ability to impact upon pupil learning and achievement. This baseline subsequently informed the more detailed analysis of the views of 300 teachers who took part in the three-year longitudinal study.

3. To initiate the development of an empirically based analytical framework for interpreting the factors affecting teacher effectiveness.

The questionnaire survey was informed by an initial review of relevant literature (see Day et al., 2005) and examination of a number of instruments used in a variety of earlier surveys. The instrument was piloted with several groups of teachers and the wording of some items revised prior to the main survey. As the questionnaire was designed to fulfil each of the major aims of the project, it contained sections that covered:

- Personal factors, for example reasons for teaching, motivation, career intentions;

- Pupils factors such as behaviour, motivation and self-esteem;

- School policies and staff relationships;

- External policies involving DfES, Ofsted and LAs;

- Opportunities for Continuing Professional Development (CPD).

A total of 1378 primary and 250 secondary schools were sent questionnaires. Returns from 1186 (810 primary and 376 secondary) teachers were received.

\section{Interviews}

During phase two of the study, participating teachers were interviewed six times in total, during the autumn and summer term of each of the three years of fieldwork. The approach changed depending on the purpose and focus of the interview, but included semi-structured, hierarchically-focused, telephone, narrative and critical incident approaches. Each approach was chosen for its specific strengths in gathering particular types of data and relevant interview protocols were adopted as necessary. 
Over the three year data collection period, these protocols were developed in order to ensure reliable and robust data generation and maintenance of participant confidentiality and anonymity, without preventing the research team from developing a rapport with participant teachers. As far as possible, a designated researcher remained with the same teachers and schools for the duration of the project.

All rounds of interviews were digitally recorded, saved on sound files and subsequently as anonymised files onto a PC. The first stage analysis on this data took place shortly after the interview was conducted, by the researcher who has undertaken the interview. This resulted in a preliminary understanding of the responses given and the development of analytical codes. Having subjected all 300 case study interviews to the first stage analysis, a second stage analysis was conducted in order to further interrogate the emerging findings and to establish what, if any, were the predominant themes.

This second stage analysis included the use of NVivo (computer-assisted data analysis software) which provided a powerful tool for the storage and synthesis of data collected and a range of key attributes which were linked to the interview data at an individual teacher level. These attributes were based on prior analysis and classification of different data sets (interviews, surveys, pupil progress measures etc). For example, attributes included the characteristics of the school in which the teacher worked (e. g. more or less disadvantaged context, based on the percentage of pupils eligible for FSM ranging from top to bottom quartile; also high to low attainment in national assessment results ranging from top to bottom quartile). Other attributes included teachers' years in teaching, posts of responsibility and gender. In the same way, value added indicators of academic effectiveness and measures based on pupils' views were also added to the NVivo teacher profiles each year.

Analyses of the interviews and other data in NVivo helped to produce groupings of teachers and create new variables that were tested as additional explanatory measures in exploring differences in the value-added measures of pupils' academic progress or other affective outcomes. 
In this way the qualitative and quantitative analyses fed into each other and thus increased understanding and contributed to the development of linkages between different features of teachers' lives, work, identities and their potential effects on pupils' outcomes.

\subsubsection{Methods of data collection with school leaders}

Semi-structured interviews were used (summer, 2003) with school leaders,

(Headteachers, Heads of Department, Key Stage coordinators). Due to the representiveness of the case study teacher sample, there were a number of participating teachers who were also involved in aspects of leadership in the school. In order to accommodate this and to balance the responses, a number of leaders were interviewed in each school rather than just the headteacher.

\subsubsection{Methods of data collection with pupils}

A number of methods were used to collect data from pupils of the participating teachers. These included:

- prior attainment measures - using standardised National Foundation for Educational Research (NFER) assessments designed to be compatible with the national curriculum to provide data that would be subsequently linked to outcome measures collected towards the end of the school year (discussed further in Chapter Four);

- outcome measures - which were linked to the results of pupils' baseline assessments in order to give a measure of value-added attainment;

- questionnaire survey - to collect attitudinal data relating to pupils' experiences and perceptions of school; and,

- focus group interviews - which allowed open discussion regarding pupils' views on school, learning, and their current class.

\subsubsection{Data analysis}

Data were analysed using either qualitative or statistical approaches. Once independent analyses were complete, analytical matrices (Miles and Huberman, 1994) were constructed in order to combine data from a variety of sources in relation to key 
'data cuts' ${ }^{6}$. The areas on which this integrated analysis focused were professional life phase, identity, and commitment. Each of these was explored in relation to teachers' effectiveness, both perceived and in terms of value-added pupil attainment. Individual profiles (cameos) were constructed for teachers and updated after each round of data collection. These profiles, which included information regarding (for example) teachers' professional life phases, identities, and value-added data, were shown to teachers during the final round of interviews as a means of validating researcher interpretation of results. Excerpts (including value-added data) from these cameos are used in this report to illustrate particular individual or collective characteristics or features of teachers.

\subsection{Validity and reliability}

In order to ensure validity of data collected and reliability of instruments used, two main measures were adopted.

\subsubsection{Piloting of each instrument with a group of 'similar' participants.}

In the case of teacher interviews, one group of teachers participated in the piloting for each round of interviews in order to ensure continuity of questions between visits. In addition, other teachers were also involved who had not been included in the piloting of previous rounds (content validity, construct validity, internal consistency). Where there were differences in an instrument relating to age, for example the pupil attitudinal survey, piloting was conducted with a group from each age group to ensure suitability of the instrument.

\subsubsection{Interviewer training.}

Training was given post-pilot interview, to all members of the research team, in order to gain inter- and intra-judge reliability (Tashakkori and Teddlie, 1998).

\footnotetext{
${ }^{6}$ Although the total number of teachers involved in the study was 314, the number of teachers included in the analysis of each 'data cut' varied depending on the availability of relevant data at an individual teacher level. For example, analysis of professional life phases involved 309 teachers, and analysis of teacher identities involved 295 teachers.
} 


\subsection{Ethical Issues}

The development of our research design was also influenced by a number of ethical considerations $^{7}$. The project adhered to the BERA ethical guidelines. Twp of the most important considerations in conducting the research were to protect the welfare of the research participants and the principle of informed consent. In line with such a principle, all headteachers and participating teachers were visited by a member of the research team and informed of the aims of the study, including the level of commitment that would be involved. They were then asked whether they wished to participate. In addition to having the right to refuse to take part, it was also accepted that individual teachers or schools had the right to withdraw from the sample at any point during the research, without the need to give a reason for this.

The issue of consent was also addressed with regard to the selective interviewing of pupils. Great care was taken in this aspect of the design of this research project and, although access and consent was carefully negotiated between the researcher, members of staff and parents of the pupils (where necessary), the pupils were also asked for their consent and, therefore, participated on a voluntary basis. As with the teachers, at the beginning of each focus group interview, permission was obtained by the researcher to digitally record the interview. The confidentiality of information given was stressed, and they were informed that opportunities would be available to ask the researcher any questions, regarding the study, in a non-threatening environment. In addition, the pupils were made aware that if they wanted to withdraw from the study at any time, they could do so without needing to give reason.

Finally, all participants were assured of confidentiality and anonymity to ensure that neither individuals, nor institutions could be identified. This represented an important function in the process of building solid relationships and rapport as it provided both schools and teachers assurance of anonymity and thus encouraged open, honest discussion whilst allowing for the reporting of contentious issues. Headteachers and local authority officials were also informed that they would not have any access to interview data (or data interpretation) regarding individual teachers, and that pupils' test and survey results would only be given (upon requests) to the class teachers,

\footnotetext{
${ }^{7}$ A Code of Conduct was developed for use during the project.
} 
aggregated to the class level to protect confidentiality in the case of pupil attitudinal data. Assurances were given that all information would be treated in the strictest confidence, and that schools, teachers and pupils would remain anonymous in the presentation of research findings. In accordance with these principles, identification codes and fictitious pseudonyms were used for all research participants at the outset of the study in order to protect their identities and ensure 'non-traceability'. All participants received regular project newsletters and were promised a copy of the Executive Summary of the final project report.

\subsection{Schools}

The total number of primary schools within the VITAE case study sample was 71 (74\%) and there were 25 (26\%) secondary schools. The breakdown by LA was:

- Barnet (8 primary and 2 secondary)

- Devon (13 primary and 4 secondary)

- Lancashire (20 primary and 8 secondary)

- Lewisham (10 primary and 1 secondary)

- North East Lincolnshire (3 primary and 2 secondary)

- Nottingham (6 primary and 3 secondary)

- Warwickshire (11 primary and 5 secondary).

Over half (54\%) of the 96 schools were classified as urban $(\mathrm{N}=52)$. A further $15 \%$ were classified as suburban $(\mathrm{N}=14)$ and the remaining $31 \%(\mathrm{~N}=30)$ were classified as rural.

Tables 1.4 and 1.5 show the proportion of case study schools in terms of size (number of pupils on roll), as compared to the national figures. 
Table 1.4: Size of primary schools in case study sample compared to national figures

\begin{tabular}{|l|c|c|c|}
\hline Size of school & $\begin{array}{l}\text { Number of primary } \\
\text { schools sample (N=71) }\end{array}$ & $\begin{array}{l}\text { Percentage of total } \\
\text { primary sample }\end{array}$ & $\begin{array}{l}\text { National } \\
\text { percentage }\end{array}$ \\
\hline $\begin{array}{l}\text { Very small } \\
\text { (up to 100 pupils) }\end{array}$ & 9 & 13 & 14 \\
\hline $\begin{array}{l}\text { Small } \\
(101-200 \text { pupils) }\end{array}$ & 19 & 26 & 29 \\
\hline $\begin{array}{l}\text { Medium } \\
(201-300 \text { pupils) }\end{array}$ & 31 & 44 & 30 \\
\hline $\begin{array}{l}\text { Large } \\
\text { (301-400 pupils) }\end{array}$ & 6 & 8 & 14 \\
\hline $\begin{array}{l}\text { Very large } \\
\text { (400+ pupils) }\end{array}$ & 6 & 9 & 8 \\
\hline TOTAL & 71 & 100 & 100 \\
\hline
\end{tabular}

Percentages may not total 100 due to rounding of figures

Missing data excluded

Table 1.5: Size of secondary schools in case study sample compared to national figures

\begin{tabular}{|l|c|c|c|}
\hline Size of school & $\begin{array}{l}\text { Number of secondary } \\
\text { schools sample (N=25) }\end{array}$ & $\begin{array}{l}\text { Percentage of total } \\
\text { secondary sample }\end{array}$ & $\begin{array}{l}\text { National } \\
\text { percentage }\end{array}$ \\
\hline $\begin{array}{l}\text { Very small } \\
\text { (up to 400 pupils) }\end{array}$ & 1 & 4 & 1 \\
\hline $\begin{array}{l}\text { Small } \\
(401-800 \text { pupils) }\end{array}$ & 8 & 32 & 35 \\
\hline $\begin{array}{l}\text { Medium } \\
(801-1200 \text { pupils) }\end{array}$ & 10 & 40 & 40 \\
\hline $\begin{array}{l}\text { Large } \\
(1201-1600 \text { pupils) }\end{array}$ & 5 & 20 & 22 \\
\hline $\begin{array}{l}\text { Very large } \\
(1600+\text { pupils) }\end{array}$ & 1 & 4 & 100 \\
\hline TOTAL & 25 & 100 & \\
\hline
\end{tabular}

Percentages may not total 100 due to rounding of figures

Missing data excluded

The sample also represented the national profile in terms of pupils' eligibility for free schools meals (Tables 1.6 and 1.7).

Table 1.6: Primary school pupils' eligibility for free school meals compared to national figures

\begin{tabular}{|l|c|c|c|}
\hline $\begin{array}{l}\text { Percentage of pupils } \\
\text { eligible for free } \\
\text { school meals }\end{array}$ & $\begin{array}{l}\text { Number of primary } \\
\text { schools sample (N=71) }\end{array}$ & $\begin{array}{l}\text { Percentage of total } \\
\text { primary sample }\end{array}$ & $\begin{array}{l}\text { National } \\
\text { percentage }\end{array}$ \\
\hline 0-8\% FSM & 22 & 31 & 33 \\
\hline 9-20\% FSM & 19 & 27 & 29 \\
\hline $21-35 \%$ FSM & 14 & 20 & 19 \\
\hline Over 35\% FSM & 16 & 23 & 19 \\
\hline TOTAL & 71 & 100 & 100 \\
\hline
\end{tabular}

Percentages may not total 100 due to rounding of figures Missing data excluded 
Table 1.7: Secondary school pupils' eligibility for free school meals compared to national figures

\begin{tabular}{|l|c|c|c|}
\hline $\begin{array}{l}\text { Percentage of pupils } \\
\text { eligible for free } \\
\text { school meals }\end{array}$ & $\begin{array}{l}\text { Number of secondary } \\
\text { schools sample (N=25) }\end{array}$ & $\begin{array}{l}\text { Percentage of total } \\
\text { secondary sample }\end{array}$ & $\begin{array}{l}\text { National } \\
\text { percentage }\end{array}$ \\
\hline $0-13 \%$ FSM & 10 & 40 & 45 \\
\hline $14-35 \%$ FSM & 9 & 36 & 36 \\
\hline Over 35\% FSM & 5 & 20 & 14 \\
\hline Grammar Schools & 1 & 5 & 5 \\
\hline TOTAL & 25 & 100 & 100 \\
\hline
\end{tabular}

Percentages may not total 100 due to rounding of figures

Missing data excluded

FSM is a proxy to describe the socio-economic status of schools' pupil catchment areas. An overall measure of FSM context for both primary and secondary schools was adopted, based on that used in inspection benchmarking, for the purposes of grouping participating teachers and schools, as follows:

FSM 1 - 0-8 per cent FSM

FSM 2 - 9-20 per cent FSM

FSM 3 - 21-35 per cent FSM

FSM 4 - over 35 per cent FSM

\subsection{Conclusion}

This part of the report has provided a summary of previous research and the rationale for this study. It has also described the research design, the development of the conceptual framework, the methods of data collection and analysis, and the actual sample. Part Two provides a brief discussion of the characteristics of the teachers and pupils involved in the research, the primary project hypotheses, and definitions of key terms. 


\section{PART TWO \\ CHAPTER TWO: \\ THE TEACHERS AND THE PUPILS}

\subsection{Introduction}

This chapter gives an overview of the characteristics of the a) teachers, relating to their professional roles and personal lives, and b) pupils, relating to their attitudes to schools, their classes and their teachers.

\subsection{Teachers}

The 300 teachers who participated in the study were involved in a variety of schoolbased activities and roles which influenced their work and personal lives. This section reports on the three most common characteristics shared by the sample motivations, additional responsibilities, pupil behaviour, classrooms, and life events.

\subsubsection{Initial motivation for teaching}

In an initial questionnaire, teachers were asked, by means of an open-ended question, what had first attracted them to the teaching profession. A total of 253 (145 primary and 108 secondary) case study teachers returned the questionnaire. Just over half of teachers $(51 \%, \mathrm{~N}=129)$ gave 'working with children' as the reason.

I love to be with children and find their minds fascinating (Primary teacher).

I wanted to work with young children and I felt that teaching would be a rewarding and fun job (Primary teacher).

This was followed by wanting to make a difference ( $\mathrm{N}=43,17 \%$ of 253 ), which included the desire to inspire children ( $5 \%$ of $43, \mathrm{~N}=2$ ), to provide them with a foundation for life and having a hand in educating the next generation ( $1 \%$ of $43, \mathrm{~N}=$ 1) continued along the theme of wanting to make a difference. This was in line with Sternberg's (1994) 'crusaders'.

I believed I could make a difference, make learning a pleasure

(Primary teacher). 
I wished to make more of a contribution to tomorrow's generation (Secondary teacher).

Like Sternberg's (1994) 'content specialists', an interest in a particular subject (10\%, $\mathrm{N}=25$ ) and the desire to be involved in fulfilling work and, with that, job satisfaction $(8 \%, \mathrm{~N}=20)$ were also given as reasons for becoming a teacher by survey respondents.

I was attracted to teaching because I thought I could inspire and motivate young people through literature (Secondary teacher).

While most reasons given for the attraction to the teaching profession were fairly equal across both primary and secondary sectors, unsurprisingly the interest or love of a particular subject was more apparent in the secondary sector (32\% of $108, \mathrm{~N}=35)$, with only 1 per cent of the 145 primary teachers $(\mathrm{N}=1)$ giving this as a reason. Likewise the desire to share their knowledge and enthusiasm for a subject was indicated by $16 \%$ of the 108 secondary teachers $(\mathrm{N}=17)$. No primary teachers gave this as a reason.

Other reasons given for the attraction to teaching included, always wanting to be a teacher $(5 \%$ of $253, \mathrm{~N}=13)$, seeing teaching as a career or vocation $(6 \%, \mathrm{~N}=15)$ and an interest in teaching and education in general $(5 \%, \mathrm{~N}=13)$.

Just something I had always wanted to do (Primary teacher).

I wanted to teach from age 5. Helping a child to develop and learn is an honour (Primary teacher).

For some, predominantly primary teachers ( $9 \%$ of $145, \mathrm{~N}=13$ ) in contrast to secondary teachers $(3 \%$ of $108, \mathrm{~N}=3)$, the variety of roles that the job offered was an attractive aspect, as was the opportunity for creativity ( $4 \%$ of $253, \mathrm{~N}=10)$ and relative independence and control of ones own work ( $2 \%$ of $253, \mathrm{~N}=5)$. For others in the sample of 253 teachers, it fitted in with family life (3\%, N=8), offered job security $(2 \%, \mathrm{~N}=5)$, good pay $(1 \%, \mathrm{~N}=3)$ and holidays $(4 \%, \mathrm{~N}=10)$.

The holidays! A career which would enable me to spend time with my children (Primary teacher).

Flexible working hours that fitted in with my own children when they were young (Primary teacher). 
A few teachers indicated that when they became teachers it was the only career opportunity available to them ( $2 \%$ of $253, \mathrm{~N}=5)$.

\subsubsection{Changes in policy}

There were a number of policies which had a direct impact on teachers work and their feelings of effectiveness. An example of this was recent policy stemming from the National Agreement on Raising Standards and Tackling Workload (DfES, 2003b). This reform was beginning to impact on primary teachers by the end of the project, though there was much more limited application in secondary schools. While there were some initial concerns expressed by primary teachers about what they were not encouraged to do (e.g. wall displays), there was a welcome for the freeing up of time during the working day and the opportunities this gave for planning, marking and discussion. The increased provision of Teaching Assistants was also generally welcomed, though with some reservations about the additional preparation that required their management and, in secondary schools, the criteria for allocation to classes e.g. there was a tendency for them to provide support 'lower' sets in Year 9, where the numbers were also smaller than higher ability sets.

\subsubsection{Additional responsibilities}

In all, $70 \%$ of all secondary teachers and $90 \%$ of all primary teachers in the sample had roles in addition to their own class teaching responsibilities. The profile of roles outside the classroom for secondary teachers was different from that for primary teachers because secondary teachers' extra responsibilities usually related either to their subject department or to a pastoral team of teachers overseeing a year group.

The nature of roles outside the classroom, their intensity and the amount they distracted from classroom teaching varied immensely. The roles included overseeing one or more school subjects - ranging from high profile curriculum areas like numeracy, literacy or ICT to other curriculum subjects such as history, geography, science, design and technology, music or physical education. There were also other rather different whole school responsibilities such as overseeing a Key Stage, raising the profile of gifted and talented children or government initiatives of relevance to the particular the schools, such as Education Action Zones. 
Compared to earlier generations of teachers and to those in other countries, these teachers had quickly taken on additional responsibilities - particularly in primary schools - and carried them through the length of their careers. Three-quarters of teachers with 4-7 years experience had additional responsibilities. These responsibilities played a significant role in teachers' identities and challenged their capacities to sustain the quality of their classroom teaching. Not all teachers in all phases perceived themselves to benefit from additional responsibilities. Thus the early phases of teachers' professional lives was not a 'stabilisation' phase (cf Huberman, 1989) so much as a period of continuing change and challenge to stability as teachers began to look beyond the classroom and take additional responsibilities.

\subsection{Pupil-Teacher Relationships}

\subsubsection{Teacher attitudes to relationships and behaviour}

Contributing to the development and learning of pupils is central to teachers' sense of vocation and effectiveness. How pupils respond, the 'pupil climate', was therefore a key element for teachers. Our survey across the seven participating LAs (2001) reported that primary teachers' reasons for becoming teachers were primarily about wanting to work with pupils and wanting to make a difference to their lives. This also applied to secondary teachers, though for a third their subject enthusiasm was a key motivation. Teachers' relationships with their pupils were, therefore, central to their motivation and commitment, sense of self-efficacy and job satisfaction.

Our analyses found that, for nine out of ten teachers, ratings of their relationships with pupils were positive, irrespective of the pupils' levels of motivation (Pupil attitudinal surveys 2003-5). The $10 \%$ reporting negative relationships were drawn from across all the professional life phases. We would, therefore, take as a 'constant', teachers' beliefs that most have good relationships with their pupils, a perception generally supported by the majority of pupils' ratings of their teachers in the pupil attitude surveys, although there was significant variation between teaching in pupils' views. 
What did vary were teachers' attitudes about pupils' behaviour, with half the teachers seeing this as having a negative impact on their effectiveness. Not surprisingly, it was teachers in their first three years of teaching for whom pupil behaviour was a strongly negative factor. Of the 19 teachers with ratings in this group, of whom two thirds were secondary, 16 were negative. The three positive ratings all taught in FSM 1 schools (the lowest proportion of Free School Meals). Across the other professional life phases there was little consistency, with the 8-15 years phase the most positive (two thirds). This phase had the highest proportion of primary teachers - who were generally more positive about behaviour than secondary teachers. Both the 4-7 and 16-23 phases had over half the teachers rating behaviour as a positive, while the $31+$ years phase had over half seeing it as negative.

For the primary and secondary teachers in schools in social and economically disadvantaged contexts, work was exacting. For many, increased workload (not only during working hours but after them) was largely perceived as being caused by a range of DfES policies over a number of years, and was seen to be intrusive on their personal lives. Meeting what they regarded as excessive government targets was challenging, particularly in contexts which were perceived to include a mix of pupils who did not value education and who misbehaved in class regularly. This seemed to be more frequent and more disruptive in secondary than primary schools. In some of these schools, again mostly secondary, parental support was poor also. Secondary teachers spoke in detail of a range of social and policy challenges to their perceived ability to maintain their effectiveness. Those who worked in schools in challenging social and economic contexts were especially vocal about the difficulties they faced the negative effects of excessive workloads related to marking and planning, external government changes, government bureaucracy, negative effects on teaching of the 'inclusion' policy, and behaviour/discipline issues.

Whilst almost all teachers referred to deteriorating pupil behaviour and the impact of central government initiatives on workload and class composition (by means of the 'inclusion' agenda, for example), it was those in schools in areas of social and economic deprivation that referred more frequently to these issues, to lack of parental support and to associated problems of demoralisation, failing energy and ill health. 
It was this group of teachers, working in especially challenging circumstances, that may be said to be at greater risk of having their resilience eroded and potentially losing their motivation and commitment to their work.

\subsubsection{Pupil attitudes}

As part of our methodology, we sought the views of pupils about their schools, classrooms and teachers. This was achieved through a (voluntary) pupil attitude survey of all classes (Years 2 and 6) or a specific teaching group (Year 9) which was complemented by pupil focus groups in a sample of schools. There were three forms of the survey for Year 2, Year 6 and Year 9. The surveys were conducted towards the end of the spring term/early summer term for in each of three years (2003-5).

Pupils' responses are used here to provide a context in which to interpret teacher ratings and responses. Younger pupils were much more positive about school than older pupils. This was illustrated by the fact that just over $77 \%$ of the questions on the 2003 Year 2 pupil survey were given the most positive response by over half of the pupils responding. This compared with $36 \%$ of Year 6 pupils and 20 per cent for Year 9 pupils.

Year 2 children were much more likely to report they had been bullied (49\%) than those in Year $6(33 \%)$ or Year $9(29 \%)$. Name calling and bullying of other children was more likely to be reported by pupils in Year 9 (21\% reported other children were often bullied and $36 \%$ reported that other children experienced name calling often) than Year 6 (where the figures were 15\% and 21\% respectively). Year 2 pupils were not asked this question.

Year 6 pupils were more likely to agree with the statement teachers in this school make us want to work' than Year 9 pupils (a quarter of Year 6 and only one in ten Year 9 pupils were in strong agreement with this). Similarly, almost half of Year 6 pupils compared to less than a quarter of Year 9 pupils were in strong agreement with the statement 'teachers at this school really believe that all pupils can achieve'. Over two thirds of Year 6 pupils rated their teachers as being there at the start of lessons 'a lot', for Year 9 this was only just over half. 
Another difference was that nearly half the Year 9 pupils responded that teachers were not interested in them 'as a person' compared to only one in five of Year 6 pupils. This indicates that pupil-teacher relationships were less positively viewed by pupils in secondary school. This may be affected by pupil age but also by the organization of teaching in secondary schools where pupils are taught by many different subject teachers and have reduced opportunities for sustained interaction with particular teachers.

We also found predictable gender effects (girls having generally more positive attitudes), which lessened with age, and less predictable socio-economic effects, with FSM pupils often being more positive about their teachers than non-FSM pupils (see below).

\subsubsection{Change over time}

Because we conducted the pupil survey over three years we were able to capture the attitudes of three different groups of pupils for the same teacher. This fed into our investigation of variation over time. Did different groups rate the same teacher in the same way? In relation to the pupil context, the interest was whether pupils' responses remained consistent over the three consecutive years - or were there changes in the three cohorts' attitudes?

Year 2 and 6 pupils remained positive and largely consistent in their responses over the three years, while Year 9 pupils were consistent though less positive. Indeed, the evidence suggested that Year 9 pupils were relatively more negative about their schools, classrooms and teachers than pupils in Years 2 and 6.

Some questions, related to their teacher and classroom experiences, showed an increase in positive responses over time for both Year 6 and Year 9 pupils: 
My teacher:

Makes sure when we work on our own, I know exactly what to do;

Checks on my progress regularly;

Praises pupils more often than he/she criticises them;

Treats me fairly;

Seems to like all the pupils.

The one item that became progressively more negative for both Year 9 English and mathematics pupils was a perception that hard work is rewarded in this school.

\subsubsection{Socio-economic status and attitude}

Pupils entitled to free school meals were often more positive about their teachers and classes than other pupils, though a minority were more negative (pupils eligible for free school meals, (FSM) used the 'strongly' response more frequently, both for 'agree' and 'disagree'). Thus Year 2 (FSM) pupils were more likely than non-FSM

pupils to find school interesting while Year 6 and Year 9 (FSM) pupils were more likely to strongly agree that the teachers in this school make us want to work and I like school tasks the best that really make me think. However, despite this, there was a negative strand in Year 9 (FSM) pupils, for example with 16\% strongly disagreeing about teachers wanting them to work, against $4 \%$ of non-FSM pupils. Year 9 (FSM) pupils were also more likely to respond 'very often' to my teacher sets me my own targets for learning.

FSM pupils were less positive was around safety and bullying. Consistently across Years 2, 6 and 9 FSM pupils would report that they felt less safe in school and that they had witnessed and experienced more bullying and name calling. This supports the earlier conclusions concerning the higher incidents of behaviour difficulties in schools in challenging circumstances. An implication of this is that teachers working in high FSM schools were more likely to be dealing with pupils who were having problems with other pupils more than colleagues in more affluent schools, and some of the behavioural issues were likely to be more pronounced. 


\subsubsection{Classroom contexts}

While the overall pattern of results was consistent over time and generally positive about schools and teachers, this does not mean that there were not considerable differences about how classes regarded their teachers. Using multilevel modelling techniques (see Chapter Four) we were able to estimate the amount of variation that existed between classes in their views of school. The views of Year 2, 6 and 9 pupils about their school and the classroom environment were found to differ significantly from class to class. The survey data showed larger differences between classes for older pupils. This may partly be because of setting at Year 9 in some schools and some subjects.

For Year 2 pupils, the largest differences between classes were found for reported noise levels in the class, finding school interesting and liking their teachers. In Year 6, the biggest differences were around bullying, whether the school was perceived as a friendly place, and the setting and marking of homework, class agreement with 'sets us homework every week' ranging from 0 to $100 \%$. In addition, there was considerable variance between Year 6 classes in perceptions of whether the teacher made the lessons interesting, was 'good at explaining what we are doing' and 'seems to like all the children'.

For both Year 9 subject groups, views about the classroom environment differed much more than views about the school in general. For both English and maths classes there were large differences around the extent to which teachers set and marked homework, made lessons interesting, were clear about the aims of the lesson and made sure a lot was learned. There were a number of questions where only English or maths showed large differences between classes. In English these were mainly around homework and marking, in mathematics around teaching methods and keeping order.

\subsubsection{Pupil attitudes and attainment}

We also looked at the relationship between pupil attitudes and their progress once pupil background and prior attainment had been taken into account. We found limited evidence of classes' perceptions of their classroom or school environment related to the amount of progress they made in reading or maths in Year 6. However, some 
significant results were found for items relating classroom climate to pupil progress at Year 9. For example, classes which reported more positively that, 'my teacher seems to like all the pupils', showed greater progress in English (Year 9). Six items related to teacher behaviour were found to be positively related to pupils' progress in maths in Year 9.

- Praises pupils more than he/she criticizes them

- Is interested in what the pupils think

- Helps pupils who are having problems in understanding the work

- Makes the lessons interesting

- Treats all pupils the same

- Seems to like all the pupils.

When the average class attainment level was included in the analysis (see Chapter 4 for the detailed discussion of pupils' progress) these items were no longer statistically significant. This may indicate that behaviour, attitudes and expectations vary more for maths teachers in relation to the average attainment for their classes. Setting is more common in maths and this may in part account for such differences. The results indicate that pupils perceived more variation in practice in maths in Year 9 than in English and point to features of teaching that may be especially important to promote engagement and achievement in this subject in Key Stage3.

These findings were complemented by an analysis of whether pupils' own perceptions of their school and classroom were in any way related to the amount of progress that they made over the academic year. Again there was limited evidence of a direct relationship between attitude and progress. However, for a few items a more positive response were related to greater progress:

The teacher is good at explaining what we are learning (Maths, Year 6)

The teacher treats me fairly (English and maths, Year 9)

The other subject specific Year 9 items involved, in mathematics, expectations, making clear what was to be done and accepting mistakes. In English the items involved targets, classroom behaviour, praise and setting homework. 


\subsubsection{Summary}

1. Teachers viewed positive relationships with pupils as a central factor in their professional identity.

2. The impact of pupil behaviour was more mixed. While for many it was a positive factor, particularly for more experienced primary teachers, it had a negative impact for most new teachers and those with $30+$ years experience.

3. Pupils' attitudes to school and the classroom environment were age-related and progressively moved from being highly positive in Year 2 to more mixed, generally positive and relatively more negative, in Year 9. By Year 9 there were strong class level effects, though it is possible that setting may account for some of these differences.

4. Pupils' attitudes remained largely the same during the three years of the survey. Some items showed increasingly positive responses, but the reducing response rate may account for this pattern.

5. Pupils eligible for free school meals were sometimes more positive about enjoying their schooling and had more positive views of teachers than nonFSM pupils. However, they were consistently less positive about safety and bullying in school.

6. At the whole class level there were considerable differences in the responses to items on noise, bullying, homework, interest and clarity of aims. These, therefore, were important aspects of teaching practice and classroom climate that differed amongst the sample.

7. There appeared to be little relationship between individuals' attitudes and their attainment levels at primary school. This may suggest that specific features of teaching are more likely to affect attainment and progress. For maths in Year 9, there was greater evidence that particular features of teacher behaviour were important, and that these were mediated by the average attainment level of the class (which may affect the use of setting in this subject). 


\subsection{Conclusion}

This chapter has summarized the motivations for entering teaching of the VITAE teachers, and the impact of additional responsibilities on their work and lives. It has reported also on pupil relationships, attitudes and behaviour. Key findings were:

- Reasons for entering the teaching profession fell into five main categories: making a contribution, professional challenge, personal benefits, identity of being a teacher, subject area.

- In all, $70 \%$ of all secondary teachers and $90 \%$ of all primary teachers in the sample had roles in addition to their own class teaching responsibilities.

- Three-quarters of teachers with 4-7 years experience had additional responsibilities.

- Teachers viewed positive relationships with pupils as a central factor in their professional identity.

- Overall, pupil attitudes to school and the classroom environment progressively moved from being highly positive in Year 2 to more mixed, generally positive but relatively more negative, in Year 9. By Year 9 there were strong class level differences in pupils' perceptions in how positive pupils felt although these may be mediated in part by the average attainment level of classes (which reflect the use of setting).

- Significant school and class level differences were identified in pupils' perceptions of certain aspects of teacher behaviour. In some schools and classes, pupils had significantly less favourable perceptions than in others.

- There appeared to be little relationship between individual pupils' attitudes and their attainment for primary pupils, but in maths in Year 9, significant differences relating to teacher behaviour emerged.

- Female teachers in the sample were somewhat more likely to report that home life supported their teaching, than male teachers.

The next chapter (Chapter Three) focuses on the project hypotheses and definitions of key terms. 


\section{CHAPTER THREE: HYPOTHESES AND DEFINITIONS}

\subsection{Introduction}

A review of literature and responses to the original questionnaire indicated that variations in teachers' work occur at different times, in different contexts and for different reasons and that variations in teachers' work and lives can have both positive and negative influences on their relative and relational effectiveness. This led to the development of five primary working hypotheses under which a number of subsidiary hypotheses were arranged which helped in the focusing of our enquiry. This chapter gives a summary of the primary hypotheses. This is followed by definitions of key terms used during the project.

\subsection{Hypotheses}

\subsection{Primary hypothesis 1}

There may be associations between teachers' perceived effectiveness and relative effectiveness measured by the value added to pupils' attainments.

\subsection{Primary hypothesis 2}

Variations in teachers' effectiveness can be identified by investigating individual teachers and groups of teachers in particular phases of their working lives.

\subsection{Primary hypothesis 3}

Teachers' sense of positive identity is closely related to their perceived effectiveness. Their capacities to manage their identities in changing life and work circumstances are fundamental to their abilities to sustain effective teaching.

\subsection{Primary hypothesis 4}

Commitment and resilience are key factors in establishing and maintaining teachers' effectiveness. It is possible to identify patterns of influences which affect teachers' commitment and resilience which will assist in understanding the complexities of teacher's work, lives and identities in particular contexts. 


\subsection{Primary hypothesis 5}

Teachers' effectiveness is moderated by their professional life phases and identities; and these are mediated positively and negatively by the interaction between personal factors (values, beliefs, life events and circumstances), situated factors (school leadership, culture, colleagues, working conditions and pupils) and professional factors (roles, CPD, external policies). Commitment and resilience are key outcomes of the management of the moderating and mediating influences and these are associated with both perceived effectiveness and relative effectiveness defined by value-added measures of pupil attainment.

\subsection{Definition of terms}

This brief section explains our use of various terms: agency, commitment, resilience, and well-being.

Agency: $\quad$ a person's ability to pursue their own goals; an action or intervention to produce a particular result.

The concept of agency has been applied in research studies (Gergen, 1987; McAdams, 1993) in order to explain the behaviour and perception of individuals, and to highlight aspects of their personality, identity, etc. This concept has been defined as 'intentional acting aiming at self-protection, self-expansion, and mastery of social reality' (Pulkkinen and Aaltonen, 2003:146). Theorists (Russell, 1996; Brandt, 1996) have agreed that agency relates to actions that are intentionally initiated and, although reliant on various factors and opportunities, is ascribed to those who attempt to modify their environment according to their aims and necessity. Moreover, a sense of agency has to be driven by the individual - 'By a sense of agency I mean a sense of oneself as an actor or a sense that actions are one's own' (Marcel, 2003).

Strength of agency has been associated with the level of success of a particular action; a causal relationship between the intention of an individual and a behaviour that results in the successful achievement of change. Sosa (2001) described agency as a 'capacity to intentionally control a part of life' but went on to suggest that the strength of agency is dependent on the awareness of an individual of what and how they intend to fulfil the chosen action in their particular circumstances. 
The importance of agency in relation to teachers' work and lives is underpinned by Giddens' (1991) notion that human agency and social structure are not separate concepts or constructs, but two complementary ways of considering social action; the first comprising individuals who undertake social action and interaction in various situations, and the second involving the rules, resources, and social relationships that are a result of social interaction (Giddens, 1986). A sense of agency, therefore, is developed when an individual feels able to pursue their goals within the context of positive and negative interactions within and between internal, situated (e.g. colleagues, school context, leadership) and personal (e.g. health, family) factors, and external, professional factors (e.g. workload, career structure). A focus on agency provides new insight into issues relating to teachers' ability to sustain commitment, their effectiveness, and the impact on pupils.

\section{Commitment: the manifestation of belief and motivation.}

Teacher commitment has been identified as one of the most critical factors in the success of education (Huberman, 1997, Nais, 1981). Commitment has been defined as a predictor of teachers' performance, burnout, attrition as well as having an important influence on students' cognitive, social, behavioural and affective outcomes (Firestone, 1996; Louise, 1998; Day et al, 2005). It is a term often used by teachers to describe themselves and each other (Nias, 1981, 1989), is a part of their professional identity (Elliott and Cresswell, 2001), and may be enhanced or diminished by factors such as student behaviour, collegial and administrative support, parental demands, and national education policies (Day, 2000; Louis, 1998; Riehl and Sipple, 1996; Tsui and Cheng, 1999).

Ebmeier and Nicklaus (1999) connected the concepts of commitment and emotion and defined commitment as part of a teacher's affective or emotional reaction to their experience in a school setting and part of the process regarding the level of personal investment to make to a particular school or group of pupils. This connection is central to understanding teachers' perceptions of their work, colleagues, school leadership, and the interaction between these and personal life. It is also key, therefore, to professional life phase, identity and the discourse between these and educational reform. 
Resilience: the ability of an individual to withstand or recover quickly from difficult conditions related to self-efficacy.

Resilience is a multi-faceted (Oswald et al., 2003) and unstable construct. The nature of resilience is determined by the interaction between the internal assets of the individual and the external environments in which the individual live and grow. Thus, the manifestations of resilience vary from person to person and fluctuate over time. Rutter (1985) defines resilience as facing '... stress at a time and in a way that allows self-confidence and social competence to increase through mastery and appropriate responsibility' (cited in Gordon et al., 2000: 1). The idea of resilience recognises the pain, struggle and suffering involved in the adaptation process but focuses more on strengths instead of deficits (Henderson and Milstein, 2003: 3).

The need to foster teachers' sense of resilience is twofold: firstly, it is unrealistic to expect students to be resilient if their teachers, who constitute a primary source of their role models, do not demonstrate resilient qualities (Henderson and Milstein, 2003). Secondly, an understanding of teacher resilience in the process of meeting professional expectations and a range of externally and internally generated targets and managing work-life tensions over the course of a career and in different contexts will contribute to the existing knowledge of teacher professional development, commitment and effectiveness. More importantly, it provides a new perspective on teacher quality, effectiveness and retention issues. Research on teacher retention tends to focus on factors affecting teachers' decisions to leave the teaching profession. Instead what is required is a better understanding of the factors that have enabled the majority of teachers to sustain their motivation, commitment and effectiveness in the profession. It is, therefore, likely to be fruitful to examine why and how generally teachers maintain commitment (i.e. are resilient) despite the range of unfavourable experiences they can encounter in their work environments.

Well-being: the state of feeling healthy and happy.

Warr (1987, 1999) identified several situational and environmental factors (e.g. opportunity for control) which interact with personal factors in their influence on well-being. The concept of well-being has often been connected with the balance of work and personal life, and the often competing demands which arise between these two roles. The demands that are experienced by individuals were characterised by 
Grant-Vallone and Donaldson (2001) as 'work-stressors' and 'non-work stressors'. 'Work stressors' included the number of hours worked and workload, whereas the 'non-work stressors' were described as children, relationships, health, etc. Also included in this latter category was the interaction between work and family commitments (Frone et al, 1997; Higgins et al, 1994).

Threats to personal outcomes of work and/or family have centred on the conflict between these two roles'. The potential impact of a lack of balance between work and life has been found to lead to higher stress levels (Chapman et al, 1994), increased depression (Googins, 1991), physical ailments (Frone et al, 1997), decreased quality of family life (Higgins et al, 1992) and lower energy levels (Googins, 1991). The research evidence suggests, therefore, that conflicting pressures at work and home are related to health and well-being. This threat of work-life conflict to employee wellbeing has implications, not only for those who must cope with stress and illness, but also for the organizations, governments, and society on the whole. From the employer's perspective, the inability to balance work and family demands has been linked to reduced work performance, increased absenteeism, high turnover, and poor morale (Duxbury and Higgins, 1994).

However, the conceptualisation of well-being is contested and has shifted from a concern with stress and illness to a focus on positive experiences. In the USA, a recent focus on 'positive psychology' is concerned with factors leading to well-being (Kahneman et al, 1999; Snyder and Lopez, 2002). Positive psychology at the subjective level is about positive experience: well-being, optimism, hope, and happiness. At the individual level it is about the character strengths, the capacity for emotion and vocation, interpersonal skill, aesthetic sensibility, and perseverance, amongst others. Recent research has proposed a broader perspective on the work and home balance, which encompasses the positive aspects, not just the negative effects, as mentioned previously (Grzywacz and Marks, 2000). For example, work may positively 'spill over' to home by developing a sense of competence, by developing a career, or maintaining contact with friends and peers. Whereas, negative spill-over can be associated with poorer physical and mental health (Grzywacz, 2000), conversely, positive spill over from work to home has been associated with better physical and mental health. 
Work may also be a source of solace and focus for those experiencing negative personal or health issues such as divorce and bereavement. For example, it is recognised that depression and ill health is much higher for unemployed than employed people.

\subsection{Conclusion}

This chapter directly informs the following discussions (Part Three) which focus upon findings relating to variations in pupils' value added progress and attainment, teachers' professional life phases, CPD and identities. 


\section{PART THREE:}

\section{VARIATIONS IN EFFECTIVENESS}

This part of the report identifies key variations in teachers' relative effectiveness as defined by value-added measures of progress and attainment, their professional life phase, and identities, and how each may be affected to a different degree by key personal life events, perceptions of policy, adverse pupil behaviour, in-school support and the impact of workload on work-life management. Chapter Four gives an account of relative teacher effectiveness as measured by the value-added analysis of pupil progress and attainment. Chapter Five explores teachers', the influences on teachers at different points during their professional life phases. Chapter Six reports our teachers' experiences of CPD in these professional life phases. Finally, Chapter Seven investigates teacher identities, the roles of 'Scenarios', and their impact on well-being, resilience and vulnerability. These chapters directly address the primary hypotheses described in Chapter Three. 


\section{CHAPTER FOUR \\ RELATIVE EFFECTIVENESS: \\ USING VALUE-ADDED APPROACHES TO EXPLORE PUPIL ATTAINMENT AND PROGRESS}

Hypothesis 1: There may be associations between teachers' perceived effectiveness and relative effectiveness defined by value-added measures of pupils' attainment and progress.

\subsection{Introduction}

The VITAE study chose to use an educational effectiveness component as part of its mixed methods research design. The study has sought to explore two aspects of effectiveness: relational and relative. Teachers' own perceptions of their effectiveness were identified through surveys and interviews. Changes in perceptions of effectiveness over the course of their teaching careers, including changes over the three years of the research, were identified. In addition, and related to these, an important feature of the research was the use of external indicators of effectiveness based on the study of pupil attainments. This feature of the study drew on the concept of 'value added' (a form of analysis that seeks to measure the school or teachers' contribution to pupils' progress, social behavioural or affective outcomes).

Pupils' attainments in three year groups in classes taught by the VITAE teacher sample were analysed in each of the three years of the fieldwork. This feature of the quantitative component was used to establish the relative effectiveness of different project teachers in promoting pupils' attainment in English and mathematics. The results of these analyses were fed into the qualitative strand of the project and form an integral component of the chapters on professional life phase, identities and commitment and resilience. They provided the means of exploring whether there were relationships between perceived effectiveness and relative effectiveness in promoting pupils' attainment and progress. 
This illustrates both the limitations of quantitative and qualitative only designs and the advantages (to understanding the nature of effectiveness) of being able to explore the influence of mediating and outcome factors when making judgements about effectiveness. In other words, multilevel modelling and value added pupil attainment themselves are important to identify differences in teacher effects on pupil outcomes but cannot fully explain the reasons for differences between teachers' relative effectiveness.

One important limitation of the VITAE research design was the absence of classroom observation data (a component of the original proposal that was not funded due to budget constraints) for the 300 teachers in the case study sample. The effect of this was that data on different aspects of teachers' classroom practice - including teacherpupil interactions, etc - were not collected. Thus, teaching effectiveness and variations between teachers in specific aspects of their classroom teaching and pupils' responses to this could not be researched. As a consequence, the multilevel analysis was not able to measure and test a number of important features of effective teaching behaviours identified in the school and teacher effectiveness literature (see section 1.1) nor investigate the extent to which they were empirically confirmed for the VITAE sample. Instead, the multilevel analysis was primarily used to identify, measure and categorise teachers' relative effectiveness in promoting the pupil attainment and progress across three consecutive school years (2002/03 to 2004/05) and to investigate stability and consistency in effects for teachers of different year groups and in different curriculum areas.

The multilevel analysis strategy can be split into two main parts:

i) Identifying the amount of variation that exists across schools in pupil attainment levels in Year 2 in comparison with the pattern in schools with similar intake characteristics $^{8}$. These contextualized analyses adopt statistical control for differences in student intakes (in terms of pupil level and school level characteristics) and create an attainment indicator for each school after adjusting for the net impact of statistically significant pupil background and school context characteristics.

\footnotetext{
${ }^{8}$ No prior attainment baseline data were collected at the beginning of the school year for teachers in Year 2 classes, so value-added measures of pupil progress could not be calculated.
} 
This measure of relative effectiveness indicated how well children from each school achieved, compared with the attainment levels of similar children in other schools ${ }^{9}$.

ii) Assessing the extent of differences between teachers in Year 6 and Year 9 in pupils' progress (attainment gains) over a school year and their relative value added effectiveness, taking into account a range of pupil characteristics and measures of pupil prior attainment. This analysis produced value added measures of teachers' relative effectiveness for the Year 6 and Year 9 sample. Further details of the statistical models and results are given in Appendix 2.

The most recent contextualised value added models adopted by the DfES incorporate PLASC data on pupil characteristics as well as measures of prior attainment. These are very similar to the modelling approach adopted by VITAE, with the exceptions that the DfES examine overall performance (using a composite outcome covering English, maths and science at Key Stage 2 and 3) rather than producing separate models for English and mathematics and, in VITAE, progress is assessed across individual school years rather than Key Stages. Thus, the DfES models examine school rather than potential individual teacher effects by examining progress for all children in a given year group across different Key Stages. The VITAE models provided a more fine grained analysis of effectiveness that enabled a focus on the question of relative effectiveness at the teacher level by studying progress over one academic year in different classes or teaching groups, but following the same teachers for three years.

\subsection{School improvement and effectiveness knowledge base}

A review of school and teacher effectiveness literature was used to inform the VITAE research design and a brief synthesis is included here to provide a context for the effectiveness as defined by pupil value added attainment component of the VITAE study. School and teacher effectiveness research is characterised by its specific attempts to measure differences between schools, departments or teachers in their impact on pupils' educational outcomes, taking into account differences in the prior

\footnotetext{
${ }^{9}$ For further discussion of value-added measures, see McPherson, 1992; Goldstein, 1995; Sammons et al, 1997).
} 
attainments and other characteristics of their pupil intakes (Mortimore et al., 1988). A more effective school or teacher is defined as one where pupil progress or other educational outcomes is better than that predicted on the basis of intake. From this view point, effectiveness is thus a relative and sometimes politically contested term which is both outcome and time specific (Sammons, 1996). As noted above, since the inception of the VITAE study, the DfES has developed a national system of value added analyses that examine pupil progress across key stages and this is comparable to the relative effectiveness approach included in VITAE.

Fundamental to the study of school or teacher effectiveness studies is the use of multilevel statistical models that recognise the nested (i.e., multilevel) characteristic of schools as organisations. Higher-level conditions (aspects concerning school leadership, policy and organisation, for example) are hypothesised in some way to facilitate conditions at lower levels (the quality of teaching and learning in classrooms) which, in turn, have a direct impact on pupils' academic outcomes (see Teddlie and Reynolds, 2000; Bosker and Scheerens, 1994, Hill and Rowe, 1996, 1998). Such value added multilevel models were used to study pupil progress and identify teacher effects in VITAE as described later in this section.

School effectiveness research has developed models of educational effectiveness which attempt to demonstrate the nature and direction of links between particular school and classroom processes and pupil outcomes. The framework of input-processoutput has been commonly adopted, and the importance of context especially in terms of SES has also been widely recognised (Teddlie and Stringfield, 1993; Henchey, 2001; Muijs et al, 2004; Sammons et al, 1997; Sammons, 2005; James et al, 2005). The levels involved comprise the individual pupil, the classroom, and the school.

For VITAE, a particular focus has been on the classroom level with the study of pupil outcomes in two academic areas, English and mathematics, and different measures of pupil attitudes (see Chapter 2). In addition, we have given particular attention to context in terms of level of socio-economic disadvantage (as measured by the percentage of pupils' eligible for free school meals). 
Creemers (1994) and Scheerens (1992) have argued that theories of learning and instruction are at the core of multilevel educational effectiveness models. The models they propose define school-level factors as facilitating conditions for classroom-level factors. Hill and Rowe (1998) report results which point to the importance of attentiveness, time and appropriateness of instruction. These variables are closely related to the concept of effective learning time.

Creemers' (1994) model of effective teaching considers not only the activities within individual classrooms, but also wider aspects that affect teaching and learning, such as the quality of leadership within the school. Creemers (1994) also looks closely at the research evidence concerning effective instruction within the classroom. Cognitive outcomes remain important in any definitions of effectiveness. It is well documented by both cohort and other studies that children with low cognitive outcomes and poor educational achievement are likely to be at higher risk of poor attendance and poor behaviour in school, lower motivation and of becoming involved in criminal or other anti-social activities later in life (Rutter et al, 1979; Parsons and Bynner, 1998). The close connections between school effectiveness research and the study and promotion of equity in education have been reviewed by Sammons (2006).

Our review of teacher and school effectiveness, highlighted several aspects, namely the importance of school effectiveness for disadvantaged groups of pupils, centrality of teaching and learning, pupil learning and teachers' classroom activity, effectiveness across curriculum subjects, and the impact of context. The more detailed review (see Appendix 1) looked at literature related to the specific features of teaching behaviour including the teaching of literacy and numeracy. Unfortunately, the absence of classroom observation data of the VITAE teachers meant that the study was unable to investigate directly aspects of teachers' classroom practice identified in the literature review that may have affected pupils' outcomes. Thus the study cannot draw conclusions on the efficacy of different features of teaching behaviour and classroom organisation.

\subsection{The Impact of Context}

Studies relating to school and teacher effectiveness are increasingly concerned to explore the impact of context, whether this be at the national or at the local level. 
Scheerens (1995) notes that 'combinations of effectiveness enhancing conditions may work better given specific contextual contingencies' (ibid p 8). Fraser's (1989) overview of research syntheses on school and instructional effectiveness with a particular focus on curriculum and classroom environment variables concluded that no single factor is sufficient (or has an impact on student learning by itself) but rather that combinations of factors must be optimised for improved learning as measured by cognitive gains.

Sammons et al (1997) point to quality of teaching, academic emphasis, high expectations of students, an absence of staff shortages, positive morale and low levels of staff absence as being related to academic effectiveness in the secondary school Harris, Jamieson and Russ (1995) identified similar features of academically more effective departments. Research in Greece (Verdis, 2002) likewise identified the quality of teaching (measured by students' questionnaires) as an important predictor for results in all academic subjects. This study suggests that certain important characteristics of teaching at the secondary level are likely to be generalisable, rather than different aspects being important for only some subjects

The socio-economic status (SES) context of a school may also influence teacher, student and community expectations and behaviours (Freeman, 1997). The 10 year Louisiana School Effectiveness study explored low SES context effective schools in comparison with high SES effective schools and identified some differences in approach and teaching strategies (Teddlie and Stringfield, 1993).

Reynolds (1998) draws attention to Borich's (1996) analysis of teacher factors that may be necessary to obtain high achievement gains in low versus high SES contexts. These may also be applicable to those working with lower attaining groups of pupils, while behaviours identified for high SES contexts may be relevant for those teaching pupils with higher attainment levels.

\section{Low SES context teacher behaviours:}

- Generating a warm and supportive affect by letting children know help is available 
- $\quad$ Getting a response, any response, before moving on to new material

- $\quad$ Presenting material in small bits, with a chance to practice before moving on;

- $\quad$ Showing how bits fit together before moving on;

- Emphasising knowledge and applications before abstractions, putting the concrete first;

- $\quad$ Generating strong structure and well planned transitions

- $\quad$ The use of individual differentiated material

- $\quad$ The use of the experiences of pupils.

High SES context teacher behaviours

- $\quad$ Requiring extended reasoning

- $\quad$ Posing questions that require associations and generalisations

- $\quad$ Giving difficult material

- $\quad$ The use of projects that require independent judgement, difficult problem solving and the use of original information

- $\quad$ Encouraging learners to take responsibility for their own learning

- $\quad$ Very rich verbalising.

Hay McBer (2000) developed a model of teacher effectiveness which links three factors (professional characteristics, teaching skills and classroom climate) to pupil progress. The most effective teachers identified in this study demonstrated certain combinations of characteristics within the following five clusters: 
- $\quad$ Professionalism

- $\quad$ Analytical and conceptual thinking

- $\quad$ Planning and setting expectations

- $\quad$ Leading

- $\quad$ Relating to others

The teacher's role in creating an 'excellent classroom climate' was also stressed. In primary schools outstanding teachers scored more highly in terms of behaviours related to high expectations, time and resource management, assessment and homework. At the secondary level the biggest differences were in high expectations, planning and homework. They conclude that effective teachers make use of their professional knowledge by consistently deploying appropriate teaching skills whilst using a range of professional characteristics - ongoing patterns of behaviour- which make them effective. Hay McBer identified three factors which they argued are particularly significant to maximising pupils' learning opportunity: lack of disruption, encouragement to engage, and high expectations.

Stoll and Fink (1996) reviewed studies concerning the characteristics of ineffective schools and highlight four aspects: lack of vision; unfocused leadership; dysfunctional staff relationships; ineffective classroom practices. Ineffective classroom practices were characterised by: inconsistent approaches to the curriculum and teaching; generally lower expectations for students of low SES; an emphasis on supervising and communicating about routines; low levels of teacher-pupil interaction; low levels of pupil involvement in their work; pupil perceptions of their teachers as people who did not care, praise, provide help, or consider learning as important; and more frequent use of criticism and negative feedback.

There may, however, be some dangers in adopting different teaching strategies for different 'types' of students based on SES context because of potential problems of reinforcing stereotypes and lower expectations. Such adjustment could lead to different experiences of the curriculum for disadvantaged groups. An important wideranging review of teacher effectiveness has compared the impact of constructivist approaches to teaching and direct instruction. It found that, in general, pupils attained 
less highly if taught by constructivist methods and that such approaches tended to widen the equity gap. It was concluded that low SES, younger and less able pupils in particular did less well if taught using these methods (Van der Grift, 2006). The VITAE research has collected information on SES context to explore its role in relation to teachers' lives and work as well as in relation to relative and relational effectiveness.

\subsection{Multilevel Modelling, Contextualised and Value Added Attainment Results}

To assess the impact of an individual teacher on the progress in attainment their pupils make over one academic year, it is important that factors beyond the influence of the teacher that are related to pupil attainment are identified. These factors include characteristics such as age, gender, socio-economic status, English as an Additional language and ethnicity which have been shown to have strong statistical associations with attainment (Mortimore et al, 1988; Thomas and Mortimore, 1996; Strand, 2000). School effectiveness research has shown consistently that there are significant statistical associations between certain pupil characteristics and level of attainment. Thus, as a group, pupils from some backgrounds (especially those which are socioeconomically disadvantaged) may come to the classroom with either an educational advantage or disadvantage. However, it is important to remember these findings do not apply to all children in such groups (only to average differences) and should therefore not lower teachers' expectations of individual pupils. VITAE reveals that the intake characteristics of different classes can differ widely, so it is essential that pupil characteristics that show a statistically significant association with attainment are adjusted for before we compare teachers or schools in terms of their contribution to pupils' attainment and progress. In this way we can more accurately and fairly compare the impact of teachers who are teaching very different pupil groups. Multilevel modelling can both identify these significant factors and produce 'valueadded scores' (residual) of teacher effectiveness that have been statistically adjusted to take them into account by controlling for intake influences. 
The aim of the Year 2 contextualised analysis was to identify the contribution of particular pupil and school characteristics to children's outcomes (in this case Key Stage 1 attainment) when prior attainment was not available. Thus, for example, the net impact of family socio-economic status (using the pupils' eligibility for FSM as a quasi indicator of SES), is established while taking into account the influence of pupil gender, age in months, EAL status, SEN and ethnicity. These significant characteristics can then be adjusted for when producing a 'contexualised' indicator of a school's effectiveness in promoting attainment for the Year 2 sample. This sort of analysis is not as precise as the value added analyses of pupil progress over an individual school year adopted for the sample of Year 6 and Year 9 teachers (which included prior attainment as well as pupil/school characteristics), and cannot identify individual teacher effects related to the progress made by particular Year 2 classes, but is a fairer way of comparing schools than unadjusted attainment indicators such as the $\%$ of pupils achieving level $2 \mathrm{a}, \mathrm{b}$ or $\mathrm{c}$, or level 3 at Key Stage 1.

The contextualised and value added score indicates whether a school or class shows better or worse attainment than expected based on their pupil/school intake characteristics. In order to study effectiveness in more detail, the confidence limits associated with the value added or contextualised estimates were calculated. For the purpose of the project, the estimates (residuals measuring the difference between predicted and actual pupil attainment levels) were categorised into five 'effectiveness' groupings (Table 4.1). Schools with contextualised residuals significantly above or below expectation at the $95 \%(+/-1.96 \mathrm{se})$ and $68 \%$ confidence limit $(+/-1 \mathrm{se})$ were identified by calculating confidence intervals for each contextualised residual ${ }^{10}$.

Table 4.1 Categorisation of contexualised residuals

\begin{tabular}{|l|l|l|l|l|}
\hline $\begin{array}{l}\text { Below } \\
\text { expectation } \mathbf{9 5 \%} \\
\text { significance) }\end{array}$ & $\begin{array}{l}\text { Below } \\
\text { expectation } \mathbf{6 8 \%} \\
\text { significance) }\end{array}$ & As expected & $\begin{array}{l}\text { Above } \\
\text { expectation }(\mathbf{6 8 \%} \\
\text { significance) }\end{array}$ & $\begin{array}{l}\text { Above } \\
\text { expectation } \mathbf{9 5 \%} \\
\text { significance) }\end{array}$ \\
\hline-- & - & As expected & + & ++ \\
\hline $\begin{array}{l}95 \% \text { chance the } \\
\text { school or class is } \\
\text { performing worse } \\
\text { than expected }\end{array}$ & $\begin{array}{l}\text { 68\% chance the } \\
\text { school or class is } \\
\text { performing worse } \\
\text { than expected }\end{array}$ & $\begin{array}{l}\text { The school or } \\
\text { class performance } \\
\text { is statistically as } \\
\text { expected }\end{array}$ & $\begin{array}{l}\text { 68\% chance the } \\
\text { school or class is } \\
\text { performing better } \\
\text { than expected }\end{array}$ & $\begin{array}{l}\text { 95\% chance the } \\
\text { school or class is } \\
\text { performing better } \\
\text { than expected }\end{array}$ \\
\hline
\end{tabular}

\footnotetext{
${ }^{10}$ Confidence intervals at the $95 \%$ confidence limit $=$ residual $+/-1.96$ standard error. Confidence intervals at the $68 \%$ confidence limit $=$ residual $+/-1.00$ standard error.
} 
Schools (Year 2) or classes (Years 6 and 9) were classified as 'statistical outliers' where the residual estimates in the multilevel model are statistically significant at the $95 \%$ confidence interval. This means there is a $95 \%$ chance that attainment (year 2) or progress (year 6 and 9) is significantly better (++) or, by contrast, significantly lower (--) than predicted on the basis of intake.

\subsection{The sample}

Because the analysis of Key Stage 1 outcomes was a contextualised analysis the data were obtained directly from nationally datasets, so all schools completing the national assessments could be included. New assessment arrangements were being piloted in around $25 \%$ of LAs in cohort 2 (2003-2004). The schools involved in the pilot were not required to return test/task data. Because of this, some schools did not have enough data to be included in the cohort 2 analysis.

Table 4.2: The numbers of pupils, classes and school in the multilevel analysis

\begin{tabular}{|c|c|c|c|c|c|c|}
\hline & \multicolumn{6}{|c|}{ Year 2 (Key stage 1) } \\
\hline & \multicolumn{2}{|c|}{ Cohort 1 2002/03 } & \multicolumn{2}{|c|}{ Cohort 2 2003/04 } & \multicolumn{2}{|c|}{ Cohort 3 2004/05 } \\
\hline & Maths & English & Maths & English & Maths & English \\
\hline Number of schools & 66 & 66 & 52 & 52 & 69 & 69 \\
\hline \multirow[t]{5}{*}{ Number of pupils } & 1955 & 1954 & 1543 & 1536 & 2014 & 2014 \\
\hline & \multicolumn{6}{|c|}{ Year 6 (Key stage 2) } \\
\hline & \multicolumn{2}{|c|}{ Cohort 1} & \multicolumn{2}{|c|}{ Cohort 2} & \multicolumn{2}{|c|}{ Cohort 3} \\
\hline & \multicolumn{2}{|c|}{ Primary year 6} & \multicolumn{2}{|c|}{ Primary year 6} & \multicolumn{2}{|c|}{ Primary year 6} \\
\hline & Maths & English & Maths & English & Maths & English \\
\hline Number of schools & 59 & 59 & 44 & 44 & 29 & 29 \\
\hline Number of classes & 63 & 63 & 45 & 45 & 29 & 29 \\
\hline \multirow[t]{4}{*}{ Number of pupils } & 1232 & 1235 & 935 & 934 & 612 & 612 \\
\hline & \multicolumn{6}{|c|}{ Year 9 (Key stage 3) } \\
\hline & \multicolumn{2}{|c|}{ Cohort 1} & \multicolumn{2}{|c|}{$\begin{array}{c}\text { Cohort } 2 \\
\end{array}$} & \multicolumn{2}{|c|}{ Cohort 3} \\
\hline & Maths & English & Maths & English & Maths & English \\
\hline Number of schools & 16 & 17 & 18 & 13 & 17 & 13 \\
\hline Number of classes & 43 & 49 & 43 & 29 & 28 & 19 \\
\hline Number of pupils & 1046 & 1068 & 1066 & 723 & 670 & 436 \\
\hline
\end{tabular}

Table 4.2 shows the number of pupils, classes and schools for which sufficient data were available for inclusion in the multilevel analyses for each successive cohort.

\subsection{Data collection}

Data from multiple sources were collected to conduct the multilevel analyses and produce indicators of school or teacher relative effectiveness. 
- Baseline prior attainment data for individual pupils were collected from teachers by the VITAE project at the beginning of the 2002/2003 academic year for Year 6 and 9 pupils $^{11}$.

- Outcome data in the form of Key stage 1,2 and 3 attainment (levels and test scores) were provided by the DfES at the end of the academic year.

- Pupil background information such as age within the year group, ethnicity, SEN, EAL etc was collected from the PLASC dataset, also provided by the DfES.

- Some school level information was also collected from the PLASC dataset such as proportion of pupils in the school entitled to Free School meals.

\subsubsection{Key predictors of progress and attainment}

As would be anticipated, prior attainment (at the beginning of the autumn term) was the strongest predictor of later Key Stage attainment for Year 6 and 9 in both English and maths at the end of the academic year (summer term). Including prior attainment adjusts for differences at the start of the academic year, so allowing relative progress rates for pupils to be investigated. Nonetheless, progress for different pupil groups was found to vary over the single academic year. The results are summarised in Tables 4.3 and 4.4 and display the pupil and school factors found to have a significant relationship (positive indicating better progress and negative indicating less progress) with progress for the sample.

\footnotetext{
${ }^{11}$ The baseline assessments were part of the NFER-Nelson 'progress 5-14' series (NFER assessments " progress in English/maths 10' and 'Progress in English/maths 13'). They provide raw and age standardised scores that adjust pupils' performance according to their age, and provide comparisons with a nationally representative sample.
} 
Table 4.3: Child and school factors significantly related to attainment (Year 2)

\begin{tabular}{|c|c|c|}
\hline \multicolumn{3}{|c|}{ Year 2 (Key stage 1) } \\
\hline Total Maths - cohort 1 & Total Maths - cohort 2 & Total Maths - cohort 3 \\
\hline Age within year & Age within year & Age within year \\
\hline Gender (Boys) & Gender (Boys) & Gender (Boys) \\
\hline FSM entitlement & FSM entitlement & FSM entitlement \\
\hline SEN:any stage & SEN:any stage & SEN:any stage \\
\hline New pupil* & New pupil* & \\
\hline Ethnicity;Other white $\quad(-)$ & & Ethnicity;Other white \\
\hline Bangladeshi & & Mixed \\
\hline Black caribbean $(-)$ & & Black caribbean $(-)$ \\
\hline$\%$ of sch entitled to FSM & $\%$ of sch entitled to FSM (-) & $\begin{array}{l}\% \text { of school entitled to FSM (-) } \\
\% \text { of school with statement }(-)\end{array}$ \\
\hline Total English - cohort 1 & Total English - cohort 2 & Total English - cohort 3 \\
\hline Age within year & Age within year & Age within year \\
\hline Gender (Girls) & Gender (Girls) & Gender (Girls) \\
\hline FSM entitlement & FSM entitlement & FSM entitlement \\
\hline New pupil* & New pupil* & New pupil* \\
\hline SEN:any stage & SEN:any stage & SEN:any stage \\
\hline & & Ethnicity;Other white \\
\hline$\%$ of sch entitled to FSM ( -$)$ & $\%$ of sch entitled to FSM $(-)$ & $\%$ of sch entitled to FSM \\
\hline & & $\%$ of sch with statement \\
\hline
\end{tabular}

* Joined school in this or previous academic year

Table 4.4: Child and school factors significantly related to progress after control for prior attainment (Years 6 and 9)

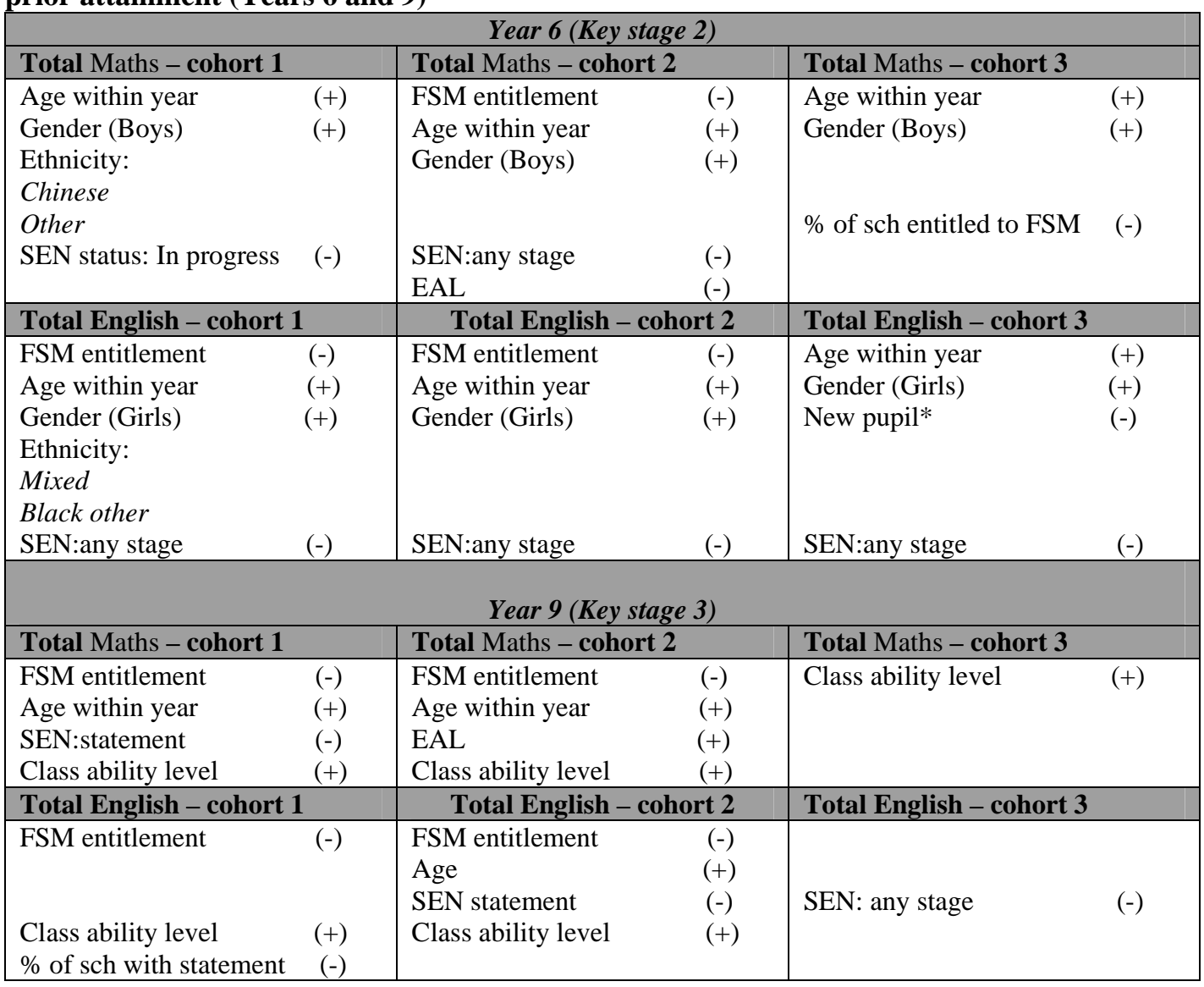

* Joined school after Year 1 
The results of the influence of pupil characteristics are broadly in line with those of other researchers on the factors that relate to pupil progress (e.g. Strand 1997; 1999; 2002) and the results of DfES studies of value added using contextualised value added models of progress across Key Stages. For example, girls showed better results in English, but boys made more progress in mathematics in Year 6. Pupils eligible for FSM showed poorer attainment and made less progress in all years. Older pupils in each year group (autumn born compared with summer born) tended to show higher attainment and make more progress than their younger classmates.

\subsubsection{The impact of average ability level of the class}

The value added analyses of progress showed that the average prior attainment levels of classes varied significantly and at Key Stage 3 this can be associated with setting by ability level within the Year 9 sample, especially for maths. Earlier studies in other contexts have suggested (Sukhanandan and Lee, 1998) that higher ability pupils make greater gains in high ability sets than in mixed groups. However, lower ability pupils tend to attain less well if taught in lower ability rather than mixed ability groups. Value added analyses on Dutch data have similarly pointed to the impact of the average ability level of the class (De Fraine et al 2003).

The VITAE study of pupil progress confirms the impact of the average ability level of the class (measured at the beginning of the academic year) on pupils' subsequent progress in Year 9 of secondary school, though no significant impact was identified in the analysis of pupil progress in primary classes ${ }^{12}$. The findings suggested that the ability group a pupil is placed in can have an impact on progress in Year 9, even after the individual prior attainment ability levels of the pupils had been taken into account. This suggests that being in a higher ability group confers an advantage in the amount of progress made, whereas being in a lower ability group is a disadvantage. These findings are in line with those reported on setting by Hallam (2002) which concluded that pupils with a similar level of prior attainment make more progress if in a higher set rather than a lower set.

\footnotetext{
${ }^{12}$ The Year 9 Value Added analysis of cohort 3 showed only a small ability group effect for maths and none for English (although it was close to significance). This is likely to be due to the much smaller sample size for this cohort.
} 
The explanation for the influence of the average attainment level of the class is not likely to be straightforward. A high ability class may be relatively easier to teach than a lower ability class, due to better behaviour, or greater levels of pupil motivation. An alternative hypothesis is that more experienced or highly skilled teachers may be allocated to higher ability classes in some schools. It may also be that both teachers and pupils' expectations are shaped by being in a higher or a lower set, and also curriculum coverage may be more rapid or extensive in higher ability classes, particularly in mathematics where setting is most common and where decisions may be made to teach at a slower pace or a reduced content in low ability sets. The tiering of maths papers may also have an impact. Evidence presented in Chapter 2 on pupils' views indicated that there was a relationship between pupils' responses to particular items and their progress, and that there was particular variation in Year 9 maths classes in aspects of teacher behaviour as perceived by pupils. The impact of variation in class average prior attainment level was strongest in the Year 9 maths analysis, and maths

\subsection{Variations in teacher effectiveness}

Overall, significant school (Year 2) or class level variation in progress was identified in each year group (2, 6 and 9) and in each of the three years studied (see Table 4.5). These consistent results confirm the existence of important differences in relative effectiveness and indicate that variations between teachers in terms of promoting pupil progress in their classes or teaching groups are highly significant. For example, from the intra school correlations it can be seen that in Year 6 between 17 and 29 per cent of the variance in pupil progress (after controlling for prior attainment and background) was found to relate to the class in which a pupil is taught. In KS3 the results show that differences between teachers and classes in progress results are also strong (15 to $30 \%$ in English; 10-26\% for maths).

Table 4.5 reports the intra school correlations for each cohort in the value-added analyses across three cohorts. 
Table 4.5: Intra school correlations - Maths and English value-added results for Year 6 and Year 9 teachers

\begin{tabular}{|l|l|l|l|l|l|}
\hline Year of study & Year 1 & Year 2 & Year 3 & $\begin{array}{l}\text { N classes } \\
\text { English }\end{array}$ & $\begin{array}{l}\text { N classes } \\
\text { maths }\end{array}$ \\
\hline $\begin{array}{l}\text { Yr 6 } \\
\text { English }\end{array}$ & 0.29 & 0.27 & 0.17 & Yr 1 $=63$ & Yr 1 $=63$ \\
Maths & 0.15 & 0.17 & 0.11 & Yr 2 $=45$ & Yr 2 $=45$ \\
$\begin{array}{l}\text { Yr 9 } \\
\text { English }\end{array}$ & 0.15 & 0.16 & 0.30 & Yr 3 $=29$ & Yr 3 $=29$ \\
Maths & 0.23 & 0.26 & 0.10 & Yr 2 $=43$ & Yr 2 $=29$ \\
\hline
\end{tabular}

A substantial number of teachers' classes were identified as statistical outliers in each year group studied on the basis of the multilevel analysis. In other words, differences in the characteristics of pupils taught did not account fully for the differences in levels of pupil attainment and progress. This indicates that teachers were not all equally effective in promoting pupil progress. Appendix 2 gives full details but the results are illustrated in Table 4.6 for the Year 6 and Year 9 samples. Overall, around $40 \%$ of Year 6 teachers' classes were classified as significant outliers (showed significantly better or significantly poorer than expected progress in cohort 1 and 2) for English and around $33 \%$ for mathematics. In Year 9 the results showed slightly more fluctuation across the three years but nonetheless results were broadly in accord. 
Table 4.6: Distribution of Value Added results for Year 6 and 9 outcomes

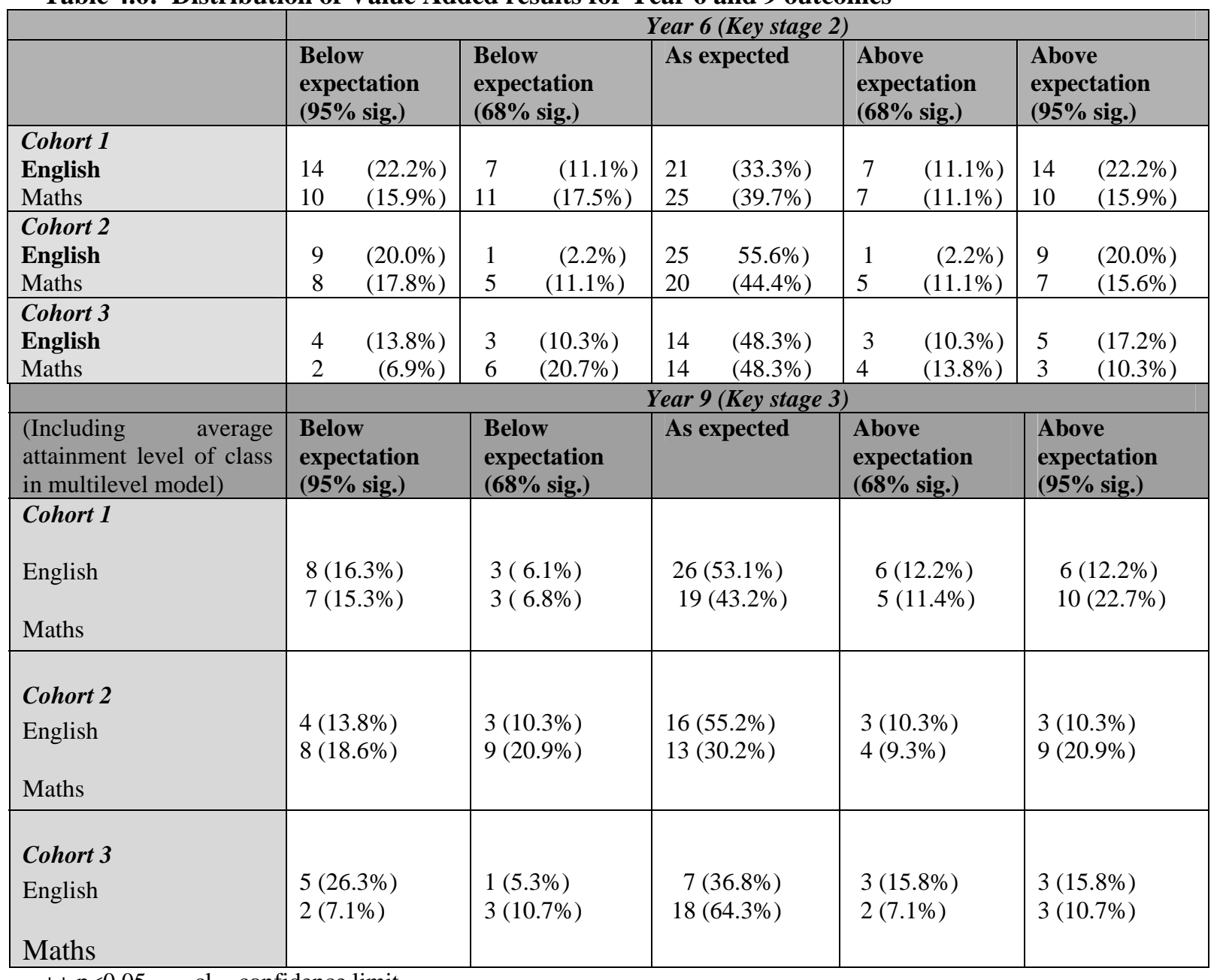

$++\mathrm{p}<0.05 \quad \mathrm{cl}=$ confidence limit

An important question for the project concerned stability in teachers' relative effectiveness across years. The analysis focused on cohorts 1 and 2 for which more value-added results were available, and Years 6 and 9 where pupil progress was measured over the school year. The results suggested greater stability for mathematics than English results in terms of teachers' relative effectiveness from one year to another. For maths in Year 6, the correlation was significant and moderate $(0.48, \mathrm{p}<0.01)$ but was weak and non-significant for English. In Year 9, the correlation was $0.51(\mathrm{p}<0.05)$ for maths but was not significant when class ability level was controlled. Nonetheless some teachers showed positive results across more than one year whereas others showed negative results. A small number showed positive results in one year and negative results the following year in the same subject. Table 4.7 illustrates these patterns for the Year 6 teachers. 
Table 4.7: Relationships between teachers' relative effectiveness (value-added) across cohorts 1 and 2 for the Year 6 sample

\begin{tabular}{|c|c|c|c|}
\hline English Year 6 & \multicolumn{3}{|c|}{ Cohort 2 } \\
\hline Cohort 1 & Positive & As expected & Negative \\
\hline Positive & 2 & 5 & 2 \\
\hline As expected & 4 & 8 & 4 \\
\hline Negative & 3 & 6 & Negative \\
\hline Maths Year 6 & \multicolumn{3}{|c|}{ Cohort 2 } \\
\hline Cohort 1 & Positive & As expected & 4 \\
\hline Positive & 5 & 5 & 5 \\
\hline As expected & 3 & 10 & 5 \\
\hline Negative & 0 &
\end{tabular}

In all, 14 teachers out of $37(38 \%)$ showed a stable pattern of results for English in Year 6 across the two cohorts, while $6(16 \%)$ showed unstable results (moving from negative to positive and vice versa). For maths in Year 6, 20 teachers out of 37 (54\%) showed stable results, and none moved from negative to positive or vice versa across the two years. The equivalent results are shown for Year 9 teachers in Table 4.8

Table 4.8: Relationships between teachers' relative effectiveness (value-added) across cohorts 1 and 2 for the Year 9 sample (controlling for class ability level)

\begin{tabular}{|c|c|c|c|}
\hline English Year 9 & \multicolumn{3}{|c|}{ Cohort 2 } \\
\hline Cohort 1 & Positive & As expected & Negative \\
\hline Positive & 0 & 7 & 1 \\
\hline As expected & 3 & 5 & 1 \\
\hline Negative & 0 & 2 & Negative \\
\hline Maths Year 9 & \multicolumn{3}{|c|}{ Cohort 2 } \\
\hline Cohort 1 & Positive & As expected & 5 \\
\hline Positive & 3 & 2 & 3 \\
\hline As expected & 4 & 2 & 1 \\
\hline Negative & 1 &
\end{tabular}


It can be seen that $6(26 \%)$ of the 23 English teachers showed stable results across the two years while only one moved from positive to negative in the same time period. For maths, $8(31 \%)$ of the 26 teachers showed stable results across the two years, but $6(23 \%)$ moved from negative to positive or vice versa. These results indicate that for some teachers their relative effectiveness levels remained broadly stable over time while for others there was a change from one year to another.

In order to explore variations in teachers' relative effectiveness in teaching different curriculum areas, the value-added results for Year 6 teaching were compared for maths and English (Table 4.9).

Table 4.9: Comparison of relative effectiveness in English and maths - Year 6 teachers (cohort 1)

\begin{tabular}{|c|c|c|c|}
\hline & \multicolumn{2}{|c|}{ Maths } \\
\hline English & Positive & As expected & Negative \\
\hline Positive & 8 & 9 & 6 \\
\hline As expected & 5 & 10 & 11 \\
\hline Negative & 4 & 6 & 4 \\
\hline
\end{tabular}

It can be seen that $29(46 \%)$ out of 63 teachers in cohort 1 Year 6 analysis showed similar levels of effectiveness in both curriculum areas. By contrast 8 (13\%) were effective in one area but ineffective in the other. This result was supported by the comparisons for cohort 2. Here the analysis was based on 46 teachers. In all 25 (54\%) of the 46 teachers showed similar levels of effectiveness in both English and maths, while none were more effective in one area but ineffective in the other. (Table 4.10).

Table 4.10: Comparison of relative effectiveness in English and maths - Year 6 teachers (cohort 2)

\begin{tabular}{|c|c|c|c|}
\hline & \multicolumn{3}{|c|}{ Maths } \\
\hline English & Positive & As expected & 0 \\
\hline Positive & 5 & 5 & 5 \\
\hline As expected & 7 & 14 & 6 \\
\hline Negative & 0 & 4 & Negative \\
\hline
\end{tabular}




\subsection{Exploring the characteristics of more and less effective teachers}

In order to link the quantitative value added data on teachers' relative effectiveness with the qualitative datasets on variations in teachers' lives and work further analyses were conducted. Due to the smaller number of teachers for whom value added data were available for cohort 3 (2004/05) this report concentrates on findings for cohorts 1 and 2, where the numbers give greater confidence in the robustness of the results.

Of the 314 teachers in the VITAE study there were 243 teachers who had a value added score for at least one year cohort and 136 (56\% of the sample) teachers who had a value added score for two year cohorts (2002/03 and 2003/04). Tables 4.11 and 4.12 show the sample for which it was possible to link qualitative and quantitative data sets to explore the following hypothesis: There are both positive and negative relationships between variations in teachers' work and lives and their relative effectiveness, as measured by value added analyses of pupil progress.

Table 4.11: Number and Gender of Teachers with Value Added Results for at least one of the first two cohorts

\begin{tabular}{|l|c|c|c|}
\hline & Number of Teachers & Female & Male \\
\hline Year 2 & 74 & 70 & 4 \\
\hline Year 6 & 66 & 57 & 9 \\
\hline Year 9 English & 49 & 39 & 10 \\
\hline Year 9 Maths & 54 & 28 & 26 \\
\hline Total & $\mathbf{2 4 3}$ & $\mathbf{1 9 4}(\mathbf{8 0 \%})$ & $\mathbf{4 9}(\mathbf{2 0 \%})$ \\
\hline
\end{tabular}

Table 4.12: Percentage of Teachers with Value Added Results for both Year Cohorts

\begin{tabular}{|l|c|c|c|}
\hline & $\begin{array}{c}\text { Number of } \\
\text { teachers with VA } \\
\text { scores for at least } \\
\text { one cohort }\end{array}$ & $\begin{array}{c}\text { Number of Teachers } \\
\text { with VA scores for } \\
\text { both year cohorts }\end{array}$ & $\begin{array}{c}\text { Percent of Teachers } \\
\text { with VA scores for } \\
\text { both year cohorts }\end{array}$ \\
\hline Year 2 & 74 & 50 & $68 \%$ \\
\hline Year 6 & 66 & 37 & $56 \%$ \\
\hline Year 9 English & 49 & 23 & $47 \%$ \\
\hline Year 9 Maths & 54 & 26 & $48 \%$ \\
\hline Total & $\mathbf{2 4 3}$ & $\mathbf{1 3 6}$ & $\mathbf{5 6 \%}$ \\
\hline
\end{tabular}

The initial data cut explored teacher profiles for the 'more effective' and 'less effective' as identified by the multilevel analysis of relative effectiveness. The criterion for greater or lesser effectiveness included teachers with above or below expectation (++ or + compared with -, or --) in either of the two main year cohorts 
(due to reduced numbers the third cohort were not included in this analysis to maximise sample size). Two broad outlier groups were thus formed, a group comprising of more effective teachers i.e. pupils of those with largely positive results and no negative results in either or both of the two year cohorts and a group of less effective teachers i.e. pupils of those with mainly negative results and no positive results over the two years. Of the 243 teachers nearly $24 \%(\mathrm{~N}=58)$ were included in the more effective group and 23\% ( $\mathrm{N}=56)$ in the less effective group (Table 4.13). Other teachers had results in line with expectation in both years or mixed results. These results point to important variations in relative effectiveness levels in all three Year groups (2, 6 and 9) studied.

Table 4.13: Numbers of Broadly More Effective and Less Effective Teachers in Cohorts 1 and 2 by Year group

\begin{tabular}{|l|l|l|c|c|c|}
\hline \multicolumn{2}{|c|}{ Total N } & \multicolumn{2}{c|}{ More Effective } & \multicolumn{2}{c|}{ Less Effective } \\
\hline & & $\mathbf{\%}$ & $\mathbf{N}$ & $\mathbf{\%}$ & $\mathbf{N}$ \\
\hline Year 2 & 74 & 18 & 13 & 18 & 13 \\
\hline Year 6 & 66 & 26 & 17 & 24 & 16 \\
\hline Year 9 English & 49 & 25 & 12 & 25 & 12 \\
\hline Year 9 Maths & 54 & 30 & 16 & 28 & 15 \\
\hline Total & $\mathbf{2 4 3}$ & $\mathbf{2 4}$ & $\mathbf{5 8}$ & $\mathbf{2 3}$ & $\mathbf{5 6}$ \\
\hline
\end{tabular}

The value-added data were examined in the light of the overall teacher profiles in order to illustrate some of the different experiences and characteristics of teachers included in the more and less effective groups. It was clear as a result of this process that teachers' experiences were very varied and that some in adverse circumstances were highly effective despite personal or professional difficulties.

Seven teacher portraits were selected of teachers with different degrees of relative effectiveness and from a range of school contexts. These illustrate the complexity of differences and perceptions of teachers in the study and indicate the main conclusion from the systematic comparisons of the more and less effective group, that there is no single explanation for the extent of variation in terms of personal, pupil, professional or policy factors. 


\section{Michael (FSM 2 Attainment Band 2)}

Michael was 48 years old and taught Year 6 . He had been teaching for 23 years. The headteacher of his school retired towards the end of the project and Michael was appointed acting deputy. He applied successfully for the permanent post which had increased his confidence. Michael described the school as having a 'lovely atmosphere' where the staff was supportive of each other. He had generally a high sense of commitment, job satisfaction and self-efficacy but described his motivation at the end of Year 3 of the project as moderate (Round 4). Michael felt that his personal life, professional role and current teaching situation were in harmony and he looked forward to being at work. He generally worked up to 55 hours per week. There was no mention of any personal difficulties which have had an impact on his work as a teacher. (VA scores Cohort 1: above expectation in English and maths, Cohort 2: above expectation in English and maths; Sustained Commitment).

\section{Simone (FSM 1 Attainment Band 2)}

Simone was 40 years old and taught Year 6 in a school with low levels of disadvantage. She had stayed at the same school in a career of seven years. Simone had some health concerns in Year 2 of the Project which had a major impact on her. Following on from these incidents she became more realistic about managing her workload. She now spends more time with her family and feels less stressed and thinks as a result her level of self-efficacy has increased. Simone had a low achieving class at the beginning of the Project. She struggled, but with the help of the deputy head teacher, she was pleased to see her pupils making good progress. In Year 3 of the Project she reported that she had a more placid class and that she felt more effective. (VA scores Year 1: above expectation in English / as expected in maths, Year 2: above expectation in English and maths; Sustained Commitment)

\section{Salman (FSM4 Attainment Band 4)}

Salman was 32 years old and had taught for 7 years. He was Head of maths in a highly disadvantaged school and had been teaching Year 9 in his current school for the last two to three years, having previously served in one other 'difficult' school with 'difficult children'. The recent shift in senior management had 'a demotivating effect' on him. He worked long hours. He was highly confident that he was an effective teacher and derived immense satisfaction from his pupils' excellent 
achievements in exams. He was also very satisfied with his behaviour management skills and liked to work independently without assistance of support teachers. As Head of Department, he reported he had built an effective team and as a teacher, he had achieved the highest residual in the department in their own analysis of their assessment results. As a result, his motivation and self-efficacy continued to develop. (VA scores Cohort 1: above expectation (regardless of class ability), Cohort 2: as expected (excluding class ability) and above expectation (including class ability); Sustained Commitment despite adverse situations)

\section{$\underline{\text { Katie (FSM } 1 \text { Attainment Band 2) }}$}

Katie was 48 years old and was a Year 6 teacher who had taught for 11 years. She felt she had good support and trust from the headteacher which gave her more motivation and job satisfaction. She also valued the professional support from colleagues. Although in a school with low levels of pupil socio-economic disadvantage, she expressed many concerns about the deteriorating behaviour of pupils and commented that pupil behavioural difficulties have negative effects on her 'enjoyment of teaching'. She also complained about the negative influence of educational policies and Ofsted inspection and felt the financial constraints of her current school negatively impact on her effectiveness. Generally she felt dissatisfied with her ability to make a real difference to her pupils' learning. She worked up to 55 hours per week and experienced high stress levels. No specific personal difficulties were reported by Katie in the interviews. (VA scores Cohort 1: below expectation in English and maths, Cohort 2: below expectation in English and maths; Sustained Commitment).

\section{Marvin (FSM 4 Attainment Band 4)}

Marvin was a Year 9 teacher 47 years old and had taught English for over 25 years. He worked in a low SES school. He believed the school had management and other difficulties and he did not get on with the headteacher or his line manager. He felt the school was badly run, but said he still loved the school and the staff. He wanted to resign twice in the last three years but was unable to as he felt it was hard to move elsewhere at his current salary level. He felt he had good relationships with pupils, and that they liked his classes. He had experienced several stressful personal issues in recent years and had been recently divorced; this placed him under financial pressures in consequence. Marvin felt undervalued at school and his job satisfaction had 
decreased in recent years. (VA scores Cohort 1: below expectation (regardless of class ability level), Cohort 2: no data; Declining Commitment)

\section{Ivan (FSM 2 Attainment Band 2)}

Ivan was 53 years old and had taught for 32 years. He was head of maths and had been teaching in this school for over 16 years, having previously served in three others. He taught a bottom set Year 9, working mainly with children who had special needs. He was remarried and had two step-daughters together with two boys from his first marriage. Ivan's motivation as a teacher had been decreasing and he saw this as long term because he felt there were no prospects for him in the last phase of his career. Ivan felt stuck in his current position. He knew that his low motivation was 'bound to have consequences' for his effectiveness, but said he tried 'not to let it affect his lessons'. (VA scores Cohort 1: below expectation (regardless of class ability level), Cohort 2: below expectation (regardless of class ability level); Declining Commitment)

\section{$\underline{\text { Julie (FSM } 3 \text { Attainment Band 3) }}$}

Julie, a Year 9 English teacher, was in her early 50s years old and had been teaching for 12 years, all in this current FSM3 school of approximately 1,000 pupils. Julie chose to be a teacher because she wanted to motivate children and pass on her enthusiasm and love of English. She believed she had become more effective over years through experience and was respected more by the children now. Julie was considering a change of career in future in line with her spiritual interests.

Julie felt that she had a good Head of Department who allowed teachers some independence and that her school was well managed. She had good colleagues in the school though her particular friends had moved over the years. The overall behaviour of the pupils in the school was quite difficult, but had improved recently.

Personal stresses in the past included a divorce, other relationship and health issues, and caring for a child with long-term illness. She tried to keep this part of her life separate from work. Currently, her personal life, professional role and situation were in harmony. She felt this had a positive impact on her teaching as she 'still does what [she] wants in her own time' so doesn't feel resentful. (VA: Cohort 1: As expected 
(regardless of class ability level); Cohort 2: As expected (regardless of class ability level))

\subsection{Summary of key findings}

The results of the value added analysis of relative effectiveness indicate that there was considerable variation amongst the VITAE teacher sample. Pupils in different classes made different amounts of progress during a school year in reading and mathematics. More and less effective teachers were identified in a range of school SES contexts. At KS3, average class attainment levels (that may reflect setting especially in maths) helps to account for some of the difference, but considerable variation remained even when this was controlled for in the analysis in addition to pupil prior attainment and background. There is evidence that teachers varied in their relative effectiveness from one year to another, but, across years the tendency was for more effective teachers to remain more effective or show typical levels of effectiveness (progress as expected) and less effective teachers to remain less effective or move to typical levels of effectiveness. Relatively few teachers moved from effective to ineffective or vice versa over a two-year period.

The findings indicate that one feature for greater effectiveness may be how well the teachers were able to keep their work and lives (or their Scenario) in balance or in equilibrium. It seemed that negative aspects affected stress levels, workload and morale particularly in more challenging contexts and that these influenced relative effectiveness. For those 'less effective' teachers who had mentioned at least one major negative aspect, the extent of perceived professional support within the school seemed to have a considerable impact on their professional life. The negative aspects reported were in the areas of practice, adverse personal events, concerns about poor pupil behaviour or the perception of 'negative' policy influences such as changes related to new educational initiatives, and the impact of inspection. The Year 9 results indicated that there were likely to be school and departmental influences affecting teacher effectiveness at the secondary level. Several of the more effective teachers were in the same school and department and this was also the case for several of the ineffective teachers. 
This may reflect school or departmental culture and climate but may also be related to accepted methods of organisation and classroom practice not studied in this project.

- School context (level of socio-economic disadvantage) did not appear to differentiate between the more and the less effective groups. This may be accounted for by the inclusion of both the individual pupil's entitlement to FSM and an additional contextual indicator of pupils' eligible for FSM at the school level in the value added models, due to their known link with both attainment and progress. This finding indicates that contextualised value added measures (which have since been adopted by the DfES to add to School Performance tables) are fairer than raw comparisons such as the \% pupils at level 4 (KS2), \% at level 5 (KS3) or \% 5A*-C (GCSE) because they are less biased by contextual features, such as the level of socio-economic disadvantage in a school.

- Personal background characteristics such as teachers' age, professional life phase and gender were not found to be associated in any systematic or linear way with differences in relative effectiveness. This confirms earlier research which suggests such factors are not the main features of importance in promoting better pupil outcomes. Teachers of different characteristics can be equally effective, and effectiveness does not necessarily increase or decrease during a teachers career in a linear fashion.

- For Year 2, the main difference found between the 'more effective' and 'less effective' teachers appeared to relate to issues of professional practice including leadership within the school. The 'more effective' teachers were more likely than the less effective group to make positive comments about professional practice and support and also about their perceived self-efficacy.

- Both sets of Year 6 'more effective' and 'less effective' teachers made equivalent positive and negative responses in each of the areas of personal, practice and pupil influences. The main difference here appears to relate to how well the teachers reported that they maintain a successful work-life balance. For primary teachers it appears that a better work-life balance has positive associations with better pupil progress. 
- Year 9 English teachers showed some differences in personal and professional practice factors. The 'less effective' teachers were found to have discussed more negative personal events in their lives ( 73 per cent compared to 20 per cent for 'more effective' teachers). However, the trend was not observed for Year 9 maths teachers where the 'less effective' teachers noted somewhat fewer negative personal events compared to the 'more effective' teachers (46 per cent compared to 67 per cent). Here the gender difference may be relevant since proportionately more male teachers taught mathematics.

- The 'more effective' Year 9 English teachers also made more positive comments about professional practice, 73 per cent compared to 42 per cent for the 'less effective' teachers.

The conclusions that can be drawn from this analysis are as follows:

- Differences in the characteristics of pupils do not account fully for the differences in levels of pupil attainment or progress between classes and teaching groups.

- Variations between teachers in terms of promoting pupil progress in their classes or teaching groups in Year 6 and 9 are highly significant and account for between $15 \%$ and $30 \%$ of the variance in pupil progress.

- Overall, $40 \%$ of Year 6 classes and 33\% for mathematics had value-added results that were either significantly above or significantly below those expected given pupil intake characteristics and the result for Year 9 are broadly in accord.

- Of the 243 teachers with value-added (Years 6 and 9) or contextualised (Year 2) effectiveness scores for 2 years, $24 \%(\mathrm{~N}=58)$ were classified as more effective and $23 \%(\mathrm{~N}=56)$ as broadly less effective. Few teachers moved from more to less effective or vice versa over two years.

- There is no single or simple explanation for the extent of variation in relative effectiveness in terms of personal, pupil professional or policy factors.

These quantitative data and the qualitative teacher profiles provide indications of the strengths of the mixed method design. The quantitative component demonstrates that pupil background and prior attainment as well as the socio-economic contexts of schools are powerful predictors of performance. Because of this it is necessary to control for such influences in order to make fair comparisons of relative effectiveness 
for schools and teachers serving different communities. Teachers were found to vary in their influence on pupils' cognitive outcomes, even when intake differences are controlled. In some classes pupils made greater progress in a school year. The use of profiles to link the quantitative measures with information from teacher interviews and other sources enabled the study to explore the potential influence of a range of other factors. The results show that context, external policy initiatives and school phase may be, but are not necessarily, factors which moderate teachers' relative effectiveness defined by value-added measures of pupil attainment and progress. The limitations concern the difficulties of accessing a broader range of contexts which impact upon teachers' work and lives, and the influence they have on teachers' perceptions of their effectiveness. This points to the need for further investigation of teachers' work and lives in these contexts and that school and departmental leadership, colleagues, and pupil behaviour may be mediating factors. The following chapters (5, 6, 7 and 8) do this by focusing upon key moderating and mediating influences upon variations in teachers' professional life phases, identities, and CPD; the impact of these on their commitment and resilience; and associations between these and their perceived and relative effectiveness. 


\section{CHAPTER FIVE: PROFESSIONAL LIFE PHASES}

Hypothesis 2: Variation in teachers' effectiveness can be understood by examining teachers and groups of teachers in particular phases of their work lives.

\subsection{Introduction}

An important objective of the VITAE research was to enhance understandings of teachers' work, lives and their effects on pupils. A key focus of our research, therefore, was on variations in teachers' work, lives, perceived effectiveness and possible features within and between particular phases of their professional lives. The VITAE work on the progression of teachers' professional lives builds on Huberman's seminal study on the lives of Swiss secondary school teachers, which has been widely cited for its development of a non-linear empirically-based schematic model of a fivephase teaching career cycle. One major contribution of Huberman's research was his identification that 'a large part of development is neither externally programmed nor personally engineered but rather discontinuous' (Huberman, 1993, p.195). Our study extends Huberman's work and provides additional, previously un-researched dimensions of teachers' professional lives by examining teachers in both primary and secondary schools in England over a 'real time' three year period. Distinctive differences in teachers' professional life patterns were observed in our research.

The analysis identifies key influences on teachers' work in different phases of their professional lives and the differential impact of these on their motivation and commitment, and perceived effectiveness. We analysed over 300 teachers' work and lives spanning six professional life phases - 0-3, 4-7, 8-15, 16-23, 24-30 and 31+ years of teaching. The division of the six phases was based upon an extensive review of previous studies on teachers' careers and professional development. 'Professional life phase' refers to the number of years that a teacher has been teaching. Although years of experience generally relates closely to a teacher's age, some teachers have less experience than might be expected for their age as a result of being late entrants to teaching or through taking a career break. 


\subsection{Previous research}

There is as yet little empirically based knowledge of the ways in which teachers' commitment, resilience and perceived effectiveness in the profession grows and/or diminishes over the course of a professional life and in different contexts.

1) Studies on teachers' professional careers in England have been relatively small scale (Ball and Goodson, 1985; Sikes et al, 1985; Nias, 1989; Bolam, 1990). It is, therefore, timely that the results of the VITAE research provide new evidence in this area.

2) There has been an unhelpful conflation between 'career stage' and 'professional development phase' which has limited understandings and appreciations of the different needs of teachers which are necessary to sustain effectiveness over a career. For example, DfES' (1998) career structure for teachers sets out prescribed stages of recruitment, training and promotion and targets aimed at rewarding teachers for role-related high performance. TDA (formerly TTA) and NCSL both provide for teachers and headteachers in relation to organisational needs for role performance only at particular promotion-related stages. Though the TDA has now begun to promote CPD for a broader range of teachers, it remains the case that a disproportionate amount of resources is provided for role related training and development - for example, through the establishment of the National College for School Leadership and the emphasis on management and management training and development at all levels through TDA and LA funding.

Studies on teachers and teaching have also defined teachers' careers in a sense that they are closely related to role-related promotion: 'it [teaching career] implies a commitment on the part of a person to obtaining promotion through the status hierarchy that exists according to some time schedule' (Maclean 1992: 188; also Hughes, 1952, Pavalko, 1971, Ritzer, 1972, Huberman, 1989, Prick, 1989, Butt and Raymond 1989). The evidence from VITAE shows that for the majority of teachers, their original call to teach was the opportunity to work with children, and that pupils, not necessarily career promotions, remained the main source of their motivation and commitment. Our research has found that teachers derive commitment and resilience to sustain such commitment from differing sources in 
different contexts and in different phases of their professional and personal lives. Their functional positions/role-related career advancement only comprises part of these. The notion of teachers' professional lives, rather than careers, therefore, enabled us to form an holistic understanding of the complex factors which influence teachers in different phases of their work and how these affected their commitment.

3) The impact of the interaction between professional and personal contexts on teachers' career development tends to be overlooked in research on teachers' lives. Huberman (1993) emphasised that the importance of the concept of career is that it

... contains in itself both psychological and sociological variables. This means, for example, that we can explore the trajectory of individuals in organisations and thereby understand how the characteristics of these individuals influence that organisation and, at the same time, how they are influenced by it.

(Huberman 1993: 4)

However, the analysis of teachers' professional life phases in our study suggests that the portrayal of teachers requires an investigation into factors not only within the organisational settings but also how these factors interact with and are managed in conjunction with factors arising from teachers' personal lives.

4) Studies viewing teachers' career patterns from the perspective of age ranges (see Sikes et al, 1985) fail to take into account factors independent of age and therefore, are limited in their ability to explain the complexity of teacher, professional life development. Sikes et al (1985) argue that 'teachers are first and foremost people, and like everyone else they are subject to changes which are associated with ageing, and how the process is viewed in the society' (1985: 56). Whilst this is undoubtedly true, our findings suggest that it is the complex interplay between teachers' professional and personal needs at different times in their work and lives, as well as between situated, professional and personal factors and external structures, that influence the trajectories of teachers' professional life journeys. 
5) Research samples in previous studies were often drawn from the same school phase (for example, secondary teachers in Huberman's study and primary teachers in Sikes et al). One important advantage of our VITAE work was that the research sample included both primary and secondary teachers. This enabled us to investigate the interaction between a greater range of school phases and teachers' professional lives.

6) Huberman asserts that teachers' professional career journeys are 'not adequately linear, predictable or identical' (1993: 264). In common with Huberman's observation, our study recognises the complexity of teachers' development. However, in contrast with Huberman, our study shows that despite individual and work context differences, it is possible to discern distinctive key influences, tensions, shared professional and personal concerns and 'effectiveness' pathways or trajectories relevant to most teachers in different phases of their careers.

The VITAE research worked from an holistic perspective through which teachers' experiences, identities and professional trajectories were interpreted in the light of a wide range of influences relating both on the one hand to the teachers' professional worlds and on the other hand to their personal lives. The key influences identified as shaping teachers' professional lives were: i) situated factors such as pupil characteristics, site-based leadership and staff collegiality; ii) professional factors such as teachers' roles and responsibilities and educational policies and government initiatives; iii) personal factors (personal level) such as health issues and family support and demands. Our study suggests that over a professional life span it is the interaction between these factors and the ways in which tensions between these and personal/professional identities are played out and managed that produces relatively positive or negative outcomes in terms of teachers' motivation, commitment, resilience and perceived effectiveness; and that such perceived effectiveness may itself influence effectiveness as measured by value added attainments of pupils. The tensions between teachers' work and personal lives are shown to be a significant influence on the stability of their identities and their effectiveness at certain moments of their professional lives. 
Drawing upon previous research on teacher careers and professional development, this chapter begins with a detailed discussion of each of the six professional life phases. This is followed by an overview of variations across the six phases. The potential impact of school socio-economic context (measured by the school's FSM band), pupil behaviour, workload, school phase and gender on teachers' professional lives was also investigated. Observations of key characteristics of professional life phases from the initial teacher questionnaires complement and strongly support key findings from the qualitative data. This both enhances the internal validity of the research findings and strengthens the advantages of the mixed method approaches adopted by this research project. Finally, the chapter portrays the continuity and discontinuity in some transitional $^{13}$ teachers' professional life trajectories. The transition in these teachers' professional identity, efficacy and perceived effectiveness demonstrates the dynamic nature of teachers' professional life phases.

\subsection{Findings}

Provisional key themes and expected trajectories were identified for teachers in each professional life phase. On the basis of their perceived identity, motivation, commitment and effectiveness, teachers within each professional life phase were further categorised into sub-groups. Key characteristics and sub-groups of the six professional life phases were:

\section{Professional life phase 0-3 - Commitment: Support and Challenge (N=26, 8\% of 309)}

Sub-groups: a) Developing sense of efficacy; or

b) Reduced sense of efficacy

\section{Professional life phase 4-7 - Identity and Efficacy in Classroom (N=75, 24\% of 309)}

Sub-groups: a) Sustaining a strong sense of identity, self-efficacy and effectiveness; or

b) Sustaining identity, efficacy and effectiveness; or

c) Identity, efficacy and effectiveness at risk

\footnotetext{
${ }^{13}$ The term 'transitional' describes teachers who have changed professional life phases or trajectories.
} 
Professional life phase 8-15 - Managing Changes in Role and Identity: Growing Tensions and Transitions $(N=86,28 \%$ of 309$)$

Sub-groups: a) Sustained engagement; or

b) Detachment/ loss of motivation

\section{Professional life phase 16-23 - Work-life Tensions: Challenges to Motivation and} Commitment $(N=46,15 \%$ of 309$)$

Sub-groups: a) Further career advancement and good pupil results have led to increased motivation/commitment; or

b) Sustained motivation, commitment and effectiveness; or

c) Workload/managing competing tensions/career stagnation have led to decreased motivation, commitment and effectiveness

\section{Professional life phase 24-30 - Challenges to Sustaining Motivation ( $N=52,17 \%$ of 309)}

Sub-groups: a) Sustained a strong sense of motivation and commitment; or

b) Holding on but losing motivation

Professional life phase 31+ - Sustaining/Declining Motivation, Ability to Cope with Change, Looking to Retire ( $N=22,7 \%$ of 309)

Sub-groups:

a) Maintaining commitment; or

b) Tired and trapped

Each of these groups will be discussed in turn, focusing on the key characteristics and defining features of the sub-groups. Excerpts from teacher cameos, which combine data generated by a number of methods (questionnaire, interview, pupil attainment) are used for illustrative purposes at the beginning of the discussion of each professional life phase in order to highlight trends for different groups of teachers and provide indications of relationships between perceived effectiveness and effectiveness as defined by value-added pupil attainment scores $^{14}$.

\footnotetext{
${ }^{14}$ In the teacher profiles, value-added attainment scores are shown in the following way: above expectation (+ or ++ ), below expectation (- or --), as expected (0). In the case of primary teachers, there are separate scores for maths and English. Where these scores are the same, only one score is provided. Where these scores are different, the term 'mixed impact' is used and the score for English is given, followed by the score for maths. For example $(+/ 0)$ would indicate a score 'above expectation' in English and 'as expected' in maths.
} 


\title{
2.1 Professional life phase 0-3 years (n=26: 9xPrimary, 17xSecondary $)^{15}$ Commitment: Support and Challenge
}

\section{Illustration of teachers}

\author{
A Portrait of Nikita - Developing sense of efficacy \\ Value-added: cohort 1 - As expected (0) / cohort 2 - As expected (0)
}

Nikita was 22 years old and had been teaching for two years. She always wanted to be a teacher and had no additional responsibilities as yet.

She taught English in a larger than average secondary school with 1400 pupils on roll aged 11-18 years. The percentage of pupils entitled to free school meals was in line with the national average (FSM2). The majority of pupils were white, with about $8 \%$ from other ethnic groups for whom English was an additional language.

Nikita felt that there was 'a big gap' between classroom teachers and the senior Management Team, especially heads of department and that they had lost touch with what went on in the classroom. Staff relationships had a positive impact on her work as a teacher. Pupil behaviour had deteriorated due to having a number of supply teachers in the past, but Nikita found that this was gradually improving. She respected that her relationship with pupils underpinned her high level of commitment to teaching. Nikita felt that her motivation and sense of efficacy remained high. She was undertaking a Master's degree because she wanted to carry on studying and developing her career further.

\section{Darius - Reduced sense of efficacy}

Value-added: Cohort 1 - as expected (0)

Darius was 31 years old and had been teaching for 2 years, both in this mixed (FSM4) comprehensive school with 710 pupils aged 11-16. Having completed a degree, Darius worked in retail for a number of years. He then embarked on the Graduate Teaching Programme offered at this school for a year (2001/2) before becoming a member of staff. Since starting his teaching career, Darius had been teaching the majority of year groups, became the literacy coordinator and, in 2003, was temporarily given the responsibility of Deputy Head of Year. He had also been nominated for best newcomer in the Teacher of the Year Awards.

Darius thought that, in general, the senior management were supportive and attempted to consult staff on potential changes, new initiatives, etc. However, he felt as if 'they [were] picking on me' during his NQT year because he was continually being asked if he could be observed. Darius started to build relationships with colleagues whilst on the GTP which he found useful once he had qualified and had a much heavier workload. However, towards the end of his first year, his views altered and he stopped spending much time in the staffroom because the atmosphere had changed and the feelings of camaraderie had been lost. Pupil behaviour was given as the biggest negative impact his work in his initial year and this continued to impact on his work.

Not long after Darius had started his NQT year at this school (November 2002), his relationship with his girlfriend of 8 years ended. This meant that he had to move out of the house they had bought together which took until the end of January 2003. Now that he was single, he spent a lot of his time marking without someone else complaining about it! - being single was an advantage at this phase of his career.

Although having remained highly committed to the school and to the children, Darius's level of motivation had decreased. This had been caused by his resentment towards his department and the rest of the staff. He had started his career feeling very confident in his abilities - 'On average for the majority of the year I have been confident or even cocky about my abilities as a teacher', but his confidence seemed to waver during this school year - 'And sometimes I feel like I'm hitting my head against a brick wall'. He regretted that 'I would have to say that my group's biggest failing was having me as a teacher'.

\footnotetext{
${ }^{15}$ One teacher had very little data and therefore could not be categorised into subgroups.
} 


\subsubsection{Sub-groups and possible trajectories}

Teachers in this cohort were in the 20s-40s age range. The outstanding characteristic of the large majority of teachers (85\%) was their high level of commitment to teaching. This stemmed largely from their original motivation for entering the teaching profession. Over half of the teachers in this cohort (61\%) indicated that they were primarily attracted to teaching because of their teaching family background and/or their expectation of a rewarding opportunity to work with children and contribute to their progress.

My father was a teacher. I didn't really think I'd be anything else (Ruth, Secondary).

I wanted to be part of children's education to inspire them (Eleanor, Primary)

Nineteen per cent, almost all secondary teachers entered the teaching profession for a love of subject.

I like working with people and to pass on my love and understanding of English literature (Cheryl, Secondary)

Two sub-groups were observed within this professional life phase: one with a developing sense of efficacy $\left(+15^{16}\right)(6$ Primary $=67 \%, 9$ Secondary $=53 \%)$ and the other with a reducing sense of efficacy $(-10)$ (3 Primary $=33 \%$; 7 Secondary $=41 \%$ ). Four late entrants to teaching were found in the former sub-group and three in the latter, which suggests that age is unlikely to be an important factor in the formation and change of teacher identity in this professional life phase. Figures 5.1 and 5.2 below illustrate key influences on teachers within each sub-group.

\footnotetext{
${ }^{16}$ The '+' or (-) in combination with the number refers to the teachers who have demonstrated upward or downward professional life phase trajectories.
} 
Figure 5.1: Developing Efficacy $(0-3)(\mathrm{N}=15)$

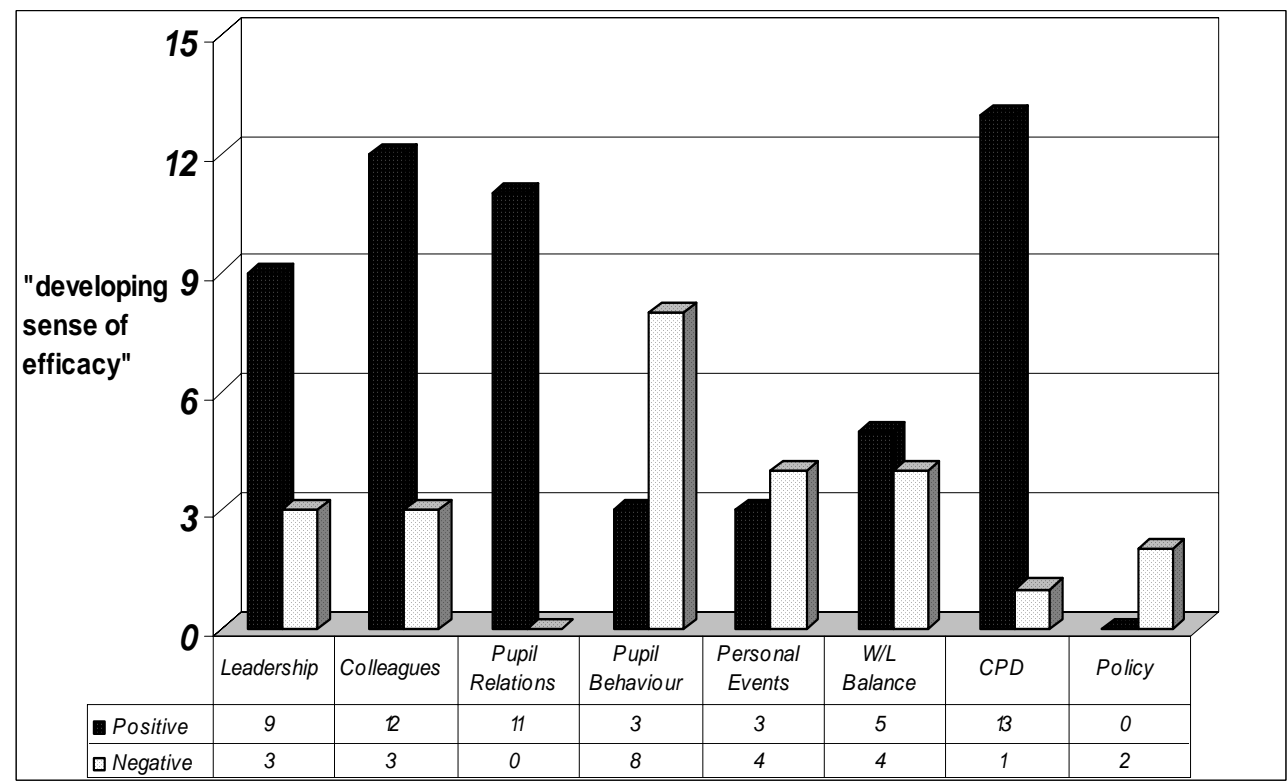

Figure 5.2: Reduced Efficacy (0-3) $N=10)$

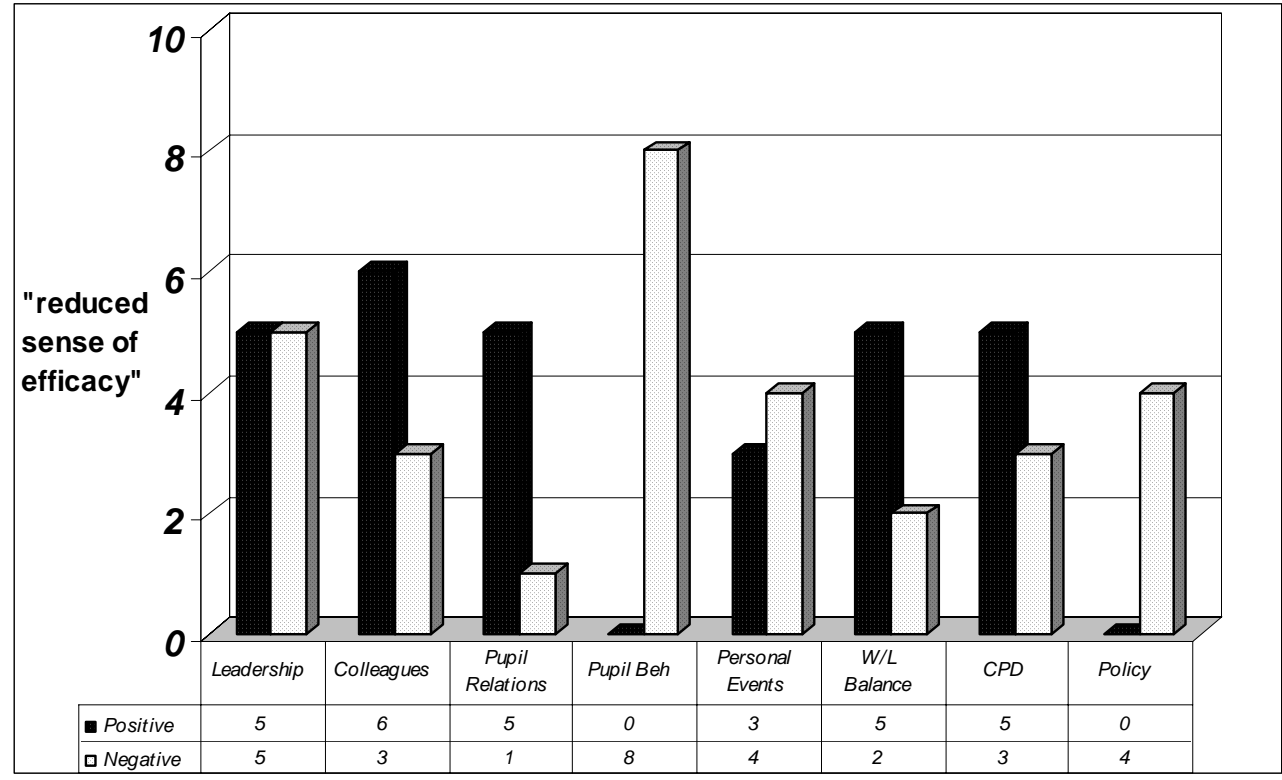


Our findings confirm the view that teachers who had an 'easy beginning' (Huberman 1993) benefited from a combination of influences that were more positive than those for teachers with a 'painful beginning' (Huberman 1993). Teachers in both groups reported the negative impact of poor pupil behaviour on their work as a teacher. However, in contrast with the 'easy beginning' group whose work had mostly benefited from leadership support, more teachers in the 'painful beginning' group had experienced a lack of support from the school and/or departmental leadership. This shows that even at this time school/departmental leaders are a key mediating influence on the work and morale of beginning teachers. It also finds, like Huberman (1993), that the concept of 'survival' found resonance in teachers with two or three years' experience.

This is interesting, given the emphasis in recent years on work-based experience in initial teacher training courses. For new teachers who are struggling to survive the challenges of a new professional life in the reality of the classroom, the impact of combined support from the school/departmental leadership and colleagues can be highly significant in helping to build their confidence and self-efficacy and deciding the direction of their next professional life path. In addition to the issue of support, the realisation that teaching is a 'demanding' job appeared to have a negative impact upon some new teachers' determination to stay in the teaching profession.

\subsubsection{Possible trajectories}

The key influences on these teachers' potential professional life trajectories were found to be the level of support and recognition of their work from the school culture. As a consequence, teachers in this phase would be likely to follow one of two distinct professional life paths. These would be:

a) those who would enjoy career advancement with increased selfefficacy $(N=15,60 \%$ of 25$)$; and

b) those who would suffer a declining sense of efficacy which led to change of school or career $(N=10,40 \%$ of 25$)$. 


\subsection{Professional life phase 4-7 years $(n=75 \text { : } 36 x \text { Primary, 39xSecondary })^{17}$ Identity and Efficacy in Classroom}

\section{Illustration of teachers}

\section{A Portrait of Ralph - Coping}

Value-added: Cohort 1 - below expectation (-) / Cohort 3 - as expected (0)

Ralph was 26 years old and had been teaching for six years at his first school, an urban low socio-economic status (FSM4) primary school of 391 pupils. He was originally attracted to teaching because of the security it offered, which still applied. He was a Year 2 teacher and History, Music and EAZ Co-ordinator.

Ralph described the pupils in this school as 'challenging, lively and interesting'. The staff probably put up with a 'percentage of behaviour not tolerated elsewhere'. Ralph had experienced pupil behaviour problems in the past, particularly in Year 1 of the Project, but had gradually found that his classroom management strategies had worked with his pupils. He gained great satisfaction from the progress of his 'most stressful class' and his motivation and commitment had increased as a result.

Initially Ralph thought that the new SMT had a firm management structure in place at his school, but later in the project he felt that the school management had negatively impacted on his work and motivation. He felt that the team leaders expected everyone to do everything in the same way, and that at times this undermined his professional judgment. He did not feel valued and found that his enthusiasm waned.

Ralph's partner was Spanish and he had decided to move to Spain. He did not think the children or staff would have noticed any differences in him. However, he felt different. This was a 'turning point' in his career path. He felt that he had done sufficient at his school and was taking a 'sideways' move (and a pay decrease) in order to start a new phase of teaching. Ralph realised that he wanted more time for 'life now, not career'. Nevertheless, he still enjoyed working in his current school and the challenge of taking on a problematic class.

\section{A Portrait of Eleanor - Growing identity}

Value-added: cohort 1 - mixed impact $(0 /+) /$ cohort 2 - above expectation $(+) /$ cohort 3 - mixed impact $(0 /+)$

Eleanor was 24 years old and had been teaching for 4 years, both at this C of E FSM1 school with 113 pupils on roll. Her school had a diverse socio-economic background and all pupils had English as a first language. In addition to being a Yr2 teacher, she was also Coordinator for Geography, Art and Music. Eleanor was primarily attracted to teaching because she wanted to be part of children's education and to inspire them.

Eleanor felt that, being a small school, the teachers and the headteacher got along well. Initially she saw pupils as the factor that had had the biggest negative impact on her work as a teacher. However, later in the Project she had a good class and enjoyed the respect from her pupils. Eleanor and her partner moved in their own home in April 2002, which was quite a big change for her, as she had been living with her parents. Her family was very supportive of her and her mother had been into school to help her with displays. She also enjoyed going out with friends and going to the gym. She described herself as a confident, motivated and committed teacher. She tried to join in some of the extra-curricula activities at school which gave her a feeling of being involved.

\footnotetext{
${ }^{17}$ One teacher provided very little data and therefore could not be categorised into subgroups.
} 


\section{A Portrait of Scarlett - Vulnerable/Declining}

Value-added: cohort 1 - as expected (0) / cohort 2 - as expected (0)

Scarlett's experience illustrates a decline in motivation and commitment to teaching because of a perceived lack of support in the school culture and her heavy workload. She was 27 years old and had taught English for five years, four of which had been at this urban, FSM 4 school. She had wanted to be a journalist on completion of her first degree, but because she could not afford the course, she undertook a teaching qualification and enjoyed it. She came from a teaching family who tried to change her mind on becoming a teacher, but she ignored their advice. At the beginning of the Project, she had grown to love teaching.

Scarlett viewed the senior management team as positively, but felt less positive about the leadership in her department. Nevertheless, staff at her current school were 'incredibly supportive and friendly' and she enjoyed the pleasant environment in the school. She lamented a lack of sharing of good practice in her department. Scarlett had established a good relationship with her pupils, but found that, overall, pupil behaviour had become more challenging.

Her growing professional experience had increased her perceived effectiveness as a teacher. Her self-efficacy and confidence in managing the classroom had improved since she began teaching. At the beginning of the project she was highly committed to teaching and was very pleased to see that she could make a difference to pupils both academically and personally. She saw teaching as 'a life as well as a job.' Not surprisingly, she enjoyed an extremely high level of job satisfaction. Scarlett suggested that three critical incidents had improved her effectiveness as a teacher in her initial four years in teaching - gaining a permanent contract, recovering from a broken relationship, and taking on new responsibilities after OFSTED.

However, in her fifth year Scarlett regretted that her motivation had decreased because of her increased workload and ill health. She had nearly three months off school and believed that her illness was work-related. Although Scarlett had wanted to apply for promotion as second in department, she now felt that she was 'not utterly convinced' that she wanted to stay in teaching.

\subsubsection{Sub-groups and possible trajectories}

Teachers in this cohort were aged between 20 years and 40 years. Support from the school/departmental leadership, colleagues and pupils continued to be of importance to their work. Teachers in this professional life phase demonstrated a primary concern over their confidence and feelings of being an effective teacher, which is only partly in accord with Huberman's findings that teachers with 4-6 years of career experience were found to be going through a phase of 'stabilization, consolidation of a pedagogical repertoire' (1993: 13). In contrast with professional life phase 0-3, there were more frequent references made by teachers to heavy workload which was seen as reducing their teaching effectiveness.

Unlike Huberman's work, an important characteristic of teachers in this phase that was identified by this research was that promotion and additional responsibilities had already begun to play a significant role in teachers' perceived identities, motivation and sense of effectiveness. 
Fifty-eight teachers ( $78 \%$ out of 175 ) in this cohort (30 primary $=86 \% ; 28$ secondary $=72 \%)$ had additional responsibilities and 23 (31\%) particularly stressed the importance of promotion to their growing professional identity $(6$ primary $=17 \% ; 17$ secondary $=44 \%)$. Among these 23 teachers, $16(70 \%)$ had 4-6 years' experience. This suggests that for many teachers this professional life phase is not a stabilisation period. It is a period in which teachers, whilst consolidating their professional identities in their classrooms, also have challenges beyond these.

Figure 5.3 summarises the levels of motivation and commitment of teachers in the three sub-groups. They are based on researchers' interpretation of teachers' self-rated motivation and commitment levels over each year of the project period. The difference in teachers' identities and perceived effectiveness between the three groups is clearly reflected in their levels of motivation in the profession and commitment to the school.

Figure 5.3: Variations in levels of commitment (4-7) $(\mathrm{N}=75)$

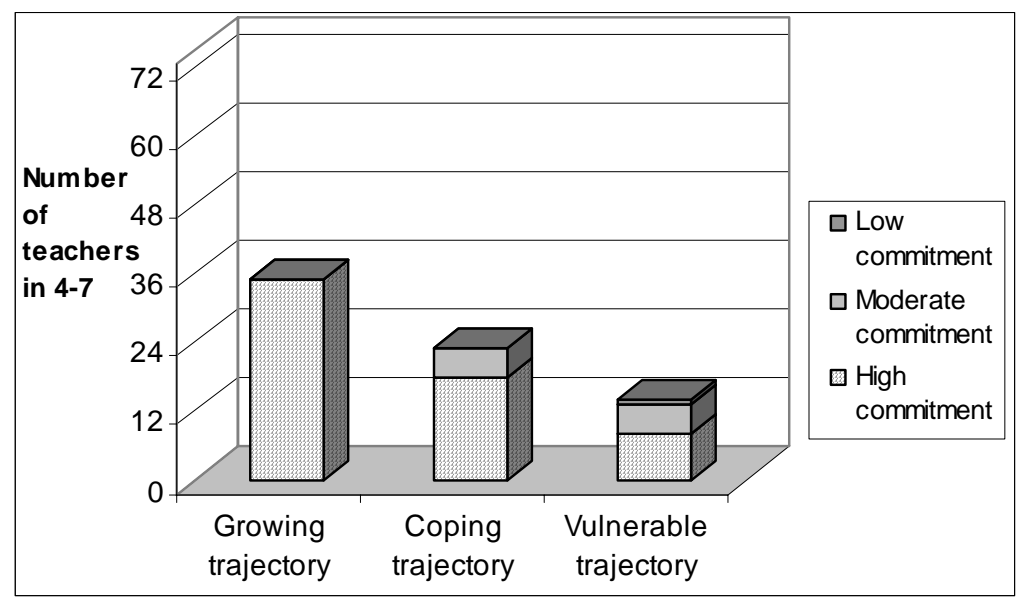

Sub-group a): Growing: Teachers with a strong sense of identity, self-efficacy and perceived effectiveness. (14 Primary $(39 \%)=2 \mathrm{M}, 12 \mathrm{~F} ; 22$ Secondary $(56 \%)=7 \mathrm{M}$, $15 \mathrm{~F})$

Huberman (1993: 7) discusses a phase of experimentation and diversification after the 'stabilization'/ 'pedagogical consolidation' phase. He posits that teachers, with between 7 and 25 years' experience, 'having made an initial tour of duty in the classroomm'. set off in search of new challenges and new stimulations (1993: 8). 
In our sample we observed a group of teachers with strong desire for new commitments, but, in comparison with Huberman's work, these teachers were in an earlier professional life phase: the 4-7 phase.

Teachers' early career promotions (not professional lives) are discussed in Hilsum and Start's (1974) and Maclean's (1992) studies on teachers' career and promotion patterns. Hilsum and Start noted that the first promotion could be achieved after three years in teaching for secondary teachers and after seven years for primary teachers. In contrast, Maclean found that one quarter of primary teachers in his study obtained their first promotion after between three and six years of teaching experience, but with an average level of eleven years.

The differences in teachers' promotion timetables and patterns observed in different studies may be consequences of the differing educational contexts and dates when these studies were carried out, as well as differences in definitions and the specific promotion positions considered. There have been recent changes in the way that the teaching profession has been structured, resulting in a greater differentiated pay scale to reward successful headteachers and teachers for high performance, and more posts of responsibility (DfES, 1998; DfES, 2003). Also, staff recruitment and retention is more difficult in some contexts (inner city and disadvantaged schools) and thus responsibilities and promotion may be more rapid for staff in such schools. Figure 5.4 below illustrates the weighting of key influences on teachers' work. Substantial support from leadership and colleagues is a contributing factor in these teachers' growing sense of identity. 
Figure 5.4: Key influences on teachers with growing identity, increased efficacy (4-7) (N=36)

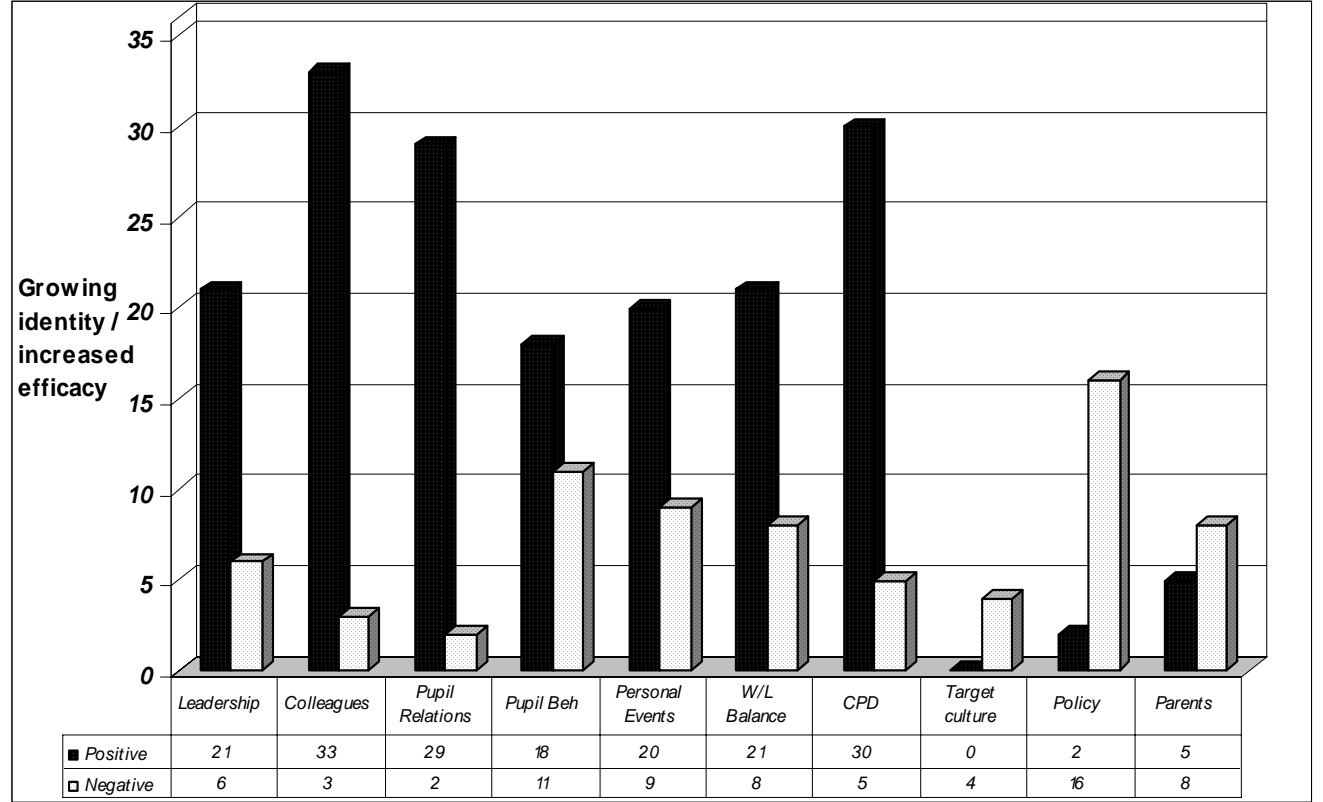

Analysis of our data strongly suggests the crucial importance of promotion and recognition to the professional development of teachers within this phase of their careers. In this sub-group 29 out of 36 had additional responsibilities (81\%) and 19 $(53 \%)(5$ Primary $=36 \% ; 14$ Secondary $=64 \%)$ indicated the significance of promotion to their increased motivation, confidence and perceived efficacy. It is apparent that teachers in this sub-group had greatly benefited from their consolidated experience in the classroom which was a contributing factor to their growing sense of professional identity, their feelings of becoming an effective classroom teacher and their ambition to climb up the career ladder.

Enjoying [my] job, absolutely love teaching the kids, and I love running the department (Winona, age 31-40, Secondary)

Being here is too easy. I need to be challenged, if things are too easy it becomes boring (Tania, age 31-40, Primary)

Sub-group b): Coping/Managing: Teachers who had sustained a relatively moderate level of identity, efficacy and effectiveness (16 Primary (44\%)=3M, 13F; 7 Secondary $(18 \%)=1 \mathrm{M}, 6 \mathrm{~F})$ 
Figure 5.5 shows the key influences on the work of the 23 teachers in this sub-group. In comparison with the key influences summarised in Figure 13, the overall weighting of the influences appears to be slightly more negative.

Figure 5.5: Key influences on teachers who had sustained a moderate level of efficacy (4-7) $(\mathrm{N}=23)$

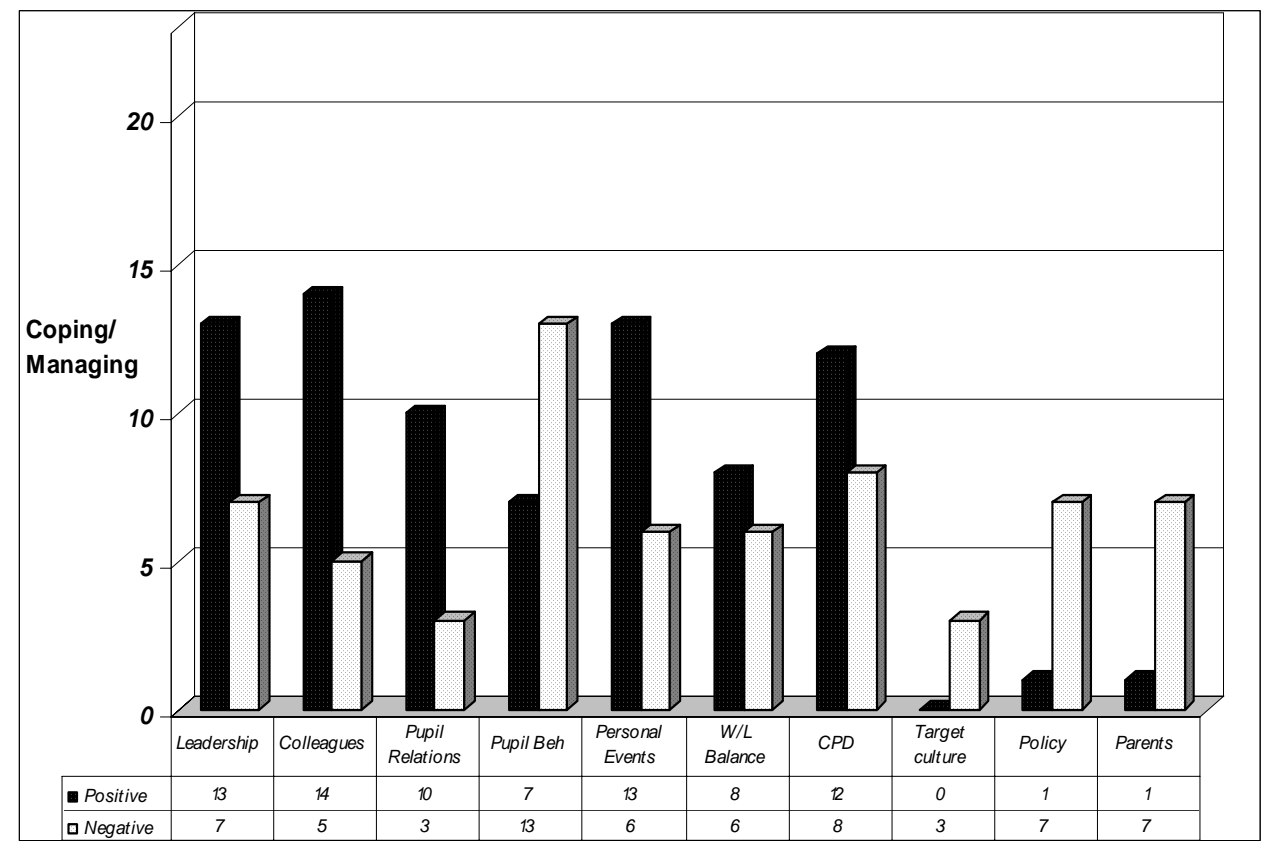

In contrast with teachers in sub-group $a, 18$ out 23 had additional responsibilities $(78 \%)$ but only four $(17 \%)$ (1 primary $=6 \% ; 3$ secondary=43\%) emphasised the positive impact of promotion on their motivation and self-efficacy. However, in common with sub-group $a$, most teachers in this sub-group also expressed an enjoyment in seeing their experience and confidence increase - 'feel more experienced, happier and more confident' (Jayne, age 41-50, Primary); 'increased confidence and effectiveness with experience' (Nadia, age 31-40, Primary).

An important difference between sub-groups $a$ and $b$ appears to be that these teachers had a stronger concern over the management of their heavy workloads and that some teachers had shown an inclination to focus on classroom teaching in order to keep a balanced work and life. 
I enjoy it [teaching] I think. The enthusiasm I had a couple of years ago has waned a little and everybody used to say I made them sick how enthusiastic I was. Sometimes you just get tired or a bit of a rough day with the kids, a lot of things affect it........ I don't think a lot of people enjoy the fact that it [teaching] can push too far into your social life. ... I suppose from a personal point of view I've made a conscious effort to try and keep weekends free instead of spending Sunday afternoon doing planning for them for the following week, because that spoils weekend. That's made a big difference. That's balancing work and play and it's been quite effective (Ricky, age 4150, Primary)

Sub-group c): Vulnerable/Declining: Teachers who had felt that their identity, efficacy and effectiveness were at risk because of workload and difficult life events. (6 Primary $(17 \%)=1 \mathrm{M}, 5 \mathrm{~F} ; 9$ Secondary $(23 \%)=3 \mathrm{M} ; 6 \mathrm{~F})$

Few teachers in this sub-group mentioned the encouraging impact of promotion. Figure 5.6 indicates the impact of key influences on teachers' work. In comparison with the previous two sub-groups, a larger proportion of teachers in this sub-group reported a lack of leadership support, adverse personal events and work-life tensions.

Figure 5.6: Key influences on teachers whose identity and efficacy are at risk (4-7) $(\mathrm{N}=15)$

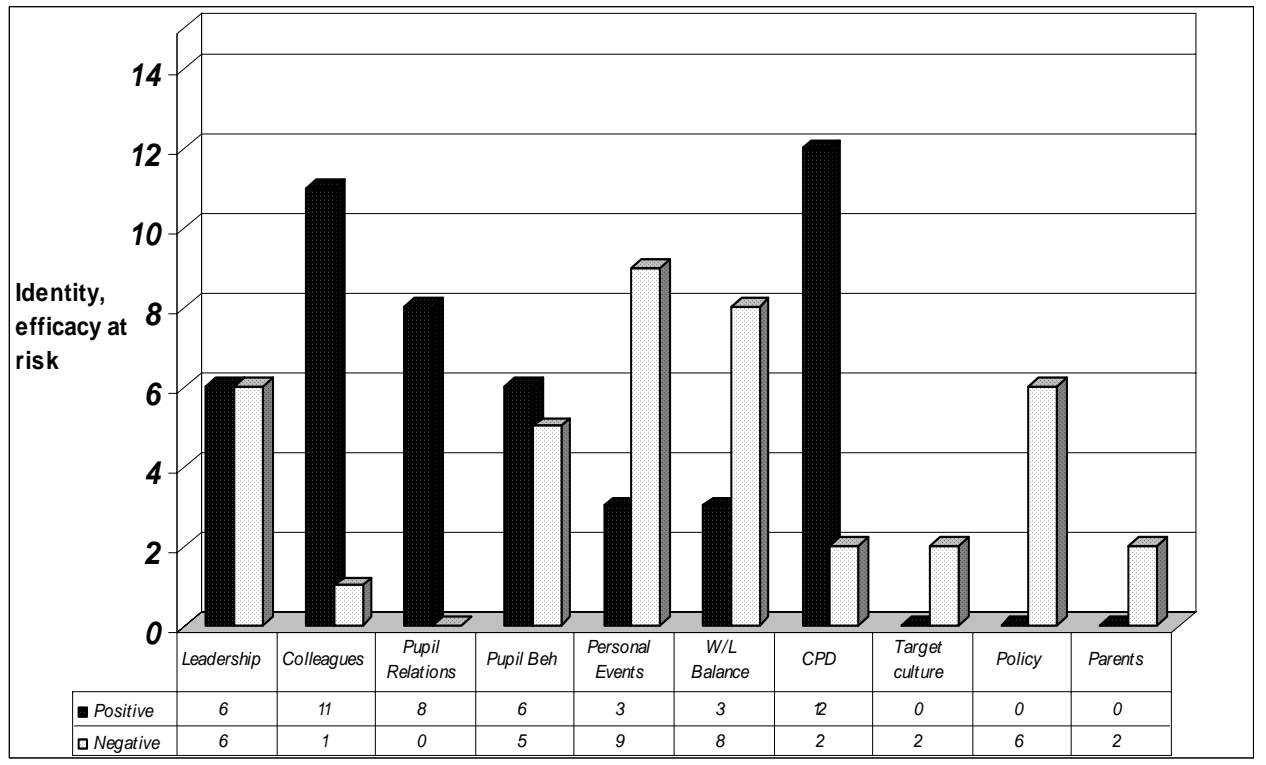

The negative influence of workload and adverse personal events on teachers' declining identity and perceived efficacy is illustrated in the following quotation: 
A major one [change] is going down with depression. I'm on antidepressants at the moment. I've been going downhill since I started full time. It's just a combination of factors, two teenage children, a husband with a busy job that needs supporting and the school as well.... It's just more than I can manage (Faith, age 41-50, Primary)

Whilst analysis of the initial VITAE teacher questionnaire indicated that there is no statistically significant difference in the distribution of 'older' teachers (mostly late entrants and teachers with career breaks ${ }^{18}$ ) in terms of their motivation, commitment and professional outlook, nevertheless, an analysis of teachers' worklines suggested that although these 'older' teachers exhibit a similar outlook to that of their younger peers, they appear to have different concerns and face different tensions in comparison with their younger colleagues in the same professional life phase. The implication is that the influence of age and life experience on teachers' identity and professional life growth is not a linear one, depending on issues such as their vocationalism and how the tensions are managed.

Whilst it has been argued that 'ageing, occupational development and identity are inextricably linked' (Sikes et al, 1985: 23) and in our research age-related personal issues were found to impact upon teachers' work, we also found that chronological age alone does not adequately explain the complexity of teacher career development. First and foremost, viewing teachers' career patterns from the perspective of age ranges fails to take into account experiences of late entrants and teachers with career breaks. Huberman argues that the ontogenic model of teachers' careers is 'invalid'.

Evidence from the VITAE research supports Huberman's argument. For example, for teachers with 4-7 years' experience, it is the profession-related factor - promotion and recognition - that was shown to have a more influential impact than biographical factors on teachers' sense of effectiveness and professional life advancement. Discussion on professional life phase 8-15 below indicates that this phase of a teacher's career, rather than the 'age 30' transition' as suggested by Sikes et al (1985: 228), is a key watershed in teachers' professional lives.

\footnotetext{
18 The distribution of late entrants and career-break teachers in the 4-7 professional life phase is: 'growing' group: 6 late entrants; 'coping/managing' group: 7 late entrants, 2 career-break teachers; 'vulnerable/declining' group: 5 late entrants, 1 career-break teacher.
} 
Sikes et al's model of the life-cycle of the teacher describes teachers' growth through age patterns, presumably on the assumption that teachers all enter teaching at roughly the same age and remain in the profession with no career breaks. In our research the investigation into teachers' professional development through different professional life phase enabled us to consider factors independent of age, such as an early promotion, and to understand teachers' professional development through a perspective which takes into account 'the arena where the expertise is played out' (Rich, 1993: 138).

\subsection{Professional life phase 8-15 years (n=86: 51xPrimary, 35xSecondary) ${ }^{19}$ Managing Changes in Role and Identity: Tensions and Transitions}

\section{Illustration of teachers}

\section{A Portrait of Charlie - Sustained engagement}

Value-added: cohort 2 - as expected $(0) /$ cohort 3 - as expected (0)

Charlie was 31 years old with 8 years teaching experience and some of that outside primary - in secondary and adult education. Yet he achieved this primary headship in April 2003. In his first VITAE interview, he said: 'It's my first term being Head. It's a whole new ball game. I found it really difficult.'

Charlie enjoyed working at his current school (FSM 1) and pupils were the main source of his job satisfaction. Because of the decrease in the school roll, Charlie felt stressed and was unhappy with the fact that his management role had distracted him from teaching. At that point he described himself as being in the lowest point of his career. Charlie felt that there was 'no happy time whatsoever' in his personal life because of his worries at school. Nevertheless, he remained optimistic and confident that his morale and self-esteem would 'go up' in the future. Charlie believed that his promotion to Headship was a positive turning point in his career: 'I just need to get through all the difficulties and carry on with my mission. Everything else has to be put on the backburner. It will get better.'

Despite the difficult situations in his current school, Charlie had demonstrated a high level of agency and resilience, and remained highly motivated and committed in his job.

\footnotetext{
${ }^{19}$ Four teachers had very little data and therefore could not be categorised into any sub-groups.
} 


\section{A portrait of Katie-Detachment/Loss of motivation}

Value-added: cohort 1 - below expectation (--) / cohort 2 - below expectation (--)

Katie was a Year 6 teacher in a rural high socio-economic status (FSM1) primary school. She was 49 years old, having taught for 13 years. Support and trust from the Headteacher and her colleagues had a positive impact on her sense of efficacy. Katie felt that her sense of effectiveness varied, depending upon the make-up of her class. 'Sometimes I feel I can be more effective simply because I have less children in the class, but then I've got this one extra child who does make life difficult.' Pupil behaviour had been a detrimental influence upon her motivation and commitment - 'There is nothing more demotivating than a class that doesn't want to be taught.' 'It's a constant drip of minor misbehaviour that builds up and wears you down.' She also felt demotivated and less committed when the parents questioned and complained about her methods of teaching.

The target-driven culture was another negative influence on her decreased motivation in the profession. She was extremely negative about the excessive workload generated by the National Curriculum and the pressure from Ofsted inspections:

This time last year ... we were in the throws of Ofsted which was the most stressful experience I had ever been through, with the worst class in the school.

She also struggled with a lack of work-life balance:

I have to be very careful how I balance the support I give my own children, as I've got a pile of books to mark. Everything has to be planned like a military operation. If my husband wants us to go somewhere, like on Saturday, then I have to know. He can't tell me on Saturday morning that he wants to go out. He has to tell me the week before, so I can get my marking done, so that my Saturday can be free.

Katie felt that there was a slim chance of promotion for her in her current professional life phase.

\subsubsection{Sub-groups and possible trajectories}

Our research suggests that this professional life phase is a key watershed in teacher professional development. Teachers in this cohort were mostly aged between 30 years and 50 years. They were beginning to face additional tensions in managing change in both their professional and personal lives. Most of these teachers had additional responsibilities (68 out of $86=79 \%)(47$ Primary=92\%, 21 Secondary $=60 \%$ ) and had to balance the effectiveness in their management role and teaching role. Heavy workloads worked against the effectiveness of their teaching.

Figure 5.7 summarises the levels of commitment related to teachers' values and dedication to the profession and their desire to actively participate in the processes of teaching and learning of teachers in the above two sub-groups. Once again, the difference in teachers' identity and perceived effectiveness between the two groups is clearly reflected in their levels of motivation and commitment in the profession. 
Figure 5.7: Variations in levels of commitment (8-15) $(\mathrm{N}=86)$

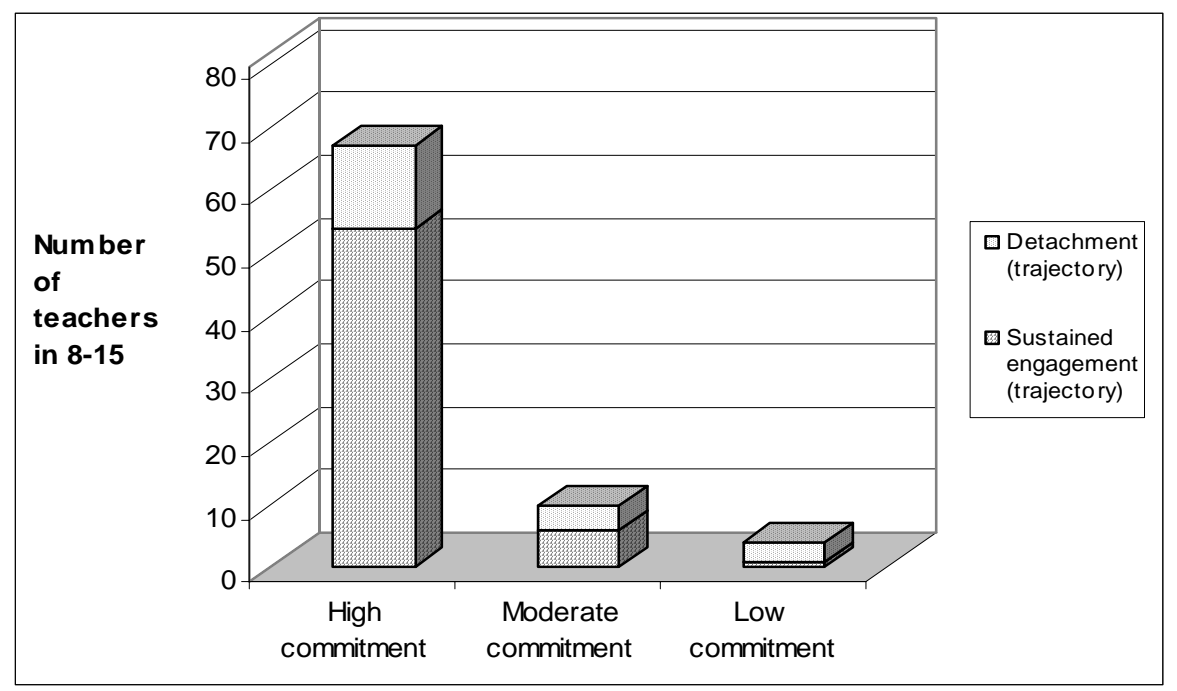

Two sub-groups were identified on the basis of their current levels of motivation and commitment, as follows:

Sub-group a). Teachers with sustained engagement whose expected trajectories were career advancement with increased self-efficacy and commitment (+62) (40 Primary $=78 \% ; 22$ Secondary $=63 \%$ ).

Forty-two within this sub-group (67\%) had additional responsibilities. The combined support from leadership, staff collegiality, rapport with the pupils and CPD was a contributing factor in this sub-group's positive sense of effectiveness. This is illustrated in Figure 5.8. 
Figure 5.8: Key influences on teachers with sustained engagement $(8-15)(\mathrm{N}=62)$

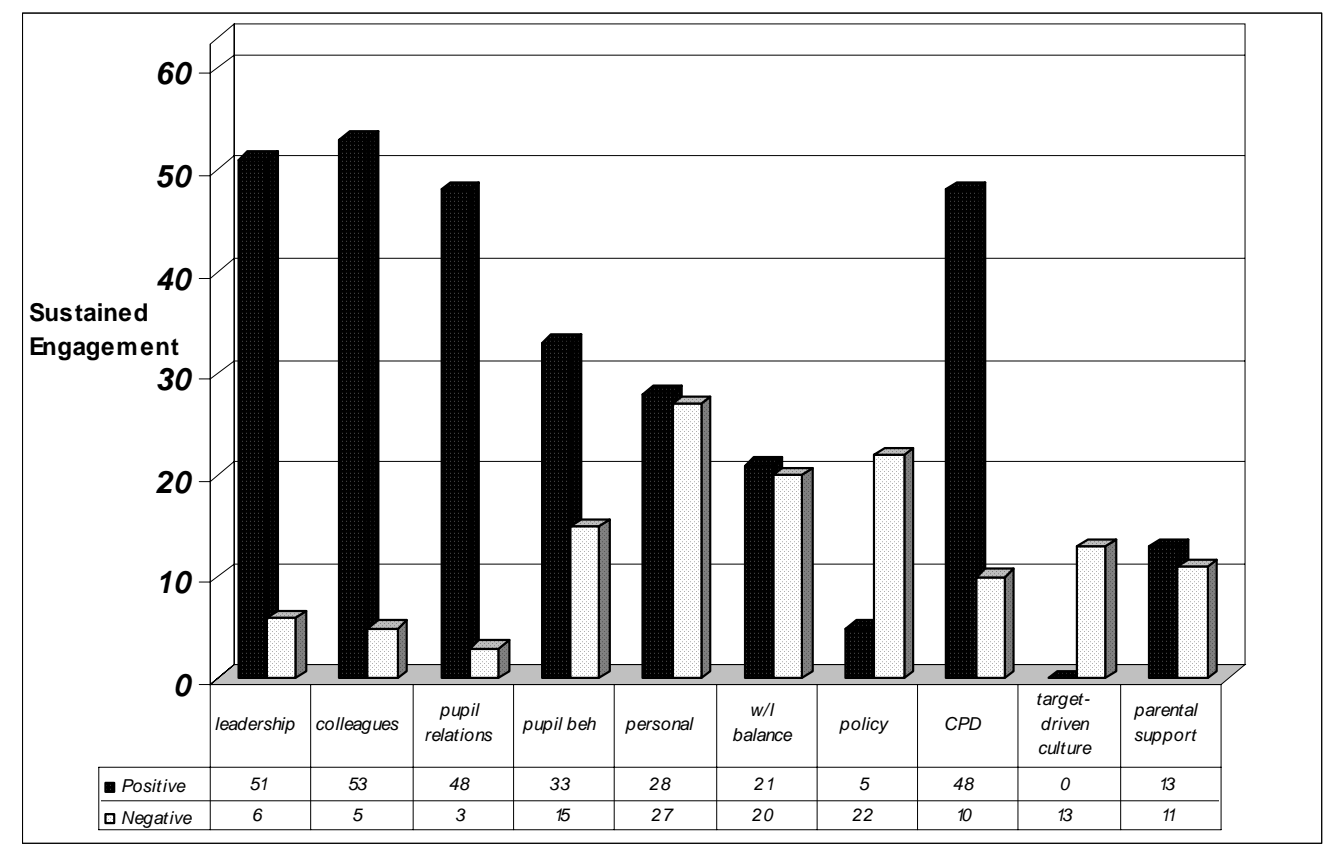

For the majority of these teachers, their managerial roles comprised an important part of their professional identity:

- looking into further promotion, aiming at Head of Department, Deputy Headship and/or headship

○ having become established in current managerial roles and considering further career advancement

- settling in current managerial and/or pastoral roles and experiencing a change in identity: deciding whether to be an effective teacher or effective manager

In his study on teachers, Prick (1986) observed a period of 'crisis' in men between 36 and 55 and in women between 39 and 45 in terms of questioning the further advancement of their career in teaching. In our study teachers with 8-15 years' experience and at an earlier life stage were clearly experiencing a transitional period in their professional lives. However, the difference is that they were not necessarily considering whether to continue or to leave teaching. 
Rather, they were at the crossroads of deciding the direction of their professional identity within the profession - whether to climb up the management ladder or to remain in the classroom fulfilling the original 'call to teach'.

A small group of teachers within this sub-group appeared to have already experienced this transitional, 'crossroads' period. They were 'content' and 'happy' with their current work-life balance and had no intention of taking up any further additional duties. Some teachers wanted to focus on improving their effectiveness in teaching, whereas some late entrants such were enjoying a high level of motivation, commitment and sense of effectiveness, but had no interest in promotion because they were nearing retirement age.

I've got a management plan and I've got a reasonably good balance and I stop even if the job's not done. I think it's the interaction with the children that is the important thing not the reams of paper that are produced. My ability to stop work means that the quality of my home life is reasonably good. (Sharon, age 41-50, Primary)

Sub-group b). Teachers who felt a sense of detachment and a lack of motivation and who were most likely to experience declining self-efficacy in their next professional life phase or even career change (-20). (7 Primary=14\%; 13 Secondary=37\%).

Figure 5.9 illustrates key influences on this sub-group's work. Around half of these teachers reported a lack of support from leadership (50\%) and colleagues (60\%). Adverse personal events and tensions between work and life were also important issues. CPD continued to be a positive influence on these teachers' professional lives. Three late entrants and one 'career break' teacher were identified here. 
Figure 5.9: Key influences on teachers with decreased motivation $(8-15)(\mathrm{N}=20)$

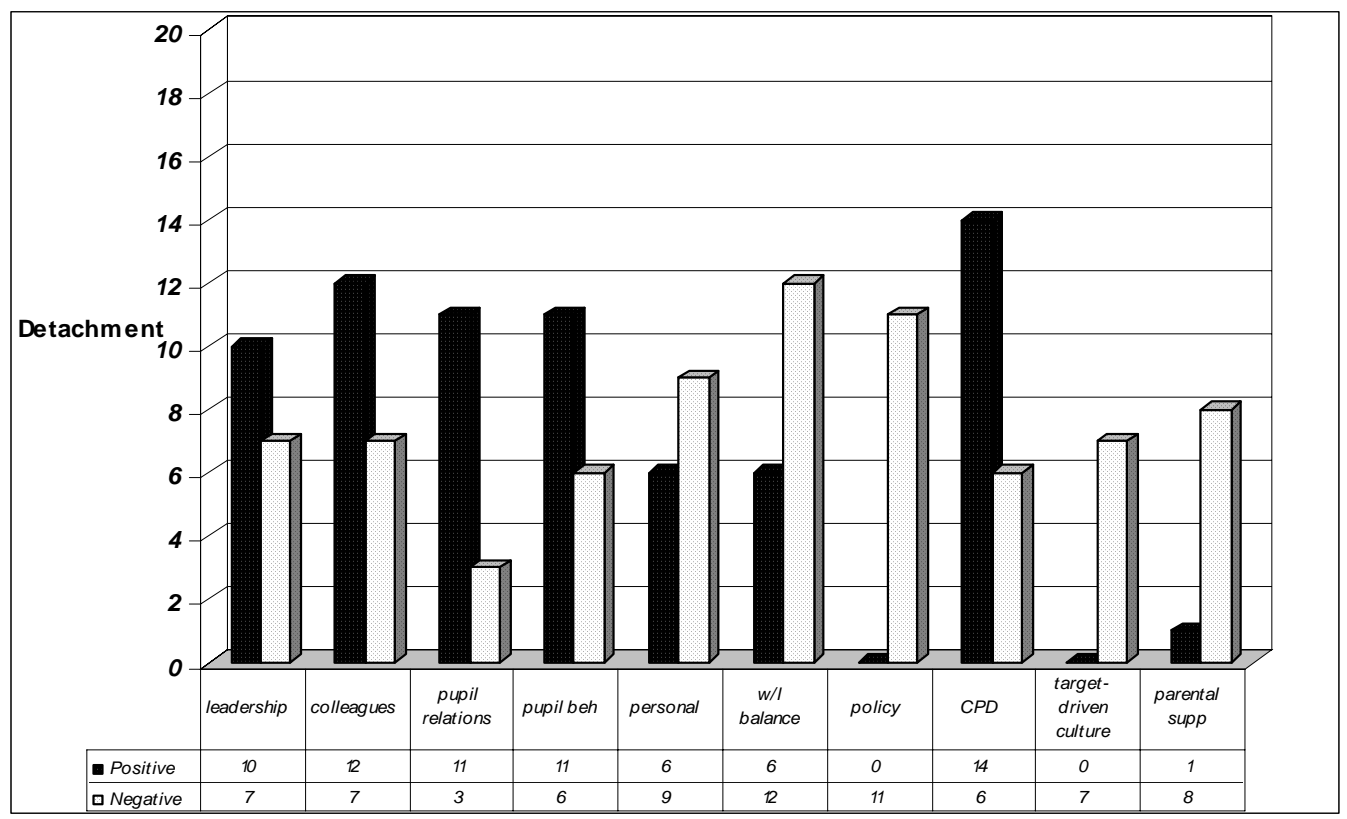

Eight teachers (40\%) reported their intention of leaving teaching. For Shaun, teaching had become ' a job' - he felt tired and did not take work issues home any more.

I've made a conscious decision not to pursue promotion or extra workload when I felt that I would rather spend that time at home. I'm happy doing what I'm doing and I would not want to sacrifice time at home for more responsibility and few more thousands pounds.

...

I think it's nice to be a father and it renews your faith in life, children, whatever and it puts a smile on your face. As far as a hindrance I'm more tired than I was. It also puts things into perspective that at the end of the day work it's work. Yes I'll work hard and try my best but it's not the most important thing in life, not now anyway. (Shaun, age 31-40, Secondary)

Other key characteristics of this sub-group include: giving up management roles because of adverse personal events (e.g. ill health, increased family commitments); decreased motivation and commitment had led to early retirement (e.g. one late entrant and one 'career-break' teacher); and, disillusioned/ low self-efficacy/decreased motivation and commitment. 


\subsection{Professional life phase 16-23 years $(n=46 \text { : } 27 x \text { Primary, 19xSecondary })^{20}$ Work-life Tensions: Challenges to Motivation and Commitment}

\section{Illustration of teachers}

\section{A portrait of Cathy - Continuing to cope}

Value-added: cohort 1 - as expected (0)

Cathy was 44 years old when the project began and had been teaching English for 22 years, almost all in this school. Prior to this, she taught in one other over a period of 2 years. Her school is an 11-16 yrs, oversubscribed is an oversubscribed, suburban secondary school (High School and Arts College) with 1000 pupils and FSM at $21 \%$. She had responsibility for the library and had recently been appointed as KS3 co-ordinator and Deputy Head of Department. She regularly attended CPD events, all connected directly with her role. Her motivation over the 3 years prior to the project was high and she had been attracted to teaching because she wanted 'to help pupils of all abilities achieve their full potential'. This was still the case. She worked 46-55 hours per week and experienced high levels of stress. These only occasionally affected her work. She felt that the changing nature of society characterized by a loss of community and deterioration in pupil behaviour was having an impact on teaching. A significant change occurred in 1999 when pupil intake to the school changed. Pupils' behaviour deteriorated and the SMT did not provide leadership to combat this, being 'over tolerant'.

A newly appointed Head had, however, 'done a lot for the school....new facilities, decorating the corridors, and, 'the ethos of the school has changed. The children are more valued'. Members of the Department supported each other with 'difficult' pupils in order to minimize disruption to others: 'We're very positive ... we want to do our best for children ... we don't give up on them ...' Cathy was generally content with the job, though felt that having a large gap between her two children had curtailed her career ambitions. Because she had one school age son who needed her to sit with him when he did his homework, Cathy often did not start work on school related work until 9:00pm. Cathy had considerable home support from her husband and mother. Without this it was doubtful as to whether she could have maintained her commitment to, and effectiveness in, teaching particularly when her own children were of school age.

She now spent significant 'teaching' time in managing pupil behaviour. Whilst her self-efficacy, commitment and motivation remained high, therefore, her job satisfaction was declining. Her recent promotion to KS3 Coordinator, however, had renewed her motivation and interest in her career which, prior to this had become 'a little stagnant!' Cathy had not really changed other than 'more hours working at home' because of her new responsibility. She was established in the school, having taught parents of present pupils and was comfortable with her 'kind' approach with pupils. She spent more time now in 'training for the tests': 'They are having lessons before school, at break, after school as well as booster lessons. They're being overwhelmed.' In the final year of the project an unfavourable Ofsted had dented the morale of the department.

\footnotetext{
${ }^{20}$ Two teachers had little data.
} 


\section{A portrait of Gerard - declining motivation and commitment}

Value-added: cohort 1 - as expected (0) / cohort 2 - below expectation (-)

Gerard was 51 years old and had taught for 16 years. Currently he was a Year 9 maths teacher and Numeracy Coordinator and form tutor in an urban socio-economic status (FSM3) school of over 1000 pupils. Prior to teaching, Gerard worked in his father's business for 12 years after leaving school and went into teaching for its stability when he had a family. Because of this, he felt his own parents respected him less. In addition to coping with two demanding teenage boys, he had to spend extra time on his family business. He did not have sufficient time for his hobbies and felt that his personal life and professional life were poles apart.

Gerard found both the school and departmental leadership supportive. He felt that there was less respect for teachers from parents. Gerard saw his motivation and job satisfaction decrease mainly because of the deteriorating behaviour of his pupils. He disapproved of the results-driven culture and realised that his beliefs and values about education were different from those in his current school. Nevertheless, he still liked teaching his subject.

Family issues, such as his mother's illness, remained a primary concern for him. Gerard had struggled with work-life balance - 'I worked too hard years ago and went off with stress, (which) made me more aware of life-work balance.' He found that his job satisfaction had declined - '[I] never get up wanting to go to school.' He experienced a moderate level of stress in his work as a teacher and saw it as having frequently affected his effectiveness.

On the whole, Gerard felt that his professional life was in a 'survival' phase.

\section{A Portrait of Michael - Growing motivation and commitment}

Value-added: cohort 1 - above expectation $(++) /$ cohort 2 - above expectation $(+) /$ cohort 3 - mixed impact $(0 /+)$

Michael was 48 years old and had been teaching for 23 years. He taught in two small, rural schools before taking his current post which he had held for 15 years. In addition to being a Year 6 teacher, Michael was also a subject coordinator. He was Acting Deputy Head for two terms in his school with under 250 pupils on roll, drawn from a wide range of backgrounds (FSM2).

Michael saw his school as a nice place to work, led by the Head who had a strong character. The headteacher retired in mid-2004, which was expected, and the role was assumed by the Deputy Head. Her post was then advertised but not filled and Michael was appointed as Acting Deputy. Although later he was not successful in his application for this permanent post, the experience had increased his confidence. He became more involved with other staff and in school activities. Michael saw the new Head as 'a breath of fresh air' who was calm, approachable and supportive.

There was a 'lovely atmosphere' at his school where the staff was supportive of each other and shared good teaching practice. He had developed good relationships with his pupils and described the overall behaviour throughout the school as 'wonderful'. Pupils were the main source of his motivation and job satisfaction 'The actual kids have motivated me more than anything else.' He resented the endless changes and excessive paperwork and saw them as having a negative influence on his work as a teacher. Michael felt that he still looked forward to being at work. He was thinking of looking for posts with promotion in other schools. 


\subsubsection{Sub-groups and possible trajectories}

Teachers in this cohort were mostly aged between 30 years and 50 years. Almost all (41 out of $46=89.1 \%$; 25 primary $=92.6 \%$; 16 secondary $=84.2 \%$ ) had additional managerial responsibilities. In common with the previous two professional life phases (4-7 and 8-15), excessive paperwork and heavy workload were seen as key hindrances to their effectiveness. In contrast with teachers from the earlier professional life phases, events in personal lives, coupled with additional duties, had a stronger impact on the work of this cohort, and as a consequence, a larger proportion of teachers had struggled with a negative work-life balance. These teachers were categorised into three sub-groups on the basis of their management of the challenges of work life and home events:

i) Sub-group a). Teachers who had seen their motivation and commitment increase as a result of their further career advancement and good pupil results/relationships and who were most likely to see their motivation and commitment continue to grow $(+23)(17$ primary $=63 \%$; 6 secondary $=31.6 \%)$;

ii) Sub-group b). Teachers who maintained their motivation, commitment and sense of effectiveness as a consequence of their agency and determination to improve time management and who were most likely to cope with work-life tensions in their next professional life phase $(+15)(8$ primary $=29.7 \%$; 7 secondary $=36.8 \%)$;

iii) Sub-group c). Teachers whose workload, management of competing tensions and career stagnation had led to decreased motivation, commitment and perceived effectiveness and whose career trajectories were expected to be coupled with declining motivation and commitment (-6) (1 primary $=3.7 \%$; 5 secondary $=26.3 \%)$.

Figures 5.10 and 5.11 summarise key influences on the work of two of these subgroups, which clearly demonstrate the negative influence of work-life tensions on teachers with 16-23 years' experience. Figure 5.11 shows that in addition to work-life tensions, the combined negative effects of pupil behaviour, personal events, policy, leadership and CPD had strongly contributed to sub-group $c$ teachers' decreased motivation and career stagnation. For example, 
I'm tired. You're always dealing with three or four things at a time. ... You either draw a line and do not do what you know needs doing and spend time with the family and go out, or you do work and lock yourself away. I do a combination of both. ... I consider now I'm approaching my 40th year, thinking of what I'm doing now for the next 20 years fills me with horror. I would like to ease back and keep the same salary. (Jo, age 31-40, Secondary)

Figure 5.10: Key influences on teachers with sustained Motivation (16-23) $(\mathrm{N}=23)$

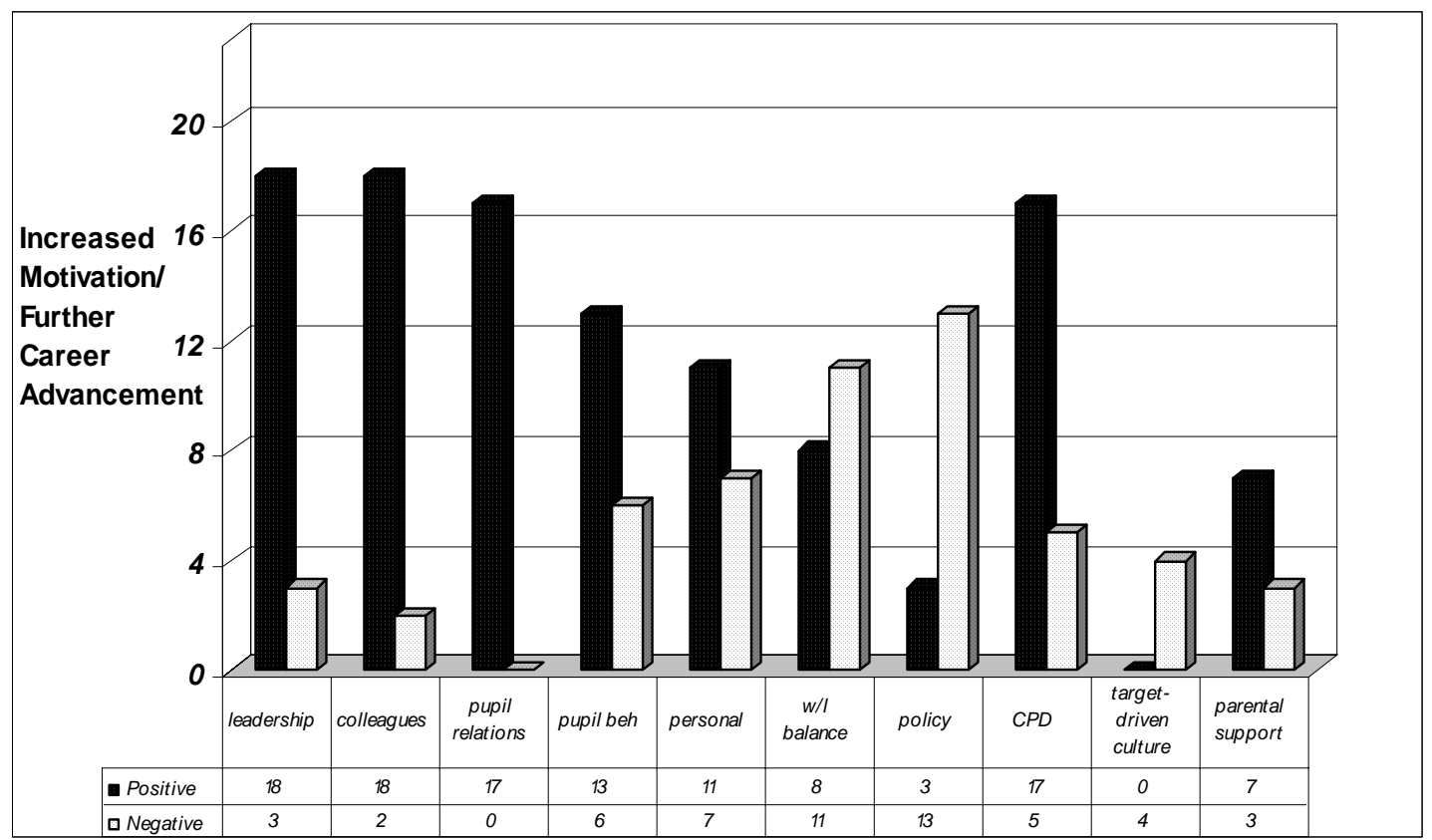

Figure 5.11: Key influences on teachers with decreased motivation (16-23) $(\mathrm{N}=6)$

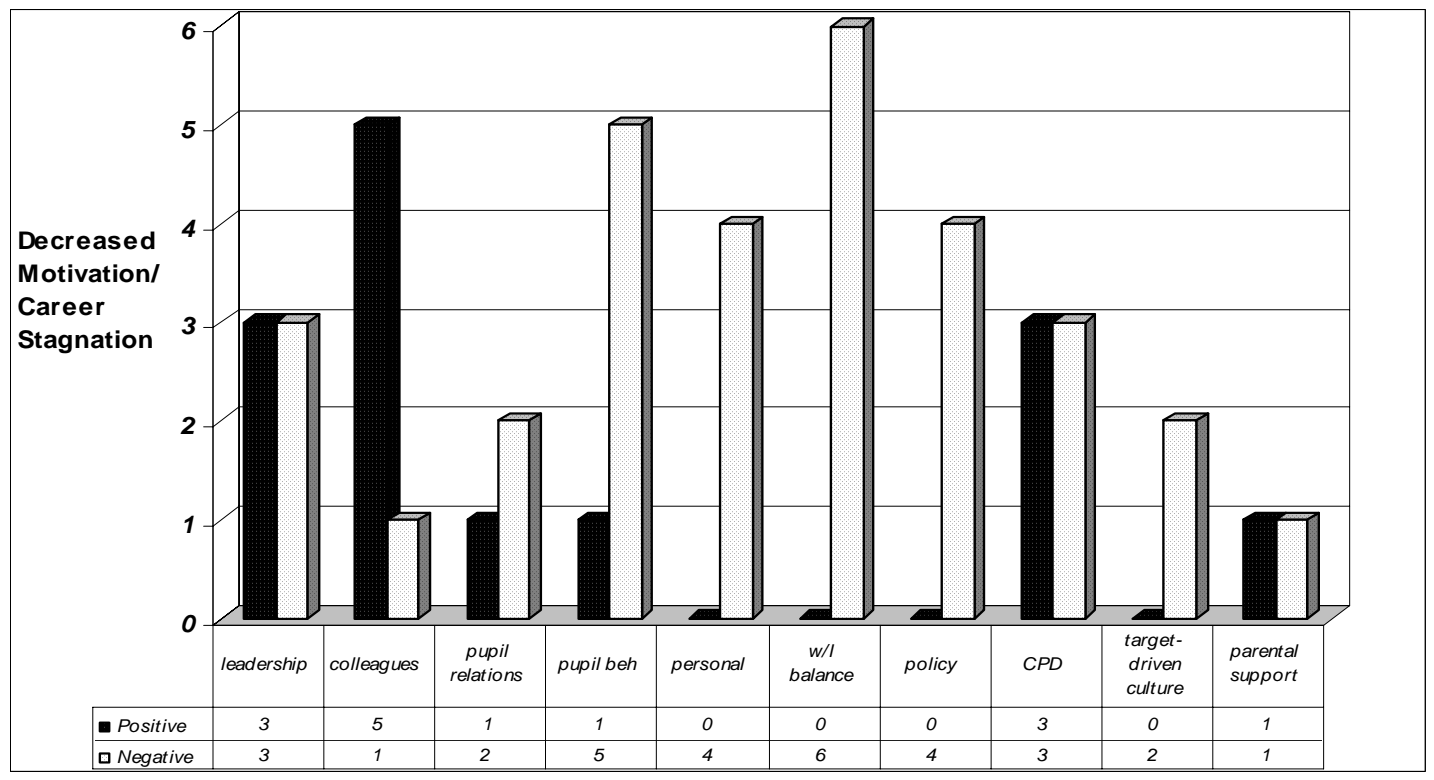


The impact of the above key influences on these sub-groups' commitment can be seen in Figure 5.12.

Figure 5.12: Variations in levels of commitment (16-23) $(\mathrm{N}=46)$

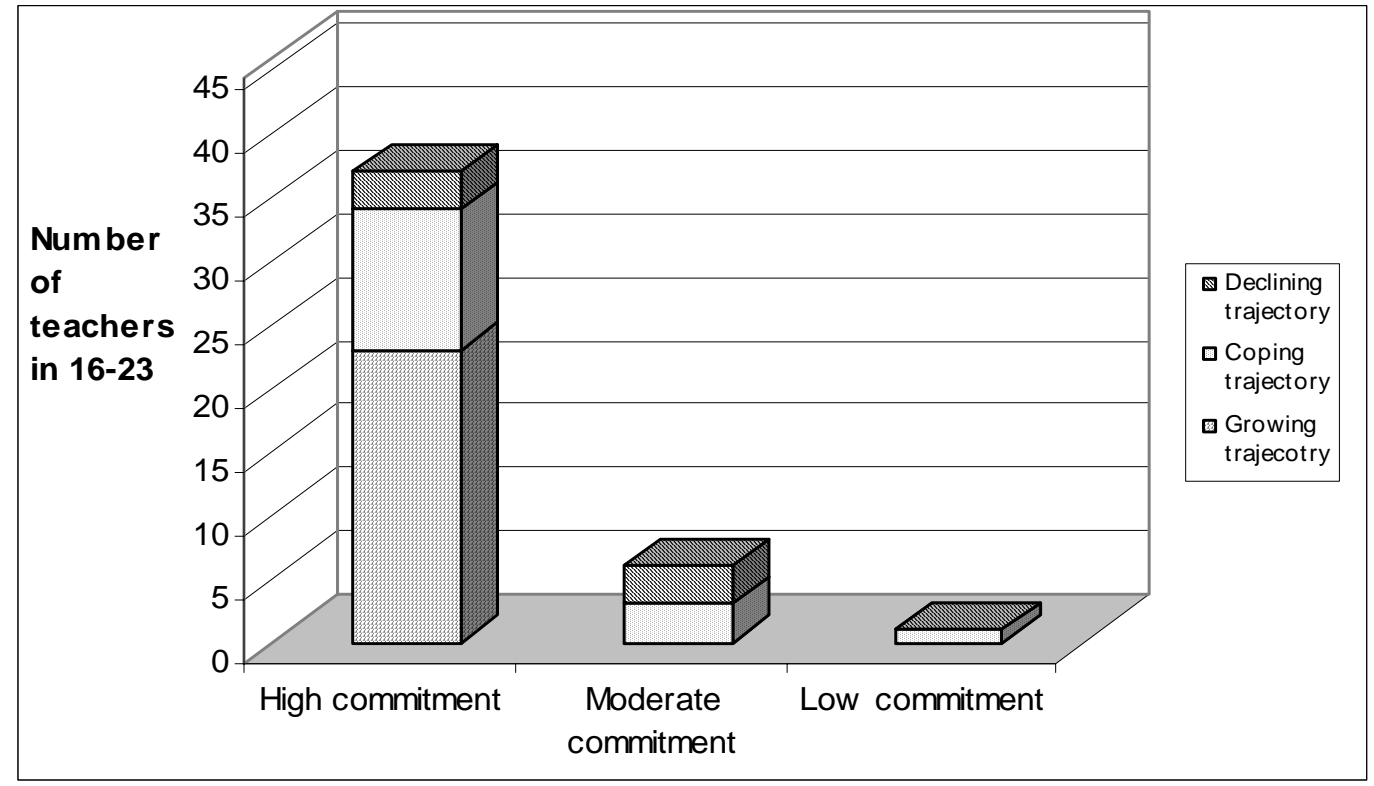

\subsection{Professional life phase 24-30 years (n=52: 32xPrimary, 20xSecondary) - Challenges to Sustaining Motivation}

\section{Illustration of teachers}

\section{A Portrait of Abbie - increasing motivation and self-efficacy}

Value-added: cohort 1 - As expected (0) / Cohort 2 Above expectation (+)

Returning to teaching after a career break of eight years as a supply teacher Abbie was teaching outside her experience - in middle schools rather than secondary and teaching subjects other than her own. Both her confidence and her reputation as a competent teacher improved during this period.

Abbie, now 58 years old, had taught for 28 years. She was Head of English in an 11-16, predominately white, rural FSM1 school. She saw her department as 'a happy department' and described good staff relationships as 'the most important for the quality of your life.' Good pupil behaviour helped to establish a 'creative atmosphere' in her class. She enjoyed good relationships with her pupils and felt relaxed and more ambitious in teaching - 'dare to do different things.'

Her elderly mother became ill recently and she drove 60 miles to help care for her every weekend and sometimes in the week too. She had no life outside school but coped. She had a supportive husband who was an ex-teacher and who was now retired at home. She felt that she was still being effective at school but it was making her reconsider her priorities and where she wanted to be in a year's time.

Abbie worked with the Head of Mathematics in her current school on strategies to raise achievement across the school. It involved some school-wide research and then delivering school-based INSET to focus staff on improving teaching and learning. Through this whole-school experience she became determined that her English Department should be one in which staff worked collaboratively, shared good practice, worked positively with incoming initiatives interpreting them in ways that benefited their students. The whole experience greatly increased her job-satisfaction despite the greater work-load. She became an AST and the motivation associated with these experiences was still present.

Her motivation had generally increased over the last three years. She was particularly motivated in this later phase of her career because she did not have much time left to share her knowledge of Shakespeare with the children. She still loved teaching, but found that the teaching situation was 'much worse than 15 years ago' because of the greater pressure from paperwork and accountability. 


\section{A Portrait of Patty - Detachment/ early retirement}

Value-added: cohort 1 - below expectation (--) / cohort 2 - below expectation (--) / cohort 3 - below expectation (-)

Patty was 59 years old and had been teaching for 25 years. Changes in the school and the struggle to balance demands at work and at home had confronted her with challenges to sustain motivation. Her level of perceived effectiveness was fairly steady for the majority of her career, with no sudden peaks and troughs. She had been primarily attracted to teaching by the chance of working with children and developing their skills and personalities. Patty had taught in three schools and had been in her current post for approximately 13 years. In addition to being a Year 2 teacher, Patty was also the Key Stage one manager. She enjoyed teaching because she liked to see the progress that the pupils made during the year.

Patty found it a difficult time in the summer of 2003 when both the and the Deputy Head said they were going to retire. This left many members of staff wondering what would happen to the school in terms of change. She felt that, due to the school having a large staff, they did not always have the time or opportunity to talk to each other. However, she believed that colleagues were very supportive of personal problems. She had experiencing difficult pupil behaviour, especially from boys. Patty's husband worked on the farm where they lived and Patty did the accounts. The incident to most impact on her identity was the news that her Year 2 colleague was moving to Year 1 and being replaced by two job share teachers. Patty found it more difficult to work with two other people. Although her job satisfaction had remained constant, her level of self-efficacy had decreased. This was largely due to the amount of time she had to spend on the farm accounts rather than on school work. Patty felt that in recent years this had become more difficult for her as she had to take more paperwork home from school. She had decided to retire soon.

\subsubsection{Sub-groups and career trajectories}

Teachers in this cohort were aged between 40 years and 50 years. Forty-six out of fifty-two teachers (88\%) (31 Primary=97\%; 15 Secondary=75\%) had additional responsibilities. In common with professional life phase 16-23, external policies and initiatives continued to demonstrate a strong negative impact on teachers' sense of effectiveness. Deteriorating pupil behaviour, the impact of personal life events, resentment at 'being forced to jump through hoops by a constant stream of new initiatives', taking stock of their careers (and lives) and length of service in the school were key influences on the effectiveness of teachers in this cohort. As a consequence, these teachers were facing challenges to sustaining motivation. On the basis of their levels of motivation two sub-groups were identified.

i) Sub-group a). Teachers who had sustained a strong sense of motivation and commitment (+28) (19 Primary=59.4\%; 9 Secondary $=45 \%$ ) and who were most likely to continue to enjoy an increase in their self-efficacy, motivation and commitment;

ii) Sub-group b). Teachers holding on but losing motivation which was most likely to lead to a sense of detachment and early retirement (-24) ( 13 Primary $=40.6 \% ; 11$ Secondary $=55 \%$ ). 
The difference in teachers' motivation and commitment between these two subgroups is illustrated in Figure 5.13.

Figure 5.13: Variations in levels of commitment (24-30) $(\mathrm{N}=52)$

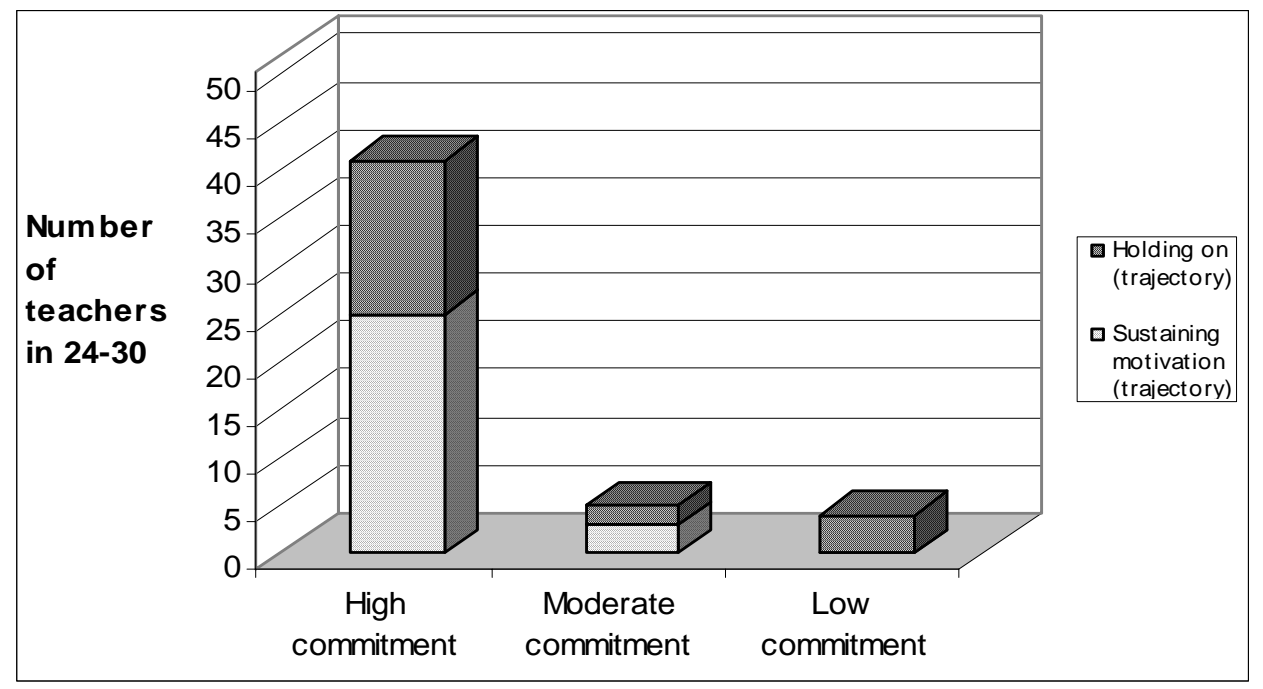

Figures 5.14 and 5.15 illustrate key influences on these two sub-groups' work.

Figure 5.14: Key influences on teachers with sustaining motivation (24-30) $(\mathrm{N}=28)$

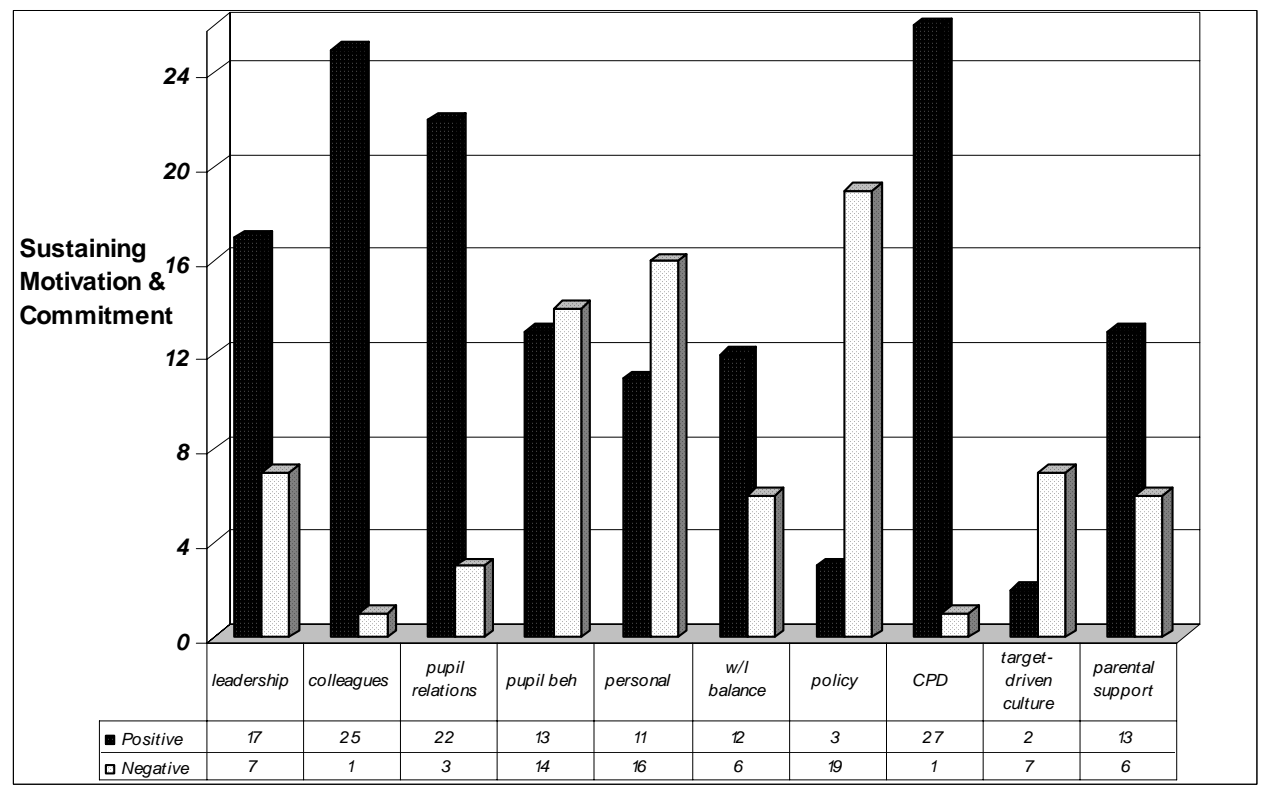


Figure 5.15: Key influences on teachers who are holding on but losing motivation (24-30) $(\mathrm{N}=24)$

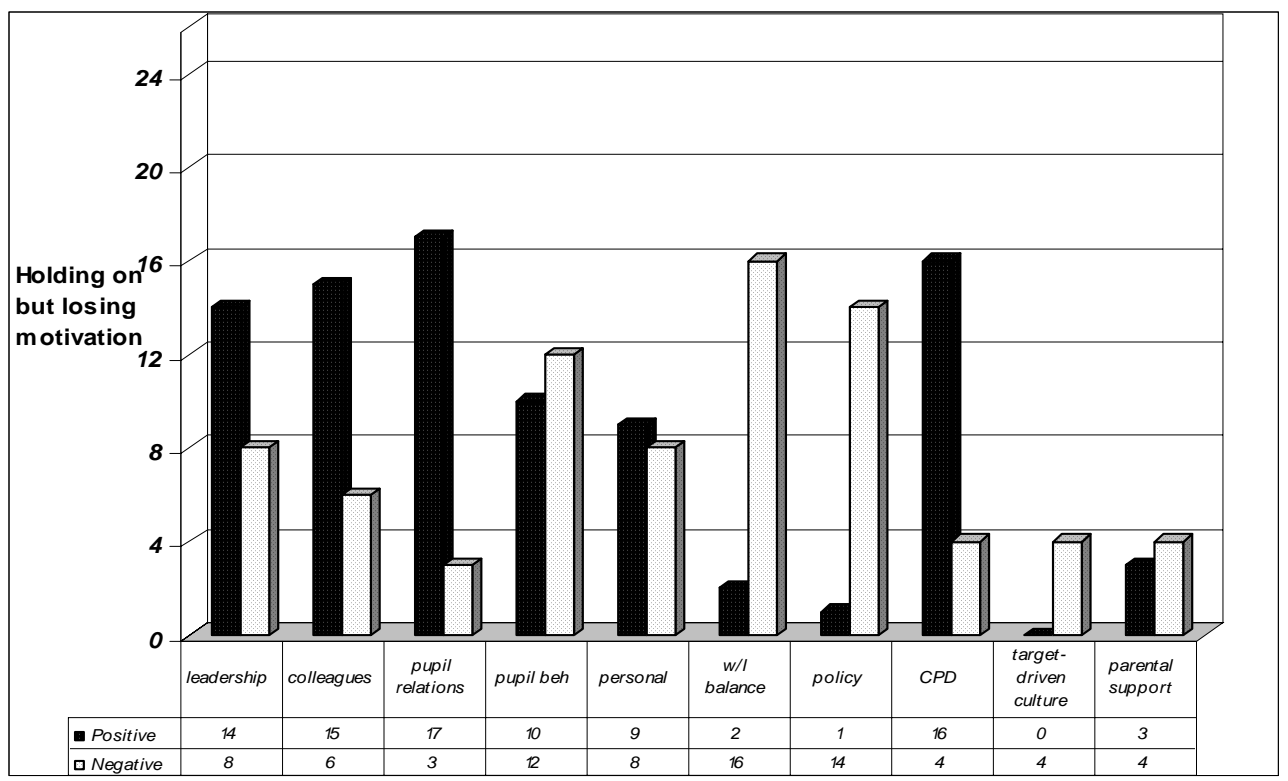

In common with professional life phase 16-23, policy dictates continued to demonstrate a strong negative impact on teachers' sense of effectiveness. It appears that the negative impact of work-life tensions and pupil behaviour had made a major contribution to the professional outlook of teachers who were holding on but losing motivation and who would consider early retirement or part-time teaching if their financial situation permitted. 


\subsection{Professional life phase 31+ (n=22: 11xPrimary, 11xSecondary) - Sustaining/Declining Motivation, Ability to Cope with Change, Looking to Retire}

\section{Illustration of teachers}

\section{A Portrait of Jeremy -sustained motivation and commitment}

Value-added: cohort 1 - as expected (0)

Jeremy was 54 years old and had been teaching for 33 years. Despite his ill health in the final phase of his career, Jeremy had remained highly motivated and committed to teaching and to his pupils. There were no significant troughs in his level of perceived effectiveness throughout his teaching career. Since his promotion to Head of Year in his early career, Jeremy had seen a steady increase in his sense of effectiveness. He had been in his current school (FSM 4) for 19 years, having served previously in several others. With several more years of teaching to retirement he did not intend to move to another school.

Jeremy was supported positively by the headteacher and the Local Authority and felt that they had helped him in making improvements to the department of which he was head and the school more generally. He had recently been invited to be a member of the Senior Management Team. Jeremy found that staff morale had had the biggest positive impact on his work. Jeremy enjoyed teaching because of the success he had with the pupils and the department. Jeremy was committed to working with children from impoverished home environments and identified himself strongly with them, having high expectations. He acknowledged, however, that pupil behaviour was, on the whole, deteriorating.

Jeremy had been diagnosed with high blood pressure and had tried to cut down on the amount of time he spent working 'after hours'. Nevertheless, he continued to work on Saturdays and even sometimes on Sundays. He remained highly motivated and committed to teaching.

\section{A portrait of Jacqueline - Tired and trapped}

Value-added: cohort 1 - mixed impact (0/-) / cohort 2 - as expected (0)

Jacqueline was 53 years old and had taught for 31 years. She was a Year 6 teacher, Deputy Head and Planning and Assessment Co-ordinator in an urban FSM2 primary school of 285 pupils. She came from a teaching family and was originally attracted to teaching because of the opportunity 'to change things for the better through education'. This still applied but she found it 'harder to see the possibility'.

She appreciated support from the school leadership and her 'charismatic colleagues' but felt that the deteriorating behaviour of the pupils had a negative effect on her teaching. She also found that parental pressure had greatly increased over time.

She wanted to either retire at the age of 55 or become part-time because she did not think that she 'could keep up this kind of pressure for the next five years.' She believed that she had maintained her commitment over the long term, but regretted that her enthusiasm had diminished. Because of government initiatives and changes, Jacqueline found teaching a difficult job - 'nothing is ever finished'. She resented the paperwork - 'I didn't come into teaching to fill in bits of paper.' She also felt strongly about the target-driven culture because she did not think SATS had much value in improving her teaching or her pupils' learning. After over 30 years' teaching, she felt tired and 'trapped'. 


\subsubsection{Sub-groups and possible trajectories}

Teachers in this cohort were mostly aged between 50 years and 60 years. Government policies, excessively bureaucratic results-driven systems, pupil behaviour, poor health, increased paperwork, heavy workloads and the consequent long working hours had had a negative impact on their motivation and perceived effectiveness.

Pupils' progress and positive teacher-pupil relationships were the main source of job satisfaction for these teachers. This cohort were categorised into two sub-groups.

i) Sub-group a). Teachers whose motivation and commitment remained high despite or because of changing personal, professional and organisation contexts and whose expected trajectories were strong agency, efficacy and achievement (+14) (7 Primary=63.6\%; 7 Secondary=63.6\%);

ii) Sub-group b). Teachers whose motivation was declining or had declined and whose expected trajectories were increased fatigue, disillusionment and exit (-8) (4 Primary=36.4\%; 4 Secondary $=36.4 \%$ ).

Figures 5.16 and 5.17 indicate key influences on these two sub-groups' work, the outcome of which can be seen in Figure 5.18. 
Figure 5.16: Key influences on teachers who sustained commitment $(31+)(\mathrm{N}=14)$

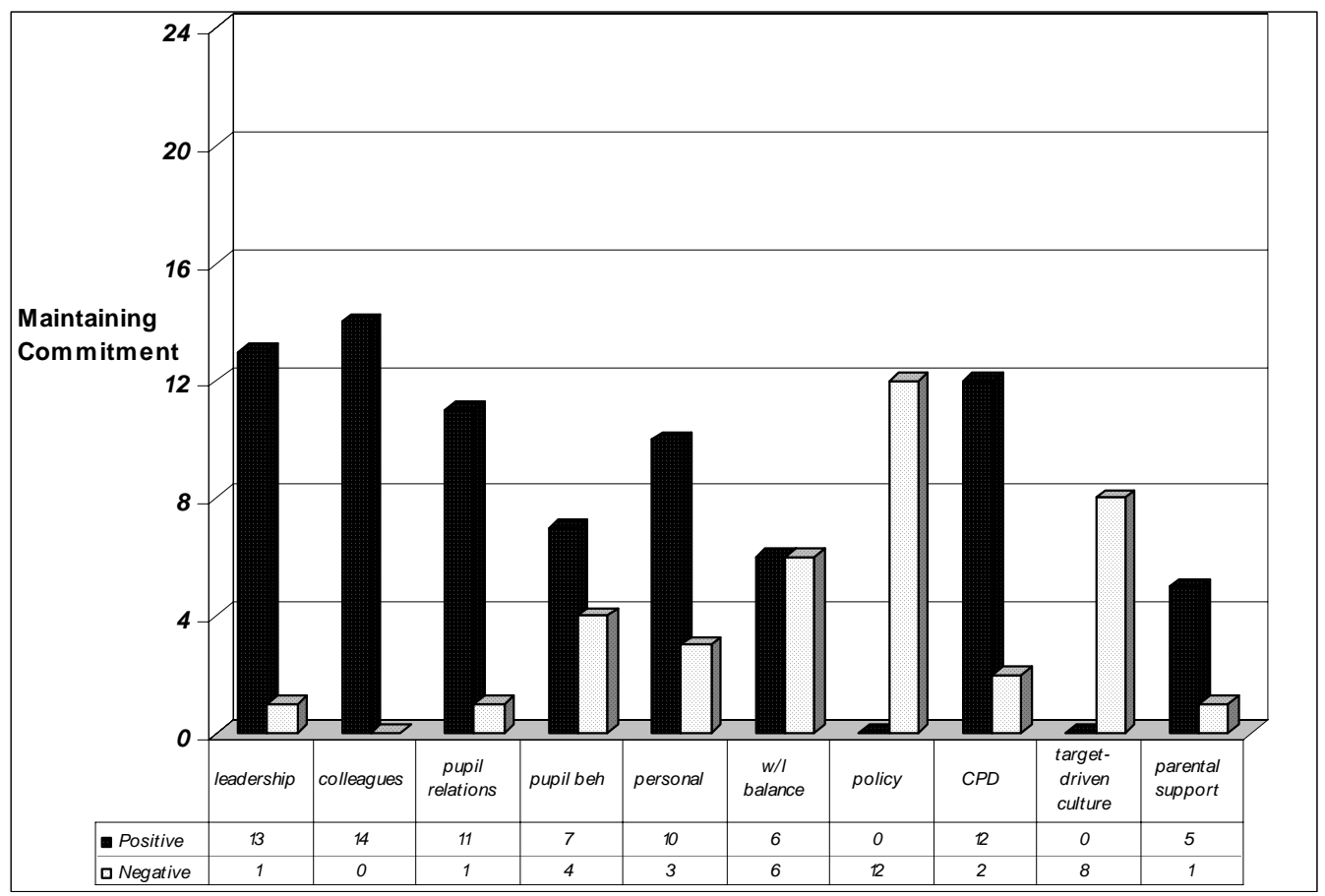

Figure 5.17: Key influences on teachers who felt tired and trapped $(31+)(\mathrm{N}=8)$

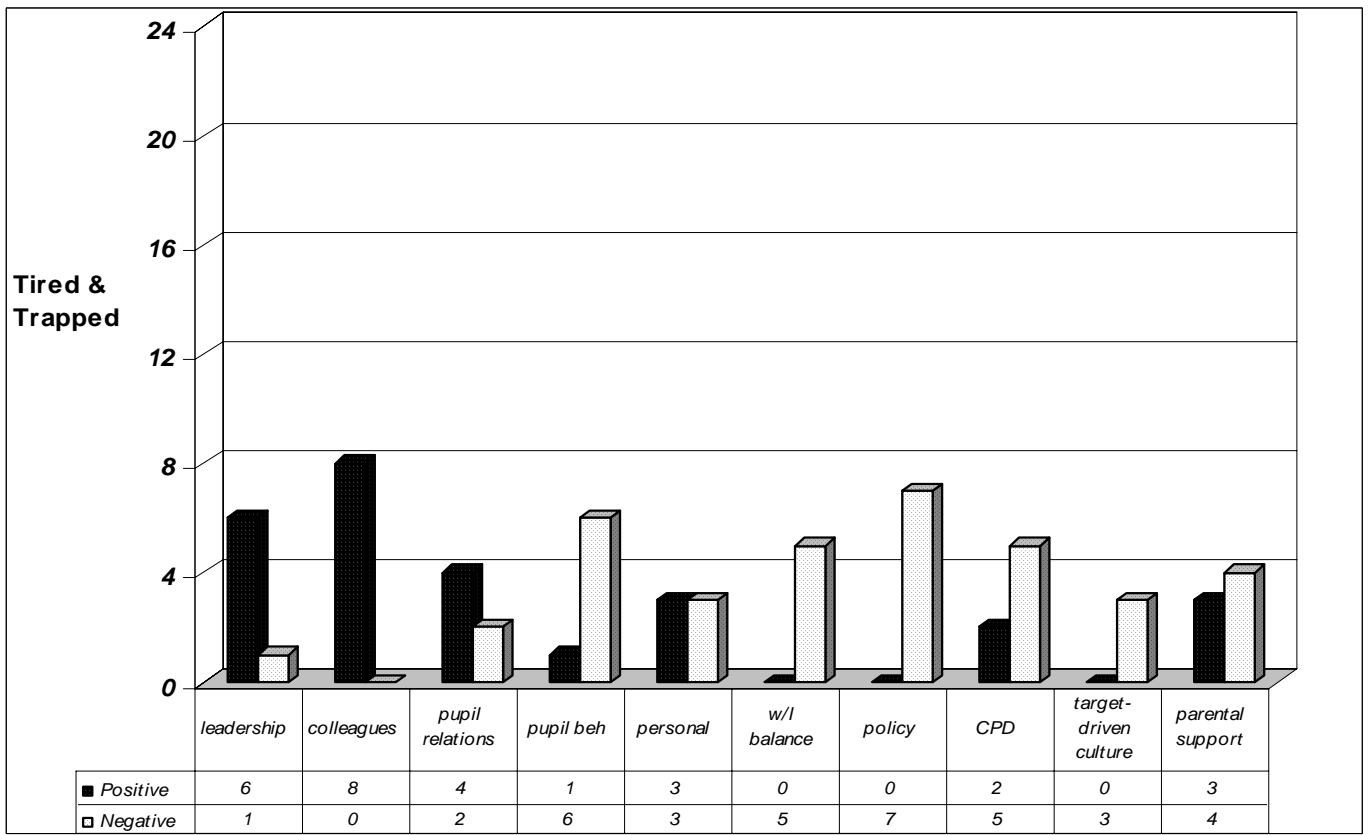


Figure 5.18: Variations in levels of motivation $(31+)(\mathrm{N}=22)$

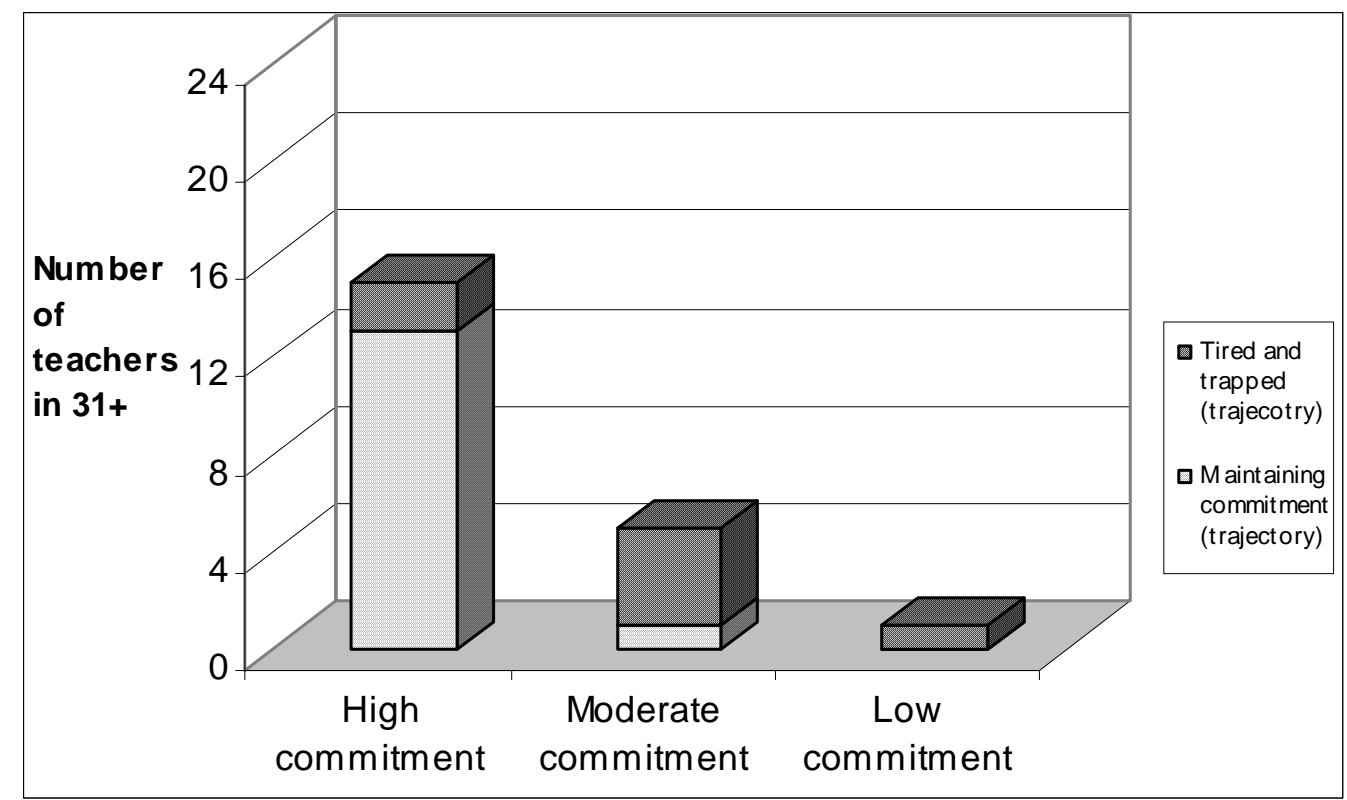

Huberman (1993) maintains that there is a 'distinct phase of 'disengagement' (serene or bitter)' towards the end of teachers' careers:

... the data of the present study do support the thesis of an increasing detachment near or at the conclusion of the career cycle, characterised mostly by a greater focusing on preferred classes, preferred tasks and preferred aspects of the academic programme. (Huberman 1993: 12)

Such a sense of bitter disengagement and disillusion was also found in our study, but not to the same extent. In contrast with Huberman's observation of disengagement, most of the teachers in the first sub-group had continued to demonstrate a high level of motivation and commitment and a strong sense of 'active' engagement in the teaching profession. They remained highly committed to improving their knowledge within the classroom. Our analysis suggests that supportive school cultures were of crucial importance to teachers' sense of effectiveness across all six professional life phases. 


\subsection{The dynamic nature of professional life phases}

The analysis of teachers' professional life phases over time enabled us to observe the change that had occurred to two groups of teachers: a) those who had followed the upward or downward trajectories as predicted on the basis of previous experiences when moved to the next professional life phase; and b) those who moved to a different sub-group (e.g. from an upward trajectory to a downward trajectory) within the same professional life phase. The transitional experiences of these teachers reveal the dynamic nature of professional life phases in relation to teachers' professional development. There were twenty teachers $(6 \%)$ who had moved to a later professional phase since the beginning of the project. Their transitional experiences clearly supported our observation of the key characteristics and expected trajectories of the six phases of teachers' professional lives. All twenty teachers reported, in the final interview, a professional outlook that was characteristic of their new professional phases. Seventeen of these twenty teachers continued to follow an upward or downward professional life trajectory as predicted on the basis of previous experiences. (For examples of teachers who had experienced a transition across phases, see Appendix 3).

Three teachers, all with between 4-7 years' experience, showed discontinuity in their perceived identity, motivation and commitment when they entered professional life phase 8-15 - the key watershed in teachers' professional life development. Change in professional factors, such as promotion and educational initiatives, was shown to be the key influence on the transition of the three teachers' professional life trajectories.

We also identified a group of 22 (7\% of 300) teachers whose self-efficacy, motivation and commitment had changed as a consequence of certain changes in their work and/or personal lives. Almost half of the transitional teachers were in professional life phase 4-7 - a period where teachers were in the process of establishing their professional identity and efficacy in the classroom as well as in the profession but also one in which many were taking on additional management responsibilities. Positive professional and situated factors, such as promotion, leadership and staff support, and increased confidence in teaching, were shown to have positively impacted on these teachers' perceived identity and self-efficacy and consequently, led to positive 
transitions in their professional life trajectories. As discussed in previous sections, teachers' development requires differing support in different phases of their professional lives.

Thus, when these positive influences and much needed support were missing, teachers could see a decrease in their motivation and sense of efficacy and effectiveness, as evidenced in the experience of the other three teachers in the same professional life phase (4-7). After professional life phase 8-15 - the key watershed in teachers' careers - all changes in teachers' professional life trajectories were distinctively negative. Analysis of teachers' professional life phases suggests that teachers in the final phases of their professional life became increasingly dissatisfied with educational policies and initiatives. Changes in situated school factors (a lack of leadership support and deteriorating pupil behaviour) and disillusionment with the educational culture were shown to have led to the remaining four teachers' transition to negative professional life trajectories.

The changes in these teachers' career pathways confirms the significant impact that certain key influences can have on teachers' work in different phases of their professional lives. Such discontinuous and diverse professional development routes had led Huberman (1993: 263) to conclude that 'we do not claim to be able to qualitatively or statistically to 'predict' professional satisfaction' in his study. Our study, however, suggests that the provision of responsive support to meet teachers' professional and personal needs at different times in their work and lives can help counter declining commitment trajectories and/or enhance the continuity of positive development of teachers' professional life paths. The key influences that we have identified in our research provide a departure point for teachers, school/departmental leaders and policy makers to recognise teachers' needs and identify appropriate support. 


\subsection{Conclusion}

Our analysis of teachers' professional life phases suggests that the portrayal of teachers' professional life progression requires an investigation into factors not only within the organisational settings but also how these factors interact with and are managed in conjunction with factors arising from teachers' personal lives. Whilst there are a number of common influences which affect teachers positively or negatively across their professional life phases, there are variations in the impact of these on teachers' professional lives and their diverse professional life trajectories.

FSM appears to have a more significant impact on the work of teachers in their early professional life phases (0-7). Teachers in FSM1 and FSM2 ${ }^{21}$ schools (a total of 48 teachers) demonstrated a somewhat greater sense of sustained motivation and commitment than their counterparts $(\mathrm{N}=53)$ in FSM3 and FSM4 schools. Nonetheless, throughout the six professional life phases, despite their relatively more negative attitudes towards disruptive pupil behaviours, the majority of teachers in FSM4 schools showed increased motivation, commitment and self-efficacy. The conclusions from this analysis are:

1. Teachers' professional life phases are by no means static. They are dynamic in nature. The interaction between teachers' commitment, resilience and a range of influential factors in their work and personal contexts is a sophisticated and continuous process and impacts differentially on teachers' motivation, commitment and perceived effectiveness within the same and across different phases of their professional lives.

2. There is an important interaction between teachers' work, lives, and experience and their perceived effectiveness in the profession. In particular, situated factors - leadership of school and department, staff collegiality and teacher-pupil relationships and behaviour of pupils - were contributing influences on teachers' motivation and commitment, resilience, and perceived effectiveness across all professional life phases.

\footnotetext{
${ }^{21}$ FSM 1 describes schools with $0-8 \%$ of pupils eligible for free school meals. This percentage rises to 9-20\% for FSM 2 schools, 21-35\% for FSM 3 schools, and over 35\% for FSM 4 schools.
} 
3. External policy contexts, heavy workload and work-life tensions appear to have had stronger influences on teachers' sense of effectiveness in the middle and final professional life phases (from 8-15 years). In early years the importance of in-school support predominates.

4. School phase, also, was shown to be a significant influence on teachers' motivation and commitment in their middle careers (4-7, 8-15, 16-23). Primary teachers were more likely to report positive experiences than their secondary peers. Certain situated factors within primary schools such as more opportunities for promotion and less complicated school structures may have contributed to teachers' positive professional outlooks.

5. Recognising the impact of such interactions between situational, external (structure), professional and personal factors is of crucial importance to achieve an holistic understanding of teachers' professional lives.

6. Situated factors - leadership/management, staff collegiality and pupil relations - had a mostly positive impact on teachers' work. These factors were closely related to the issue of in-school support that was shown to be crucially important to teachers' motivation, commitment and perceived effectiveness in all professional life phases.

7. CPD was shown to be a consistently positive influence on teachers across the six professional life phases, among which 16-23 rates the influence of CPD as the lowest (46\%) and 24-30 the highest (85\%).

8. Behaviour management was a predominant concern for teachers in the first three years of teaching. Over $60 \%$ of teachers within this professional life phase reported negative impact of pupil behaviour on their feelings of being an effective teacher. Such negative effect decreased to less than 35 per cent of teachers with 4-7 (32\%), 8-15 (24\%) and 16-23 (33\%) years' experience and around 50\% among teachers in professional life phases 24-30 (50\%) and 31+ (45\%). Overall pupil behaviour appeared to be a consistent concern for a substantial proportion of teachers in all the six professional life phases, but particularly for those in their early and later professional life phases.

9. The perceived negative influence of policy changes became increasingly significant in teachers' later years of experience - from $23 \%$ of teachers in $0-3$ professional life phase to $86 \%$ in the professional life phase of $31+$. 
10. Work-life balance began to emerge as a significant influence on teachers' sense of effectiveness when they had entered professional life phase 8-15. Analysis of teachers' professional life phases supports this finding. There were continuing and growing tensions of balancing work and life during and beyond professional life phase 8-15 - the key watershed of teachers' professional lives. From then until the final phase of $31+$, teachers who were struggling to manage the tensions between their workload and personal life outnumbered those whose perceived effectiveness had benefited from having a personal/social life outside of school. 


\section{CHAPTER SIX: CONTINUING PROFESSIONAL DEVELOPMENT (CPD)}

\subsection{Introduction}

This chapter sets out the key findings of an analysis of teachers' experiences of, and opportunities offered by, continuing professional development (CPD). They are derived from analysis of responses to the CPD questions in the initial teacher questionnaire and the interview questions on CPD. VITAE teachers were asked once in each of the three years about their experiences of CPD as part of the interview schedules. Teachers' interests in CPD were found to relate to their specific needs and concerns in the different phases of their professional lives identified in the previous chapter. On the whole, teachers were satisfied with what was offered to help improve their professional development. Teachers across all professional life phases felt that heavy workload, a lack of time and financial constraints were important inhibitors in their pursuit of professional development. CPD was described by teachers in this study as an important professional life investment, a means of re-charging their batteries. The least favourably viewed areas were the time and opportunities they had to reflect on their own teaching and to share practice with their colleagues - which Boyle et al (2005) found were the most popular longer term professional development activities that had an impact on the change of one or more aspects of teachers' practice in the classroom.

The DfES' wide-ranging CPD strategy, launched in 2001, reflected the government's recognition of the significance of $\mathrm{CPD}$ in raising the standards of teaching and learning (DfEE, 2001). This strategy, together with its revised version, aimed to help teachers make the most of the CPD opportunities available to them and to integrate CPD with performance management and school improvement. The DfES CPD strategy has resulted in a range of progressive initiatives. Among these, the pilot programme to make Early Professional Development (EPD) available to teachers in the second and third years of their careers was found to have led participating teachers becoming more effective members of their school communities (DfES, 2005). The National College for School Leadership's (NCSL) Networked Learning Communities (NLC) programme has involved over 1,500 schools working collaboratively to improve opportunities and raise standards for their pupils since 2002. 
The Training and Development Agency (TDA) has taken on a new remit to work with schools and help them develop their whole school workforce, and, from April 2005 took on specific responsibilities in relation to teachers' CPD. The GTC's (General Teaching Council for England) Teachers' Professional Learning Framework (TPLF) and the LA CPD partnership project have also involved and positively affected many teachers, CPD leaders and schools (NFER, 2005; Sturman et al, 2005).

\subsection{Findings}

\subsection{An overview}

Figure 6.1 below shows the frequency distribution of responses categorised into five dimensions. This is an analysis of CPD activities that 285 teachers had undertaken, were undertaking and/or planning to undertake at the time of the third round interview. These CPD are labelled positive experiences because they only include activities that teachers chose to participate in or that they had seen as having positively impacted on their development. Because one teacher may have been involved in more than one type of CPD, the total frequency of responses adds to more than the total of 285 teachers who responded.

Figure 6.1: Summary of Teachers' Positive Experiences of CPD

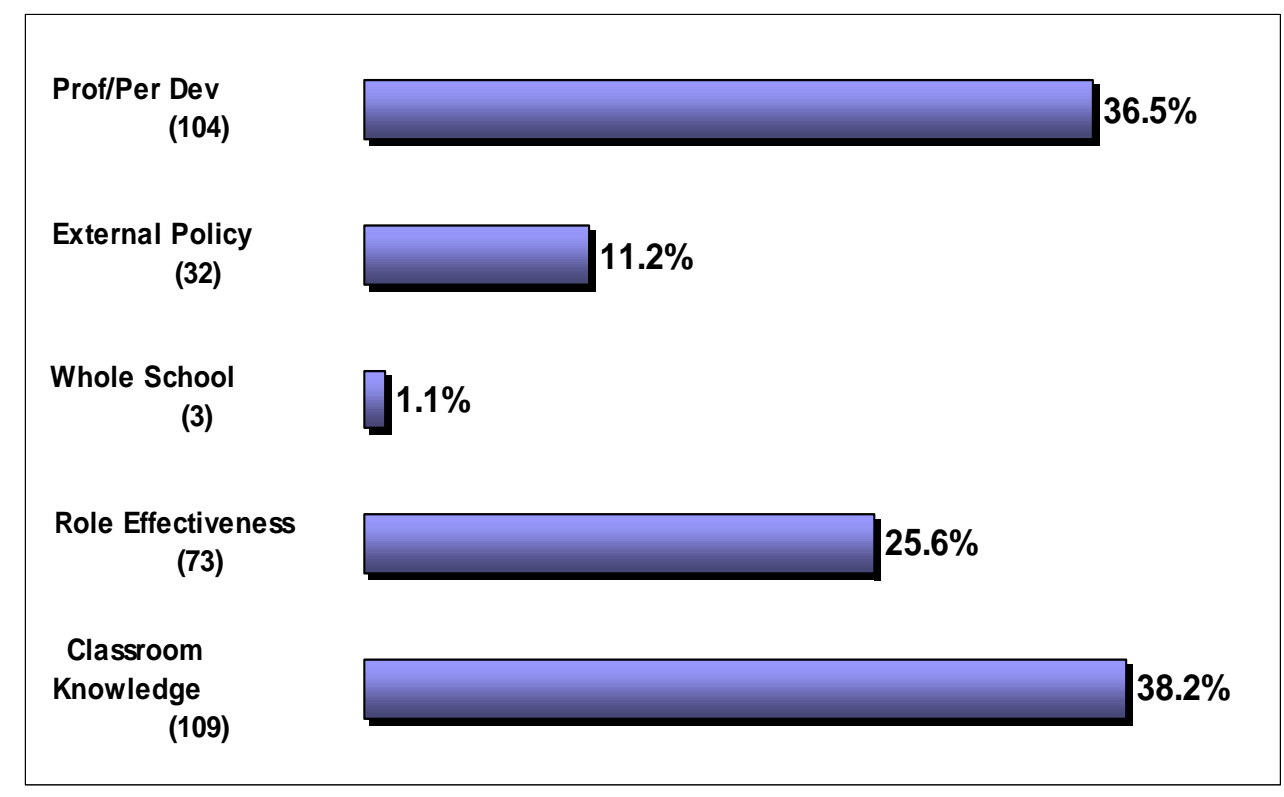

Figure 6.1 shows that the most frequent reason for undertaking CPD was to enhance Classroom Knowledge (38.2\%) (such as 'subject matter update', 'the use of ICT in 
teaching', and 'classroom management'). In their discussion on models of outcomes for professional development, Joyce and Showers (1980) and Harland and Kinder (1997) reported teachers' appreciation of CPD schemes where knowledge and skills and new awareness of the appropriate content and delivery of a particular curriculum area were the main priority. In the interviews, VITAE teachers clearly demonstrated their personal motivation to enhance their knowledge of teaching and learning in the classroom as well as their lives in the profession. This was closely followed by Professional/Personal Development such as 'renewal/refreshment' and promotion/ career advancement $(36.5 \%)$.

The extent to which 'the personal driver' of teacher professional development (Grundy and Robinson, 2004: 146) dominates in reasons for undertaking CPD is striking. Grundy and Robinson stress the importance of taking account of factors which relate to teachers' internal needs and concerns. They argue that these 'personal drivers recognise life histories, personal circumstances and professional life trajectories as prime determinants of receptiveness to and enthusiasm for professional development' (2004: 163) and in the 2003 EPPI CPD review, the review group recommend policy-makers to 'take full account of the specific needs and concerns of teachers in their implementation strategies' (2003: 8-9).

The next most important reason for undertaking CPD was Role Effectiveness (25.6\%). This was important for teachers with additional responsibilities, such as middle and senior management and cross-school coordinator roles, and such teachers found activities enabling them to improve their managerial abilities useful. Fewer teachers perceived that they had, either compulsorily or voluntarily, participated in activities relevant to External Policy (11.2\%) or Whole School development such as 'community participation' and curriculum development plans (1.1\%). This may be because, in contrast with Hustler et al's study (2003), our interview question was quite general and did not directly ask about specific aspects of CPD. As a result it would be expected that teachers would be more likely to discuss activities relevant to their own professional and personal development rather than those of more general benefit to the school. Teachers' rather narrow perceptions of CPD may be another factor that has affected the range of CPD activities reported in their responses. 
In the next section we look at the relationship between the five dimensions of CPD and the way their relative importance changed over the different professional life phases of the teachers.

\subsection{CPD and professional life phases}

There was an overall satisfaction with the current CPD opportunities and the focus, quality and balance of CPD across six professional life phases identified in the study (see Chapter Five). The two-way Chi-Square tests indicated no significant association between professional life phases and teachers' views regarding the opportunities and quality of CPD. Nevertheless, teachers with no more than three years of experience consistently demonstrated the most positive attitude towards the above aspects of $\mathrm{CPD}$, although the reported difference was minimal.

A significant difference was found between professional life phases and teachers' views regarding the time they had to reflect on their teaching $\left(\chi^{2}=28.858, \mathrm{df}=15\right.$, $\mathrm{p}<0.05)$ and the time they had to learn with and from colleagues $\left(\chi^{2}=47.357, \mathrm{df}=15\right.$, $\mathrm{p}<0.001)$. Figures 6.2 and 6.3 show that teachers who were at the beginning of their professional lives were the most positive about the time and opportunity they had had for self-reflection and a sharing of practice with their colleagues, in contrast with teachers in the final phase of their professional lives who had the most negative view. Figure 6.2 in particular indicates a slight inclination for more established teachers towards a more negative view. Further analysis of the interview data also revealed some patterned differences between teachers in different phases of their professional lives. 
Figure 6.2: Q17. How satisfied are you with the extent you get time to reflect on your teaching? (By professional life phase)

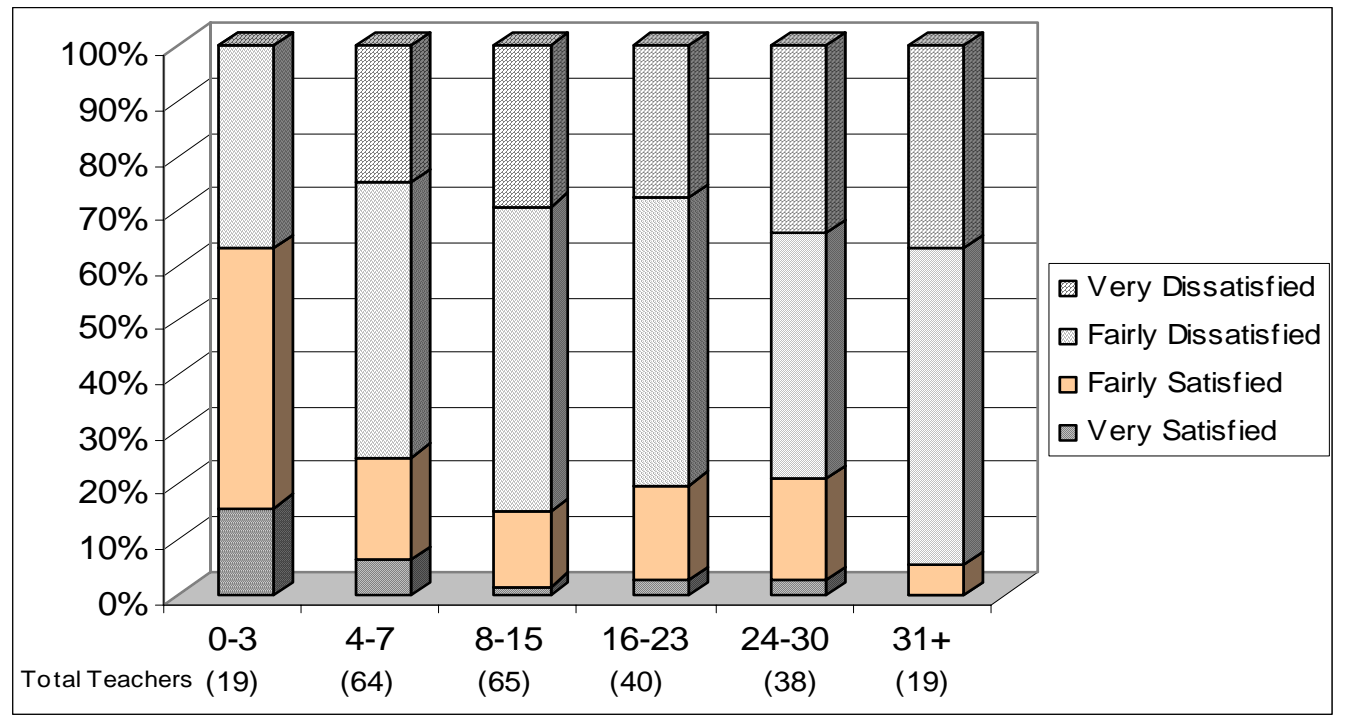

Figure 6.3: Q18. How satisfied are you with the time and opportunity to learn with and from colleagues? (By professional life phase)

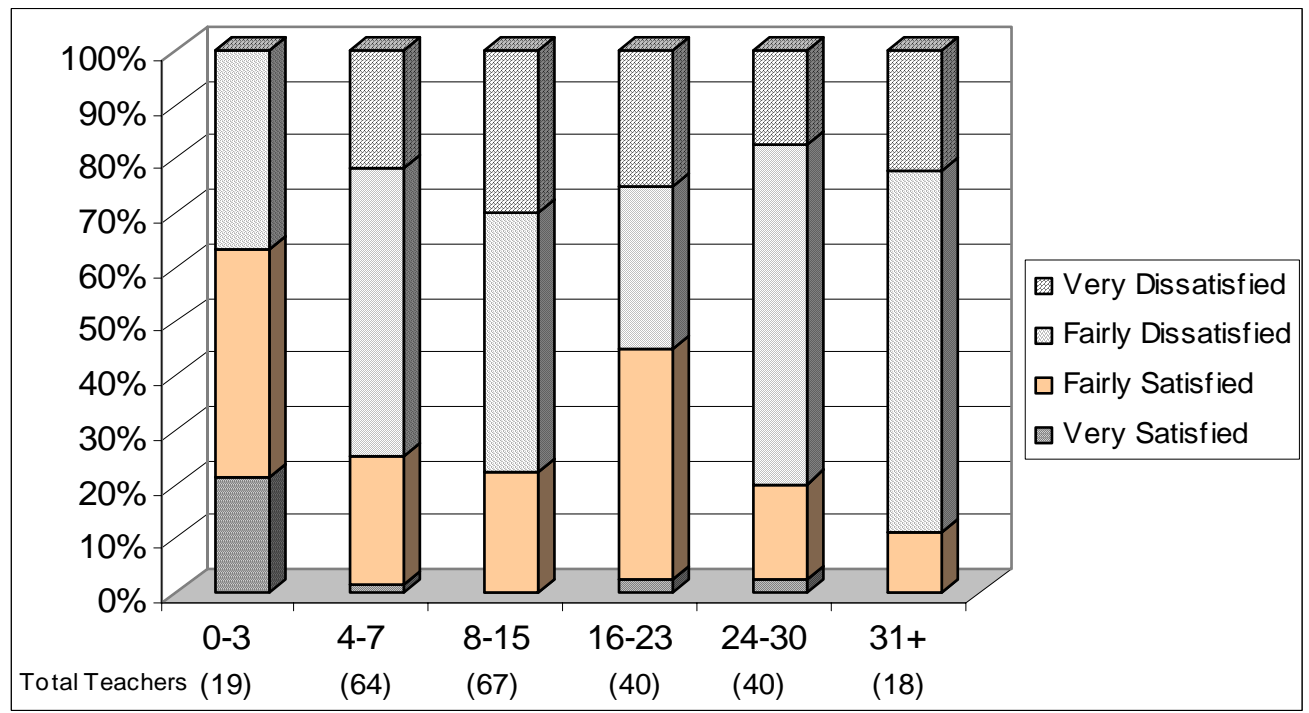

Figures 6.4 to 6.9 map out the changing relationship between the five categories of reasons for CPD over the course of the different professional life phases of the teachers. Again the attention is on positive CPD experiences in the sense that they were seen by the teachers as having improved or having been expected to improve their feelings of effectiveness. 


\subsubsection{Professional life phase 0-3}

For early years teachers, CPD activities in relation to Classroom Knowledge were most frequently reported as having a positive impact on their morale and as being significant to the stabilisation of their teaching practice. These activities included school/department-based training and INSET days, external (NQT) conferences, and visiting and working with teachers in other schools.

NQT package and the courses that I went on designed to help me, help myself become a better classroom teacher. (Jay)

There have been quite a few INSETs. I've been on a course on Tuesday on GCSE. ... I find it boosts your morale a little bit in that you are with other teachers who are in the same boat. Also I did spend a day in [...] School to observe the English Department and that had an impact in watching other teachers teach. (Adrienne)

In professional life phase 0-3, teachers with coordinators' roles also reported the importance of CPD opportunities that had helped to enhance their role effectiveness.

I suppose it [a course relating to her ICT coordinator's role] makes you more aware of your job and feeling that you can do it. (Veronica)

We've been on a number of courses for professional development and I've taken on the science coordinator's job so I've been on a few INSETs developing my own subject knowledge on that. I don't think a week goes by when I haven 't got a course. Some of them are very valuable but sometimes you feel it's the same old thing really. The best ones give you practical ideas to use in the classroom. (Celine)

Figure 6.4: CPD Dimensions and Professional life phase 0-3

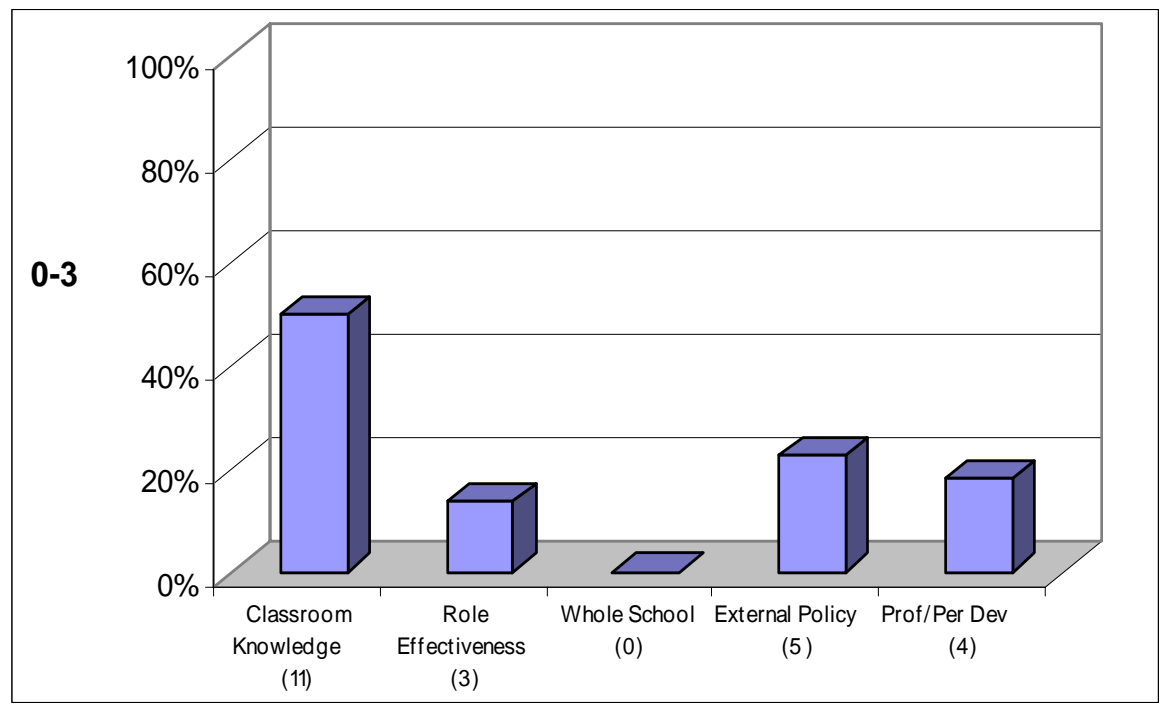


Figure 6.5: CPD Dimensions and Professional life phase 4-7

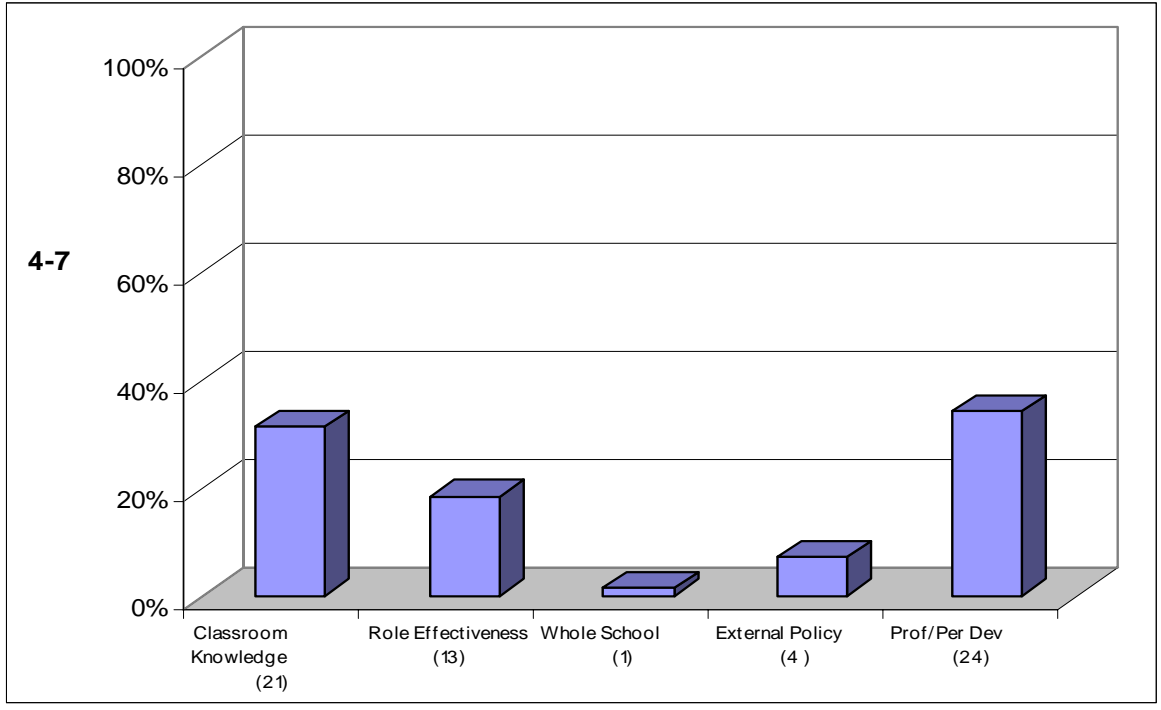

Figure 6.6: CPD Dimensions and Professional life phase 8-15

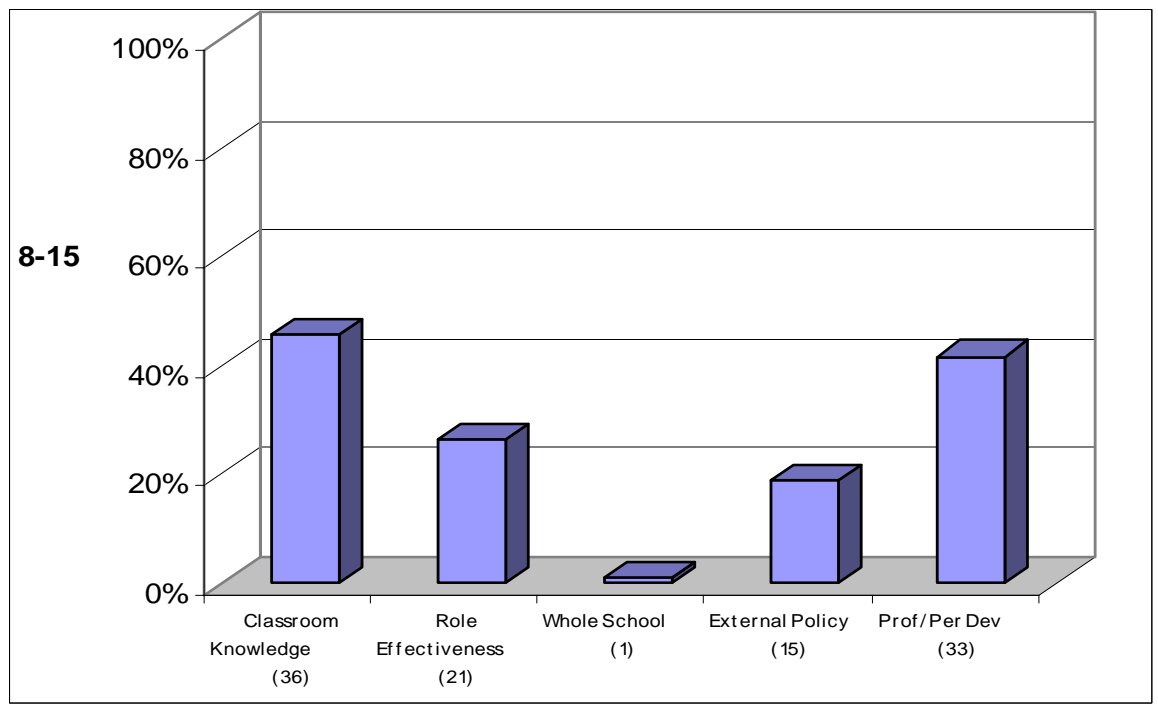

Figure 6.7: CPD Dimensions and Professional life phase 16-23

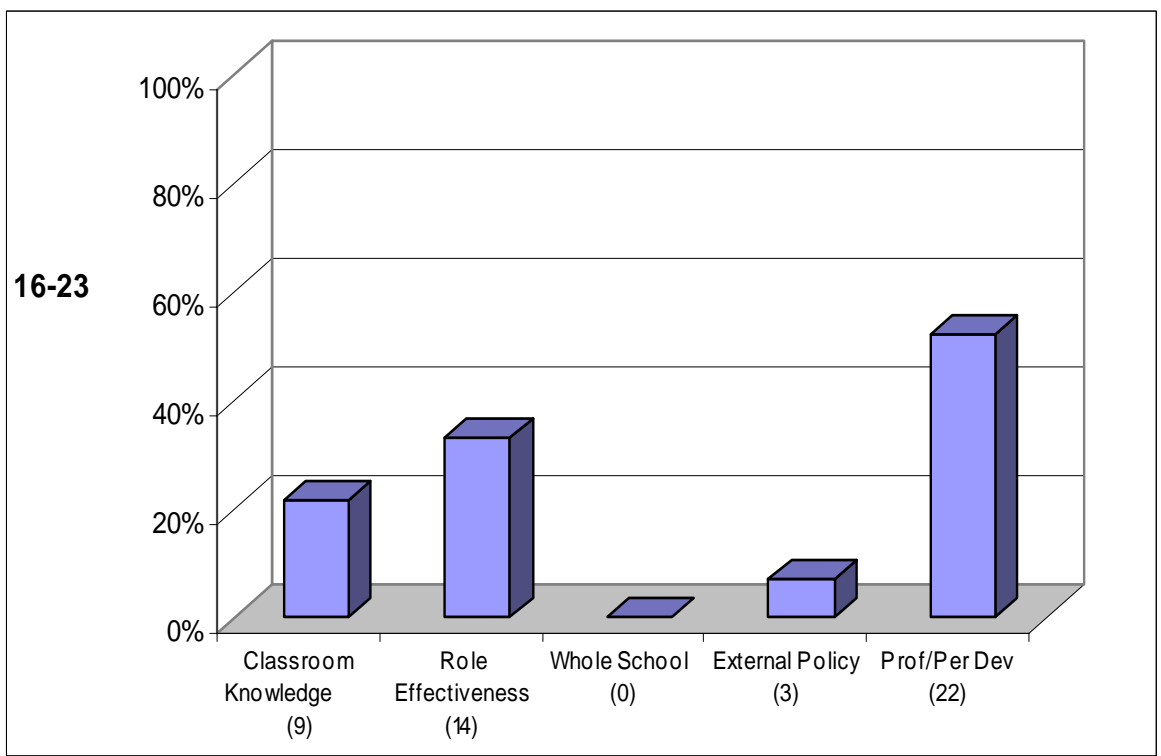


Figure 6.8: CPD Dimensions and Professional life phase 24-30

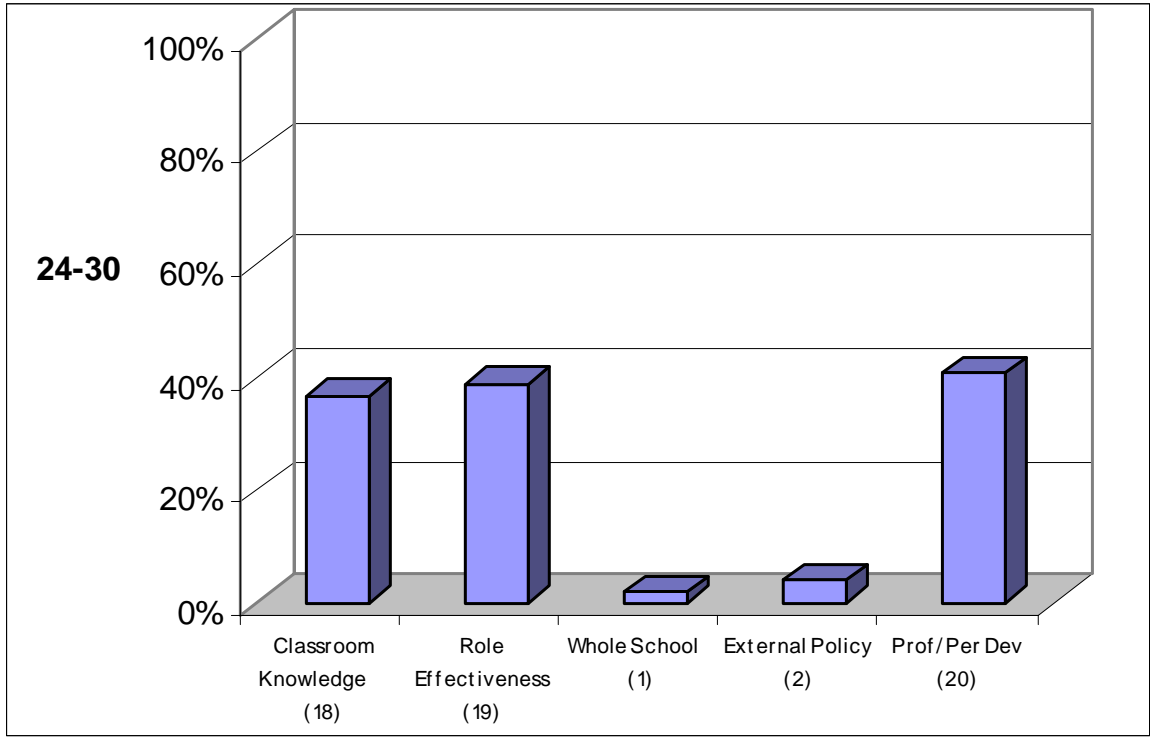

Figure 6.9: CPD Dimensions and Professional life phase 31+

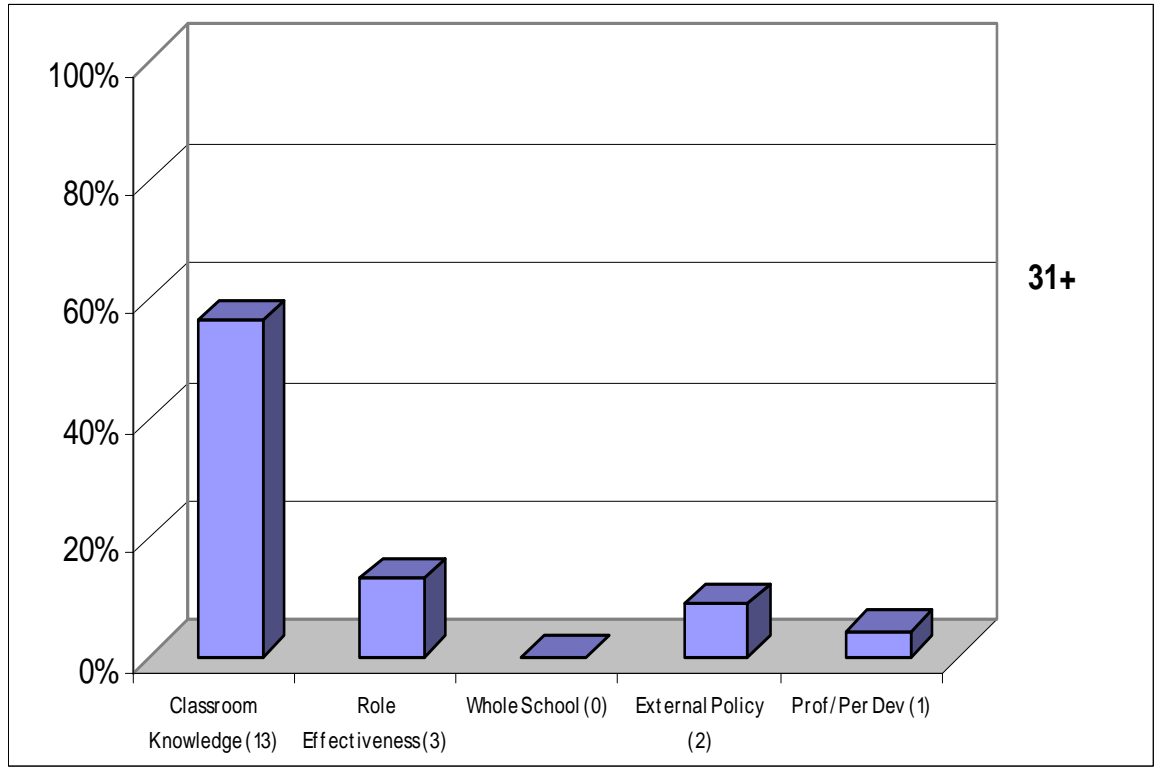

\subsubsection{Professional life phase 4-7}

An important characteristic of teachers with 4-7 years' experience was that promotion and additional responsibilities had begun to play a significant role in their identities, motivation and sense of effectiveness. 
Last year I did the leadership and management of small schools which was a 4 day course and I shadowed 2 headteachers and how they managed their schools. I've looked at SDPs and just started on a new leadership programme where you have a mentor come to the school and the head and I go to meetings. ... The head is taking a secondment in January and I'm going to take over for the 6 weeks. I will be going on the performance management training so that I can carry that on while she's away. I tend to get to go on a lot of courses because of my role in school e.g. special needs courses. (Rhonda)

I think this current one is professional development of teaching, learning, planning, and developing KS3 mathematics. I think that plays such a big part in my role as second in department and KS3 coordinator that I think it's going to be invaluable to me. All the other courses have supplemented that. (Cameron)

\subsubsection{Professional life phases 8-15, 16-23 and 24-30}

The significance of these Role Effectiveness activities continued to grow for teachers in professional life phase $8-15$ and $16-23$, where respectively $76.5 \%$ and $91.3 \%$ of teachers had additional responsibilities. These activities were also important for teachers in professional life phase 24-30.

Analysis of teachers' professional life phases suggests that professional life phase 815 is a watershed in teachers' professional development. Here, Figure 9 provides further evidence - teachers' desires to advance their professional lives in the classroom and/or in management were reflected in their primary interests in CPD activities. CPD appears to play an important role in preparing teachers for further professional life prospects, particularly for those who needed formal qualifications (e.g. NPQH) to climb up the management ladder.

Everybody had a chance to do the course on behaviour management and that was a help. ...The one outside I would recommend because the speaker was brilliant and was giving us material with a bit of humour and he was doing exactly like situations you get in classes and you could talk to other colleagues who had similar problems with difficult students and you could exchange notes. The one in school wasn't bad. It was good but you were in a circle of friends from the school and with some colleagues you could discuss things but with some you wouldn't. (Geri) 
I would love to [undertake CPD]. However, this depends on the ever increasing workload of the job as if that continued I would never find the time.' (Questionnaire) (Did NOF then NPQH -'prepare for career needs') 'I've done the sabbatical [5 weeks] on how to make life more inclusive for my target group children in school. I didn't manage to get as much done as I would have like but having had quality time to read books and documents and other sorts of things it's given me the confidence to realise that my teaching style works best for our children. (Abbie)

[CPD] mostly been valuable, particularly NPQH. (Shannon)

\subsubsection{Professional life phase 31+}

In contrast with Huberman's observation of disengagement conducted in a different era and context (1993), our study observed that a distinctive sub-group of the teachers in the final phase of their professional lives had demonstrated a high level of motivation and commitment and a strong sense of 'active' engagement in the profession. As for their involvement in CPD, Figure 6.9 indicates their continued interest in improving their knowledge within the classroom.

We were given some good ideas as to how to actually get information out of children and how to make them happy. Bullying is one of the things that is difficult to resolve because all the children have a different idea as to what is bullying. Some see the rough and tumble in the corridor as normal and some see it as bullying. To be told how to explain that to children that was helpful and how to get across to them that you can't always come to a happy conclusion. (Sam)

I'm always interested in finding new and better ways to facilitate learning - it fascinates me and motivates me. ... I'm very interested in developing a skill based curriculum rather than a content based one and I don't' have time to do this. I have a huge passion for working on this but I just don't have time apart from Saturdays when I take my mother out. (Janet)

You need to come back with something you can use or someone's brought up something that you think I can see where that's coming from. You balance those ones up with those that you think what a waste of time. I've wasted a day. I could have spent with the children. It's difficult. You can't not go to courses because by going you get new ideas. You might be there all day but that might really work with the group of children you work with. I'd be fine. I'd be happy if I picked up one thing from every course I went on. It's when you think why have I been there. (Aidan) 


\subsection{Sharing practice}

An important message from teachers in all six professional life phases was their desire to share practice and expertise with their colleagues and teachers in other schools - a dimension of CPD which was the least favourably viewed by teachers in the initial questionnaires. The need for collaboration and network support appeared to be particularly important for teachers and leaders in small primary schools.

I went on a conference for heads of maths which was really, really interesting because we looked at some maths issues and teaching maths. We also looked at how to bring in new initiatives and how to manage your staff and that was really, really beneficial and helpful over and above the teaching type courses that I've done before. (Sara, 16-23)

The leadership of small schools was really good and I got to go into other schools. Look at aspects of their SDPs, what they thought was valuable to their schools, etc. (Stchel, 4-7)

The professional learning activities for me which have worked best - but not necessarily increased my sense of professionalism - we work as group of small schools heads eight in this area as well as an academic council which I am chair and we sort out all our staff development ourselves. (Alain, 24-30)

The positive outcomes of CPD, particularly collaborative CPD, regarding changes in teachers' attitudes towards their professional development and improvement in pupil learning have been reported repeatedly by the EPPI CPD review group (2003, June 2005 and August 2005). In the VITAE study, collaborative learning with colleagues within teachers' own schools as well as across schools was also rated as a highly important and useful form of CPD activity.

\subsection{School phase}

Previous analysis of the questionnaire responses of the original larger sample showed that whilst there was satisfaction with CPD from teachers in both primary and secondary school phases, primary school teachers demonstrated higher satisfaction rates than secondary teachers in their attitudes towards CPD opportunities and the quality of what was offered. This was mirrored by the responses of the VITAE participants. In addition, VITAE teachers in primary schools are more satisfied with the overall focus and balance of CPD opportunities. 
This finding of primary teachers expressing a greater level of satisfaction with CPD than secondary teachers was also reported by the DfES Teachers' Perceptions of Continuing Professional Development study (Hustler et al, 2003) and by the recent General Teaching Council (GTC) survey (Sturman et al, 2005).

In contrast with the generally favourable attitude towards CPD amongst teachers in both primary and secondary phases, there were high levels of dissatisfaction (especially in VITAE primary schools) with the time teachers saw as being available to allow them to reflect on their teaching (primary: $82.5 \%$; secondary: $71.4 \%$ ) and to learn with and from colleagues (primary: $74.5 \%$; secondary: 69.8\%).

\subsection{School context}

Analysis of the initial teacher questionnaires indicated some significant effects of FSM on teachers' views on CPD. Overall, teachers were satisfied with what was offered. There was little association between FSM bands and teachers' views on either the focus and quality of CPD opportunities they enjoyed or on the time they had to learn with and from colleagues (Table 6.1 below). Significant differences were found in their views across the four FSM bands regarding the overall opportunities $\left(\chi^{2}=\right.$ 17.361, $\mathrm{df}=9, \mathrm{p}<0.05)$ and balance $\left(\chi^{2}=20.068, \mathrm{df}=9, \mathrm{p}<0.05\right)$ of CPD and the time they had to reflect on their teaching $\left(\chi^{2}=19.019, \mathrm{df}=9, \mathrm{p}<0.05\right)$. Figures 37 and 38 show that teachers in FSM1 schools had the greatest satisfaction with the opportunities and balance of CPD, in contrast with those in FSM3 schools who were the least satisfied with CPD activities available to meet their needs and those of the schools. In addition, teachers in FSM3 schools expressed the greatest dissatisfaction with the extent to which they had time to reflect on their teaching (Figures $6.10-$ $6.12)-40$ per cent were very dissatisfied with this aspect of CPD. 
Figure 6.10: Q14. How satisfied are you with your overall current CPD opportunities (by FSM band)?

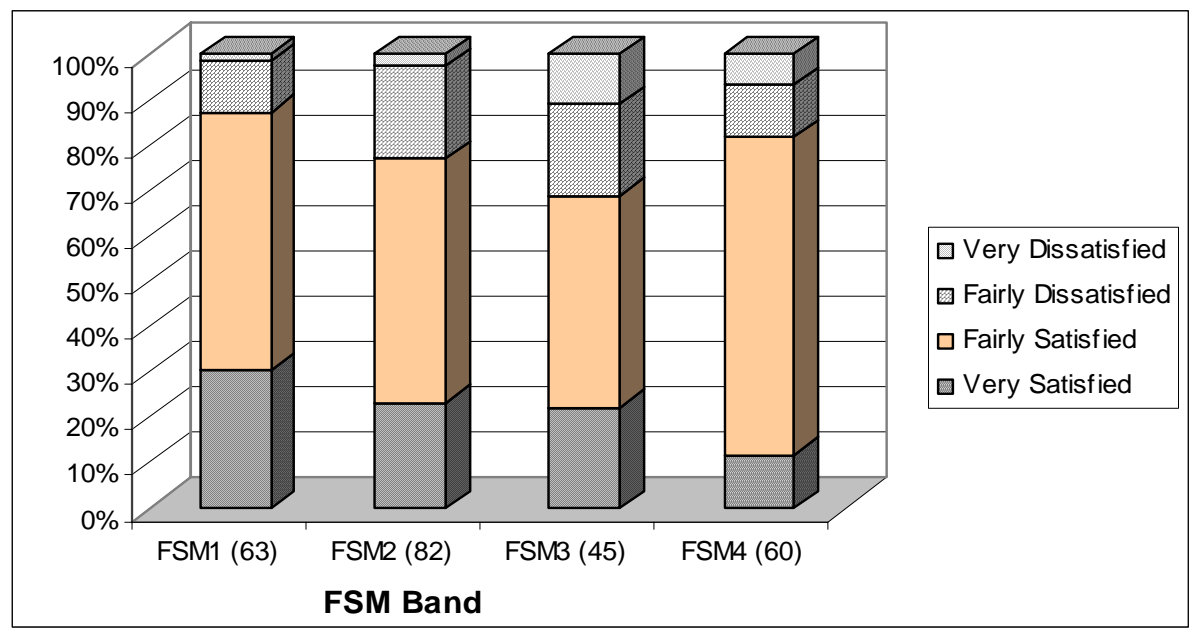

Figure 6.11: Q19. How satisfied are you with the balance of professional development opportunities your school has supported to meet your needs and those the school?

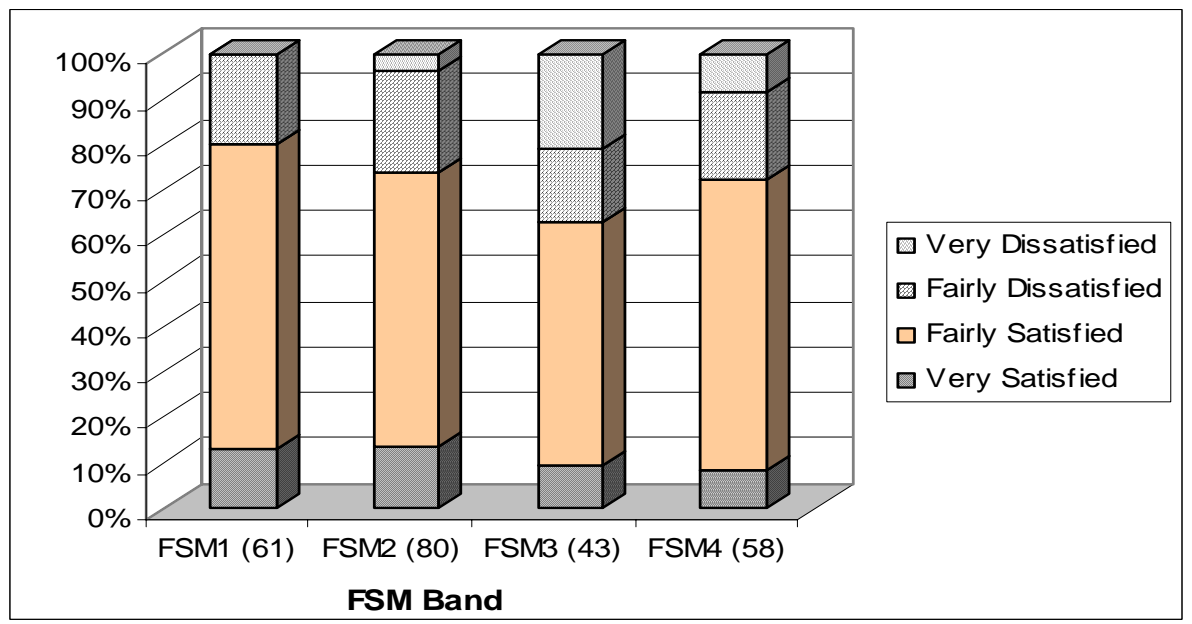

Figure 6.12: Q17. How satisfied are you with the extent to which you get time to reflect on your teaching?

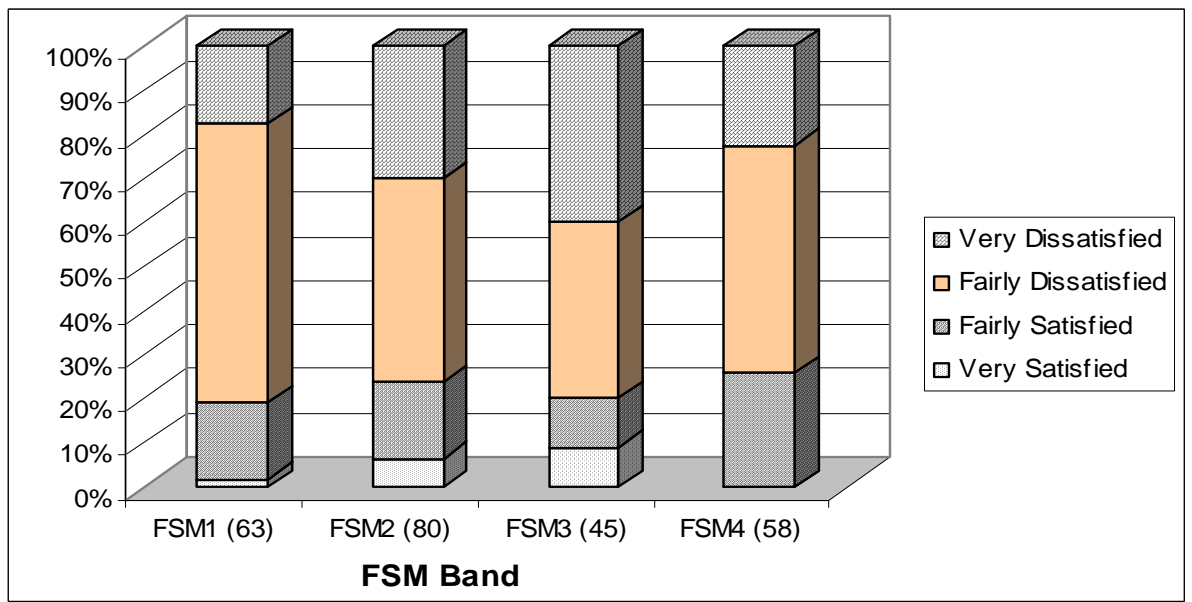


The analysis of interview data also indicated a patterned difference in reasons for undertaking CPD between different FSM schools. The frequency distributions of reasons for undertaking CPD, in relation to FSM categories are presented in Figures $6.13-6.18$, which summarise the interview data.

Apart from those in professional life phase 24-30, the remaining teachers in FSM 3 and 4 schools appeared to have stronger concerns about improving their classroom knowledge than their counterparts in FSM 1 and 2 schools. The negative impact of disruptive pupil behaviour on teachers' motivation in FMS4 schools is an important finding of our study. Given this contextual factor, it is not surprising that teachers in low socio-economic status schools were likely to comment on CPD activities that had enabled them to improve pupil learning in the classroom.

Figure 6.13: CPD Dimensions and FSM (0-3)

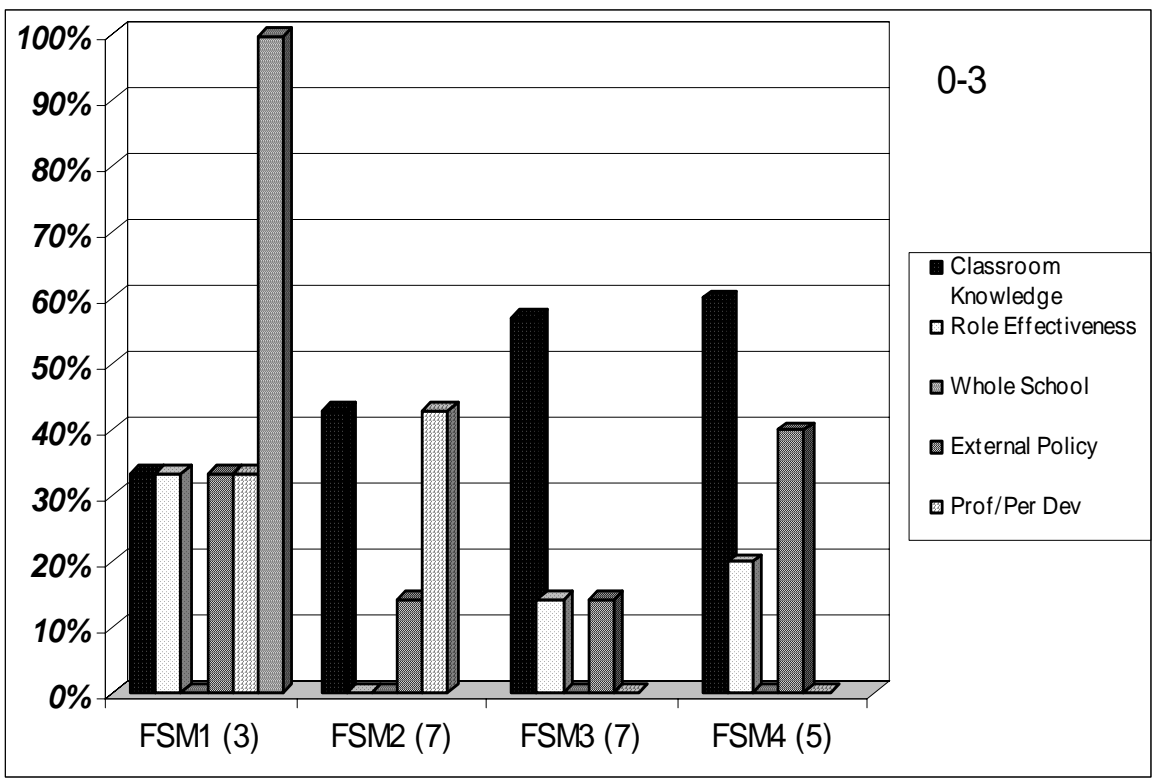


Figure 6.14: CPD Dimensions and FSM (4-7)

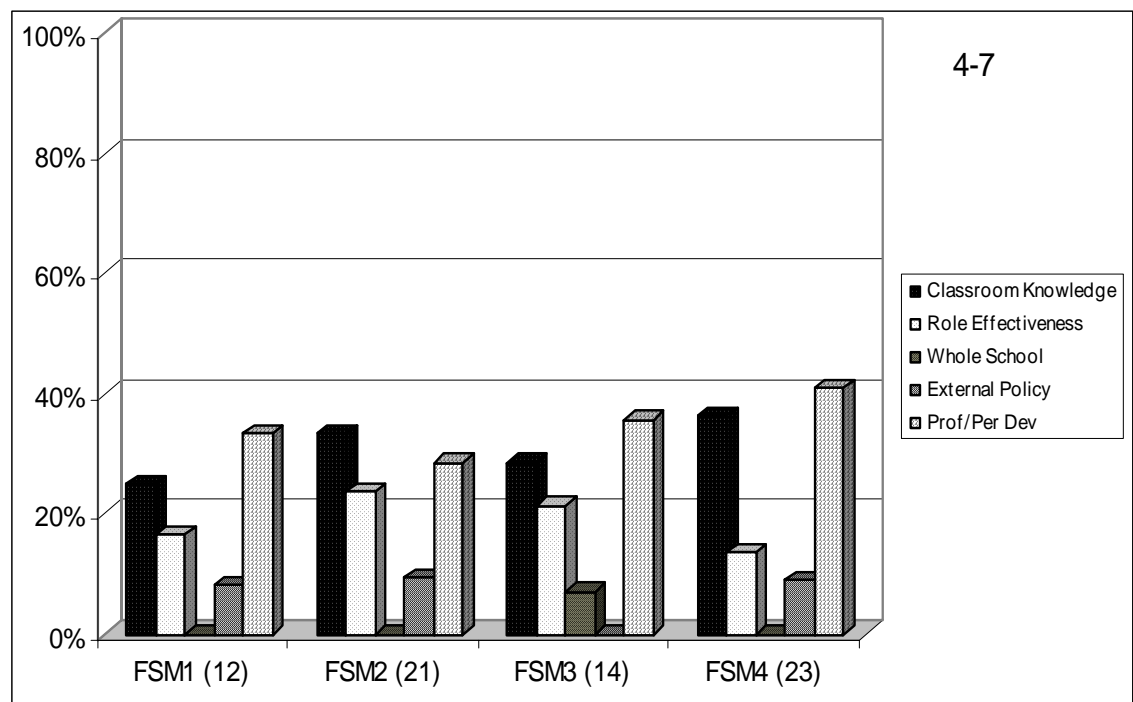

Figure 6.15: CPD Dimensions and FSM (8-15)

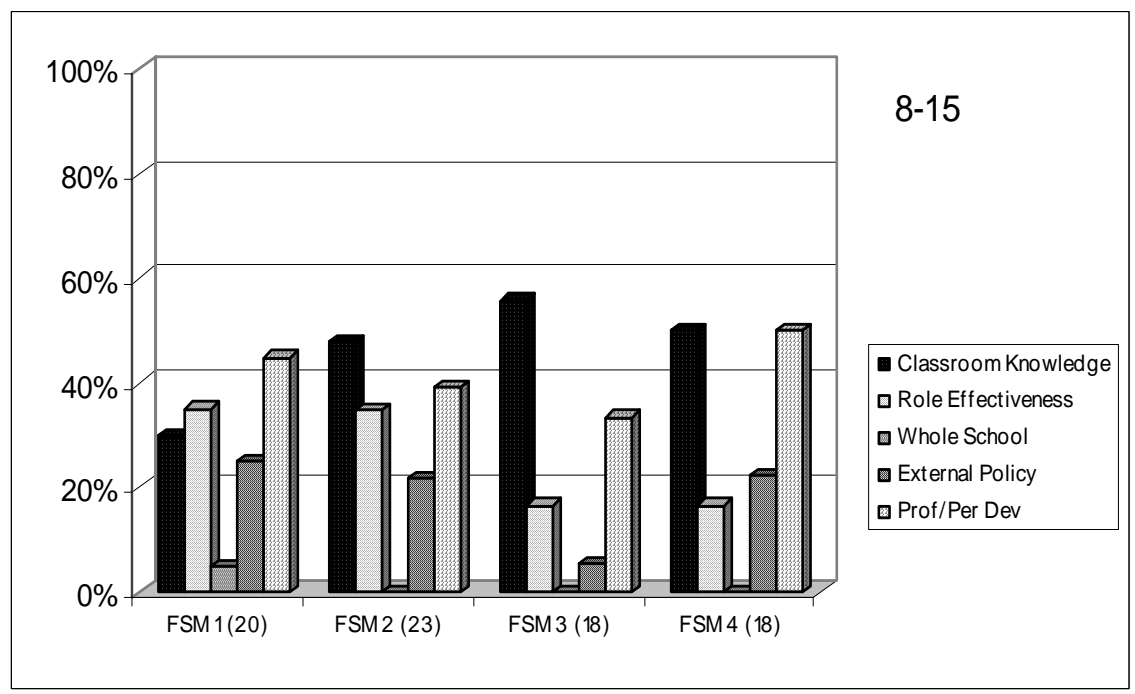

Figure 6.16: CPD Dimensions and FSM (16-23)

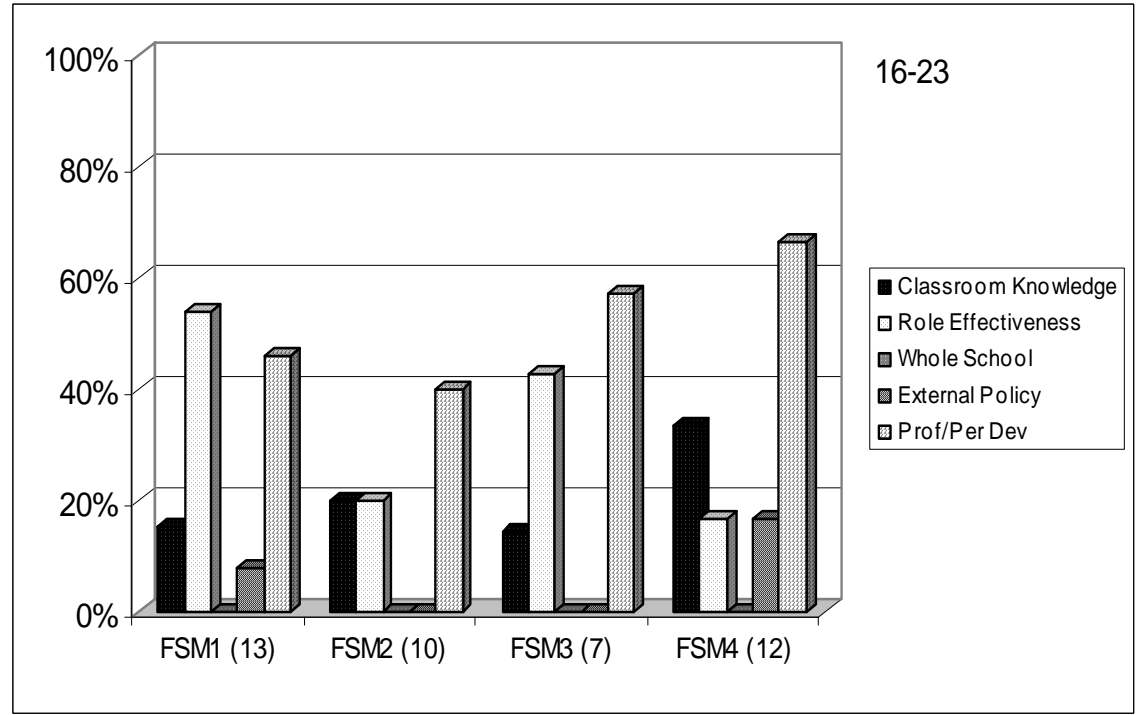


Figure 6.17: CPD Dimensions and FSM (24-30)

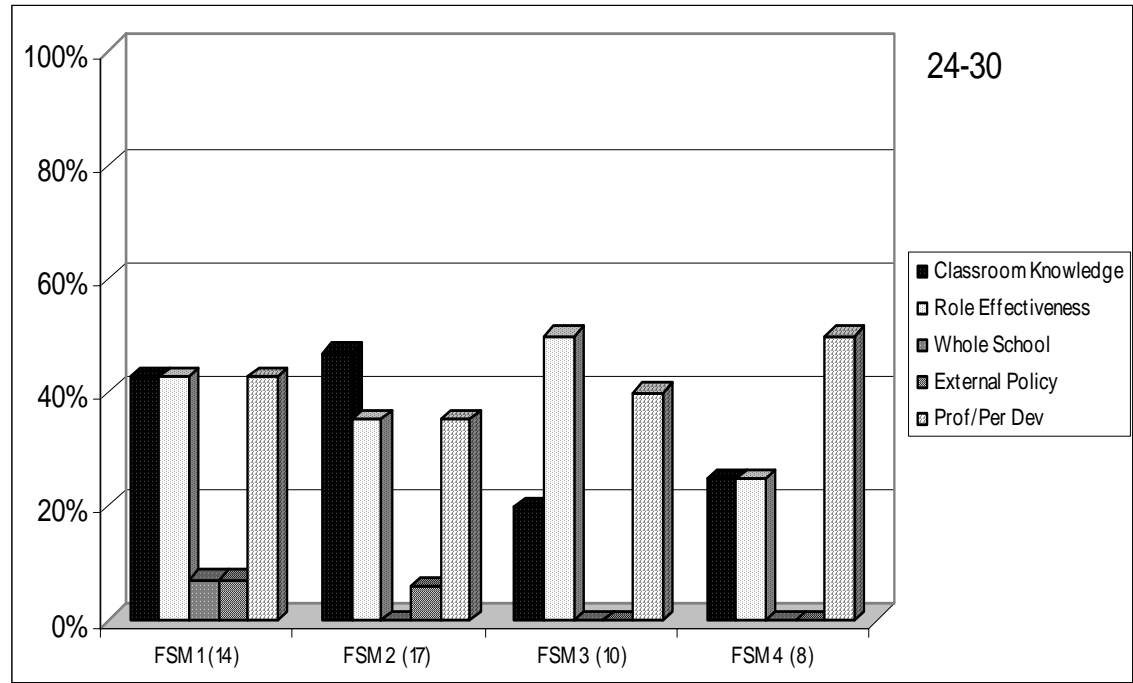

Figure 6.18: CPD Dimensions and FSM (31+)

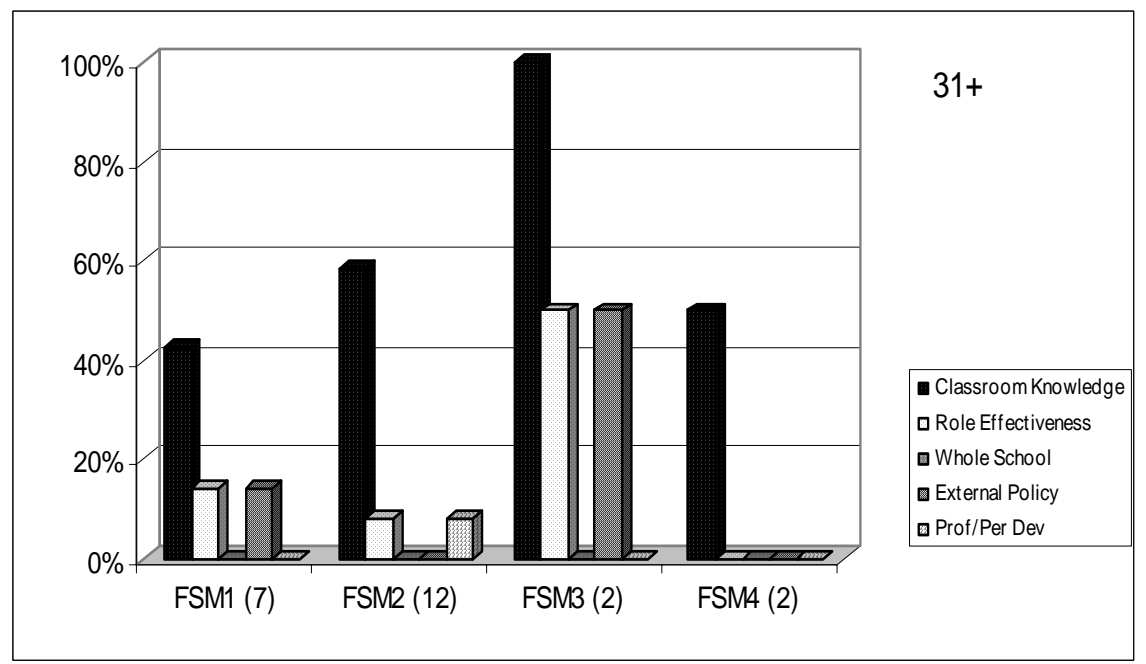

\subsection{Gender}

Table 6.1 below indicates that overall male teachers were slightly more likely to be satisfied with their CPD opportunities and the quality and balance of what was offered than their female counterparts. Although both female and male teachers were highly dissatisfied with the time they had to reflect on their teaching and to learn with and from colleagues, females appeared to have a slightly more negative attitude than males, but this was not statistically significant. 
Table 6.1: Teachers' Views of CPD by gender

\begin{tabular}{|c|c|c|c|c|c|c|c|c|c|c|}
\hline \multirow{2}{*}{$\begin{array}{l}\text { How satisfied are teachers } \\
\text { with }\end{array}$} & \multicolumn{2}{|c|}{$\begin{array}{l}\text { Number of } \\
\text { Responses }\end{array}$} & \multicolumn{2}{|c|}{ Very Satisfied } & \multicolumn{2}{|c|}{ Fairly Satisfied } & \multicolumn{2}{|c|}{$\begin{array}{l}\text { Fairly } \\
\text { Dissatisfied }\end{array}$} & \multicolumn{2}{|c|}{$\begin{array}{l}\text { Very } \\
\text { Dissatisfied }\end{array}$} \\
\hline & $\mathrm{F}$ & $\mathbf{M}$ & $\mathbf{F}$ & $\mathbf{M}$ & $\mathbf{F}$ & $\mathbf{M}$ & $\mathbf{F}$ & $\mathbf{M}$ & $\mathbf{F}$ & $\mathbf{M}$ \\
\hline $\begin{array}{l}\text { Their overall current CPD } \\
\text { opportunities? }\end{array}$ & 199 & 51 & $21.6 \%$ & $23.5 \%$ & $56.3 \%$ & $60.8 \%$ & $16.1 \%$ & $15.7 \%$ & $6.0 \%$ & $0 \%$ \\
\hline The overall focus of CPD? & 197 & 51 & $11.7 \%$ & $15.7 \%$ & $58.9 \%$ & $54.9 \%$ & $25.4 \%$ & $29.4 \%$ & $4.1 \%$ & $0 \%$ \\
\hline The overall quality of CPD? & 195 & 50 & $14.9 \%$ & $14.0 \%$ & $59.0 \%$ & $62.0 \%$ & $21.5 \%$ & $16.0 \%$ & $4.6 \%$ & $8.0 \%$ \\
\hline $\begin{array}{l}\text { The extent to which they get } \\
\text { time to reflect on their } \\
\text { teaching? }\end{array}$ & 197 & 49 & $3.6 \%$ & $6.1 \%$ & $16.8 \%$ & $24.5 \%$ & $50.3 \%$ & $53.1 \%$ & $29.4 \%$ & $16.3 \%$ \\
\hline $\begin{array}{l}\text { The time and opportunity to } \\
\text { learn with and from } \\
\text { colleagues? }\end{array}$ & 199 & 50 & $3.0 \%$ & $2.0 \%$ & $22.6 \%$ & $38.0 \%$ & $49.7 \%$ & $48.0 \%$ & $24.6 \%$ & $12.0 \%$ \\
\hline $\begin{array}{l}\text { The balance of professional } \\
\text { development opportunities? }\end{array}$ & 193 & 49 & $11.4 \%$ & $12.2 \%$ & $60.6 \%$ & $65.3 \%$ & $20.2 \%$ & $18.4 \%$ & $7.8 \%$ & $4.1 \%$ \\
\hline
\end{tabular}

The DfES CPD study (Hustler et al, 2003) reported similar minimal gender differences in teachers' overall view of CPD, although their results indicated a slightly more positive attitude in females. Again, however, these differences did not show as being significantly different from zero. As a result of its much greater sample size, the GTC survey (Sturman et al, 2005) did find statistically significant differences in views by gender, with female teachers more likely to have experienced their listed CPD activities in the past 12 months and to report the need for CPD in areas such as teaching and learning and the curriculum over the next 12 months. In reporting their results on the impact of gender on teachers' attitudes towards CPD, Hustler et al (2003: 26) caution that

... it is recognised that gender and phase factors, just like management and age factors, are interrelated. Interpretation, therefore, must be cautious here and elsewhere in relation to these factors. 


\section{$2.7 \quad$ Age}

We found little association between variations in teachers' overall view of CPD and their ages. The DfES study (Hustler et al, 2003) reported a similar finding, but suggested a slight tendency for older teachers to hold a more negative view of CPD. In our research we found that in comparison with their younger colleagues, teachers in their $40 \mathrm{~s}$ and $50 \mathrm{~s}$ were slightly more negative about the time they had to reflect on their teaching and to learn with their colleagues. However, teachers in their 50s reported a more positive attitude, although only marginally, towards the opportunities and balance of CPD. Younger teachers on this Project (in age range 21-30) appeared to be the most satisfied with the overall focus and quality of CPD.

\subsection{Conclusion}

This chapter has summarised the key findings of the analysis of 310 VITAE teachers' views on CPD. Most teachers (80\%) were satisfied with their experiences of CPD. School phase, gender, school contexts and professional and personal life phases were shown to have significant impacts on different dimensions of teacher professional development. The recognition of the impact of interactions between socio-emotional factors, personal factors and organisational/situated factors is of crucial importance to achieve an holistic understanding of the influence of CPD on teachers' professional lives and effectiveness.

Kelchtermans' 'dialogue' image of CPD implies that CPD involves an on-going interaction and negotiation between teachers' desires to pursue their professional learning and growth and the situational/organisational influences that either help or hinder their needs for and directions of development.

...the interactionist character of CPD implies that teachers are influenced in their professional development by the particularities of the context, both in time and space. This influence, however, is not a deterministic relationship, but rather a two-way 'dialogue' through which teachers make sense of their experiences and act accordingly, even if this dialogue is partly determined by structural conditions. (Kelchtermans, 2004: 225) 
The nature of this dialogue can vary in different phases of teachers' professional lives. Thus, the reasons that teachers undertake CPD may change over time -focussing on different 'development tasks' (Richardson and Placier, 2001: 910) in the course of their professional development (Ball and Goodson, 1985; Sikes et al, 1985; Huberman, 1993; Kelchtermans, 2004).

Despite the heavy investment in CPD over the last five years at policy level, the teachers in the VITAE study did not appear to have experienced the wide range of CPD that the investment represents. For the most part what they described echoes earlier nationally commissioned research (Hustler et al., 2003) which found that, overall, teachers had a traditional and rather narrow view of CPD - they thought of CPD as courses, conferences and workshops and consequently, 'a variety of forms of professional opportunity are not conceptualised as CPD' (2003: 28). What the VITAE teachers spoke about in the interviews were overwhelmingly in-service activities which focused principally upon up-dating and up-skilling them to deliver the curriculum and assessment agendas which were promoted at national level. This may be because they were teaching $\mathrm{KS} 1,2$ and 3 pupils and so were focused upon the teaching, learning and assessment needs of these groups; or it may be because of the busyness of their working lives or out-of-classroom additional leadership responsibilities that short courses which met short term management and teaching needs were the dominant experiences of which they talked.

There are two messages that arise from the limited range of CPD experiences which VITAE teachers report. The first concerns their apparent lack of experience of the relatively recent extensive CPD initiatives taken at policy level. The second is that their schools did not seem to offer a wide range of CPD opportunities which focused on both their professional knowledge and skills and their socio-emotional (well-being) needs. 


\section{CHAPTER SEVEN: \\ THE EMOTIONAL CONTEXTS OF TEACHING: TEACHER IDENTITIES}

Hypothesis 3: Teachers' sense of positive identity is closely related to their effectiveness. Their capacity to manage their identity in changing circumstances is fundamental to their ability to sustain effectiveness.

\subsection{Introduction}

The previous chapter sought to explore key characteristics of teachers' professional life phases. One of the main criticisms of 'stage theory' is that it assumes linear progression e.g. novice to expert (Dreyfus and Dreyfus, 1976). Huberman's (1993) work observed, however, that although this can be the experience for some teachers, others can return to particular phases, miss phases, or remain in certain phases for a substantial amount of time without transition. Indeed, the effectiveness of teachers in different professional life phases and the relationships between these, working conditions, organisational, pupil, life contexts both influence and are influenced by teachers' identities. Whether they were positively or negatively stable, or positively or negatively unstable, we found that identities are a key determinant of effectiveness.

Variations in teachers' work and lives are, therefore, not only moderated by their professional life phase but also their identities - and their identities are related to the result of their responses to and management of various 'Scenarios' which they experience. These occur within and across professional life phases.

This chapter focuses, therefore, upon an analysis of the interactions between teachers' identities and their work and life Scenarios and emotional well-being. It also examines the impact of teachers' sense of agency on resilience and teachers' ability to sustain their commitment (as defined in Chapter Three). It finds that the notion that identities are neither intrinsically stable nor intrinsically fragmented, but that they can be more, or less, stable and more or less fragmented at different times and in different ways according to the influence of the interaction of a number of personal, professional and situated factors. 
Furthermore, the empirical research reported here reveals that teachers' sense of professional and personal identity and their personal and organisational contexts are key variables in their motivation, job fulfilment, commitment and self-efficacy; and are themselves affected by the extent to which teachers' own needs for agency and well-being (autonomy, competence and relatedness) are met and managed.

Teachers' sense of professional and personal identity are key variables in their motivation, job fulfilment, commitment and self efficacy; and these will themselves be affected by the extent to which teachers' own needs for autonomy, competence and relatedness are met. Emotions play a key role in the construction of identity (Zembylas, 2003). They are the necessary link between the social structures in which teachers work and the ways they act.

...emotion is a necessary link between social structures and social actor. The connection is never mechanical because emotions are normally not compelling but inclining. But without the emotions category, accounts of situated actions would be fragmentary and incomplete. Emotion is provoked by circumstance and is experienced as transformation of dispositions to act. It is through the subject's active exchange with others that emotional experiences is both stimulated in the actor and orienting of their conduct. Emotion is directly implicated in the actor's transformation of their circumstances, as well as the circumstances' transformation of the actor's disposition to act.

(Barbalet, 2002, p. 4)

There is an unavoidable interrelationship between professional and personal, cognitive and emotional identities, if only because the overwhelming evidence is that teaching demands significant personal investment of these:

the ways in which teachers form their professional identities are influenced both by how they feel about themselves and how they feel about their students. This professional identity helps them to position or situate themselves in relation to their students and to make appropriate and effective adjustments in their practice and their beliefs about and engagement with students.

(James-Wilson, 2001, p. 29) 
Identity should not be confused with role. It is the way we make sense of ourselves to ourselves and the image of ourselves which we present to others. It is culturally embedded. Kelchtermans (1993) suggests that the professional self, like the personal self, evolves over time and that it consists of five interrelated parts: Self-image: how teachers describe themselves though their career stories; Self-esteem: the evolution of self as a teacher, how good or otherwise as defined by self or others; Job-motivation: what makes teachers choose, remain committed to or leave the job; Task perception: how teachers define their jobs; Future perspective: teachers' expectations for the future development of their jobs (Kelchtermans, 1993, pp. 449-450). So teachers' identities are closely bound with their professional and personal values and aspirations.

\subsection{Previous research}

In much educational literature it is recognised that the broader social conditions in which teachers live and work, the emotional contexts, and the personal and professional elements of teachers' lives, experiences, beliefs and practices are integral to one another, and that there are often tensions between these which impact to a greater or lesser extent upon teachers' sense of self or identity. If identity is a key influencing factor on teachers' sense of purpose, self-efficacy, motivation and commitment, and effectiveness, then investigation of those factors which influence identities positively and negatively, the contexts in which these occur and the consequences for practice, is essential. Surprisingly, although notions of 'self' and personal identity are much used in educational research and theory, critical engagement with individual teachers' cognitive and emotional 'selves' has been relatively rare (Nias,1998). Yet such engagement is important to all with an interest in raising and sustaining standards of teaching, particularly in contexts which threaten to destabilise long held beliefs and practices (for a comprehensive discussion of the concept of identity, see Day et al, forthcoming). 


\subsubsection{The Role of Emotion}

A significant and ongoing part of being a teacher is the experiencing and management of strong emotions. We know that the emotional climate of the school and classroom will affect attitudes to and practices of teaching and learning. Teachers (and their students) experience an array of sometimes contrasting emotions in the classroom. It is surprising, therefore, that this dimension of identity has been given relatively little attention in much of the research. In a review of empirical research, Sutton (2000) found that love (as a social relationship) and care, surprise and joy, anger, sadness and fear, excitement and pleasure in students' progress and achievements are among the most commonly cited emotions. Thus it is not surprising that, because of their emotional investments, teachers can experience a range of negative emotions when control of long held principles and practices is challenged, or when trust and respect from parents, the public and their students is eroded. Kelchtermans (1996) has also reported on teachers' feelings of vulnerability, engendered when professional identity and moral integrity are questioned either by policy changes, parents, inspectors, or colleagues in the light of unrealistic expectations or their failure to help students achieve higher standards. In England, Jeffrey and Woods (1996) found professional uncertainty, confusion, inadequacy, anxiety, mortification and doubt among teachers when they investigated primary school teachers' responses to external (Ofsted) inspections, associating these with 'dehumanisation' and 'deprofessionalism'. Other negative emotions are: frustration; anger exacerbated by tiredness, stress and students' misbehaviour; anxiety because of the complexity of the job; guilt, sadness, blame and shame at not being able to achieve ideals or targets imposed by others.

\subsubsection{Teachers' Identities: Personal and Professional}

Several researchers (Nias, 1989, 1996; A. Hargreaves, 1994; Sumsion, 2002) have noted that teacher identities are not only constructed from technical and emotional aspects of teaching (i.e. classroom management, subject knowledge and pupil test results) and their personal lives, but, also, '... as the result of an interaction between the personal experiences of teachers and the social, cultural, and institutional environment in which they function on a daily basis' (Sleegers and Kelchtermans, 1999, p.579). 
Today's professional has been described as, 'mobilizing a complex of occasional identities in response to shifting contexts' (Stronach et al, 2002, p117). Such mobilizations occur in the space between the 'structure' (of the relations between power and status) and 'agency' (in the influence which we and others can have); and it is the interaction between these which influences how teachers see themselves i.e. their personal and professional identities. Stronach et al's (2002) research with nurses and teachers, like others before it (Nias, 1989; Kelchtermans, 1993; Hoyle and John, 1995; Bowe and Ball, 1992; Furlong et al, 2000; Friedson, 2001; Hanlon, 1998) claims that 'professionalism' is bound up in the discursive dynamics of professionals attempting to address or redress the dilemmas of the job within particular cultures (p109). Their reading of professional identities and their own data from teachers in six primary schools in England, though limited, and, 'walking the tightrope of an uncertain being' (p121), resonates with much other empirical research on teachers' plurality of roles (Sachs, 2003) within work contexts which are characterised by fragmentation and discontinuities (Huberman, 1995) and a number of tensions and dilemmas (Day et al, 2000) within what is generally agreed to be increasingly intensive external audit policy cultures (Power, 1994) which are present in many developed nations.

Reforms have an impact upon teachers' identities and, because these are both cognitive and emotional, create reactions which are both rational and non-rational. Thus, the ways and extent to which reforms are received, adopted, adapted and sustained or not sustained will be influenced by the extent to which they challenge existing identities. Existing identities may become what MacLure (1993) has described as, 'a continuing site of struggle' (p. 312). Instabilities, whether of a personal, professional or situated nature or a combination of these, create stresses in the fabric of identity and these need to be managed. Teachers need to be resilient and to be supported during these periods in order that these may be managed in ways that build or sustain positive identities and existing effectiveness. Critical of earlier notions of an essential or substantial 'self', MacLure (1993) proposed the concept of an 'active' agential teacher self which is formed and informed through the 'discursive practices' and interactions in which individuals engage. Here identity is not a stable entity that people possess, but rather is constructed within social relations and used by individuals as an interactional resource. 
Contrasting the teachers in the 'Teachers' Jobs and Lives' project with those within Nias' (1989) study which took place in a more stable policy context, MacLure argued that the teachers in her study appeared to be more varied in their senses of themselves, much less secure in their identities as teachers, and less committed to teaching as a career. In doing so, she was acknowledging, perhaps, that in the period since Nias' work, teachers have more frequently come to occupy positions of increasing constraint. This need not imply that all teachers have a reduced sense of 'agency' per se. An increase in constraint can be seen to imply, however, that the 'opportunity costs' attached to teachers' agency (Archer, 1996) have changed - that the 'costs' for teachers of asserting their agency in order to achieve their particular individual and/or professional satisfactions are now higher, for example, in respect of their personal relationships, health and well being, and the quality of learning which they provide for their pupils. The importance of MacLure's work is that, like that of others (Day and Hadfield, 1996) it indicates that teachers' identities are, in some cases, less stable, less convergent and less coherent than is often implied by notions of a 'substantive self' (Nias, 1989).

Whilst previous research is helpful in understanding teacher identities, it does, nevertheless, have limitations:

i) studies disagree over the issue of whether identities are substantive (essential) or contingent stable or unstable;

ii) all are limited by their lack of longitudinal 'real time' data;

iii) none seek to address possible relationships between identity and teachers' effectiveness, either perceived or in value-added measures of pupil attainment;

iv) more or less cognisance is taken of

- Macro structures: broad social/cultural features usually referred to in discussions of social diversity and/or government policy

- Meso structures: the social/cultural/organisational formations of schools and teacher education 
- Micro structures: talked of in terms of colleagues, pupils and parents

- Personal biographies: values, beliefs, ideologies

- Emotional factors

The literature suggests that identities are a shifting amalgam of personal biography, culture, social influence and institutional values which may change according to role and circumstance. They depend upon:

the sustaining of coherent, yet continuously revised, biographical narratives, [which] takes place in the context of multiple choice ... Reflexively organised life planning ... becomes a central feature of the structuring of self identity (Giddens, 1991, p5).

Thus, the ways and extent to which reforms are received, adopted, adapted and sustained or not sustained will not only be influenced by teachers' emotional selves but will exercise influence upon them.

\subsection{Conceptualising Teacher Identity}

The evidence from teachers in the VITAE project provided a more holistic picture of variations in teachers' lives, work and effectiveness across macro, meso and micro level contexts and different biographical and experience phases through the use of a range of qualitative and quantitative research instruments with a nationally representative sample of $295^{22}$ teachers for whom identity data were generated over a three year period. VITAE data suggested that some teachers themselves do seek and find, in different ways, their own sense of stability within what appears from the outside to be fragmented identities. Furthermore, it suggested that neither stability nor instability will necessarily influence their effectiveness. On the contrary, the research indicated that many find meaning in their work through a strong sense of personal and professional agency and moral purpose.

\footnotetext{
${ }^{22}$ The team were unable to make judgements relating to identity for 18 teachers due to lack of data.
} 


\subsubsection{Dimensions of Identity}

Our research suggests that identity itself is a composite consisting of interactions between personal, professional and situational factors. Each composite identity is made up of sub or competing identities:

1) Professional identity - is open to the influence of long term policy and social trends as to what constitutes a good teacher, classroom practitioner, etc. It could have a number of competing and conflicting elements such as local or national policy, CPD, workload, roles and responsibilities etc

2) Situated or socially located identity within a specified school, department or classroom - is affected by pupils, support and feedback loops from teachers' immediate working context, connected to long term identity.

3) Personal identity - is based with life outside of school, could have various competing elements such as identity of being a father, son, partner, etc. Feedback comes from family and friends and these often become sources of tension as the individual's sense of identity could become out of step.

Each dimension of identity is subject to a number of positive and negative influences. It is the degree of dominance which these influences have on each dimension of identity and the way teachers manage them which determine the relative stability or instability of teachers' composite identities and whether these are positive or negative (Fig. 7.1).

Figure 7.1 - Hypothesising Relationships between Variations and Effectiveness

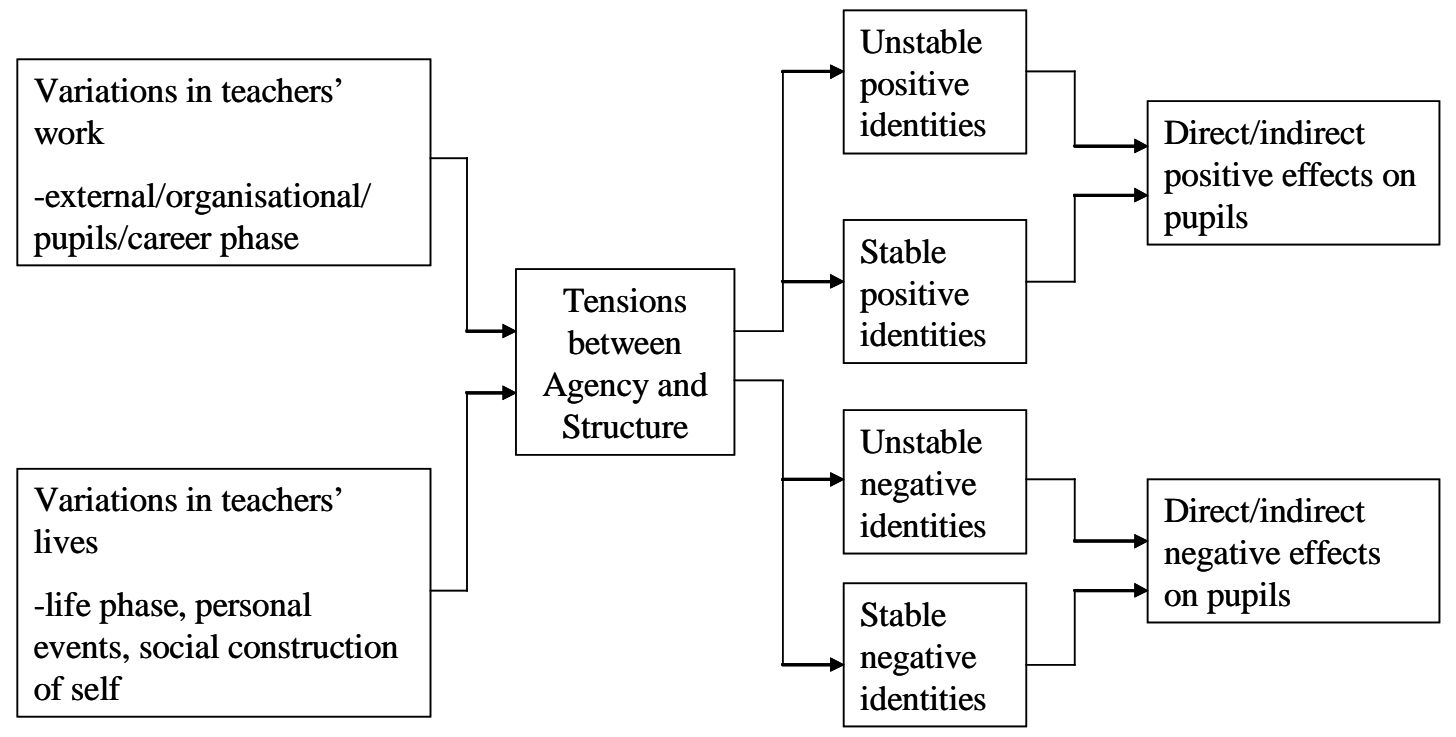


Agency, commitment, resilience, well-being and life-work management influence and are moderated by teachers' professional life phases and these impact upon their perceptions of effectiveness (cf p. 54). They are affected, but not necessarily determined by, these influences, for each of these can be mediated by teachers' strong sense of vocation/moral purpose/values and the interaction between these and their working environment. Any one (or more) of these three dimensions of identity may, at a particular time and/or in particular Scenarios, become dominant, requiring additional time and attention from the teacher and affecting their sense of commitment, well-being, agency and effectiveness. Teachers may experience tensions between these three dimensions at any given time.

In the VITAE project four Scenarios were identified: dimensions in relative balance, one dominant dimension, two dominant dimensions, and three conflicting dimensions. These were identified by the degree of dominance that each of these dimensions had on aspects of a teacher's life at a given time. Our analysis of data collected from various sources (e.g. teacher interview, survey) over three years, showed that teachers, once in a particular Scenario, were able to be grouped into one of four identity 'states': stable positive or negative and unstable positive or negative. Instability is not necessarily negative. It can stimulate a re-evaluation of current thinking and practices which may no longer be the most effective in the work situation. For example, a teacher who moves schools or takes a new role will inevitably experience a period of instability, as will a teacher who has to learn new knowledge about teaching or adopt new teaching, monitoring and/or assessment strategies. We were able to plot variations between teachers and begin to identify 'resilient' and 'vulnerable' teachers. 
Figure 7.2: Scenario 1 - dimensions in balance

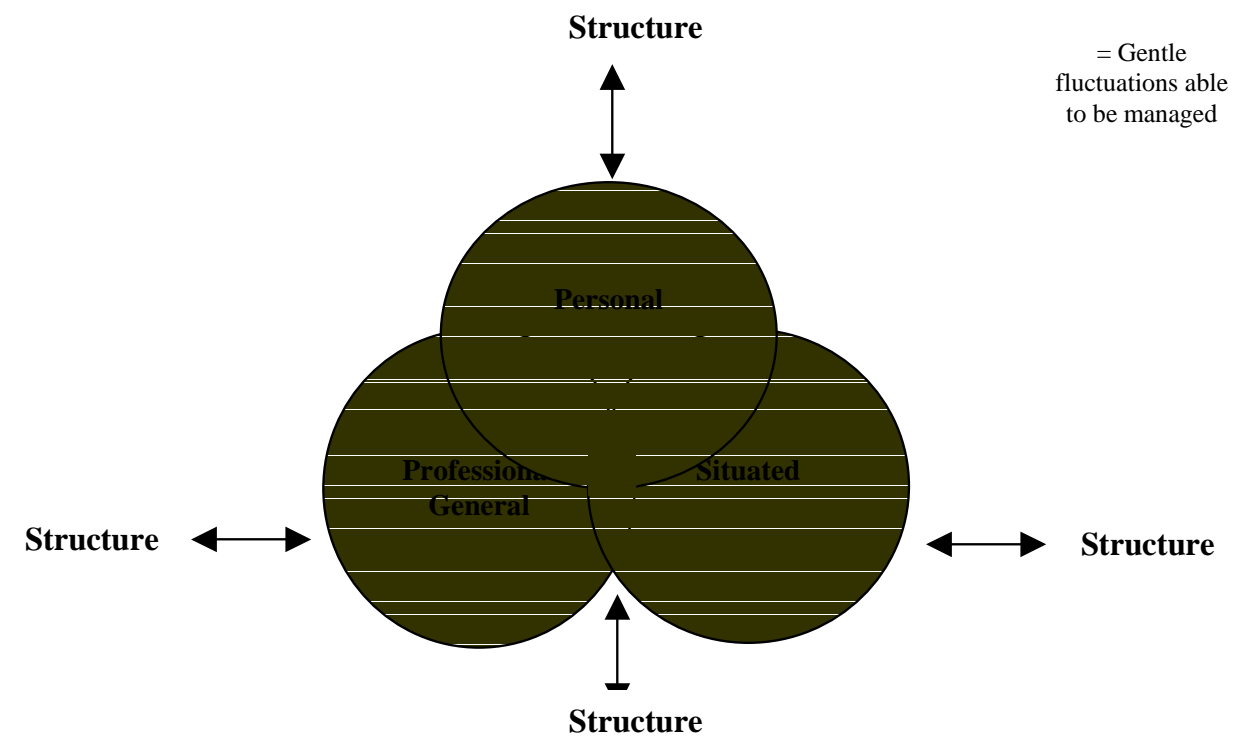

Figure 7.2 shows an identity that is stable, that is, the dimensions are being held in balance. Thus, although there would be mild fluctuation within and between these from time to time, no action would need to be taken unless stability is negative i.e. resulting in continuing ineffectiveness. However, when identity is unstable (Figures 7.3, 7.4 and 7.5) i.e. when one or more dimension is disturbed by internal or external events (e.g. personal crises, policy changes, pupil changes, school changes), then additional effort would have to be made by the individual in order to manage the imbalance.

Figure 7.3: Scenario 2 - one dominant dimension

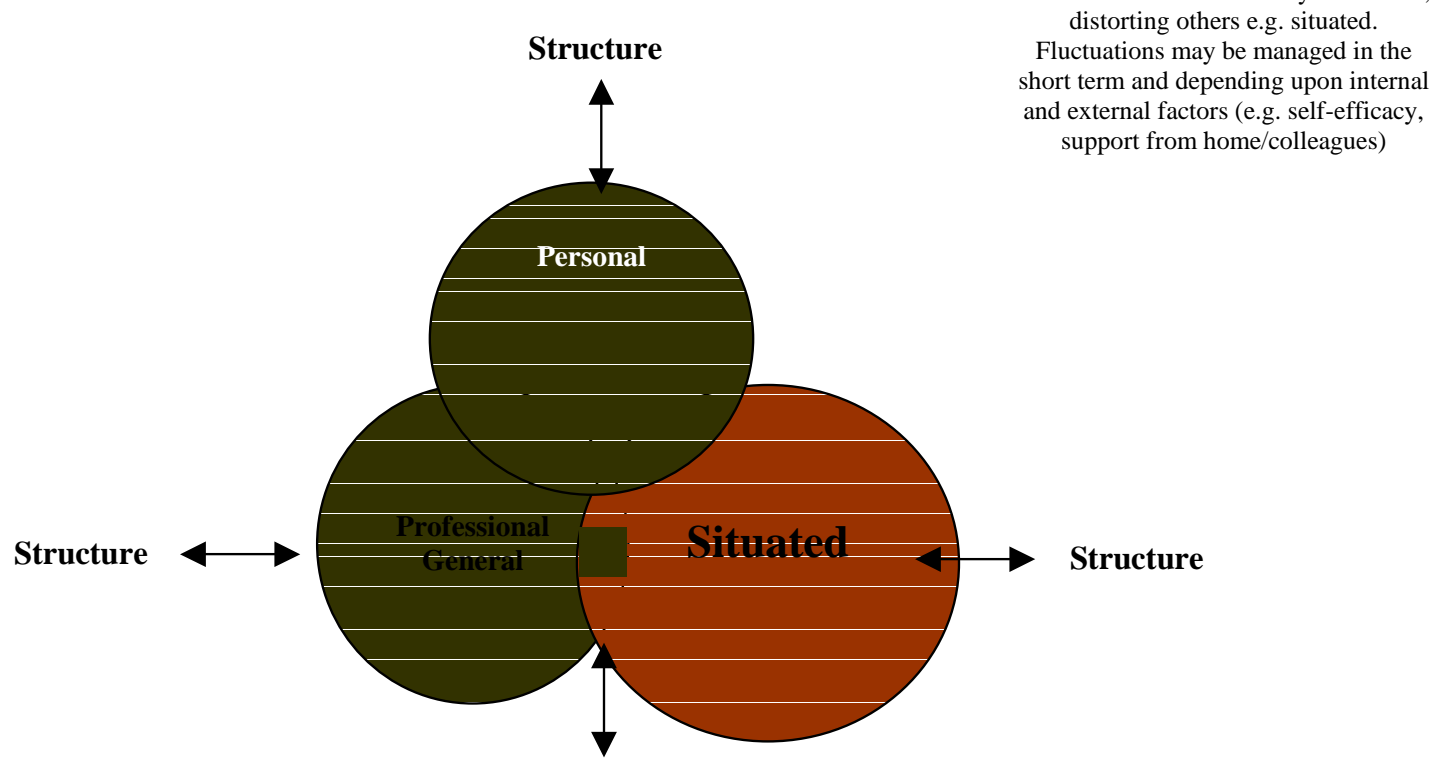

Structure 
Figure 7.4: Scenario 3 - two dominant dimensions

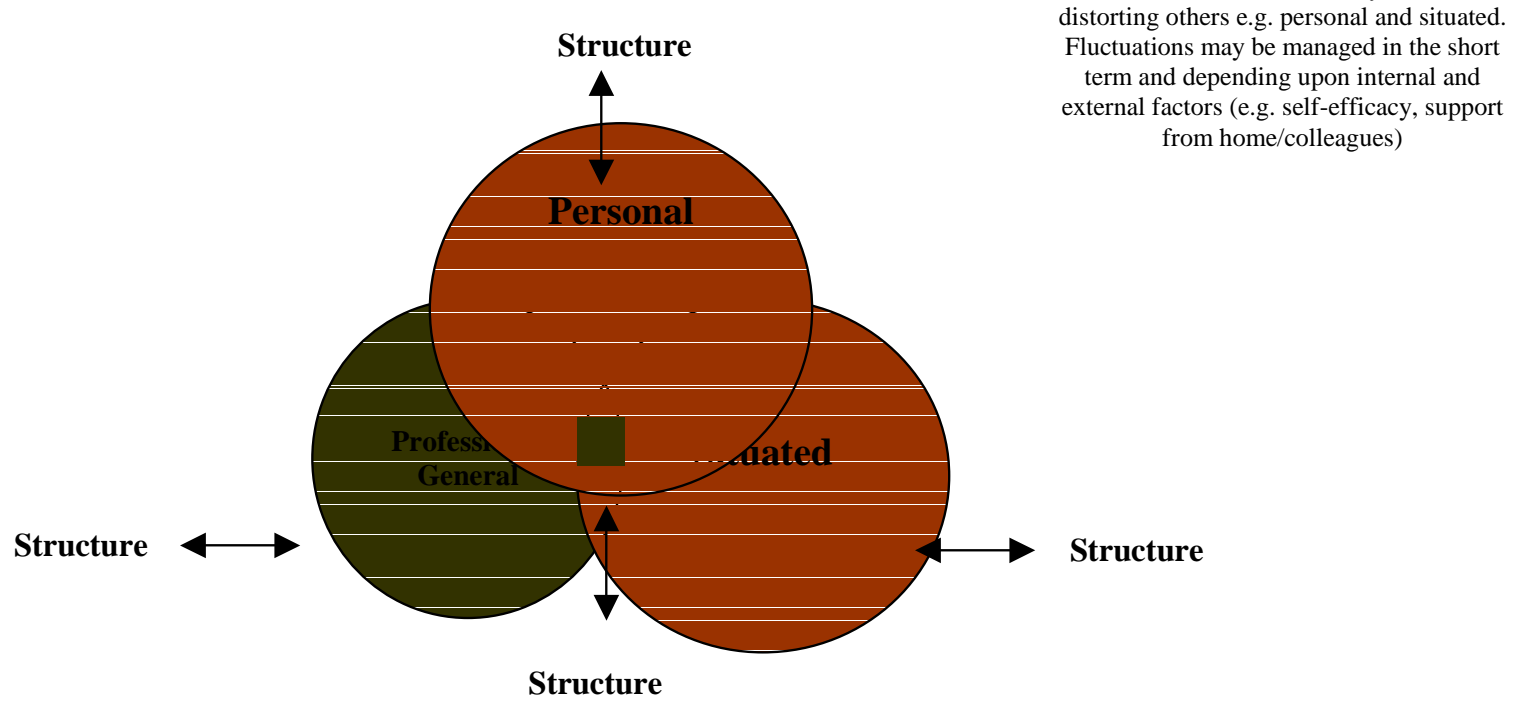

Figure 7.5: Scenario 4 - three conflicting dimensions
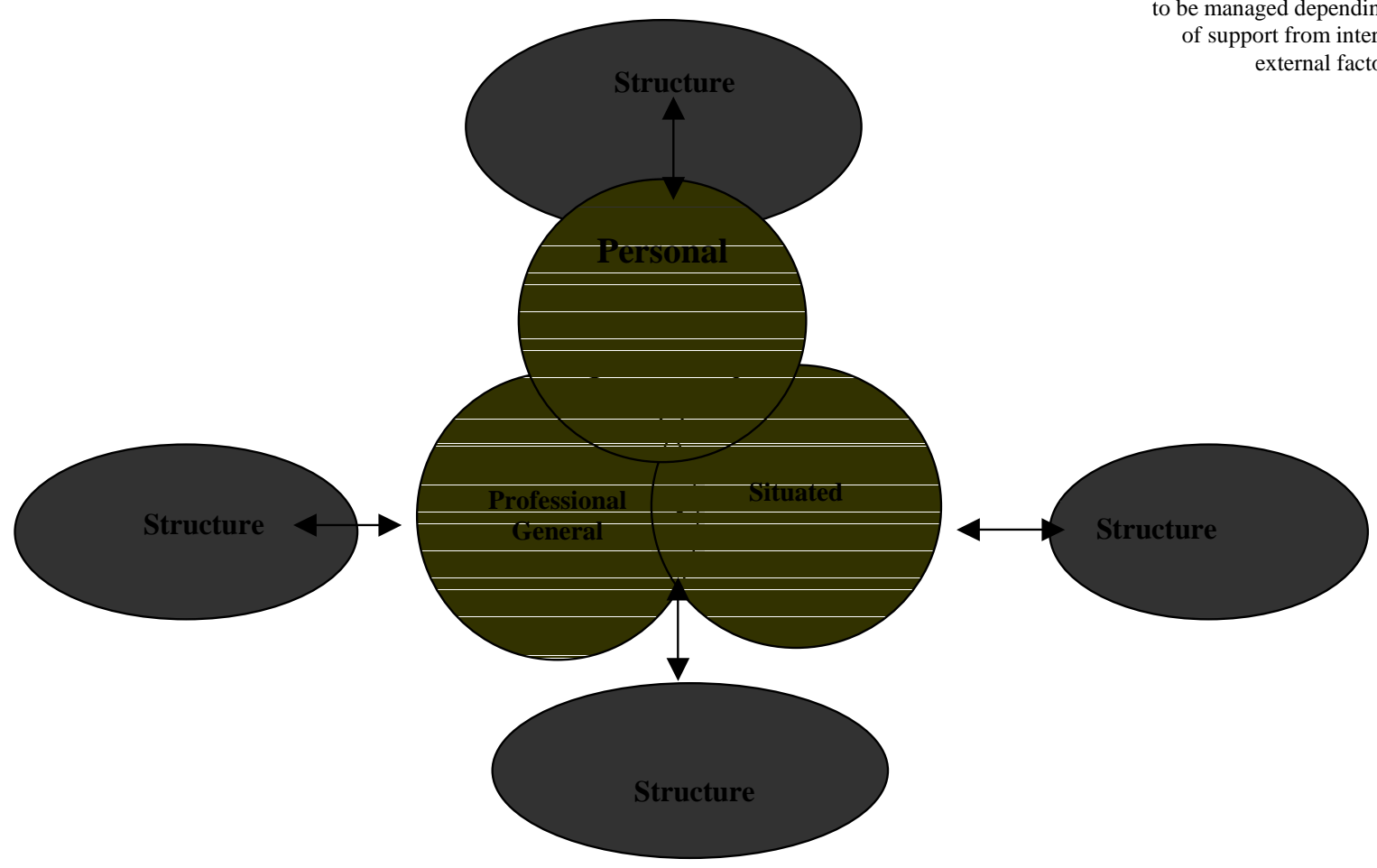

$=$ Extreme fluctuations able/not able to be managed depending on strength of support from internal and/or

We found a dynamic relationship between identity and agency (ones ability to pursue the goals that one values), commitment, resilience and effectiveness (both perceived and measured). Agency, in relation to each form of identity, is concerned with the i) fulfilment of each of the three dimensions, ii) their reconstruction where necessary, 
iii) the management of critical incidents and trends which may threaten them or which need to be managed, and iv) the extent to which people can live with contradictions and tensions within these various dimensions, and continue to be effective in their workplace i.e. the extent of their commitment and resilience.

\subsubsection{Strategic management}

In order to manage the balance (stability) or imbalance (instability) of identity, strategies were adopted, consciously or unconsciously, by teachers to deal with particular circumstances. Such management appeared to involve the conscious or unconscious use of one or a combination of a number of the following strategies:

i) Accommodating by adjusting one or more component to the needs of the others

ii) Tolerating the imbalance to the system caused by the new circumstances

iii) Subjugating one or more component to accommodate the needs of the other(s)

iv) $\quad \underline{\text { Resisting any change }}$

v) Re-evaluating the nature of the existing composite identity

vi) Accepting the imbalance positively

vii) Separating one part of work or life from another

viii) Engaging with one or more components with full commitment

ix) Re-focussing from one component to another

x) Adapting to the new situation in a positive way

Adopting these strategies was likely to affect existing identity. The impact upon motivation, self-efficacy, commitment, resilience, well-being and effectiveness related to a greater or lesser extent to a) whether the dominant dimension had to be managed over a short, medium or long term (e.g. unsatisfactory relationships in the classroom, staffroom or home); b) individual biography (i.e. the strength of their values and aspirations, their resilience/vulnerability to stress of different kinds, and physical health); c) personal and professional support (e.g. leadership, colleagues, friends, etc.); and d) sense of agency. 
The extent to which the Scenarios were managed depended in part upon the level of disturbance or fluctuation and in part upon the combination of internal influences (e.g. strength of personal values) and external influences (e.g. school leadership, teacherpupil relationships, pupil behaviour, colleague support, home circumstances). Teachers' sense of agency, well-being, resilience or vulnerability related to the degree to which these influences were perceived by them as being positive or negative.

\subsection{Findings}

Key characteristics of Scenarios and their influences on teachers' identities were identified. Teachers were grouped with other teachers on the basis of the degree of dominance of a particular influence (or combination of influences). Table 7.1 shows the number of teachers in each of the four Scenario groups:

Table 7.1: Number of teachers in each Scenario

\begin{tabular}{|c|c|c|c|c|c|}
\hline Scenario & Dimension & \multicolumn{3}{|l|}{ Sub-groups } & Total \\
\hline Scenario 1 & Dimensions in balance & & & & $102(35 \%)$ \\
\hline Scenario 2 & $\begin{array}{ll}\text { one } & \text { dominant } \\
\text { dimension } & \end{array}$ & $\begin{array}{l}\text { professional } \\
(\mathrm{N}=46)\end{array}$ & $\begin{array}{l}\text { situated } \\
(\mathrm{N}=57)\end{array}$ & $\begin{array}{l}\text { personal } \\
(\mathrm{N}=28)\end{array}$ & $131(44 \%)$ \\
\hline Scenario 3 & $\begin{array}{ll}\text { two } & \text { dominant } \\
\text { dimensions } & \end{array}$ & $\begin{array}{l}\text { Professional and } \\
\text { situated }(\mathrm{N}=15)\end{array}$ & $\begin{array}{l}\text { professional and } \\
\text { personal }(\mathrm{N}=16)\end{array}$ & $\begin{array}{l}\text { situated and } \\
\text { personal }(\mathrm{N}=13)\end{array}$ & $44(15 \%)$ \\
\hline Scenario 4 & $\begin{array}{ll}\text { three } & \text { dominant } \\
\text { dimensions } & \end{array}$ & & & & $18(6 \%)$ \\
\hline & & & & & 295 \\
\hline
\end{tabular}

Analyses of the key features of teachers' professional life phases, school context, perceived effectiveness, motivation and commitment and self-efficacy revealed dominant patterns which characterised each Scenario. Each Scenario contained teachers who were resilient (i.e. were sustaining their commitment) and those who were vulnerable (i.e. were sustaining their commitment despite the Scenario or not sustaining it). As in the professional life phase chapter (Chapter Five), key excerpts from teacher cameos, including a combination of data from the teacher questionnaire, teacher interviews, and pupil attainment data are used to illustrate key aspects of each Scenario group, highlighting patterns between various characteristics. Dominant characteristics of those teachers who were observed to be resilient and vulnerable are summarised below: 
Scenario $1(35 \%$ of $295, \mathrm{~N}=102)$ :

Dominant characteristics of group: Were more likely to be in the $4-23$ professional life phases, taught in FSM 1 and 2 schools, and were highly motivated, committed and self-efficacious

Resilient teachers (79\% of 102, N=81): had positive well-being and strong sense of agency

Vulnerable teachers $(21 \%$ of $102, \mathrm{~N}=21)$ : had negative well-being and mixed sense of agency

Scenario 2: $(44 \%$ of $295, \mathrm{~N}=131)$

Dominant characteristics of group: Were more likely to be in the 4-7 or 815 professional life phases, taught in FSM 2 schools, were highly motivated, committed and self-efficacious, and had negative well-being

Resilient teachers (65\% of 131, N=85): had a mixed sense of agency

Vulnerable teachers (35\% of 131, N=46): had a weak sense of agency

Scenario 3: (15\% of 295, N=44)

Dominant characteristics of group: Were more likely to be in the 4-7 or 2430 professional life phases, and had negative well-being

Resilient teachers ( $48 \%$ of $44, \mathrm{~N}=21$ ): tended to be highly motivated, committed and self-efficacious, and had a strong sense of agency

Vulnerable teachers (52\% of $44, \mathrm{~N}=23$ ): Were only in the $24-30$ professional life phase, were moderately motivated, committed and self-efficacious, and had a weak sense of agency

Scenario 4: $(6 \%$ of $295, \mathrm{~N}=18)$

Dominant characteristics of group: Were more likely to be in the 8-15 professional life phase, taught in FSM 3 and 4 schools, and had moderate/low self-efficacy

Resilient teachers $(17 \%$ of $18, \mathrm{~N}=3)$ : Taught in the secondary phase, were male, and were in the 24-30 professional life phase. They were moderately motivated and committed, and had a mixed sense of well-being and agency

Vulnerable teachers $(83 \%$ of $18, \mathrm{~N}=15)$ : Were female, had moderate/low motivation, but were highly committed. They had negative well-being and a weak sense of agency

\subsection{Scenario 1}

This group comprised approximately one-third $(35 \%, \mathrm{~N}=102)$ of the sample of 295 teachers. These teachers had experienced minor fluctuations in their professional, situated and/or personal lives but had been able to manage these so that no one dimension became dominant.

\subsubsection{Influences on teachers in Scenario one}

A total of 82 ( $80 \%$ of 102) teachers in Scenario one made comments regarding professional influences. The main positive influence mentioned by $43(52 \%)$ of the 82 teachers included additional responsibility in school, promotion, change in status/contract, and continuing professional development. 
The negative influences noted by 27 (33\%) of the 82 teachers were: policy changes, changing school, Ofsted, paperwork, and workload. Mixed responses were made by $12(15 \%$ of 82$)$ teachers.

A total of 101 (99\% of 102) teachers in Scenario one made comments regarding situated influences. Positive situated influences were reported by 54 (53\%) of the 102 teachers are included supportive leadership and colleagues, pupil relationships and behaviour, and teamwork. The negative influences mentioned by 41 (41\%) of the 102 teachers were: pupil behaviour, perceived lack of respect, school changing status, lack of support from Senior Management Team, inadequate discipline procedures, impact of school context, insufficient feedback on their performance. Six (6\% of 102) teachers gave mixed responses.

A total of $76(75 \%)$ of the 102 teachers in Scenario one made comments regarding personal influences. The positive personal influences referred to by 35 (46\% of 102) teachers were supportive family and friends, involvement in sports, becoming a parent, getting married, moving in with partner, coming from a similar background to the pupils/part of the community, having fewer commitments at home, improved health, and the benefit of religious belief. The negative influences mentioned by 28 (27\% of 102) teachers were: personal or family illness, bereavement, divorce or separation, menopause, young children or teenagers, no family support, and increased weight. Mixed responses were given by a minority of 13 (27\% of 102) teachers.

\subsubsection{Key characteristics of Scenario one}

Of the 102 teachers in this Scenario, the majority were female $(75 \%, N=77) .51$ of these teachers ( $66 \%$ of 77 ) were primary teachers and 26 (34\% of 77) were secondary teachers. When put in the context of the total sample, this represented nearly onethird of the total number of females $(32 \%)$ and $31 \%$ of the total number of primary teachers, compared to $34 \%(\mathrm{~N}=25)$ of the total number of males. Thus it seemed that proportionately there was no gender difference in likelihood of a balanced Scenario. The situation was similar when focusing on school phase, with $35 \%(\mathrm{~N}=59)$ of primary teachers, and $30 \%(\mathrm{~N}=43)$ of secondary teachers being in this group. Primary teachers made up over half (58\%) of the number of teachers in this Scenario. 
Over one-third of the total number of teachers in the 4-7 (35\%), 8-15 (34\%) and 16-23 (39\%) professional life phases were in this Scenario group. These were teachers who, based on an analysis of professional life phases, were characterised by their identity and positive efficacy in the classroom (4-7), were managing changes in their role and identity (8-15), or were dealing with work-life tensions which were potentially challenging to motivation, commitment and effectiveness. Therefore, it was less likely that new teachers or those approaching the latter phases of their careers would be in Scenario one. The largest proportion of teachers $(\mathrm{N}=34)$ in the Scenario taught in FSM 1 schools. This represented $45 \%$ of the total of FSM 1 teachers. The smallest proportion were teachers in FSM 3 schools $(\mathrm{N}=17)$ which represented one-quarter of the total number of FSM teachers.

Table 7.2: Summary of Scenario 1 characteristics

\begin{tabular}{|l|l|l|l|l|l|l|l|l|}
\hline Gender & N & $\%$ & $\begin{array}{l}\text { School } \\
\text { phase }\end{array}$ & N & $\%$ & FSM & N & $\%$ \\
\hline & & & & & & & & \\
\hline & & & & & & & & \\
\hline & & & & & & FSM 1 & 34 & 33 \\
\hline & & & & & & FSM 2 & 29 & 28 \\
\hline Female & 77 & 75 & Primary & 59 & 58 & FSM 3 & 17 & 17 \\
\hline Male & 25 & 25 & Secondary & 43 & 42 & FSM 4 & 22 & 22 \\
\hline Total & $\mathbf{1 0 2}$ & $\mathbf{1 0 0}$ & Total & $\mathbf{1 0 2}$ & $\mathbf{1 0 0}$ & Total & $\mathbf{1 0 2}$ & $\mathbf{1 0 0}$ \\
\hline
\end{tabular}

Over three-quarters $(77 \%, \mathrm{~N}=79)$ of the teachers in this group were highly motivated compared to only five (5\% of 102) teachers who said they had low levels of motivation.

Sometimes I wonder why I'm still here, teaching that is. I don't know why I get up and come in every morning... I don't enjoy it (James).

I don't know how you can turn up everyday if you're not motivated to do the job (Agatha). 


\section{Illustration of high motivation and commitment - Tom's Story}

Value-added: cohort 1 - mixed impact (--/0) / cohort 2 - above expectation (++) / cohort 3 - as expected (0)

Tom was 60 years old and had been teaching for 40 years, 33 years in a large primary school, with nearly 450 pupils on roll. The percentage of pupils eligible for FSM was below $8 \%$. In addition to being a Year 6 teacher, Tom was also deputy head and was retiring at the end of the school year 2004/5.

Tom, as part of the SMT, tried to influence the supportive school environment by appointing staff that would compliment current staff. Having worked in the school for 25 years, he had a clear overview of the staff and their personalities and strengths. He thought that he and the headteacher worked well together at supporting and leading the team, especially through times of change - e.g. new initiatives and policies.

Tom had always reported a high level of motivation, self-efficacy, commitment and job satisfaction and said that this was influenced by the developments seen in pupils' maturity and self-esteem in Year 6. By the end of Year 2 of the project, his job satisfaction was very high (R4 self rating) and his workline showed that he perceived his effectiveness as still on the increase. In R6, his motivation, commitment, job satisfaction and self-efficacy were all high. He felt that his motivation had stayed the same over the last three years due to positive feedback from parents, stable staff, and a lovely school.

Likewise, their commitment was more likely to be high $(88 \%, \mathrm{~N}=90)$, as was their level of self=efficacy $(74 \%, N=75)$.

I feel that I'm more committed and motivated than ever now that I have more time to spend on my work. Before, I had to split my time between work and children (Beth).

I love working with children now as much as I did when I first started teaching. I can't imagine doing anything else (Michael).

\subsubsection{Resilient teachers}

The majority of teachers who were experiencing a relatively balanced Scenario (79\% of $102 \mathrm{~N}=81$ ) were judged to have demonstrated resilience as a result of a cross-data cut analysis of professional life phase and possible trajectories. This meant that they were more likely to be positive regarding their well-being and the balance they managed to achieve between the pressures of work and home life. Of the 81 (79\%) teachers who commented on this, 69 (85\% of 81) reported a positive balance. These included 39 (57\% of 69 ) teachers who were making a conscious effort to manage and maintain a balance for the sake of their family and their health.

I have to think about when I'm going to spend time on work and when I'm going to spend time on family so that I don't wear myself down and become unable to spend time doing anything (Jacqueline). 
Seven teachers (9\% of 81 who responded) said that their work had a negative impact on their home life, finding it difficult to keep a balance with the needs of the family competing with their career and the remaining five ( $6 \%$ of 81$)$ teachers gave a mixed response.

$92 \%(\mathrm{~N}=82)$ of teachers were judged to have demonstrated a strong sense of agency during the project. In order to maintain a balance between the professional, situated and personal dimensions, these teachers were using one, or a combination of more than one, of the following strategies: accommodating, engaging or adapting.

\section{Illustration of strong agency - Ella's Story}

Value-added: cohort 1 - above expectations (++)

Ella was 26 years old and had been teaching for 4 years. She was Key Stage 3 coordinator as well as being a Year 9 maths teacher. Ella wanted to be Head of Department in the future. She became a teacher to improve the education of others (teacher questionnaire).

Ella taught in a larger than average secondary school with 1400 pupils on roll aged 11-18 years. The percentage of pupils entitled to FSM was between 9\% and 20\% (FSM2). Ella felt that the leadership within the department was very supportive and that the headteacher gave strong leadership. She said that this made her feel more effective as a teacher and encouraged her to follow her ambitions.

The remaining seven teachers ( $8 \%$ of 89 ) in this group demonstrated a weak sense of agency, in spite of maintaining a balance by managing the competing dimensions. They were either managing their situation by separating one part of their life from another or were subjugating one or more dimension to accommodate the needs of the other(s).

I try to keep my work stuff at work and my family life at home... you can't bring one to work and take the other home or how would you... I don't understand how you could cope (Michael).

I gave up the idea of going for promotion while my kids were young because I didn't think I would be able to manage both. It was self-preservation, but I feel I lost out a bit now (Janet).

This latter group of teachers were less proactive in their approach to dealing with short-term change, but did not let gentle fluctuations threaten their underlying motivation, commitment, self-efficacy and well-being. 


\subsubsection{Vulnerable teachers}

There were 21 (21\% of 102) teachers experiencing Scenario one who were thought to be vulnerable. Teachers in this group were less likely than their resilient colleagues to be positive regarding their well-being and the balance they managed to achieve between the pressures of work and home life.

I think I had a life until I got promoted, then it became a lot more difficult to keep home and work separate (Phyllis).

I don't go out in the week anymore and I'm often too tired at weekends to do much (Barry).

All the teachers in this group commented on this issue and ten (48\% of 21) teachers reported a negative sense of well-being, including comments on tensions between teacher and manager roles, reduced social life, difficulties in managing teacher, mother and wife roles.

Two teachers (10\% of 21 ) said that they had achieved a positive balance between work and home lives, one of whom said that, although the family came first, they had established a routine so that there was time for both. A further two (10\% of 21) teachers gave a mixed response.

We had to draw up a sort of contract so that we knew when things were happening and we could preserve the time together without work getting in the way (Kathleen).

It's not easy to find the energy to have a social life, but you'd start to resent work if you didn't make the effort (Shaun).

Equal numbers of teachers demonstrated strong and weak agency. Ten (48\% of 21) teachers were judged to have a strong sense of agency during the project and these teachers were adopting strategies that might, over a period of time, result in them being less vulnerable. These strategies included: re-evaluating (the nature of the existing composite identity), re-focusing (from one component to another), and accommodating (by adjusting one or more component to the needs of others). These strategies allowed these six teachers to deal with gentle fluctuations in their day-today lives. However, eleven teachers (52\% of 21) in this group demonstrated a weak 
sense of agency. They were either subjugating (one or more component to accommodate the needs of the other(s)) or accepting (the possibility of imbalance).

I've given up fighting against all the extra things we're expected to do. It's easier to keep quiet and get on with it! (Ricky).

It's a long time since I had any time to do anything except work... at least that's what it feels like (Sandy).

\subsubsection{Summary}

The main observations from this Scenario group are:

- Thirty-five \% of all teachers were in this Scenario.

- Primary school teachers made up over half of this group (58\%).

- The largest proportion of teachers were from FSM1/2 schools (62\%) and the smallest (38\%) from FSM 3/4 schools.

- Teachers in this group were more likely to be positive about their well-being and their work-life balance.

\subsection{Scenario 2 - one dominant dimension}

This Scenario comprised teachers where one of the three dimensions of identity dominates, distorting one or both of the other dimensions. It was likely that, in this situation, fluctuations could be managed in the short-term depending upon the level of teachers' motivation, commitment, self-efficacy, support from colleagues, leadership, etc. A total of $131(44 \%)$ of the 295 teachers were in this group.

\subsubsection{Influences on teachers in Scenario two}

There were a number of professional, situated and personal influences reported which distorted the two remaining dimensions and needed managing in the short-term.

\section{Professional dominant dimension}

This sub-group of teachers discussed professional influences as a dominant component in their lives and was made up of 46 teachers, $35 \%$ of the Scenario group. The positive professional influences mentioned by teachers included: promotion, taking on a new role in school, being career-oriented and having additional roles in the school. 
I feel very different about teaching since I was promoted... and it was a little unexpected which was nice (Sasha).

I've recently been shadowing the literacy coordinator so that I can take over her role soon. That's been a really good experience (Lilly).

\section{Illustration of dominant professional identity (-ve) - Jacqueline's Story}

Value-added: cohort 1 - mixed impact (0/-) / cohort 2 - as expected (0)

Jacqueline was 53 years old and had taught for 31 years. Jacqueline came from a teaching family. She was originally attracted to teaching because it 'gave an outlet for my creative side' and because of the opportunity 'to change things for the better through education'. Jacqueline was deputy head, a Year 6 teacher, and planning and assessment co-ordinator in an urban primary school of nearly 300 pupils. Twenty six per cent of pupils were from ethnic groups, of which Black Caribbean (8\%) and Black African $(5 \%)$ were the main groups.

Despite feeling positive about some aspects of her work, Jacqueline found that 'teaching has never been so hard' due to endless government initiatives and changes - 'we just get on top of something, we know what we're doing now, and then it's changed.' As a result, she did not have a strong sense of achievement - 'nothing is ever finished' which was impacting upon her job satisfaction and feeling of self-efficacy.

The negative influences noted were workload: paperwork, new initiatives, external policies, assessment and marking.

I've never known us have to do so much paperwork as we do at the moment. If there was one thing I would ask the government to change, it's the amount of paperwork which seems unnecessary (Adrian).

We have so much marking to do on top of everything else, and the kids want to know what they've got the next day (Anna).

\section{Situated dominant dimension}

This group was made up of 57 teachers, $44 \%$ of the total Scenario group. The positive situated influences mentioned by $34(60 \%)$ of the 57 teachers were: departmental and school support, personal support, motivated colleagues, pupil motivation, strong sense of teamwork, and improving behaviour management.

I love working here because everyone is so supportive and works together (Jeremy).

It gives me a great sense of satisfaction to see the children achieve more and more (Adrian). 
The negative influences reported by 44 (77\%) of the 57 teachers were: pupils' lack of respect and discipline, lack of parental responsibility, building work, no communication between the Senior Management Team and staff, and lack of support from leadership and colleagues.

Pupil behaviour is getting worse and worse and there's nothing that we can do and the head isn't really doing anything about it - it's so difficult to work like this (Patsy).

I had to set up my classroom in the hall for two terms, in fact it was nearly a year, and it was awful, people coming through all the time... I couldn't let them go outside in the rain, could I? (Margery).

\section{Personal dominant dimension}

This group was made up of 28 teachers, $21 \%$ of the Scenario group. The positive personal influences mentioned by $18(64 \%)$ of the 28 teachers were: new marriage, religious experience, and a new baby.

God is the only influence on my work and on my life... there's nothing else.

What else is there? (Alastair).

The negative influences noted by 14 (50\%) of the 28 teachers included: problems with or worries about their own children, divorce, and personal or family illness.

\section{Illustration of dominant personal identity (-ve) - Scarlett's Story}

Value-added: cohort 1 - as expected (0) / cohort 2 - as expected (0)

Scarlett was 27 years old and had taught for five years. She wanted to be a journalist on completion of her first degree, but because she could not afford the course, she undertook a teaching qualification and enjoyed it. She came from a teaching family who tried to change her mind on becoming a teacher, but she ignored their advice.

However, in her fifth year Scarlett regretted that her motivation had decreased because of her increased workload and ill health. She had nearly three months off school and believed that her illness was workrelated. Although Scarlett had previously wanted to go for a promotion as second in department, she now felt that she was 'not utterly convinced' that she wanted to stay in teaching. 


\subsubsection{Key characteristics of Scenario two}

Of the 131 teachers experiencing this Scenario, the majority were female (82\%, $\mathrm{N}=107)$. Of the total sample, this represents nearly a half of the total number of females $(45 \%)$, compared to $32 \%(\mathrm{~N}=24)$ of the total number of males. The proportions of primary and secondary teachers in this Scenario group were similar, with $44 \%(\mathrm{~N}=74)$ of all primary teachers, and $40 \%(\mathrm{~N}=57)$ of all secondary teachers being in this group, although primary teachers did make up over half $(56 \%)$ of the number of teachers in this Scenario.

Nearly half (48\%) of teachers in this group were in the 4-7 (identity and efficacy in the classroom) and 8-15 (managing changes in their role and identity) professional life phases. Over one-third of teachers $(35 \%, \mathrm{~N}=46)$ experiencing this Scenario taught in FSM 2 schools. This represented $48 \%$ of the total of FSM 2 teachers. Nearly onequarter $(23 \%, \mathrm{~N}=31)$ of teachers in this Scenario group taught in FSM 4 schools, which represented $42 \%$ of the total of FSM 4 teachers.

Table 7.3: Summary of Scenario 2 characteristics

\begin{tabular}{|l|l|l|l|l|l|l|l|l|}
\hline Gender & N & $\%$ & School phase & N & $\%$ & FSM & N & $\%$ \\
\hline & & & & & & & & \\
\hline & & & & & & & & \\
\hline & & & & & & FSM 1 & 27 & 21 \\
\hline Female & 107 & 82 & Primary & 74 & 56 & FSM 3 & 27 & 21 \\
\hline Male & 24 & 18 & Secondary & 57 & 44 & FSM 4 & 31 & 23 \\
\hline Total & $\mathbf{1 3 1}$ & $\mathbf{1 0 0}$ & Total & $\mathbf{1 3 1}$ & $\mathbf{1 0 0}$ & Total & $\mathbf{1 3 1}$ & $\mathbf{1 0 0}$ \\
\hline
\end{tabular}

As in Scenario 1, teachers in Scenario 2 tended to be highly motivated. Over twothirds $(69 \%, \mathrm{~N}=91)$ of the teachers in this group were highly motivated, whilst only ten $(8 \%)$ of 131 teachers said they had low levels of motivation.

I feel so motivated to be here, teaching, and I can't understand teachers who don't feel motivated by working with children (Samantha).

Motivation is something you either have or you don't and I do, lots of it (Charles). 


\section{Illustration of high motivation and commitment - Carmelle's Story}

Value-added: cohort 1 - mixed impact (-/0) / cohort 2 - as expected (0) / cohort 3 - as expected (0)

Carmelle was 51 years old and had been teaching for 29 years. In addition to being a Year 2 teacher in a village school, Carmelle was also the co-ordinator for maths, Assessment and Key Stage One. There were nearly 250 pupils on roll, drawn from a wide range of backgrounds. An average proportion of pupils were eligible for FSM (FSM2). She was originally attracted to teaching because of the opportunity to work with children and to help to make a difference in their lives.

Carmelle reported that the former headteacher was not supportive and the way he spoke to the staff was dreadful. Carmelle was not happy that the headteacher put pressure onto her and felt that this has had a negative impact on her commitment. The school had recently gained a headteacher which Carmelle saw as positive. She said that this allowed her to re-introduce play into the KS1 curriculum. She felt that good interaction with the leadership was very important and that this had been lacking with the previous Head.

Carmelle thought that the staff had worked well together and that the KS1 staff were particularly close, supporting and helping each other. She saw the positive staff relationship as having positively impacted on her motivation. Carmelle enjoyed working with children and had maintained a high level of commitment to teaching and to the pupils.

Likewise, their commitment was more likely to be high $(86 \%, \mathrm{~N}=113)$, as was their level of self-efficacy $(69 \%, \mathrm{~N}=90)$.

I always knew that I would be a committed teacher and not lose any of that commitment. It's the kind of person I am, I commit to everything I do (Liz).

I've always known that I was good in the classroom. The day I don't feel like that will be the day I give it up (Paul).

Teachers in this group were more likely to be negative regarding their well-being and management of work-life tensions. Of the 101 teachers who commented on this, over half $(52 \%, \mathrm{~N}=68)$ reported a negative balance.

I have no life outside of the school. That's why so many of us go to the pub after work, it's the only socialising we do (Shana).

I go home, cook something for everyone to eat, do some work and go to bed! (Samantha).

Other comments included: workload encroaching on home life, tiredness, and not having enough time for a personal life. 


\section{Illustration of negative well-being - Jenna's Story}

Value-added: cohort 1 - below expectation (--) / cohort 2 - below expectation (-) / cohort 3 - below expectation (-)

Jenna was 29 years old and had taught for seven years. She had been teaching at the school (FSM 2) for three years, having previously worked at two others. She was attracted to teaching because she saw teaching as a rewarding career and enjoyed working with children. Jenna was a Year 2 teacher and Art Co-ordinator in an urban primary school of around 200 pupils.

Jenna got married in Year 2 of the Project. She felt that her school life had benefited from aspects of her home life and vice versa. Nevertheless, Jenna found it hard at times to achieve a good work-life balance because of the amount of work that she had to do at home - 'the workload is a burden, but you do it because you love the job and you know that goes with it.' She suggested that it could sometimes get her down when it interfered with her home life 'although not to a great degree as my husband is very understanding.'

Less than one-quarter $(23 \%, \mathrm{~N}=30)$ of teachers in this Scenario reported positive wellbeing, many associating this with having a routine at work and supportive family.

You have to rely on others to help out, but you also have to make that extra bit of effort so that you have time with your family and they have time with you (Shannon).

I don't think that teaching affects my health or how I feel. I do know teachers who do feel like that though and I wonder why they carry on (Carole).

\subsubsection{Resilient teachers}

The majority of teachers in this Scenario $(\mathrm{N}=85,65 \%)$ were judged to be resilient. Although the largest proportion (26\%) of the 85 teachers were in the 8-15 professional life phase, there was a more even spread between the 4-7 (19\%), 16-23 (19\%) and 24$30(16 \%)$ than in the total Scenario 2 sample. Over half $(55 \%, \mathrm{~N}=47)$ of the resilient teachers in this Scenario were judged to have demonstrated a strong sense of agency during the project. 


\section{Illustration of strong sense of agency - Nancy's Story}

Value-added: cohort 1 - as expected ( 0 ) / cohort 2 - as expected ( 0$)$ / cohort 3 - below expectation (--)

Nancy was 27 years old and had been teaching for 6 years. She initially chose teaching as a career because she wanted to work with children. In addition to being a Year 6 class teacher, Nancy was also co-ordinator for humanities, music and assessment. Her next goal was to become Key Stage 2 manager. Nancy taught in a county primary school. There were over 250 pupils in the main school, plus a nursery. The children's attainment on entry was well below the nationally expected level for their age. The school was situated near a town and served the needs of families who had moved into this new town.

Nancy thought that the leadership of the headteacher and deputy head 'is fantastic'. Nancy called staff relationships 'excellent, very supportive, friendly, enthusiastic...'. This environment suited Nancy as she felt able to discuss issues and problems as a team without feeling exposed to potential criticism. In addition to successful and positive working relationships, the staff also socialised together and Nancy said that some of her best friends were at the school and that they had offered additional support when, last year, she was going through a difficult time in her personal life. At the beginning of the project, Nancy had just separated from her boyfriend, moved out, and had gone back to live with her parents. However, she started a new relationship a year later and has since become engaged and moved house.

In order to manage the dominant dimension being experienced, these teachers were using one, or a combination of more than one, of the following strategies: resisting (any change), re-evaluating (the nature of the existing composite identity) or separating (one part of work or life from another).

You have to learn to say 'no' to people, not just at work, but at home as well (Ted).

I've started to re-evaluate my life and want more from it so that I can enjoy it. If you don't like something, you have to learn to say 'no', like if pupils start to disrupt the class (Denis).

The remaining 45\% ( $\mathrm{N}=38)$ of teachers in Scenario 2 were showing a weak sense of agency, struggling to implement change and regain a balance. The analysis found that there were a number of teachers who were either a) resilient but had a weak sense of agency (as in this case), or b) vulnerable but demonstrated a strong sense of agency. In this Scenario, these teachers were subjugating (one or more dimension to accommodate the needs of the other(s)), accepting (the imbalance) or tolerating (the imbalance to the system caused by new circumstances). 


\subsubsection{Vulnerable teachers}

Just over one-third (35\%, $\mathrm{N}=46)$ of Scenario 2 teachers were judged to be vulnerable. These teachers followed the general trend of the Scenario group, the majority (54\%, $\mathrm{N}=25$ ) being in the 4-7 or 8-15 professional life phases. Likewise, the largest proportion of teachers taught in FSM 2 schools (43\%, N=20). There were fairly equal numbers of primary $(\mathrm{N}=24)$ and secondary $(\mathrm{N}=22)$ teachers, $14 \%$ and $15 \%$ of the overall primary and secondary sample respectively. The majority of vulnerable teachers in Scenario $2(76 \%, \mathrm{~N}=35)$ also demonstrated a weak sense of agency.

I know I shouldn't let my social life slide because of work but sometimes you have to focus on one thing at a time (Linda).

I'm sure it'll get better so - I hope it does anyway (Richie).

The main strategies adopted by this vulnerable group of teachers included: accepting (the imbalance), subjugating (one or more components to accommodate the needs of the others), or tolerating (the imbalance to the system caused by new circumstances). Ten of the 46 teachers (22\%) in this group demonstrated a strong sense of agency.

I'm quite an ambitious person so I have a career plan and I'm going to go out get the roles that I want so that I can go on to be a deputy head or a head in the next few years (Nicola).

They were either managing to accommodate (by adjusting one or more components to the needs of the others), re-focusing from one component to another), or adapting to the new situation in a positive way).

\subsubsection{Summary}

The main observations from this Scenario group were:

- $44 \%$ of all teachers experienced this Scenario.

- Most of these teachers were highly committed and self-efficacious.

- Teachers in this Scenario were more likely to be in the early-middle professional life phase (i.e. 4 - 15 years).

- The proportions of primary and secondary teachers in this group were similar. 
- As with Scenario one, the proportion of FSM 1/2 teachers was greater than that of FSM $3 / 4$ teachers (56\% and $44 \%$ respectively).

- Teachers in this group were more likely to experience a negative sense of well-being then those in Scenario one.

\subsection{Scenario 3 - two dominant dimensions}

This Scenario comprised teachers where two of the three dimensions of identity dominated, putting pressure on the other dimension. There were 44 (15\% of 295) teachers in this group

\subsubsection{Influences on teachers in Scenario three}

There were a number of professional, situated and personal influences reported by this group.

\section{Professional and situated dominant}

This group described teachers who discussed both professional and situated influences dominant in their lives. The group was made up of 15 (34\% of 44) teachers in total. The positive professional influences mentioned by seven ( $45 \%$ of 15$)$ teachers were related to ambition and career advancement.

I need to focus on my career at the moment so some other things are on the back burner for now (Charlie).

I'm looking for deputy head jobs at the moment - I feel I'm ready for the next step (George).

The negative influences noted by eight (55\% of 15) teachers were: unsuccessful promotion, and tensions between a management and teacher role.

I feel really disillusioned about not getting the job, especially as I'd been doing the job for a while (Rita).

The positive situated influences reported by eight (55\% of 15) teachers were: teamwork, support from leadership in school, staff morale, pupil motivation, pupil relationships and pupil self-esteem. 
I'm starting to see an improvement in the behaviour of the pupils in my class and I think other teachers are starting to see the same thing so something must be working (Danny).

The negative influences were mentioned by seven (45\% of 15) teachers and included: drop in school roll, lack of support from Senior Management Team, lack of teamwork, disruptive building work, pupils' lack of enthusiasm, challenging behaviour and disaffected attitude.

\section{Illustration of dominant professional (+ve) and situated dimensions (-ve) - Charlie's Story}

Value-added: cohort 2 - as expected ( 0 ) / cohort 3 - as expected ( 0 )

Charlie was 31 years old with 8 years teaching experience and some of that outside primary - in secondary and adult education. Yet he achieved his first primary headship in April 2003 - 'It's $m y$ first headship and I'm finding it really difficult'.

Because of the decrease in the school roll, Charlie felt stressed and was unhappy with the fact that his management role had distracted him from teaching. He described himself as being in the lowest point of his career. Charlie felt that there was 'no happy time whatsoever' in his personal life because of his worries at school. Nevertheless, he remained optimistic and confident that his morale and self-esteem would 'go up' in the future. Charlie believed that his promotion to Headship was a positive turning point in his career.

Despite the difficult situations in his current school, Charlie had demonstrated a high level of agency and remained highly motivated and committed in his job.

\section{Situated and personal dominant}

This Scenario describes teachers who identified situated and personal influences as dominant in their lives. This group was made up of 16 (36\% of 44) teachers in total. The positive situated influences mentioned by ten (63\% of 16) teachers were: support from Senior Management Team, feedback from them, a harmonious department, the challenges of the school context, and parental support.

I grew up in an area like this myself and I want to put something back (Isaac).

The various negative influences noted by six (37\% of 16) teachers included: perceptions of ritual humiliation of staff by school leadership, lack of communication and support, poor attitude of staff, confrontation and disrespect from pupils, deterioration of pupil behaviour, and new leadership. 
We all got on with the last Head and I'd known him for years, but the new

Head is different, young, lots of changes coming and he doesn't know how to communicate with anyone over 45 (Abbie).

The positive personal influence mentioned by two (13\% of 16) teachers was becoming a parent, whilst the negative influences reported by 14 (87\% 0f 16) teachers were: personal illness, illness of a partner or parent, bereavement, financial worries, and breakdown of a marriage.

When me and my husband split up, I started to come into work more and more to take my mind off everything and it really helped (Rene).

My father died a year ago and there have been a lot of problems with the estate which has taken a lot of time and been very upsetting (Isaac).

\section{Professional and personal dominant}

This group was made up of only 13 teachers in total. The main positive professional influence mentioned by nine (69\% of 13) teachers was having an additional responsibility in school.

It [additional responsibility] has definitely had an impact on the respect pupils' give me (Marcus).

I really enjoy my Head of Year role, the pastoral side the job. It's a different side of the job to class teaching (Salma).

The negative influences noted by four (31\% of 13$)$ teachers were: paperwork and additional roles in school which had interfered with teaching role, and in one case led to ill health.

I've had to take some time off because it got too much; the teaching, workload, marking and my management role (Margo).

The positive personal influences on this group of seven (54\% of 13) teachers were: supportive family, positive relationship issues, child getting married and child becoming a parent.

Our daughter had a baby six months ago and it's made us realise how much more there is to life. We enjoy being grandparents (Barry). 
The negative influences on six (46\% of 13) teachers were: bereavement, parental illness, personal illness, divorce, financial concerns, and child leaving home.

I still feel like a student, trying to pay loans off, and not being able to buy a house (Alison).

\section{Illustration of dominant professional (-ve) and personal dimensions (-ve) - George's Story}

Value-added: cohort 1 - as expected (0) / cohort 2 - below expectation (-)

George was 51 years old and had been teaching maths for 16 years in an urban fairly low socioeconomic status (FSM3) school of around 1000 pupils which had fairly low overall student attainment. He was a late entrant to teaching. He worked in the family business for 12 years after leaving school and went into teaching for its stability when he had a family.

George saw his beliefs and values about education as being different from those of SMT in his school He disapproved of the results-driven culture and had a low opinion of pupil behaviour in the school. His personal life had some degree of negative impact on his work as a teacher. He had two demanding teenage boys. He had struggled with work-life balance - 'I worked too hard years ago and went off with stress, (which) made me more aware of life-work balance.' - and had seen his job satisfaction decline - 'I never get up wanting to go to school.' George's father died in 2004, and, in addition to coping with his children, he had to spend extra time dealing with the estate. He had no ambition for promotion but wanted to stay in teaching for the rest of his working career.

\subsubsection{Key characteristics of teachers in Scenario three}

Of the 44 teachers experiencing this Scenario, the majority were female $(75 \%, N=33)$.

As a percentage of the total number of female teachers in the sample, this represents $14 \%$, compared to $15 \%(\mathrm{~N}=11)$ of the total number of males. Thus there was no gender difference in the proportion in this Scenario. In terms of school phase, secondary teachers made up over half $(59 \%)$ of the number of teachers in this Scenario. When examining the total sample of teachers, $11 \%(\mathrm{~N}=18)$ of primary teachers, and $18 \%(\mathrm{~N}=26)$ of secondary teachers were in this group.

Table 7.4: Summary of Scenario 3 characteristics

\begin{tabular}{|l|l|l|l|l|l|l|l|l|}
\hline Gender & N & $\%$ & School phase & N & $\%$ & FSM & N & $\%$ \\
\hline & & & & & & & & \\
\hline & & & & & & & & 25 \\
\hline & & & & & & FSM 1 & 11 & 32 \\
\hline & & & & & & FSM 2 & 14 & 20 \\
\hline Female & 33 & 75 & Primary & 18 & 41 & FSM 3 & 9 & 23 \\
\hline Male & 11 & 25 & Secondary & 26 & 59 & FSM 4 & 10 & $\mathbf{1 0 0}$ \\
\hline Total & $\mathbf{4 4}$ & $\mathbf{1 0 0}$ & Total & $\mathbf{4 4}$ & $\mathbf{1 0 0}$ & Total & $\mathbf{4 4}$ & \\
\hline
\end{tabular}


Over half $(61 \%, \mathrm{~N}=27)$ of the total number of teachers experiencing this Scenario were in the 4-7 (20\% of the total number of teachers in this phase) and $24-30$ (23\% of the total number in this phase) professional life phases. The largest single group of teachers $(\mathrm{N}=14)$ in the Scenario taught in FSM 2 schools. This represented $15 \%$ of the total of FSM 2 teachers. The percentage of FSM 1, 3 and 4 teachers in this group were $15 \%$ (14\% of the total FSM 1 teachers), 13\% (14\% of the total of FSM 3 teachers), and $14 \%$ (13\% of the total FSM 4 teachers) respectively. This suggests that teachers were fairly equally drawn from the different groups of schools.

Teachers in this group were more likely to be negative regarding their well-being and the balance they managed to achieve between work and home lives. Of the 19 teachers who commented on this issue, 31 (70\%) reported a negative balance, including: mention of tensions between teacher and manager roles, reduced social life, difficulties in managing teacher and home roles.

Work does hinder my home life because I end up working most weekends and several nights in the week. I have no energy to do other things (Margo).

Illustration of negative well-being - Serena's Story

Value-added: cohort 1 - as expected (0) / cohort 2 - below expectation (-) / cohort 3 - as expected (0)

Serena was 59 years old and had taught for 25 years, 20 in this school. She entered teaching because she felt that it was a good job for a female and that she liked to help people. It was also because it fitted in with her children needs. Serena was deputy head of maths and acting head of faculty in an urban low socio-economic status (FSM3) school of just over 1000 pupils.

Since September 2004, Serena had a new Head of Department who she was adjusting to - she applied for the job but was unsuccessful and had to go back to being 2nd in department having been acting HoD for a while. She felt very disappointed and used by the school and it made her feel as if she 'doesn't want to go the extra mile anymore'.

Serena had breast cancer and suffered from the death of her son. She considered leaving teaching as she only had two years to retirement. She appreciate the immense support she received from her husband and friends.

Five teachers (11\% of 19$)$ said that their work had a positive impact on their home life.

My husband says that I'm more enthusiastic about life now that I enjoy my work (Geraldine). 


\subsubsection{Resilient teachers}

Less than half $(48 \%, \mathrm{~N}=21)$ of the teachers in this Scenario were judged to be resilient. The school phase and gender split were consistent with the overall Scenario group sample. The largest proportion (43\% of 21) of teachers was in the 4-7 professional life phase. Teachers who were in Scenario 3 and demonstrated resilience tended to be highly motivated. Over three-quarters $(76 \%, \mathrm{~N}=16)$ of the teachers in this group were highly motivated, compared to only two teachers who said they had low levels of motivation.

I think my level of motivation is about a nine out of ten and has been for the last three years (Gary).

Likewise, their commitment was more likely to be high $(90 \%, \mathrm{~N}=19)$, as was their level of self-efficacy $(62 \%, \mathrm{~N}=13)$.

Commitment is part of being a teacher (Marvin).

It's taken me a while to believe it, but I am good at my job and I do make a difference... most days anyway! (Ivan).

Interestingly, this group of teachers were also more likely to sustain their levels of motivation, commitment and self-efficacy, with no teachers reporting any variation during the project.

\section{Illustration of high motivation and commitment - Jeremy's Story}

Value-added: cohort 1 - as expected (0)

Jeremy was 54 years old and had been teaching for 33 years. Despite his ill health in the final phase of his career, Jeremy had remained highly motivated and committed to teaching and to his pupils.

Jeremy was supported positively by the headteacher and the Local Authority and felt that they had helped him in making improvements to the maths department and the school more generally. He had recently been invited to be a member of the Senior Management Team. Jeremy found that staff morale had had the biggest positive impact on his work. Jeremy enjoyed teaching because of the success he had with the pupils and the department. Jeremy was committed to working with children from impoverished home environments and identified himself strongly with them, having high expectations.

Jeremy had been diagnosed with high blood pressure and had tried to cut down on the amount of time he spent working 'after hours'. However, he continued to work on Saturdays and even sometimes on Sundays. He remained highly motivated and committed to teaching. 
Strong sense of agency

The majority of these resilient teachers were also demonstrating a strong sense of agency. Eighty-six per cent $(\mathrm{N}=18)$ of the 21 teachers were judged to have demonstrated a strong sense of agency during the project. In order to maintain a balance between the professional, situated and/or personal dimensions, these teachers were using one, or a combination of more than one, of the following strategies:

- accommodating (by adjusting one or more component to the needs of the others);

- engaging (with one or more components with full commitment);

- $\quad$ separating (one part of work or life from another);

- $\quad$ adapting (to the new situation in a positive way);

- re-evaluating (the nature of the existing composite identity);

- re-focusing (from one component to another).

Although resilient, four (19\% of 21) teachers in this group demonstrated a weak sense of agency. They were either managing their situation by subjugating one or more dimensions to accommodate the needs of the other(s), tolerating the imbalance to the system caused by the new circumstances, or resisting any change.

\subsubsection{Vulnerable teachers}

Over half $(52 \%, \mathrm{~N}=23)$ of teachers in Scenario who were judged to be vulnerable or at risk. The school phase, FSM and gender patterns were consistent with the overall Scenario sample. Nine (39\% of 23) of the teachers were in the 24-30 professional life phase. Teachers who were in Scenario 3 and showed vulnerability were likely to have moderate motivation $(\mathrm{N}=16,70 \%)$. Only four ( $17 \%$ of 23$)$ teachers who said they had high levels of motivation.

My motivation is not as high as it was when I started teaching, not as confident either (James).

Likewise, their commitment was more likely to be moderate $(\mathrm{N}=17,74 \%)$, as was their level of self-efficacy $(\mathrm{N}=15,65 \%)$.

I'm not as confident that I make a difference anymore (Daisy). 
I'm more strongly committed to my family now, but still committed to teaching... You can be both (Calvin).

The majority $(74 \%, \mathrm{~N}=17)$ of teachers deemed to demonstrate vulnerability were also thought to demonstrate weak agency. These teachers were adopting strategies including:

- tolerating (the imbalance of the system caused by new circumstances);

- subjugating (one or more component to accommodate the needs of the other(s));

- resisting (any change); or

- separating (one part of work or life from another.

Six (26\% of 23) teachers in this group demonstrated a strong sense of agency. They were either accommodating (by adjusting one or more component to the needs of the others), or re-evaluating (the nature of the existing composite identity).

\subsubsection{Summary}

The main observations from this Scenario group were:

- $15 \%$ of all teachers experienced this Scenario.

- Secondary teachers made up over half of the numbers in this Scenario (59\%) and, as a proportion of the total number of teachers, represented $18 \%$ as against $11 \%$ primary.

- In terms of FSM, there was an even spread.

- Teachers in this group, unsurprisingly given the fluctuations, were more likely to be negative with regard to their well-being and work-life balance.

- Interestingly, this group of teachers were also more likely to sustain their levels of motivation, commitment and self-efficacy.

- Fewer than half of the teachers in this Scenario were judged to be resilient $(48 \%)$ and over half (52\%) were judged to be vulnerable. 


\subsection{Scenario 4 - three conflicting dimensions}

This Scenario comprised teachers where all three of the dimension (professional, situated and personal) were conflicting, causing extreme fluctuations in teacher identity. There were 18 (6\% of 295) teachers in this Scenario group.

\subsubsection{Influences on teachers in Scenario four}

Unlike the previous groups, Scenario 4 involved extreme fluctuations which may or may not be manageable depending on the strength of support from internal and external factors, and may result in the need for longer-term management.

All 18 teachers in Scenario 4 made comments regarding professional influences. The positive professional influences mentioned by six (33\% of 18) teachers included career advancement and having additional roles in school. The negative influences noted by 12 (66\% of 18) teachers were pressures from DfES, marking, workload, planning and new initiatives.

A total of 16 (89\% of 18) teachers in Scenario 4 made comments regarding situated influences. The positive situated influences for four (25\% of 16) teachers were support from, improving pupil behaviour, small class sizes, approachable staff, settled staff, personal support, positive pupil relationships, and support and commitment from staff. The negative influences noted by nine (56\% of 16) teachers included: pupil absence, challenging class, poor pupil behaviour, lack of recognition from leadership, impact of school context, pupil motivation.

A total of 15 (83\% of 18$)$ teachers in Scenario one made comments regarding professional influences. The positive personal influences reported by six (40\% of 15) teachers included: supportive partner, having no children, and involvement in leisure activities. The negative influences reported by seven (47\% of 15$)$ teachers included: being a single parent, problems with own children, redundancy of partner, personal illness, carer for parents, living with parents, and becoming a parent. 


\subsubsection{Key characteristics of teachers in Scenario four}

Of the 18 teachers in this Scenario group, two-thirds were female $(66 \%, \mathrm{~N}=12)$. However, when put in the context of the total sample, this represented only one per cent of the total number of females, compared to eight $\%(\mathrm{~N}=6)$ of the total number of males. The proportion of primary and secondary schools in this Scenario were fairly equal, with only five per cent $(\mathrm{N}=8)$ of all primary teachers, and only seven per cent $(\mathrm{N}=10)$ of all secondary teachers being in this group.

Table 7.5: Summary of Scenario 4 characteristics

\begin{tabular}{|l|l|l|l|l|l|l|l|l|}
\hline Gender & N & $\%$ & School phase & N & $\%$ & FSM & N & $\%$ \\
\hline & & & & & & & & \\
\hline & & & & & & & & \\
\hline & & & & & & FSM 1 & 1 & 6 \\
\hline Female & 12 & 67 & Primary & 8 & 34 & FSM 3 & 5 & 22 \\
\hline Male & 6 & 33 & Secondary & 10 & 66 & FSM 4 & 8 & 28 \\
\hline Total & $\mathbf{1 8}$ & $\mathbf{1 0 0}$ & Total & $\mathbf{1 8}$ & $\mathbf{1 0 0}$ & Total & $\mathbf{1 8}$ & 44 \\
\hline
\end{tabular}

Over one-third (39\%) of the 18 teachers in this Scenario group were in the 8-15 professional life phase. Nearly three-quarters $(72 \%, \mathrm{~N}=13)$ of the teachers taught in lower socio-economic contexts (FSM 3 and 4) schools. This represented nine per cent of the total of FSM 3 and 4 teachers in the sample, compared to four per cent of the total number of FSM 1 and 2 teachers. This suggests that the experience of conflicting pressures may be greater in more challenging contexts. An example of a teacher experiencing these conflicts is Iva (illustrated below) who, in spite of working in a school in challenging circumstances, manages to remain committed to teaching.

\section{Illustration of Scenario 4 - Iva's story}

Value-added: cohort 1 - mixed impact (--/-)/ cohort 2 - as expected $(0)$

Iva was in her 40s and had taught for nearly 25 years. She was a Year 6 teacher in an urban moderate socio-economic status (FSM3) primary school of 255 pupils. She was Assistant Headteacher and maths Co-ordinator. Iva had a difficult boy in her class in Year 1 of the Project, who played a 'dynamic' role in class. She was very dissatisfied with the amount of time she gave to behaviour management.

Iva felt that policies, either internally or externally developed, had negative influence on her work, her effectiveness and her values. This was particularly the case in her early career phase. But she added that her attitude towards policies had changed. Seven years ago Irene had thought about leaving teaching because she felt that she had had enough with the national policy overload. But her husband had been made redundant and she could not afford to give up her job. 
Iva felt that her work encroached into her personal time. She wanted to spend more time looking after her four children, but paperwork at home had taken time away from her own family and she felt guilty about this. Iva's health had suffered since Year 1 of the Project and she was on anti-depressant tablets. This was a major consequence of the pace and weight of her job, particularly the workload accrued from her multiple roles.

Iva felt that her drive, enthusiasm and motivation had decreased over the years as 'the job has become harder over the course of the year' and the 'pressures are too great.' She had spoken to the head about relinquishing her responsibilities as assistant head.

\subsubsection{Resilient teachers}

Only three $(17 \%)$ of the 18 teachers in this Scenario had demonstrated resilience during the project. All three of these teachers taught in secondary schools and were male teachers. Two of the teachers were in 24-30 professional life phase, whilst one teacher had been teaching for 8-15 years. Two taught in FSM 4 schools, whilst the remaining teacher worked in an FSM 2 school.

Teachers who were in Scenario 4 and demonstrated resilience had moderate (medium) levels of motivation.

I still feel motivated, but I wouldn't say I was highly motivated, it's just not that high (Jerome).

Two of these teachers reported positive feelings of well-being, compared to one teacher who said that he was finding it very difficult to find a balance between home and school.

I don't have any problems with work-life balance, I manage (Don).

\section{Illustration of positive well-being - Seth's Story}

Value-added: cohort 3 - as expected (0)

Seth was 47 years old and had been teaching for 23 years. Seth was primarily attracted to teaching by the prospect of working with young people and 'being to do something measurably worthwhile' (teacher questionnaire). In addition to being An English teacher, Seth was also the Deputy. Seth taught in a mixed comprehensive school with 500 pupils on roll. More than $50 \%$ of pupils were eligible for free school meals (FSM4).

Seth says that he had a 'very effective Head of Department' who did not give help to staff in a judgemental way (R3 teacher interview). He felt that the new headteacher had a big impact, although his workload as Deputy Head had increased. Seth named staff morale and team spirit as having the biggest positive impact on his work as a teacher (teacher questionnaire). He felt that there was a sense of humour in the English department and that people shared and did not feel afraid to ask for help. 
In addition to the positive working environment, Seth had a very supportive family. He had a daughter at university who was helping him take a group of pupils to Brussels. He also mentioned having good friends and being involved in several leisure activities.

Two of the teachers had a strong sense of agency and were 'accommodating' by adjusting one or more component to the needs of the others. The remaining teacher had a weak sense of agency and had adopted a 'subjugating' strategy.

\subsubsection{Vulnerable teachers}

The majority of teachers $(\mathrm{N}=15,83 \%)$ experiencing three conflicting dimensions were judged to be vulnerable or at risk. Six (40\% of 15) teachers were in the 8-15 professional life phase and 11 (73\% of 15) teachers taught in FSM 3 and 4 schools. The majority $(\mathrm{N}=12,80 \%)$ were female teachers.

This group of teachers showed vulnerability were likely have moderate - low motivation $(67 \%, \mathrm{~N}=10)$. Only two (13\% of 15$)$ teachers who said they had high levels of motivation:

I feel ok. Ok about my motivation, commitment, and job satisfaction, but that's it (Deborah).

I don't think I feel as effective as I did when I was younger, but I'm still committed to the children and that's the hardest thing to hold on to (Hannah).

Surprisingly, their commitment was more likely to be high $(67 \%, \mathrm{~N}=10)$.

Eight of the ten $(80 \%)$ teachers who commented on this issue, reported negative feelings of well-being and negative work-life balance.

I don't think I can carry on with this much stress for much longer, it can't be good for my health (LeAnn).

Some people start drowning in paperwork, but it's a matter of doing what you can do. I think it mostly affects teachers who trained a long time ago and can't adapt to new things (Deborah).

Two teachers said that they had achieved a positive balance between work and home lives. 
Four $(40 \%)$ teachers were judged to have a strong sense of agency during the project and these teachers were adopting strategies that might, over a period of time, result in them being less vulnerable.

I've felt quite depressed by my job in the past, but I remembered how much I used to love it when I got a great class and I've turned my approach around (LeAnn).

These strategies included re-evaluating (the nature of the existing composite identity), re-focusing (from one component to another), and accommodating (by adjusting one or more component to the needs of others). Eleven teachers in this group demonstrated a weak sense of agency.

I don't think I can fight anymore. Everything is set against you - policy, pensions, salary, pupils and parents (Nigel).

They were using a wider range of strategies in order to cope with the three dominant dimensions they were experiencing, including:

- subjugating (one or more component to accommodate the needs of the other(s));

- tolerating (the imbalance to the system caused by the new circumstances);

- resisting (any change); and,

- $\quad$ separating (one part of work or life from another).

\subsubsection{Summary}

The main observations for this group were:

- Only a small minority of teachers experienced this Scenario (6\%).

- In this Scenario, all of the dimensions were in flux and this caused extreme difficulties.

- The key influences in personal, situated and professional lives were overwhelmingly negative e.g. workload, leadership, pupil behaviour, family responsibilities and personal ill-health. 
- There were more FSM 3/4 teachers than others who were experiencing this Scenario (13 as against 5). This represented $9 \%$ of the total of FSM 3/4 teachers as against $4 \%$ of the total of FSM $1 / 2$ teachers.

- The majority of teachers in this Scenario were judged to be vulnerable or at risk.

- Teachers in Scenario 4 were more likely to be less motivated.

- They had to use a wide range of strategies in order to cope with the three dominant dimensions they were experiencing.

\subsection{The interactive nature of identity Scenarios}

The analysis of teachers' identities and Scenarios enabled the plotting of changes to Scenarios over time. Two groups of teachers were identified: a) those who moved to a different identity Scenario; and b) those who moved from one sub-group to another within the same Scenario. These transitions were recorded for each teacher and revealed the interactive nature of teachers' identities.

\subsection{Transitions between identity Scenarios}

The transitions observed during the project supported the key influences and characteristics determined at the beginning of the analysis. All teachers experiencing a transition between Scenarios had undergone a change in their professional, situated and/or personal dimensions which resulted in movement to a new Scenario. A summary of the transitions that occurred to teachers participating in the project is given below.

\subsubsection{Transition to Scenario 1}

Of the 102 teachers who were in Scenario one at the end of the project, only 29 (28\%) had not been in this group for the duration of the project. Of those, 23 (79\% of 29) had experienced one Scenario transition, the majority of which $(\mathrm{N}=22)$ were from Scenario two (one dominant dimension). 
The remaining six teachers ( $21 \%$ of 29 ) had experienced two Scenario transitions. All of these teachers had experienced Scenario two at some point during the project, with two teachers having been in Scenario one at the beginning of the project. Two teachers had experienced two dominant dimensions (Scenario 3) during the second year of the project.

When asked which Scenario they would put themselves in, all teachers judged to be in this group by the research team, identified themselves in this group, suggesting strong agreement with the researcher judgement.

\subsubsection{Transition to Scenario 2}

Of the 131 Scenario 2 teachers, less than one-quarter $(19 \%, \mathrm{~N}=25)$ had not been in this group for the duration of the project. Of these, 16 (64\% of 25) had experienced one Scenario transition, the majority of which $(\mathrm{N}=14)$ were from Scenario 1 (no dominant dimensions).

The remaining nine teachers had experienced two Scenario transitions. Two-thirds ( $N=6,66 \%)$ had experienced Scenario 2 during the first year of the project, and Scenario 1 in the second year of the project. The final three teachers had all experienced two dominant dimensions (Scenario 3) at some point during the project.

When asked which Scenario they would put themselves in, 122 (93\% of 131) teachers judged to be in this group by the research team verified that judgement. Eight (6\% of 131) teachers perceived themselves to be in Scenario 1, but later went on to discuss one dimension as dominant, and one (1\% of 131) teacher placed themselves in Scenario 3.

\subsubsection{Transition to Scenario 3}

Of the 44 Scenario 3 teachers, $22(50 \%)$ had been in this group for the duration of the project. Of those that had been through a Scenario transition, 18 ( $82 \%$ of 22) teachers had experienced one Scenario transition, the majority of which $(\mathrm{N}=10)$ were from Scenario 2 (one dominant dimension). 
The remaining four teachers had experienced two Scenario transitions. Two of these teachers had experienced one dominant dimension in the first year of the project; one had moved to Scenario 1 (in balance) in year 2 and the other to Scenario 4 (three dominant dimensions). Two teachers had experienced two dominant dimensions in Year 1 of the project, moved into Scenario 1 (in balance) and back again.

When asked which Scenario they would put themselves in, the vast majority $(\mathrm{N}=39$, $89 \%$ of 44 ) of teachers judged to be in this group by the research team, identified themselves in this group. The remaining five (11\% of 44) teachers perceived themselves to be in Scenario 1 (in balance).

\subsubsection{Transition to Scenario 4}

Of the 18 Scenario 4 teachers, only two (11\% of 18) had not been in this group for the duration of the project. Both of those had experienced a single Scenario transition from Scenario 2 (one dominant dimension).

When asked in which Scenario they would put themselves, all teachers judged to be in this group by the research team, identified themselves in this group, except one who perceived herself to be experiencing one dominant dimension.

\subsection{Transitions within identity Scenarios}

A group of 21 teachers (17 teachers in Scenario two and four teacher in Scenario three) were identified whose professional, situated and/or personal dimensions had changed in dominance as a result of work or life related events, but who remained in the same Scenario group in spite of this.

The majority of these teachers $(\mathrm{N}=17,81 \%$ of 21$)$ experienced one dominant dimension (Scenario 2), but, during the project, went through a transition within this Scenario between the professional and situated, situated and personal or professional and personal dimensions. Four (19\% of the 21) teachers experienced two dominant dimensions (Scenario three), but during the project, experienced a shift in the dominance of at least one of the dimensions. 


\subsection{Conclusion}

The analysis of teachers' identities found they comprised three dimensions that interacted to form a composite of teacher identity. These dimensions, individually or in combination, became dominant as events occurred in teachers' work and lives which had a professional, situated and/or personal emphasis. Based on the interaction between these dimensions, teachers experienced one of four Scenarios (based on the dominance of the dimension(s)) and adopted one or a combination of a number of strategies in order to address the (im)balance. The analyses also revealed that the interaction between these dimensions contributed to teachers' sense of commitment (manifestation of belief and motivation), agency (ability/resolve to pursue one's own goals), well-being (state of feeling happy), and resilience (the ability of an individual to withstand or recover quickly from difficult conditions related to self-efficacy).

Whilst individual teacher's experience can be dominated (to varying degrees) in terms of professional, situated and personal influences, there are also a number of factors that either 'support' or put additional 'pressure' on teachers. These factors play a significant role in how they manage variations in their work and lives and, subsequently, how these variations impact on their professional identity. The analyses also revealed that there were associations between teachers' resilience and relative effectiveness. For example, teachers who were judged to have demonstrated resilience during the project were more likely to have pupil value-added results of 'above expectations' or 'as expected'. Likewise, those teachers who were thought to have demonstrated a lack of resilience (or vulnerability) were more likely to have pupil value-added results of 'below expectations' or 'as expected'. There were, of course, some exceptions to this. This was the case for Nancy who, despite being in Scenario 2, being resilient, and having a strong sense of agency, had value-added results which were below expectation for cohort 3 of the study.

The evidence also supports the claim that teacher identities may change over time as a result of different experiences and school contexts. Although Scenarios themselves cannot be attributed to specific professional life phases, there are particular points when certain professional and personal events are more likely to occur, e.g. starting a family (4-7 and 8-15), taking on additional responsibility (4-7, 8-15 and 16-23), etc. 
These events can be paralleled by situated factors such as disruptive pupil behaviour or change of leadership. This has led to the understanding that identities are not, as earlier literature suggests, either intrinsically stable or intrinsically fragmented. Rather, teacher identities may be more, or less, stable and more or less fragmented at different times and in different ways according to the impact of personal, professional and situational factors or a combination of these and the capacities of teachers to manage the different Scenarios which they experience.

The vast majority of teachers in the study ( $79 \%$ of $295, \mathrm{~N}=233$ ) were experiencing either Scenario one (relative balance) or Scenario two (one dominant dimension). Whereas only $21 \%(\mathrm{~N}=62)$ of the 295 teachers were experiencing Scenario 3 or 4. Teachers in Scenarios 1 and 2 were more likely to be primary teachers (58\% of 233, $\mathrm{N}=135$ ), whereas in Scenario three, teachers were more likely to teach secondary phase (59\% of 44, $\mathrm{N}=26)$. Teachers in Scenario one were also more likely to teach in FSM 1 and 2 schools (62\% of 133, N=144). This was also the case for those teachers in Scenario two (56\% of 131, N=73). Conversely, teachers in Scenario four were more likely to teach in FSM 3/4 schools $(\mathrm{N}=13,72 \%$ of 18$)$.

Unsurprisingly, a higher proportion of teachers in Scenario one was positive about their well-being ( $\mathrm{N}=72,73 \%$ of 98 who commented). This was not the case for teachers in Scenario two, who found it more difficult to maintain a healthy work-life balance and felt negative ( $\mathrm{N}=101,77 \%$ of 131) about their well-being. These Scenario two teachers were also more likely to experience a negative sense of wellbeing than those in Scenario one.

The main observations in relation to resilience and vulnerability were:

- resilient teachers in all Scenarios (except Scenario 4) had high motivation, high commitment, and high self-efficacy;

- the percentage of teachers in FSM 4 who were resilient (84\%) was higher than the percentage of teachers in FSM 3 who were resilient (58\%). 
- resilient teachers were more likely to have strong or mixed (i.e. demonstrated both strong and weal agency during project) sense of agency, whereas vulnerable teachers were more likely to have weak sense of agency;

- vulnerable teachers' levels of motivation and self-efficacy decreased as the number of dominant dimensions increased;

- vulnerable teachers were likely to have negative well-being;

The key factors which contributed positively among the $198(67 \%)$ of teachers' with a positive sense of agency, resilience and commitment in all Scenarios were:
i) School/departmental leadership
ii) Supportive colleagues
iii) Family

Key negative factors among the 97 (33\%) of teachers judged to be 'vulnerable' were:
i) Pupil behaviour
ii) Workload
$(70 \%)$

The analysis of teacher identities has highlighted certain elements of work and life that can either help or hinder the ongoing process of identity construction. These elements include teachers' professional knowledge, their personal experience, the 'micro-politics' of the school setting, and wider socio-cultural contexts, and can give rise to the development of different positive or negative, stable or unstable identities.

Interplay between these different elements is clearly evident (Part Four) showing how the individual teacher draws on a variety of professional, situated and personal factors for identity construction. While, in some respects, these are integrated into a coherent sense of self, in other respects this does not happen and tensions emerge with identity that are necessarily resolved and may appear to be contradictory.

The next part of the report (Part 4) examines the associations between professional life phases and teacher identities, teachers' capacities to sustain their commitment and pupil attainment. 


\section{PART FOUR \\ CHAPTER EIGHT: \\ COMMITMENT AND RESILIENCE - HOW TEACHERS \\ SUSTAIN THEIR EFFECTIVENESS}

Hypothesis 4: Commitment and resilience are key factors in establishing and sustaining teachers' effectiveness.

\subsection{Introduction}

The previous chapters which reported the VITAE findings on teacher professional life phases and identities showed clearly that teachers who sustained positive trajectories were those who remained committed and who sustained their commitment i.e. were resilient. They were also more likely to be those who perceived they were effective in their workplace achievements and were more likely to be effective in promoting pupil progress. Drawing upon pupil value added attainment data, professional life phase and teacher identities' data presented in the previous chapters, this chapter focuses upon the influences upon these which support or do not support teachers in sustaining their commitment and resilience. It establishes relationships between variations in commitment and effectiveness as defined by pupil attainment measures. This chapter is divided into three parts: i) early commitment; VITAE teachers' motivations for teaching; ii) variations in the commitment of the VITAE teachers; mediating influences; iii) commitment and resilience; variations in VITAE teachers' effectiveness.

\subsection{Early Commitment: VITAE Teachers' Motivation for Teaching}

Teachers' initial commitment is closely associated with their motivation to enter the teaching profession. However, as this research shows, their motivation to remain in the job can be affected by a number of professional, situated and personal factors which impact upon and thus mediate their capacity to sustain commitment (i.e. be resilient). 
Those who select teaching are frequently influenced in their career choice by family members and by significant teachers in their own schooling. While some variations occur over time, these basic themes emerge even in the many studies of the teaching career choice (Andrews, 1983; Hutchinson and Johnson, 1993-94; Jantzen, 1981; Lortie, 1975; Weiner et al, 1993; Wong, 1994; Wood, 1978; Zimpher, 1989).

Research by Dinham and Scott (2000) conducted with over 4000 teachers in five countries as part of the 'Teacher 2000' Project, found that teachers were motivated intrinsically by:

- A desire to work with children;

- A desire to make a difference;

- A desire to promote their subject; and,

- A natural impulse to nurture.

Murname et al, (1991) found also that job opportunities, salary, and costs to enter or re-enter teaching all influenced the decision to teach. The extrinsic motivating factors reported by teachers participating in that study were:

- Pay;

- Prestige; and,

- Working conditions.

For those who decide to become teachers, these extrinsic rewards are stated to be secondary in importance compared to other, more altruistic, motivations.

Recent research has shown that alongside those who become teachers by choice are those who become teachers by chance (Bush and Middleton, 2005). There were relatively few of these in the VITAE research. Regardless of their motivations for entering teaching, however, it is important to acknowledge that teachers' motivations can change during a career. For example, as in this research, those who are teachers by chance may develop a passion for the job, a sense that teaching is a worthwhile and a positive career choice where they can have an impact on lives of children. 
Conversely, those who choose to become teachers may find that commitments to other priorities (personal events, for example) or to fulfilling the demands of the job itself may exceed the expectations of their initial commitment.

Participants $^{23}$ were asked why they had entered teaching. Their responses were:

(i) Making a difference - including having a positive impact on pupils' lives, helping them improve themselves, making a difference, contributing to the community, and working with children.

(ii) Professional challenge - including the variety, creativity, interest, and reward offered by teaching.

(iii) Personal - including holidays and job security.

(iv) Identity - including reasons associated with the identity of being a teacher, such as status within the community, the role played in the lives of pupils, and increased self-worth.

(v) Subject - comprising teachers who had primarily wanted to teach their subject area.

(vi) Accidental - a small group of teachers who had not intended to teach.

\section{(i) Making a difference}

This was the most common reason given by $57 \%$ of the 309 teachers $(\mathrm{N}=176)$ for choosing teaching as a career. Primary teachers' responses were largely focused on working with children, the fact that they had always wanted to be a teacher, and the impact of their job on children's lives. For example, Phoebe (Year 6) said that she wanted to be, 'part of the development of children' so that she could help in their future careers and Carmelle (Year 2) reported wanting to be a teacher 'in order to make a difference in [children's] lives'. It was also felt that being a teacher meant playing a part in addressing some of the social inequalities to which pupils were exposed. For sixty-one \% ( $\mathrm{N}=101)$ of the 166 primary teachers, their pupils remained the main source of their job satisfaction, together with the ability to contribute to their all round education:

\footnotetext{
${ }^{23}$ The number of case study teachers included in this analysis was 309 (166 primary, 143 secondary).
} 
You have to have a special relationship - the children have to feel secure in their friendship with you and trust you (Abigail, Year 6).

The main thing is you want all children to do their best - not just academic work - to develop their full potential in as many areas as possible. That's always been my driving force (Sharron, Year 6).

Over half $(52 \%, \mathrm{~N}=75)$ of 143 participating secondary teachers also gave responses in this category. Like the primary teachers, their responses also focused on giving pupils 'the best start in life' (Shaun, Year 9) and allowing pupils to develop academically and socially:

I really wanted to be a teacher so that I would be doing something that made a difference to someone (Shaun, Year 9).

You get the opportunity to see them grow, become more social and develop more skills (Pierce, Year6).

\section{(ii) Professional challenge}

Eleven \% (N=34) of the 309 teachers gave the need for a professional challenge as their primary reason for becoming a teacher:

Stimulating, varied work within my subject of interest and the opportunity to facilitate learning... This still applies (Kathleen, Year 9).

I like the challenge of working with children and helping them improve themselves (Noel, Year 9)

Teachers also reported wanting the variety and the stimulus that is provided by an ever-changing working environment.

\section{(iii) Personal}

Ten per cent $(\mathrm{N}=31)$ of the 309 teachers gave reasons within this group for becoming a teacher.

Something that was meant to be for security became a vocation (Sharron, Year 6).

The most commonly cited reason was the flexibility of teaching, which enabled the job to be accommodated around family life. Teachers reported being able to spend time with children during holidays and be at home when they finished school: 
It's great to be able to be at home to oversee my children's homework and to meet their friends (Magdelana, Year 9).

I chose teaching because I thought it would be a good job to fit around having a family, being able to have time to go to the dentists with them and see them in sports days (Jake, Year 6).

\section{(iv) Identity}

A further ten per cent $(\mathrm{N}=31)$ of the 309 teachers gave identity related responses, including the feeling that they had always wanted to teach, grew up in a family of teachers, were influenced by role models amongst their own teachers, or perceived themselves as having the appropriate skills for a career in teaching.

Always wanted to have an effect on pupils' lives and learning... wouldn't do anything else, despite the long hours (Sandra, Year 2).

It's what I always wanted to do (Philip, Year 9).

Sara's (Year 9) comment summed up the views of many secondary teachers in this group when she stated, 'It's a life as well as a job'.

Eight teachers (26\% of 31 ) in total made a connection between being a teacher and their own socio-economic background. One of these teachers was Jeremy, a Head of maths in his 50s who, despite suffering ill health, was still motivated by wanting to help pupils from a similar background to himself:

I came from a similar background to these children and want to be able to get out of the cycle... that's what motivates me (Jeremy, Year 9).

\section{(v) Subject}

Nine per cent $(\mathrm{N}=28)$ of the 309 teachers gave responses suggesting that they initially chose teaching as a career because they wanted to teach a specific subject area and further their expertise in this subject.

I always loved English at school and really wanted to do something as a career in that area. Teaching was the obvious choice (Juliet, Year 9).

It's really satisfying when a student who doesn't see the reason for a particular module in mathematics suddenly understands how useful it can be in life (Alexander, Year 9). 
The majority of the teachers in this group $(\mathrm{N}=17)$ taught in the secondary phase $(61 \%$ of 28).

vi) Accidental

A small number $(\mathrm{N}=9)$ of the 309 teachers had entered because of the security offered by the job, had 'fallen into' teaching by accident, or, in one case, 'couldn't think of anything else to do' after having had, 'a series of grotty jobs', previously.

I came into it accidentally...but it was the best decision of my life (Wilma, Year 2).

I had no idea what I wanted to do... [now].. I am absolutely and totally committed to teaching (Leon, Year 9).

The majority of teachers in this group $(\mathrm{N}=7)$ were in the primary phase (78\% of 9$)$.

\subsection{The Nature of Commitment}

Teacher commitment has been defined as the degree of psychological attachment teachers have to their profession (Chapman, 1982). It is a term often used by teachers to describe themselves and each other (Nias, 1981, 1989) and is a part of their professional identity (Elliott and Cresswell, 2001). Its outward expression is to be found in teachers who are motivated, willing to learn, and who believe that they can make a difference to the learning and achievement of students in all professional life phases. Such teachers also make huge emotional investments in their work, as the previous section on teachers' identities shows, such that their sense of personal worth becomes closely bound to their sense of professional worth (Haigh, 1995; Woods et $a l, 1997)$. Some research suggests that teachers' commitment tends to progressively decline over a course of a career and that this is caused by a number of factors - pupil behaviour, changes in national policies, and parental demands (Louis, 1998; Helsby, 1999; Fraser et al, 1998; Huberman, 1993; Tsui and Cheng, 1999). Whilst the VITAE data confirm these, identifying personal events and experiences and school leadership and culture as key contributing factors, they also challenge the notion that commitment must necessarily decline only in the later phases of a career. 
Analysis of professional life phases demonstrates that commitment may decline in any period of teachers' lives. For these reasons, it is essential that both individual and collective commitment and resilience are nurtured within the educational system if teachers are to sustain their effectiveness.

Nias (1981), in her study of primary teachers, reported that they felt the demands of teaching to be significant, requiring great personal investment (Nias, 1981) and that they often used the word 'commitment' to describe either their own or others' dedication (or lack of dedication) to the teaching profession. This latter group of teachers often limit their commitment to the school to survival and in some cases leave the profession altogether (Louis, 1998). In another study of primary school teachers, Tyree (1996) reported four dimensions of commitment: commitment as caring, commitment as occupational competence, commitment as identity and commitment as career-continuance. Sikes et al. (1985) identified four forms of teacher commitment: vocational; professional; instrumental; and political. More recently, Elliot and Cresswell (2001) reported that commitment to teaching involves at least two 'components'. The first is ideological in nature, consistent throughout a career, and is generally expressed as a combination of personal and professional values. The second refers to commitment to particular teacher practices which reflect the ideologies expressed by the teacher and relate to the teachers' specific teaching behaviours.

In a different context, others (Jackson, Boostrom, and Hansen, 1993; Goodlad, 1990; Sockett, 1993) have written of the 'moral purposes' of teachers, using words such as 'courage', 'integrity', 'honesty', 'care', 'fairness'; and it is easy to see how these may be associated with commitment. All these were present in abundance in the accounts by VITAE teachers of their commitment, alongside enthusiasm, passion for the job and the people with whom they worked, and the significant emotional investments which, for most, made teaching more than just a job.

Closely linked to 'commitment' is the notion of 'values'. Woods et al. (1997, p. 152) argue that 'teaching is a matter of values. People teach because they believe in something. They have an image of the 'good society.' Woods (1995) and Woods and Jeffrey (1996) have researched 'creative' primary school teachers who were characterised as having strong child-centred (Sugrue, 1997) principles, committed to 
innovation and experienced ownership of curriculum and pedagogy; and Nias (1996) has shown the central importance of values concerning interpersonal relationships in the primary school.

For the majority of VITAE teachers, commitment was part of their professional identity; and many in both primary and secondary schools echoed Nias (1989) findings that teachers could be so committed that the 'self' was 'inextricably bound up with the teacher role' and 'could not switch off at the end of the school day to another life and another persona' (Woods et al., 1997). Haigh (1995) has suggested that this 'isomorphic identity' can be problematic for teachers as they 'cannot help but get their sense of personal worth mixed up with their professional competence' (p.3). Our analysis of teacher identities found that this was not so much problematic as an inherent part of being an effective teacher.

Finally, the quantity, nature, and intensity of educational reforms over two decades have changed what it means to be a teacher as the locus of control has shifted from the individual to the system managers and contract has replaced covenant (Bernstein, 1996). Some research has suggested that each teacher must now be:

... a professional who clearly meets corporate goals, set elsewhere, manages a range of students well and documents their achievements and problems for public accountability purposes. The criteria of the successful professional in this corporate model is one who works efficiently and effectively in meeting the standardised criteria set for the accomplishment of both students and teachers, as well as contributing to the school's formal accountability processes'

(Brennan, 1996, p. 22).

Performativity agendas, coupled with the continuing monitoring of the efficiency with which teachers are expected to implement others' definitions of the 'best' curricula and approaches to teaching, learning and assessment, may have three consequences which are likely to reduce rather than increase commitment. They:

1) increase their workload, threaten teachers' sense of commitment and test their resilience;

2) challenge teachers' substantive identity;

3) diminish teachers' sense of effectiveness. 
It is these sources of meaning which reforms that ignore or erode core values destabilize, and which can destroy the sense of identity which is at the core of becoming and remaining a committed, effective professional.

Troman and Woods (2001) found that some teachers coped with intensified work through adjusting their careers. Some retired from teaching early, feeling 'forced out'. Some 'downshifted', taking on a role lower in status, relinquishing posts of responsibility (a step, toward 'disengagement'), or redefining their roles (for example, by becoming supply teachers). Some were determined to maintain their preferred identities by 're-routing' (finding new opportunities outside teaching), or 'relocating' (moving to another school). For the teachers involved in their study, there seemed to be a shift from vocational to more instrumental commitment to teaching, and a progressive disinvestment of the self in teaching (Troman and Woods, 2001). Kelchtermans (2005) has written of teachers' vulnerability in contexts of imposed policy reforms. A recent study (Smithers and Robinson, 2003) which investigated the factors affecting teachers' decisions to leave the profession, identified five main factors which were influential in teachers' decisions: workload, new challenges, the school context, salary and personal circumstances (Smithers and Robinson, 2003: i).

Because of their personal investment in their professional work, where teachers are opposed to the values embodied in imposed change it is difficult for them to adjust to new roles and work patterns (Woods et al., 1997). For example, Helsby (1999) in a study of secondary schools, and Menter et al. (1997) in a primary school study, found that, at least temporarily, many teachers' professional identities, in which their values were embedded, were undermined by reforms. However, Osborn et al. (1996), in a large scale study of English primary schooling, found that over the eight years of the study, while some tensions were experienced in adapting to the new values in the reforms, the main response of the teachers was one of incorporation of the changes. 


\subsection{Summary}

Much published research presents depressing portraits of the results of reform, perhaps because of the researchers' own values and perhaps because of their focus. Important though it may be, self-reports by teachers in response to surveys at least in part mirror these (GTC/MORI, 2003) and the public may be forgiven for gaining an impression that all is not well in the teaching profession as a whole.

There can be no doubt that reforms - particularly those which are poorly managed - at least temporarily disturb the relative stability of teachers' work in some cases their beliefs and practices and self-efficacy, and that in general they challenge existing and preferred notions of professionalism (Goodson and Hargreaves, 1996; Helsby, 1999; Sachs, 2003). However, the reality is that most teachers adapt and at least survive. Whether their work is more closely proscribed as a result of reform or not, they continue to do the best they can for the students they teach under changed and challenging circumstances, usually with their beliefs about their core purposes and values intact. Certainly this was so for the VITAE teachers.

\subsection{Variations in the Commitment of VITAE Teachers: Mediating influences}

A number of mediating factors have emerged across the data presented in this study, the importance of which appear to be central to teachers' motivation and sustained commitment, regardless of school phase, professional life phase or school context (as defined by FSM).

Nearly three-quarters $(71 \%, \mathrm{~N}=103)$ of the 145 primary teachers who responded to the questionnaire, stated in their responses that the reasons which first attracted them to teaching still applied. Nine per cent $(\mathrm{N}=13)$ of the 145 teachers were not sure, ambivalent or did not respond. In total $12 \%(\mathrm{~N}=17)$ felt the reasons no longer applied. At the secondary level, $73 \%$ cent $(\mathrm{N}=79)$ of 108 teachers felt that what attracted them to teaching still applied while nearly $18 \%(\mathrm{~N}=19)$ felt there was a change.

In the final round of interviews, teachers were asked whether the initial motivation for teaching had been sustained. Regardless of their initial motivations for teaching, the majority ( $89 \%$ of $309, \mathrm{~N}=275$ ) of the teachers involved in the study wanted to remain 
in teaching. Those who were planning to leave ( $11 \%$ of $275, \mathrm{~N}=32$ ) were largely those who were nearing retirement. There were, however, a small number $(\mathrm{N}=11$ of $275,4 \%$ ) who were thinking of leaving teaching to pursue another career and had become much less committed to teaching.

Three broad groups of teachers were identified as a result of the analysis of current teacher motivation and commitment; a) those who had sustained commitment $(\mathrm{N}=189), \mathrm{b})$ those who had sustained commitment despite challenging circumstances $(\mathrm{N}=39)$, and $\mathrm{c})$ those whose commitment had declined $(\mathrm{N}=81)$.

\subsubsection{Sustained commitment}

The majority of the 309 teachers $(\mathrm{N}=188,61 \%)$ were determined to remain in the teaching profession and appreciated the important role of motivation and commitment in remaining in the job.

Teaching must be the worst job in the world to do if you are not motivated and enthusiastic ... I have to stop myself working 24 hours a day (Hazel, Year 6).

Lack of commitment would prevent me getting the most out of the class (Lela, Year 2).

For another young teacher (Edith, Year 2),

If I'm not excited or motivated, I find it hard to get the children motivated. Seeing what they gain everyday makes me want to do more (Edith, Year 2).

Phyllis's (Year 2) and Casey's (Year 6) experience had taught them that:

You've got to believe in what you are doing to get the results over a period (Phyllis, Year 2).

If teaching is just a job ie. just doing the next page in a text book, then that's weak commitment and probably doesn't lead to effective teaching (Casey, Year 6).

The establishment and sustaining of relationships with pupils demanded considerable time and the emotional as well as intellectual and practical commitment of these teachers. 
Every waking hour through the week working to improve what I am doing. It's one of the best jobs, one of the most satisfying you ever have (Violet, Year 2).

\subsubsection{Sustained commitment despite challenging circumstances}

Comments relating to teachers' professional and personal Scenarios suggested that some teachers $(\mathrm{N}=40,13 \%)$ were managing to sustain their level of commitment despite working under considerable persistent and negative pressures largely connected to deteriorating pupil behaviour and attitudes, lack of parental support and the effects of government policies. For some, these negative pressures were mediated by one or more types of support - internal (values related), situated (in the school and/or department), and external (family, friends).

The combination of factors mentioned most commonly mentioned by teachers in either group a) or b) as contributing to their sustained commitment were:

- leadership ( $\mathrm{N}=174$ of the 228 teachers, $76 \%$ )

It's good to know that we have strong leadership who has a clear vision for the school (Larissa, Year 6).

- colleagues ( $\mathrm{N}=143$ of the 228 teachers, $63 \%)$

We have such supportive team here. Everyone works together and we have a common goal to work towards (Hermione, Year 2).

We all socialise together and have become friends over time. I don't know what we'd do if someone left (Leon, Year 9).

- personal support $(\mathrm{N}=217$ of the 228 teachers, $95 \%)$.

It helps having a supportive family who don't get frustrated when I'm sat working on a Sunday afternoon and they want to go to the park (Shaun, Year 9).

\subsubsection{Declining commitment}

The interview data provided some useful insights into the issues which caused the commitment of some teachers to decline. A total of $81(26 \%)$ of the 309 teachers were in this group. Those who were considering leaving the teaching profession for a new career were either looking for promotion to advisory roles or, having suffered health problems connected to the stress of teaching, were seeking different kinds of work. 
I don't think I will be able to do this job when I am 47 because of the major demands that it makes on my time and energy (Sheila, Year 9).

Perhaps more worryingly, others had made the decision to leave teaching early 'with dignity' and move on to other part-time work; or were intending to leave teaching because they recognised that they could not manage the stresses and strains for much longer.

I don't know if I can take many more years of doing what I'm doing (Martin, Year 6).

The combination of pressures mentioned by these 81 teachers were:

- $\operatorname{workload}(\mathrm{N}=55$ of the 81 teachers, $68 \%)$

It never stops, there's always something more to do and it eats away at your life until you have no social life and no time for anything but work (Jarvis, Year 6).

Your life has to go on hold - there's not enough time in the school day to do everything (Hermione, Year 2)

- pupil behaviour $(\mathrm{N}=52$ of the 81 teachers, $64 \%)$

Over the years, pupils have got worse. They have no respect for themselves or the teachers (Jenny, Year 6).

Pupil behaviour is one of the biggest problems in schools today. They know their rights and there's nothing you can do (Nancy, Year 6).

- leadership ( $\mathrm{N}=47$ of the 81 teachers, $58 \%$ ).

Unless the leadership supports the staff, you're on your own. They need to be visible and need to appreciate what teachers are doing (Carmelle, Year 2).

I feel as if I'm constantly being picked on and told I'm doing something wrong (Jude, Year 9).

Data illustrate that there is a complex interplay of factors that affect teachers' motivations for, and commitment to, teaching. These findings illustrate how, for many participating teachers, their motivation for teaching is mediated by other factors (e.g. leadership, pupils, peer and personal support), the result of which can have either positive or negative outcomes. An examination of the factors affecting teachers' ability to sustain motivation and commitment follows. 


\subsection{An examination of factors affecting teachers' capacities to sustain commitment}

Teachers reported a number of factors which had an impact on sustaining their commitment. Table 8.1 shows the main positive and negative factors mentioned by teachers. The factors relate to either professional, situated or personal issues and are discussed below under these headings.

Table 8.1: A summary of the negative and positive factors affecting teachers' motivation and commitment

\begin{tabular}{|c|c|}
\hline Negative factors & Positive factors \\
\hline $\begin{array}{l}\text { Professional factors } \\
\text { - Workload } \\
\text { - } \quad \text { Policies/initiatives - demoralising, no support }\end{array}$ & $\begin{array}{ll}\text { Professional factors } \\
\text { - Workload } \\
\text { - } & \text { Policies/initiatives - supported by SMT }\end{array}$ \\
\hline $\begin{array}{l}\text { Situated factors } \\
\text { - Pupils - disaffected, challenging behaviour } \\
\text { - Parents - unmotivated, unsupportive } \\
\text { - Leadership - inconsistent leadership }\end{array}$ & $\begin{array}{l}\text { Situated factors } \\
\text { - Pupils - positive relationships, few } \\
\text { behaviour problems } \\
\text { - Parents } \\
\text { - Leadership - support of Head } \\
\text { - Colleagues - support of other staff, feeling } \\
\text { of being in a team }\end{array}$ \\
\hline $\begin{array}{l}\text { Personal factors } \\
\text { - Health - health problems that affect family } \\
\text { - Values }\end{array}$ & $\begin{array}{l}\text { Personal factors } \\
\text { - Health - no major health worries } \\
\text { - Values - confident about making } \\
\text { difference }\end{array}$ \\
\hline
\end{tabular}

\subsubsection{Professional factors}

Professional factors are those relating to long term policy and social trends. They include factors that affect all teachers, regardless of school context, gender, or professional life phase. Professional factors were reported by 161 teachers (52\% of 309) in total as having an impact on motivation and commitment. Of these teachers, 99 (59 primary and 40 secondary) teachers reported a positive impact, whilst 62 (30 primary and 32 secondary) teachers reported a negative impact.

\section{Primary teachers}

A total of 89 primary teachers made comments regarding professional influences on their work and lives. Of the 59 primary teachers who reported positive professional influences, 35 (59\%) taught in FSM 1 and 2 schools and 24 (41\%) in FSM 3 and 4 
schools. Of the primary teachers who reported negative professional factors $(\mathrm{N}=30)$, 13 (43\%) taught in FSM 1/2 schools and 17 (57\%) taught in FSM 3/4 schools.

\section{(i) Workload}

The majority ( $72 \%$ of $48, \mathrm{~N}=35$ ) of primary teachers in FSM1/2 schools responded positively in terms of their commitment and motivation despite the fact that they were working long hours and had incurred increased paperwork. They reported that they were able to surmount the challenges of pupil attitudes, behaviour and results in spite of the workload. A few ( $13 \%$ of $48, \mathrm{~N}=6)$ teachers found that the workload meant that they did not have enough time to spend with family, or that they did not have any time to relax. The remaining five (10\% of 48$)$ teachers reported not having any time for a social or personal life outside of work as they could only cope with the workload by taking it home at weekends.

\section{I love teaching but feel de-motivated by the amount of planning, despite being} absolutely knackered (Agatha, Year 6).

I still spend every waking hour through the week working to improve what I am doing. It's one of the best jobs and one of the most satisfying jobs you can have (Violet, Year 2).

These two comments illustrate the different positive and negative attitudes of these primary teachers to workload. Of the 48 teachers in FSM 1 and 2 schools, 35 commented positively. For example, Rebecca (Year 2) was a self confessed 'workaholic', and Hazel (Year 6) had 'to stop myself working 24 hours a day'. Michael (Year 6), Nancy (Year 6) and Sarah (Year 2) were among others who were confident that they were making a difference despite, 'endless change and paperwork' and changes, 'being thrown at teachers'.

Pupils are what keep we in teaching despite having to jump through hoops to fulfil criteria and paperwork (Jenny, Year 6)

There were few overall negatives. Agnes (Year 2), the Head of a small, rural school, found that the cost of the job meant that she did not give enough time to her family; and Calvin (Year 6), also the Head of a small, rural primary school found, "no happy time whatsoever in his personal life', because he worried about the school and his job while he was at home. Janice (Year 6), shared this pressure as a headteacher of a 
small school and was beginning to lose her sense of job satisfaction due to excessive workload. Violet (Year 2) had experienced a decrease in her effectiveness as her life, 'revolved around the school', and her marriage broke down. Jeanne (Year 6), was a Deputy Head who wanted to retire and who resented paperwork - 'I didn't come into teaching to fill in bits of paper':

We just get on top of something, we know what we're doing now, and then it's changed...nothing is ever finished (Jeanne, Year 6).

Gavin (Year 6), although deriving great pleasure from pupils' personal and academic achievements, did not think he would be in the job for too much longer because of the, 'major demands that it makes on my time and energy' and David (Year 6) also resented taking work home.

Nearly half ( $43 \%$ of $41, N=18$ ) of teachers in FSM 3 and 4 schools reported that the workload was making them feel exhausted and that in some cases this meant that they did not get home from work until late evening, preventing them from having a social or personal life during the week. Many of them also commented upon the work that had to be completed at the weekend.

I go to bed at nine each night, exhausted (Roald, Year 2)

The massive workload takes away my personal life (Sheila, Year 6)

There were also positive comments, however. Nearly half $(\mathrm{N}=19,46 \%)$ of the 41 primary teachers in FSM 3 and 4 schools reported that, despite the heavy workload, they still enjoyed their job and found satisfaction in working with children:

It is really hard sometimes, but it's worth it in the end (Marion, Year2).

\section{(ii) DfES/Ofsted/Target Driven Policies}

Again, there were differences in emphasis between teachers in FSM 1 and 2 schools and those in FSM 3/4 schools. Of the 35 FSM 1/2 teachers who commented, the majority ( $76 \%$ of $35, \mathrm{~N}=27$ ) did so negatively. Despite this, they still managed to find satisfaction from their work and would not let their teaching be dominated by the Key Stage tests. Thirteen teachers (37\% of 35) commented upon the restriction they felt when having to work to the National Curriculum and tried, whenever possible, to 
explore ideas with the pupils. Twelve teachers (34\% of 35) reported that they would like to be left alone to deliver the curriculum without interference.

I feel my professionalism is being called into question when I'm being told how to teach all the time (Jenna, Year 6).

A few teachers $(\mathrm{N}=7,20 \%$ of 35$)$ held negative views about external initiatives and felt that they had a direct impact on their effectiveness, on their energy levels, and on their level of pressure they felt under. Of these seven teachers, four (57\% of 7) commented upon there being too many initiatives, demands, and targets which caused low self-efficacy, and for some, a feeling to leave the profession.

There are so many initiatives; it's difficult to know when the teaching is supposed to happen (Ricky, Year6).

Finally, three teachers (9\% of 35) commented on the accuracy of marking (of SATs), the intrusion of and impositions made by government, and the increased paperwork which left little time available for work with individual pupils' needs, marking and feedback.

Despite these negative comments, these teachers continued to find satisfaction from their work in spite of the policies. Nancy (Year 6) spoke of 'the spark of hope with children when you know you've made a difference - despite the inclusion policy'. Violet (Year 2) spoke of her pleasure in watching children develop, 'despite SATs'. Gavin (Year 6) was highly committed, with teaching approaches not dominated by SATs:

I'm determined to give them a range of experiences and opportunities in all areas of the curriculum (Gavin, Year 6).

Rebecca (Year 2) similarly, felt she was not, 'strait-jacketed', but was, 'allowed to explore ideas with the children'. Carmelle (Year 2) wanted to be seen as 'human, not a machine saying do this and you'll get the mark' and Michael (Year 6) also believed that, growing up socially and morally' was more important than, 'bits of paper'. Laila (Year 2) felt strongly that: 
I just wish the government would leave us to get on and deliver what we know we have got to deliver, raise their level of interest and self esteem... (Laila, Year 2).

Of the 41 primary teachers in FSM 3/ 4 schools who commented on professional influences, 37 ( $90 \%$ of 41 ) said they were struggling to deal with the various policies and initiatives introduced.

I can't survive any longer in this target driven culture (Heidi, Year 6).

The inclusion policy was mentioned explicitly as bringing hardships as well as rewards.

The inclusion policy brings rewards and hardships (Sheila, Year 6).

The lack of time with individual pupils and the fewer opportunities to interact socially with children were also reported to be a result of the target-driven culture that existed in their schools.

Means fewer opportunities for children to interact socially or be creative. This puts too much pressure on children and prevents them enjoying learning (Laila, Year 2).

Twenty-one teachers (57\% of 37) felt that they were increasingly under pressure to produce results and meet targets which, in turn, was having a direct negative impact on relationships in the classroom.

My biggest problem is time and energy. I put the children to bed at $8.00 \mathrm{pm}$ and start working (Jenna, Year 6).

Amongst the 89 primary teachers who reported professional factors, the key negative factors which affected their perceived effectiveness were workload and its effects upon personal life, central policies, pupil behaviour, parental support and personal health. Primary teachers in FSM 1 and 2 schools $(\mathrm{N}=48)$ appeared to be more positive in their perceptions of work and work contexts. Among the key factors which affected their perceived effectiveness were workload and its effect on personal life, central policies, pupil behaviour, parental support and personal health. However, in terms of frequency and combination, their comments did not indicate the same levels of stress as those teaching in FSM 3 and 4 schools $(\mathrm{N}=41)$. 
Of those who felt that professional factors had a positive influence on their work $(\mathrm{N}=59), 51(86 \%)$ were sustaining their commitment. Of these, 32 (63\% of 51) taught in FSM 1/ 2 schools and 9 (37\% of 51) taught in FSM 3/ 4 schools. The remaining seven teachers (14\% of 59) were experiencing a decline in their commitment. Of these, 4 (57\% of 7) taught in FSM 1/ 2 schools and 3 (43\% of 7) taught in FSM 3/ 4 schools.

Of those who felt that professional factors had a negative influence on their work $(\mathrm{N}=30), 6$ (20\% of 30$)$ were sustaining their commitment (2 (33\% of 6) in FSM 1/ 2 schools, 4 (67\% of 6) in FSM 3/ 4 schools), 9 teachers (30\% of 30) were sustaining commitment in spite of challenging circumstances (3 (33\% of 9) in FSM 1/ 2 schools, 6 (67\% of 9) in FSM 3/ 4 schools), and 15 teachers (50\% of 30) were experiencing a decline in commitment (8 (53\% of 15) in FSM 1/ 2 schools, 7 (47\% of 15) in FSM 3/ 4 schools).

\section{Secondary teachers}

A total of 72 teachers made comments regarding professional influences. Of the 40 secondary teachers (56\% of 72$)$ who reported positive professional factors, $23(58 \%$ of 40) were teaching in FSM 1 and 2 schools and 17 (42\% of 40) in FSM 3 and 4 schools. Of those secondary teachers who reported negative professional factors (N=32), 24 (75\% of 32) taught in FSM 1/2 schools and 8 (25\% of 32) taught in FSM $3 / 4$ schools.

\section{(i) Workload}

Fifty-eight secondary teachers (42 FSM 1/ 2, 16 FSM 3/ 4) commented on their workload. Twenty (48\%) of the 42 secondary teachers in FSM 1 and 2 schools who, however, mentioned workload as a factor felt they were unable to cope with the pressures of work, $22(52 \%)$ of the 42 teachers were still enjoying their work and wholly committed, in spite of the workload. Leanne (Year 9, English) had 'improved' her work-life balance, and motivation and perceived effectiveness had increased. Ben (Year 9, maths) said that, 'drive, enthusiasm, personal support' were the biggest influences in his effectiveness. On the other hand, Darrell (Year 9, maths) was, 'trying as hard', but felt, 'far less motivated' as a result of a combination of factors 
which increased his workload. Alexandra (Year 9, English) submitted her resignation because she had, 'no life outside school', was caring for her elderly mother, and dealing with a 'negative colleague' and Nikita (Year 9, English) had similar parental responsibilities and said that, 'workload has taken over my life'.

Of the 22 teachers who remained positive, Ruth (Year 9, English) did not have much of a social life but still wanted, 'to have a positive impact on young people's lives'. Ada (Year 9, maths) was only able to survive by taking work home in the evenings. Madelaine (Year 9, English) a part-time teacher commented:

The more stressed I am, the less satisfaction I get out of my job...work on top of my teaching feels like drudgery (Madelaine, Year 9).

However, Holly (Year 9, English) still, 'loved the job' and her sense of effectiveness had increased despite, 'external pressure from endless government changes'. Though Geraldine's (Year 9, English) personal life was 'squeezed out', she was, 'more committed and more satisfied' with her increasing success in making a difference as a headteacher; and Adrienne (Year 9, maths) looked forward to coming to work each day and seeing results despite the, 'long working hours and (little) amount of time for planning'.

Teachers in FSM 3/ 4 schools echoed these sentiments. Of the 16 teachers who commented upon this issue, $8(50 \%)$ teachers still felt committed and found enjoyment in their work in spite of the pressures of workload. The remaining $8(50 \%)$ teachers were struggling to maintain motivation for teaching and were feeling 'run down'.

I have gone into survival mode...worn out, run down (Barry, Year 9).

Sometimes you feel you haven't got a life (Sasha, Year 9).

\section{(ii) DfES/Ofsted/Target Driven Policies}

Nearly two-thirds ( $61 \%$ of $72, \mathrm{~N}=44$ ) of secondary teachers commented on this issue. The majority ( $77 \%$ of $44, \mathrm{~N}=34)$ of these were FSM 1 and 2 teachers (74\% of 46). Although 12 teachers (35\% of 34) were fairly positive about policies and initiatives, 15 (44\% of 34$)$ of these teachers were extremely negative about external initiatives 
and their consequences. Nana (Year 9, English) felt that there were 'too many' initiatives, demands and targets' which caused her to have, 'a negative feeling of never being able to fulfil all that is required'. Ada (Year 9, maths) was 'thinking of leaving the school and possibly teaching' as a result of an Ofsted inspection; and Alexandra (Year 9, English) had, 'no faith in the accuracy of SATs marking'.

For a further seven teachers (21\% of 34), 'impositions by government' (Sasha, Year 9, maths) left little time available for work with individual pupils, marking and feedback. Yet, although Cate (Year 9, maths) was, 'disillusioned, overworked, underpaid', she still gained, 'a lot of satisfaction' from her teaching.

Of the 10 secondary teachers in FSM 3 and 4 schools who reported policy as having an impact on their teaching, $8(67 \%)$ responded negatively.

There's more pressure on individuals to produce results all the time. You're always aiming to meet a target. They're all very subtle things that impact directly on relationships in the classroom and change the language of the classroom (Jeremy, Year 9).

Jo (Year 9, English) felt that she was 'teaching far more to the test than previously' and Sasha (Year 9, maths) was adamant that 'we are going down because of government policies - especially inclusion...It's like somebody's always looking over your shoulder'.

Although there were similar concerns expressed about a range of issues and a similar mix of motivations to teach, there were differences in the incidence of ill health, degrees of stress felt by secondary teachers in FSM 1 and 2 schools (21\% of 47, $\mathrm{N}=10$ ) compared to those in FSM 3 and 4 schools ( $48 \%$ of $25, \mathrm{~N}=12$ ). The former also had a stronger sense of agency with regard to making a difference academically and socially to the lives of pupils. Whilst similar negative and positive factors which were perceived to affect their ability were raised, the effects appeared to be more strongly felt by the secondary teachers.

Of those secondary teachers $(\mathrm{N}=40)$ who felt that professional factors had a positive influence on their work, 35 (88\%) were sustaining their commitment. Of these, 19 (54\% of 35) taught in FSM 1/ 2 schools and 16 (46\% of 35) taught in FSM 3/ 4 
schools. The remaining five teachers (12\% of 40) were experiencing a decline in their commitment. Of these, 3 (60\% of 5) taught in FSM 1/ 2 schools and 2 (40\% of 5) taught in FSM 3/ 4 schools.

Of those secondary teachers $(\mathrm{N}=32)$ who felt that professional factors had a negative influence on their work, only 2 teachers $(6 \%)$ were sustaining their commitment, and both taught in FSM 1/ 2 schools. Nine teachers (28\% of 35) were sustaining commitment in spite of challenging circumstances. Of these, 6 (67\% of 9) taught in FSM 1/ 2 schools and 3 (33\% of 9) taught in FSM 3/ 4 schools. The remaining 21 teachers (66\% of 32) were experiencing a decline in their commitment. Of these, 16 (76\%) teachers taught in FSM 1/ 2 schools and 5 (24\%) teachers taught in FSM 3/ 4 schools.

\subsubsection{Situated factors}

'Situated' describe those factors which were specific to the school a teacher works in, factors that may not necessarily be evident in any other school, department or classroom. Unsurprisingly, these factors were mentioned by the majority of teachers (95\% of $309, \mathrm{~N}=294$ ) as having an impact on motivation and commitment. Of these, $230(78 \%$ of 294$)$ reported a positive impact, as opposed to 63 (21\% of 294$)$ teachers who reported a negative impact.

\section{Primary teachers}

A total of 156 (80 FSM 1/ 2 and 76 FSM 3/ 4) primary teachers made comments in relation to situated influences. Of the 136 primary teachers who reported positive situated factors, 74 (54\%) were teaching in FSM 1 and 2 schools and 62 (46\%) in FSM 3 and 4 schools. Of those primary teachers who reported negative professional factors (N=20), 6 (30\%) taught in FSM 1/2 schools and 21 (70\%) taught in FSM 3/4 schools.

\section{(i) Organisational Support}

Almost all $(88 \%, \mathrm{~N}=70)$ of teachers in FSM 1 and 2 schools spoke of their ability to take decisions affecting the teaching and learning in their own classrooms with regard to the academic, personal and social progress of pupils. This group, by implication, received support in this from their s and colleagues. They did not feel that they were 
unduly dominated by SATs and were able to provide opportunities for a range of learning experiences. Naomi (Year 2) gained her greatest satisfaction from pastoral care, promoting 'honesty, fairness and relationships', whilst Laurette (Year 6) was, 'trying to raise the profile of PSHE in school'. Edith (Year 2) wanted, 'good SATs results and changes in children's attitude to school and learning', and Leila (Year 2) was, 'not interested in league table results'. In essence:

The school ethos allows teachers to define their own needs (Sheila, Year 6).

Those who were suffering most from stress were headteachers, especially those in small, rural schools, all of whom experienced difficulties in coping with the management, leadership and teaching workload. For Margery (Year 6) there was, 'freedom to use initiative and it makes people feel they are counted and they matter'; and for Joanna (Year 2) and Hazel (Year 6) there was good support from SMT on personal as well as professional matters.

These teachers experienced a supportive organisation and appreciated the opportunities which that gave them to exercise their own professional judgement in the classroom.

...get on well as a team and we support each other whether we're going through a good time, a bad time or whatever (Hazel, Year 6).

Of the 76 primary teachers who taught in FSM 3 and 4 schools, 77 per cent $(N=59)$ reported that they valued the support they received from within the school from colleagues and particularly enjoyed the sense of 'family' or 'community' that was sometimes evident. Some teachers had experienced collaboration and teamwork and felt that the sharing of ideas was important.

I can cope with most things as long as I can talk to my colleagues and discuss ideas with them (Lilly, Year 6).

I love the sense of teamwork we have here, I could never leave (Patty, Year 2).

Leadership was also an important issue in relation to support and there were several positive comments regarding the openness of the school leadership and the recognition that life outside work was important. Teachers often highlighted the 
support they had from school when faced with personal issues (e.g. health, marriage break-up, caring for parents, children).

My work has given me somewhere to come to when things get bad and I know that they care, even when nothing is said (Larissa, Year 2).

\section{(ii) Pupil Behaviour}

Among all primary FSM 1/ 2 teachers who made a comment regarding situated factors $(\mathrm{N}=80)$, only $11(14 \%)$ spoke negatively about pupil behaviour. Of these, Michale (Year 6) was concerned about the, 'background of some pupils'; and Jackie (Year 6) was concerned about the, 'constant drip of minor behaviour that wears you down'. Others commented that they continued to be highly motivated despite some poor behaviour. Gavin (Year 6) wanted children to, 'make up their own minds despite poor pupil behaviour'.

For Natasha (Year 2), pupils remained the main source of job satisfaction despite a number of children with behavioural difficulties, although Regina (Year 6) who associated poor behaviour with, 'low motivation and lack of support from home', had experienced doubts about her effectiveness due to the behaviour in her class. Jenny (Year 6) felt 'tired and trapped' by workload but retained her commitment despite these and, 'more challenging pupil behaviour'.

For 69 of the 80 teachers, however, pupil behaviour was not an issue. Sadie (Year 6) was:

...more satisfied working with a high calibre of children could end up being very responsible, high achieving and articulate (Sadie, Year 6).

Most of Kim's (Year 2) pupils had, 'made progress in their academic work and all have made progress socially' and Eleanor (Year 2) had, 'total respect' from the pupils. Laurette (Year 6), gained satisfaction from achieving good results and improving pupils' behaviour.

Of the 76 teachers in FSM 3 and 4 schools, comments tended to be more negative on this issue $(\mathrm{N}=34,45 \%)$, as well as it being associated with classroom disruption, pupil mobility and the 'inclusion' policy which affected class composition. In the majority 
of cases $(\mathrm{N}=30,88 \%$ of 34$)$ it meant that pupil behaviour management often took priority over the teaching and learning tasks.

I spend so much time having to make sure everyone is listening, not talking, sat still. I never have enough time to teach the actual lesson! (Michael, Year 6).

Fourteen (41\% of 34) teachers commented upon the lack of value pupils placed on education, those who did not want to work or achieve, and those who were disillusioned by the Key Stage tests and felt pressure to perform well.

You're constantly behaviour managing children with baggage and behavioural difficulties (Faith, Year 2).

\section{(iii) Parental support}

Only $9(11 \%)$ of the 80 FSM 1 and 2 teachers commented adversely on this aspect of their work. For Alice (Year 6), the school was, 'at the centre of the community' and for Rebecca (Year 2), 'everybody is so supportive'. Michael (Year 6), however, was concerned about the, 'emotionally insecure background of some pupils' and Laurette (Year 6) had some concerns about home-school relationships. Violet (Year 2) spoke of her commitment to, 'seeing a child get somewhere and come out a whole person', despite, 'a weakening of parental support' and David (Year 6) spoke of 'only 70\%' of parents supporting homework.

In FSM 3 and 4 schools, 26 (34\%) of the 76 teachers reported an increasing number of families who were not getting involved in supporting the school.

We are getting an increasing number of families who do not support the school (Samantha, Year 2).

Where challenging behaviour was also apparent, this lack of support was said to add to the demoralization of staff.

Challenging behaviour without parental and agency support is extremely demoralising (Cary, Year 6).

Parents just don't seem to see that they have a part to play in this business (Carmelle, Year 6).

The parents are unsupportive (Robin, Year 9). 
The lack of parental support was seen by some teachers to impact on pupils' aspirations.

Of the primary teachers who felt that situated factors had a positive influence on their work ( $\mathrm{N}=136), 114(84 \%)$ were sustaining their commitment. Of these, 60 (53\% of 114) taught in FSM 1/ 2 schools and 54 (47\% of 114) taught in FSM $3 / 4$ schools. Seven of the 136 positive primary teachers (5\%) were experiencing sustained commitment in spite of challenging circumstances. Of these, 3 (43\% of 7) taught in FSM 1/ 2 schools and 4 (57\% of 7) taught in FSM 3/ 4 schools. The final group of positive primary teachers were experiencing a decline in their commitment $(\mathrm{N}=15$, $11 \%$ of 136), the majority of whom were working in FSM $1 / 2$ schools ( $N=11,73 \%$ of $15)$.

Of those who felt that situated factors had a negative influence on their work $(\mathrm{N}=20)$, only one teacher was sustaining their commitment (5\% of 20). This teacher taught in an FSM 1/ 2 schools and had been teaching for 24-30 years. However, 7 teachers (35\% of 20) had managed to sustain commitment in spite of circumstances (2 (29\% of 7) in FSM 1/ 2 schools and 5 (71\% of 7) in FSM 3/ 4 schools). The remaining 12 teachers $(60 \%$ of 20$)$ were experiencing a decline in their commitment. Of these, 3 (25\% of 12) taught in FSM 1/ 2 schools and 9 (75\% of 12) taught in FSM 3/ 4 schools.

\section{Secondary teachers}

A total of 138 (85 FSM 1/ 2 and 53 FSM 3/ 4) secondary teachers made comments in relation to situated influences. Of the 94 secondary teachers who reported positive situated factors, 59 (63\%) were teaching in FSM 1 and 2 schools and 35 (37\%) in FSM 3 and 4 schools. Of those secondary teachers who reported negative professional factors $(\mathrm{N}=44), 26(59 \%)$ taught in FSM 1/2 schools and $18(41 \%)$ taught in FSM 3/4 schools.

\section{(i) Organisational support}

A total of 54 (64\% of 85) secondary teachers in FSM 1 and 2 schools were unequivocal in their appreciation of support from colleagues and SMT, 20 (24\% of $85)$ had mixed feelings and 10 (12\% of 85$)$ felt negatively about the support they 
received. Liz (Year 9, English) appreciated management's 'willingness to listen' and their support on personal issues.

Staff are like a family. There is a real sense of togetherness (Sasha, Year 9).

Ruth (Year 9, English) worked in a 'close knit' department and Hannah (Year 9, English) appreciated the support of her Head of Department. For Cate (Year 9, maths) the staff was 'wonderful'.

Negative opinions included a perceived lack of support by SMT for student behavioural issues and for promotion. Mixed opinions concerned differential support offered by the department and SMT. For example, although Claire (Year 9, English) did not, 'feel valued' professionally by her SMT, she acknowledged their support on personnel issues. Karolina (Year 9, English) and Abbie (Year 9, English) both experienced supportive departments but unsupportive SMT.

Thirty-one (58\%) of the 53 teachers in FSM 3 and 4 schools reported negative feelings regarding the organisational support of the school, whilst 17 (32\% of 53) were positive and 5 (10\% of 53) were mixed. For Daniel (Year 9, maths), 'the school is singularly successful in the aims of giving each pupil the best possible support' and for Jeremy:

One way to manage this level of challenge is to work as a team...in this type of school there is no choice but to get on with everyone (Jeremy, Year 9).

Jo (Year 9, English) experienced, 'collaboration and teamwork at every level' and Sasha (Year 9, maths) experienced 'laughter and the sharing of ideas' in her department.

As with primary teachers, secondary teachers were particularly appreciative of support from school at times of personal crisis:

Everyone was incredibly supportive...we do need that support because if you really felt isolated...I think you'd go off with stress...we have some very, very difficult pupils (Siobhan, Year 9).

Sally (Year 9, maths) worked with 'incredible departmental support', and in an, 'incredibly supportive school with a happy, dedicated staff'. For Jenni (Year 9, English) who began the job of Head of Department with the birth of a second child: 
If it hadn't been for the intervention of the head, and his support, I would probably have had a nervous breakdown (Jenni, Year 9).

\section{(ii) Pupil Behaviour}

In FSM 1 and 2 schools, $65(76 \%)$ of the 85 teachers reported positive pupil behaviour, whilst $20(24 \%)$ commented on deteriorating pupil behaviour. Of the positive remarks, 'the fulfilling part is when the students come up and say thank you' (Sasha, Year 9, maths) was a common theme. Great store was placed upon a combination of care and achievement:

Getting to know kids...having them turn around and say they understand. Helping kids through their exams is a good feeling (Linda, Year 9).

Geraldine's (Year 9, English) satisfaction came through pushing the pupils, getting them, 'to achieve their full potential, not just about exam results' and Ben (Year 9, maths) also gained most satisfaction through, 'seeing children achieve, parental comments, the good feeling at the end of the day, good results'. For him:

Meaning comes through change in people's lives. Targets will take care of themselves (Ben, Year 9).

Although the socio-economic background of pupils had 'a huge bearing' on what went on in Geraldine's (Year 9, English) classes, she was nevertheless, more committed and satisfied with her successes. Cate (Year 9, maths) was more cautious:

Teachers thrive on the idea that they do make a difference, although a lot of the time I feel I don't make a difference with the way they act socially (Cate, Year 9).

Cheryl (Year 9, English) commented that, 'a lot of pupils didn't value education' and Kathryn (Year 9, English) reported spending 'more time battling student behaviour' than teaching.

This theme was also evident in responses from FSM 3 and 4 teachers:

There are some kids who don't value education (Shaun, Year 9).

The year 9 s are more disillusioned in relation to being tested. They don't see Year 9 tests as meaning very much (George, Year 9). 
Thirty-nine (74\%) of the 53 secondary teachers in FSM 3/ 4 schools reported pupil behaviour as a negative factor. Lack of trust and the pressure that behaviour problems put upon teachers were two of the most commonly mentioned issues. For Winona (Year 9, English), 'It's hard work because the children don't trust you at first'. Jeremy (Year 9, maths) said that, having to deal with disruptive pupils made him 'feel under pressure to perform'. The remaining 14 (26\% of 53) secondary teachers in these schools commented positively with regard to pupil behaviour

\section{(iii) Parental support}

Only $18(13 \%)$ of the 138 secondary teachers commented on parental support. A majority of these were in FSM 1/ 2 schools. Most ( $\mathrm{N}=13,72 \%$ of 18) spoke negatively. Kathryn (Year 9, English) spoke of unsupportive parents but Abbie (Year 9, maths) was more direct:

Pupils do not have enough discipline at home and have unstable parental relationships (Abbie, Year 9).

Scarlett (Year 9, English) felt that parents left all the education to the school; and Caroline (Year 9, English) commented that parental expectations were (too) high.

Of those who felt that situated factors had a positive influence on their work $(\mathrm{N}=94)$, $67(71 \%)$ were sustaining their commitment. Of these, 40 (60\% of 67) taught in FSM 1/ 2 schools and 27 (40\% of 67) taught in FSM 3/ 4 schools. The remaining 21 teachers (22\% of 94) were experiencing a decline in their commitment. Of these, 13 (62\% of 21) taught in FSM 1/ 2 schools and 8 (38\% of 21) taught in FSM 3/ 4 schools.

Of those who felt that situated factors had a negative influence on their work $(\mathrm{N}=44)$, only $2(5 \%)$ teachers were sustaining their commitment (1 in FSM $1 / 2$ and 1 in FSM 3/4). A further 17 (39\% of 44) teachers, however, were sustaining commitment in spite of challenging circumstances. The majority of this group $(\mathrm{N}=11,65 \%$ of 17$)$ taught in FSM 1/ 2 schools, 6 (35\% of 17) taught in FSM 3/ 4 schools. The remaining 25 teachers (57\% of 44$)$ were experiencing a decline in their commitment. Of these, 14 (56\% of 25) taught in FSM 1/ 2 schools and 11 (44\% of 25) taught in FSM 3/ 4 schools. 


\subsubsection{Personal factors}

Personal factors are those based around life outside of school, connected, for example, with being a father, son, partner, etc. These factors were reported by 269 teachers as having an impact in their motivation and commitment. Of these, 162 (100 primary and 62 secondary) teachers reported a positive impact, whereas 107 (44 primary and 63 secondary) teachers reported a negative impact.

\section{Primary teachers}

A total of 144 (77 FSM 1/ 2 and 67 FSM 3/ 4) primary teachers made comments in relation to personal influences. Of the 100 primary teachers who reported positive personal factors, 58 (58\%) were teaching in FSM 1 and 2 schools and 42 (42\%) in FSM 3 and 4 schools. Of those primary teachers who reported negative personal factors (N=44), 19 (43\%) taught in FSM 1/2 schools and 25 (57\%) taught in FSM 3/4 schools.

\section{(i) Personal Health}

As a teacher in an FSM 1/ 2 school, Rachael (Year 2) did not think she could become, 'any more committed' and Violet (Year 2) still spent 'every waking hour through the week working to improve what I'm doing'. Alison (Year 6) went to school every day, 'to a job that I love' and Hazel (Year 6) was, 'still, after 29 years, motivated'.

Of the 77 primary teachers in FSM 1/ 2 schools who commented on personal factors, nearly one-quarter $(\mathrm{N}=19,25 \%)$ of them had been away from work due to ill health. For example, Beverley (Year 6) and Sheila (Year 6) loved what they did, despite ill health. One teacher had suffered ill health which did affect her ability to teach effectively. Agatha (Year 2) had been away from school for 5 months with a serious illness.

The percentage of teachers suffering with health problems in FSM 3 and 4 schools was higher with over one-third $(\mathrm{N}=25,37 \%)$ of the 69 teachers reporting illness. One teacher (Sheila, Year 6) had recurrent throat problems, another suffered from depression as work encroached more and more on her personal life (Laila, Year 2); and another (Alanis, Year 6) had 'time off' for several operations and did not know if 
he could take many more years of teaching.

\section{(ii) Positive values}

What kept the majority ( $\mathrm{N}=58,75 \%$ of 77) of the teachers in FSM 1 and 2 schools motivated and committed to their agendas were their core values, their 'desire to make a difference to children's learning' (Larissa, Year 6); 'always looking for the good' (Adrian, Year 6); increasing their knowledge, independence, skills - getting their voice heard' (Abigail, Year 6); and, giving them, 'a range of experiences and opportunities in all areas of the curriculum"' (Gavin, Year 6). One teacher said:

Teaching must be the worst job to do if you are not motivated and enthusiastic (Hazel, Year 6).

Being with children and 'developing relationships' was what interested Carmelle (Year 2) and these sentiments were repeated by almost all the teachers. It was the satisfaction gained from working with pupils that kept them in teaching despite pressures from policy, the challenges of pupil behaviour, parental pressure and excessive workloads.

Teachers in FSM 3 and 4 schools ( $N=42,63 \%$ of 67$)$ were motivated by the challenge of their chosen context and what could be achieved with pupils:

I get immense satisfaction from pupils' progress and achievements (Larissa, Year 6).

I can make a difference to what children think and learn (Adrian, Year 6).

Of the primary teachers who felt that personal factors had a positive influence on their work $(\mathrm{N}=100), 83(83 \%)$ were sustaining their commitment. Of these, 49 (59\% of 83$)$ taught in FSM 1/ 2 schools and 34 (41\% of 85) taught in FSM 3/ 4 schools. A further 5 teachers were sustaining commitment in spite of challenging circumstances (2 FSM $1 / 2$ and 3 FSM 3/4). The remaining 12 teachers (12\% of 100) were experiencing a decline in their commitment. Of these, 7 (58\% of 12) taught in FSM $1 / 2$ schools and 5 (42\% of 12) taught in FSM $3 / 4$ schools. 
Of the primary teachers who felt that personal factors had a negative influence on their work ( $\mathrm{N}=44), 22(50 \%)$ were sustaining their commitment. Of these, 10 (45\% of 22) taught in FSM 1/ 2 schools and 12 (55\% of 22) taught in FSM 3/ 4 schools. A further 8 teachers $(18 \%$ of 44$)$ were sustaining commitment in spite of challenging circumstances ( 3 FSM $1 / 2$ and 5 FSM 3/4). The remaining 14 teachers (32\% of 44) were experiencing a decline in their commitment. Of these, 6 (43\% of 14) taught in FSM 1/ 2 schools and 8 (57\% of 14) taught in FSM 3/ 4 schools.

\section{Secondary teachers}

A total of 125 (76 FSM 1/ 2 and 49 FSM 3/ 4) secondary teachers made comments in relation to personal influences. Of the 62 secondary teachers who reported positive personal factors, 44 (71\%) were teaching in FSM 1 and 2 schools and 18 (29\%) in FSM 3 and 4 schools. Of those secondary teachers who reported negative professional factors $(\mathrm{N}=63), 32(52 \%)$ taught in FSM 1/2 schools and $31(48 \%)$ taught in FSM 3/4 schools.

\section{(i) Personal health}

There were 32 (42\% of 76) teachers in FSM 1 and 2 schools who reported suffering from ill health that was directly impacting upon their motivation and commitment. These included recurrent throat problems, miscarriage, depression, and the need for time away from school for recuperation/operations. Other issues raised included being worn out by young children at home, being the main carer for elderly parents, and emerging from a difficult marriage or relationship. Personal health was also said to have a negative impact on others in the school with the re-distribution of work, and discontinuity for pupils.

For example, Ruth (Year 9, English) had a major operation, returned to work too soon, had a relapse and had to take a term's leave and Georgina (Year 9, English) suffered from a blood disorder. Cate (Year 9, maths) and Darrell (Year 9, maths) both complained of a loss of energy and motivation.

A higher proportion ( $\mathrm{N}=31,63 \%$ of 49$)$ of teachers in FSM 3 and 4 schools reported health problems. Among this group of secondary teachers, Ben was worn out, in part because of looking after his young child, and Jo and Cameron, similarly, had two 
school age children to care for. Sasha (Year 9, maths) was emerging from a difficult marriage relationship and suffered from high blood pressure as did Shaun (Year 9, maths). Sasha (Year 9, maths) suffered from diabetes and Serina's health was causing her to lose job satisfaction. Jeanette (Year 9, English) had become worried at how tired she had become and Danny (Year 9, English) was 'exhausted and disillusioned'.

Ten teachers (20\% of 49) reported having a 'carer' role in addition to their work and parental activities. For example, Serena (Year 9, maths) was the main carer for elderly parents, as were Cheryl (Year 9, English) and Laurent (Year 9, maths).

\section{(ii) Positive values}

Fifty-one teachers (67\% of 76) in FSM 1 and 2 secondary schools were motivated by their core educative values. They had entered teaching deliberately in order to ' $h e l p$ raise standards' in their subject discipline, to 'contribute to the community', and 'have a positive impact on the lives of young people'.

Teachers in FSM 3 and 4 schools ( $\mathrm{N}=29,59 \%$ of 49) were largely concerned with their ability to, 'make a difference in pupils' learning' (Ivan, Year 9, maths). Darrell (Year 9, maths) loved working with pupils:

It's not a job you can do if your commitment's not there...I don't spend time moaning...I just do it (Darrell, Year 9).

He was concerned about other teachers' lack of effectiveness. Stella (Year 9, English) had always wanted, 'to work with pupils, care for them and make a difference in their lives', whilst Gary (Year 9, maths) loved his subject and wanted to share it with others.

Jude (Year 9, maths) had entered and remained in teaching in the belief that 'pupils need a good education', as had Seth (Year 9, English) who had, 'wanted to do something which was measurably worthwhile'. Shaun (Year 9, maths) had entered teaching because he, 'thought I could do better' than his teachers. For him, it was, ' $a$ teachers' moral obligation to make a difference to pupils learning'. 
Ruth (Year 9, English) loved teaching, loved the pupils:

If I didn't make a difference, I wouldn't come (Ruth, Year9).

Isaac (Year 9, maths) remained, 'absolutely and utterly committed to making a difference in social and academic terms' and for Stella too (Year 9, English):

What keeps me motivated is that I'm making a difference in kids' lives. If I wasn't doing that, then my motivation would go (Stella, Year 9).

Of those secondary teachers who felt that personal factors had a positive influence on their work (N=62), 46 (74\%) were sustaining their commitment. Of these, 31 (67\% of 46) taught in FSM 1/ 2 schools and 15 (33\% of 46) taught in FSM 3/ 4 schools. Five teachers were sustaining commitment in spite of adverse circumstances (4 FSM 1/ 2 and 1 FSM 3/4). The remaining 11 teachers (18\% of 62) were experiencing a decline in their commitment. Of these, the majority $(\mathrm{N}=9,82 \%$ of 11$)$ taught in FSM 1/ 2 schools and 3 (18\% of 11) taught in FSM 3/ 4 schools.

Of those who felt that personal factors had a negative influence on their work $(\mathrm{N}=63)$, $20(32 \%)$ were sustaining their commitment. Of these, 7 (35\%) taught in FSM 1/ 2 schools and 13 (65\%) taught in FSM 3/ 4 schools. Another 15 teachers were sustaining commitment in spite of challenges, with two-thirds $(\mathrm{N}=10,67 \%$ of 15) working in FSM 1 and 2 schools and 5 teachers (33\% of 15) working in FSM 3 and 4 schools. A further 27 teachers (43\% of 63) were experiencing a decline in their commitment. Of these, 15 (56\% of 27) taught in FSM 1/ 2 schools and 12 (44\% of 27) taught in FSM 3/ 4 schools.

\subsection{Commitment and Resilience: Variations in VITAE Teachers' Effectiveness}

In the VITAE research a large majority of teachers did not leave the profession and did sustain their sense of commitment despite challenges. The work, lives, resilience and effectiveness of such teachers have been largely neglected in the research literature. This is perhaps, also, why there is little research prior to this on the nature of resilience which is fundamental to ongoing commitment and effectiveness. Resilience research has predominantly focussed upon the search for ways of

promoting a set of qualities in children and adolescents to 'foster a process of 
successful adaptation and transformation despite risk and adversity' (Benard, 1995: 1). The idea of resilience recognises the pain, struggle and suffering involved in the adaptation process but focuses more on strengths instead of deficits. The nature of resilience is multidimensional (Richardson et al., 1990; Benard, 1991, 1995; Gordon, 1995; Luthar et al., 2000; Henderson and Milstein, 2003). Firstly, it encompasses a personal characteristic of the individual or a personal trait (Block and Block, 1980). Benard (1995: 1) points to 'the biological imperative for growth and development that exists in the human organism and that unfolds naturally in the presence of certain environmental characteristics' and suggests a biological basis for resilient capacity:

We are all born with an innate capacity for resilience, by which we are able to develop social competence, problem-solving skills, a critical consciousness, autonomy, and a sense of purpose.

However, the VITAE research suggests that resilience should not be seen just as a biologically fixed quality, and that it is more than a set of personal traits. Rather, it develops along with and manifests itself as a result of a dynamic process within a given context. In other words it can be thought of as an evolving not a static concept. An individual may demonstrate resilience in a certain Scenario and/or in a certain professional/life phase, but fail to display similar qualities when these change. Benard (1995) calls for a caring and supportive environment which promotes cooperation, shared responsibility and a sense of belonging, and where individuals are helped to develop all the traits of resilience and thrive socially and academically.

Gordon (1995) also argues that a resilient personality is not sufficient to ensure increased competence, and that one must draw upon all their biological (temperament), psychological (internal locus of control) and environmental resources to increase competence. Those teachers in the VITAE study who had relatively stable identities which were supported by such factors, were sustaining their commitment and effectiveness.

Henderson and Milstein (2003) compare characteristics of resilient children, as described by Benard (1991), and those of resilient adults as noted by Higgins (1994). They claim that the process of resilience building is remarkably similar for children and for adults. Characteristics that both resilient children and resilient adults share 
include: socially positive relationships, adept problem solving, a sense of purpose and motivation for self-improvement.

Thus, the nature of resilience outlined here, although drawn mostly from a review of resilience research on children, may also be applied to teachers.

VITAE teachers had common characteristics and concerns according to their years of experience and, within these groupings, there were those whose perceived commitment was being sustained and others whose commitment was declining. It was not only in teachers' minds that commitment was perceived to be closely associated with perceived effectiveness - we found, also, there was a statistically significant association between commitment and effectiveness defined by pupil attainment.

In both our analyses of teachers' professional life phases and identities, we found that teachers' capacities to sustain their commitment (i.e. resilience) were influenced by their values and the contexts in which they lived and worked. Teachers' sense of identity (i.e. their self-understanding - Kelchtermans, 1993, 2005) was key to their capacities to sustain their commitment within all their professional life phases. These were found to consist of three dimensions: the personal (related to their lives outside school); the situated (related to their lives in school); and the professional (related to their values, beliefs and the impact on these of external policy agendas). These dimensions were not static. Change in one dimension of their world affect teachers' abilities to manage the others. At any given time, teachers were experiencing fluctuations of different intensity in these dimensions which affected the relative stability/instabilities of their identities as has been shown in the discussion of four 'Scenarios' in Chapter Seven.

The more extreme the Scenario, the more energy it took to manage and the more likely it was to test teachers' resilience. Thus, where teachers experienced relatively mild fluctuations (e.g. positive, stable personal life, few problems at school in teaching and learning and with pupil relationships or behaviour, few threats to their sense of self as professional) then the less they needed to call upon their resilience. 
For example, an ineffective or unsympathetic Head of Department or headteacher would tend to erode resilience at a time of personal or classroom crisis; so too would unsympathetic responses to additional pressures at home or during the sustained illness of a close relative or child. However, strong personal support, humane professional leadership or a combination of these, would result in the teacher sustaining resilience.

Thus resilience was found to be both a product of personal disposition and values, and socially constructed.

The VITAE research indicates that teacher commitment to their work is a necessary but insufficient condition for perceived and value added measures of relative effectiveness. Commitment must be sustained across the positive and negative Scenarios which they experience over a professional life span. This requires resilience. This research demonstrates that resilience comes from within but that the relative strength of such resilience is influenced also by external factors i.e. personal, professional and situational.

As the Scenarios in which teachers work become more complex - as in the case in FSM 4 schools - so it might be expected, that, in order to maintain commitment and effectiveness, teachers would need to be resilient. The data show that this is indeed the case. Figure 8.1 shows clearly that as Scenarios become more complex, so resilience among teachers became more difficult to sustain. Figure 8.2 shows that teachers in relatively unstable Scenarios were relatively more likely to work in FSM3 and 4 schools. 
Fig. 8.1: Scenarios and resilience

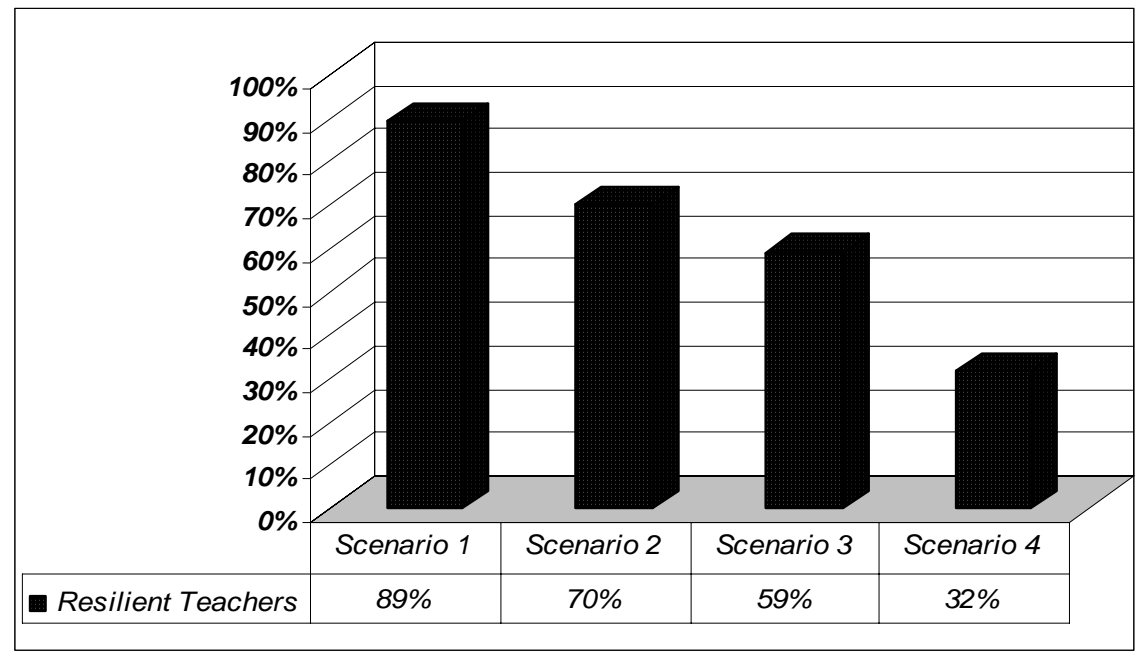

Figure 8.3 shows that the large majority of teachers in FSM 4 schools were resilient, but the smallest percentage of resilient teachers worked in FSM 3 schools (relative to the total teachers). These analyses suggest that:

- Teachers within early and middle careers were more likely to retain resilience than those in late career (Fig. 8.4)

- There were more teachers in stable Scenarios who maintained their resilience (Fig. $8.1)$

- Teachers who worked in FSM1 and 2 schools were more likely to experience relatively stable Scenarios than those who worked in FSM3 and 4 schools (Fig. 8.2)

- Teachers who worked in FSM4 schools were more likely to experience extremely unstable Scenarios than others (Fig. 8.2)

- Teachers who worked in FSM3 schools may be said to have been more likely to experience a greater range of Scenarios than others (Fig. 8.3)

The incidence of resilience among teachers is not always directly connected to school context as measured by the school FSM. For example, Fig. 8.3 shows that the large majority of teachers in FSM4 schools were still resilient. This may be because in order to survive in these challenging circumstances, it is necessary. However, our data has shown that many of these teachers were committed by disposition to working with 
pupils from disadvantaged backgrounds. This may, therefore, account for the higher levels of resilience. There were no significant differences between primary and secondary school teachers' resilience in different school contexts and professional life phases.

Teachers in FSM3 schools were less likely to be resilient that those in other schools (Fig. 8.3). This may be because these schools are still disadvantaged but, because they are not severely disadvantaged, do not receive as much extra support or enhanced resources. It may be, also, that teachers in these schools were less likely to be committed to working in the particular socio-economic contexts to which those in FSM4 schools had committed themselves; and so find it more difficult to sustain resilience.

Fig. 8.2: Scenarios and FSM

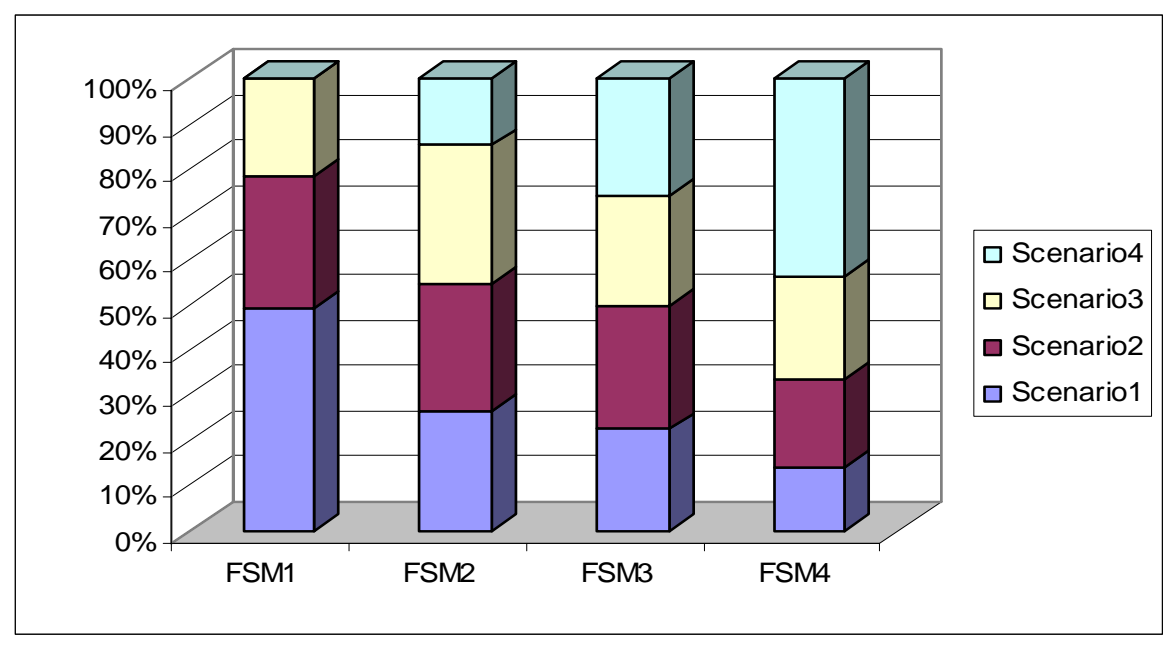

Fig. 8.3: Resilience and FSM

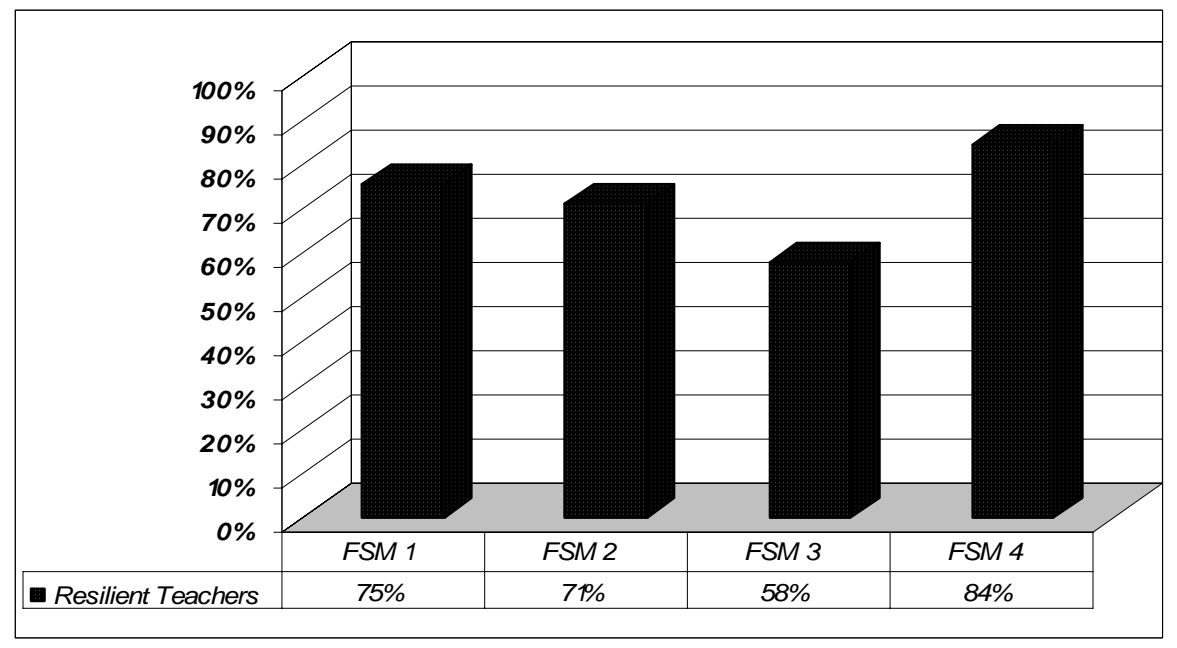


Fig. 8.4: Resilience and professional life phase

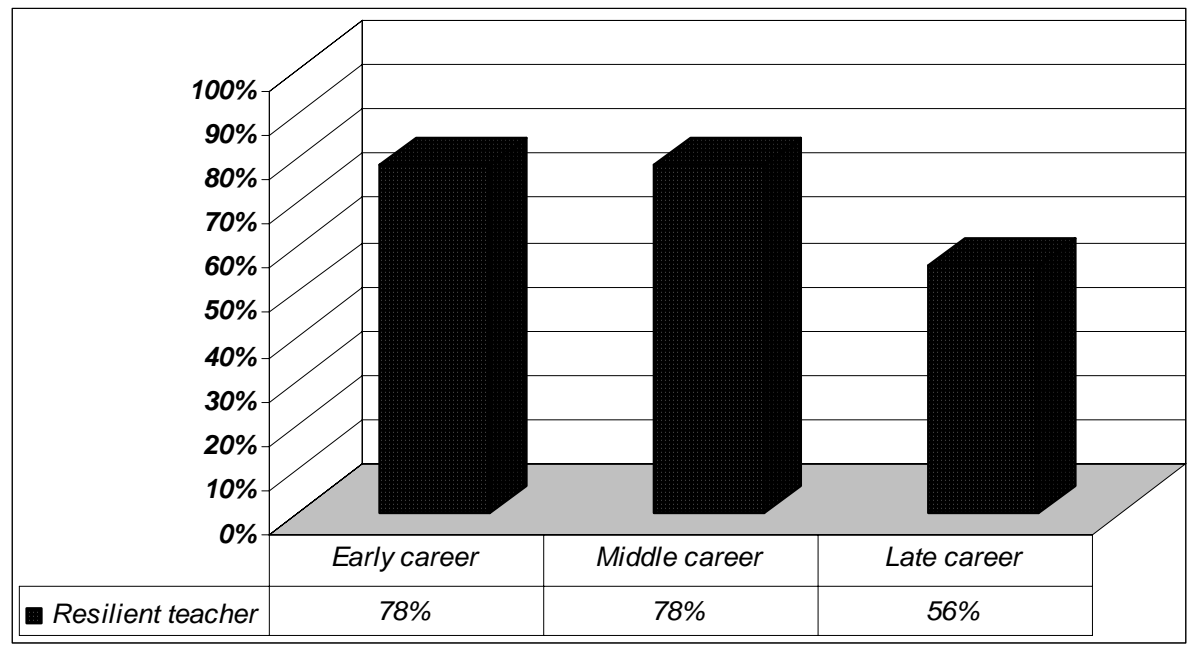

The VITAE research has revealed key differences between teachers in relation to the extent to which their commitment was being sustained or declining. Its design has enabled these differences to be analysed in terms of moderating factors such as professional life phase and teacher identities and mediating factors (the personal, the situated and the professional). We have been able to analyse teachers' commitment, also, by school phase, school context, teacher Scenarios and, uniquely, relate these to variations in teachers' effectiveness defined both by their own perceptions and pupil attainments.

\subsection{School phase}

There was a connection, for primary and secondary teachers, between feeling positive about particular influences and being able to sustain commitment; secondary teachers being proportionately more negative overall than primary teachers. For example, of the 166 primary teachers involved in the study, over one-third $(\mathrm{N}=59,36 \%)$ made positive comments regarding professional factors such as workload and external policies/initiatives. Of these teachers, $86 \%$ had sustained their commitment, compared to 7 teachers (14\% of 59) whose commitment had declined. It was a different picture for the 30 (18\% of 166) primary teachers who felt negatively about these issues. Half $(\mathrm{N}=15,50 \%)$ of these teachers were able to sustain their commitment ( 9 (60\% of 15$)$ in challenging circumstances. The remaining 15 teachers (50\% of 30) were experiencing a decline in their motivation. Likewise, of the 143 secondary teachers involved in the study, two-thirds $(\mathrm{N}=94,66 \%)$ responded 
positively regarding situated issues. The proportion of these teachers able to sustain their commitment was $71 \%$ of $94(\mathrm{~N}=67)$, whilst the proportion of secondary teachers who made negative comments $(\mathrm{N}=44,31 \%$ of 143$)$ and was able to sustain commitment was $43 \%$ of the 44 teachers $(\mathrm{N}=19)$.

Figure 8.5 shows that teachers in primary schools were significantly more likely to sustain their commitment ( $81 \%$ v $65 \%)$ and less likely to experience a decline in their commitment (19\% v 35\%) than their colleagues in secondary schools.

\section{Figure 8.5: Teachers' Commitment by School Phase}

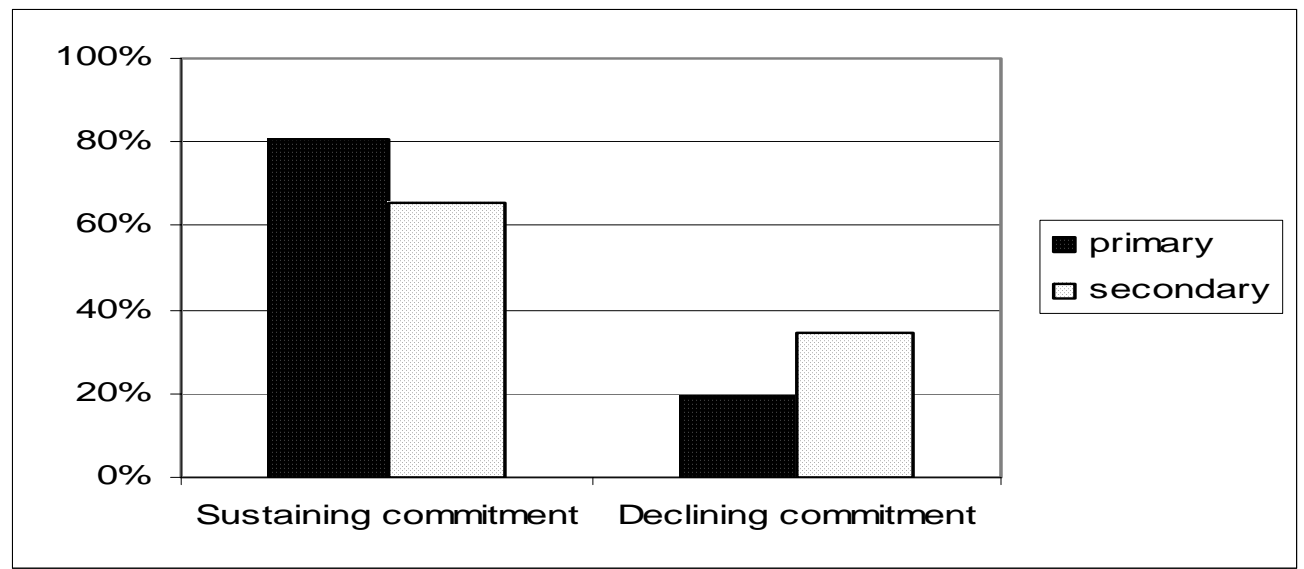

\subsection{Professional life phase}

Regardless of when they entered teaching, teachers were as likely to maintain their initial motivation for teaching. However, Figure 8.6 below shows that there was a relatively greater decline in commitment among 'late' professional life phase teachers. 
Figure 8.6: Teachers' Commitment by Professional Life Phase

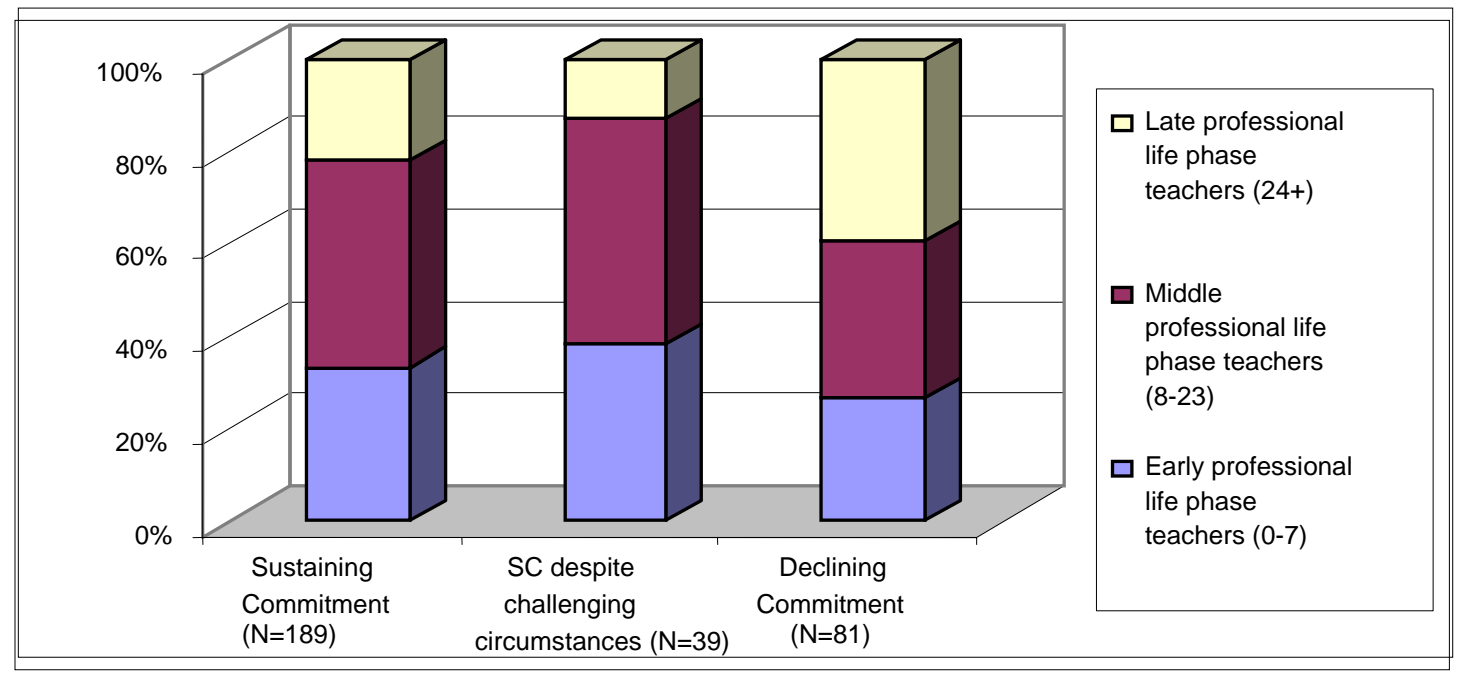

A breakdown by factors (professional) suggests that, for primary and secondary teachers, the 4-7 professional life phase was prominent in those teachers who are both positive and sustaining commitment. It was also the case that proportionately more teachers who were negative and experiencing declining commitment were in the 8-15, 24-30 and 31+ phases. In the case of the situated factors, the pattern was slightly different in that, for both primary and secondary teachers, those who were positive about situated issues and who were sustaining commitment were more likely to be in either the 4-7 or 8-15 professional life phases. The 8-15 phase was also prominent for those teachers who were negative yet sustaining commitment. Likewise, primary and secondary teachers who were positive or negative regarding personal factors were also more likely to be between 4 and 15 years of teaching.

\subsection{The school context influence}

Differences between teachers in different school phases, school SES (socio-economic status), and in different life and work Scenarios were also plotted. For example, in this phase, as in others, there were clear differences between Primary and Secondary school teachers. 
Figure 8.7: Key Characteristics and Distribution of Primary and Secondary Teachers (8-15)
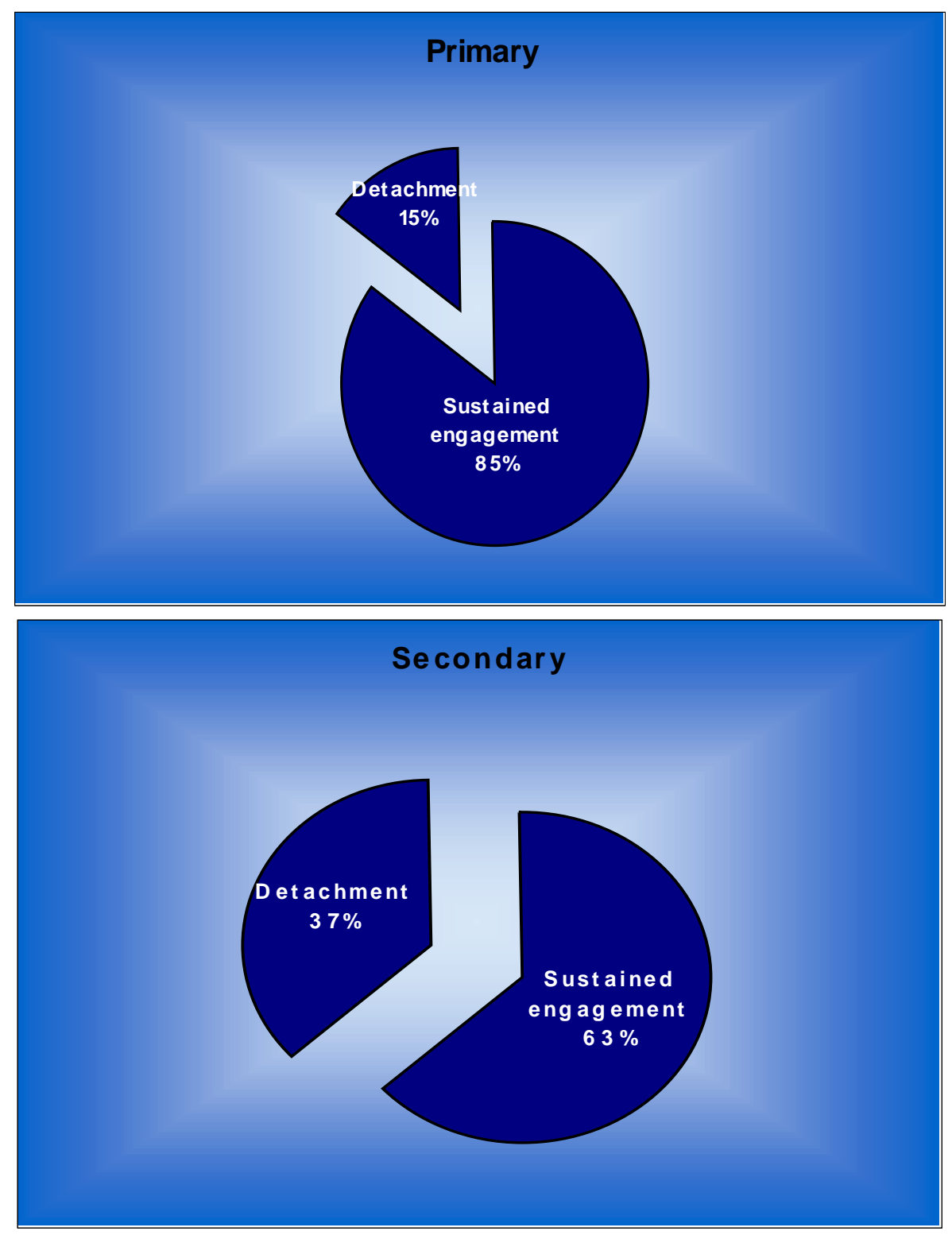

We also developed from the data four 'Scenarios' which challenged teachers capacity to sustain commitment. The complexity and intensity of the challenges varied in relation to the socio-economic status of the school. For example, whilst almost all teachers referred to deteriorating pupil behaviour and the impact of central government initiatives on workload and class composition, it was those in schools in areas of social and economic deprivation who referred more frequently to these, to lack of parental support and to associated problems of demoralisation, failing energy 
and ill health. It is this group of teachers, working in especially challenging circumstances that may be said to be at greater risk of sooner or later losing their motivation and commitment to their work.

\section{Figure 8.8: School Contexts by Teacher Scenarios}

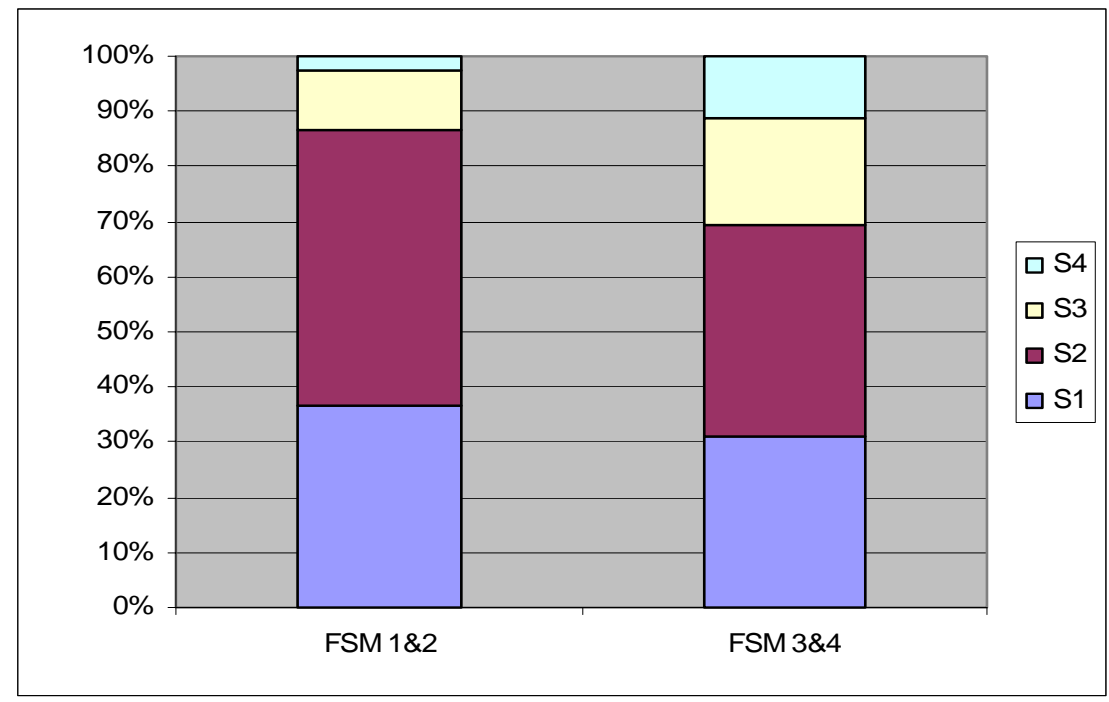

Our findings suggest that there is a difference in the range and intensity of pupil, parental and government originated challenges which teachers experience according to the relative level of socio-economically deprived contexts in which they work; and that teachers in secondary schools experience these more keenly and more frequently than those in primary schools. Teachers in these schools - particularly secondary teachers - seem to face not one or two but a combination of challenges as a regular feature of their day-to-day working lives. It is the extent to which the combination is able to be ameliorated by other intrinsic and extrinsic support that determines whether teachers are able to survive and - even within difficult circumstances - flourish. In other words, risk and resilience must be understood in the context of these policy, pupil, personal and practice factors.

These contexts must be of concern in terms of the focus upon raising quality in teaching, learning and achievement and the broader school improvement agenda. More important are their effects upon teacher motivation, commitment, job satisfaction and health. The majority of primary and secondary VITAE teachers continued to sustain to the values and purposes for becoming teachers and, regardless 
of school context, produced a similar range of pupil attainment results.

However, many were under considerable personal stress, whether this related to physical illness or stress in their home life.

\subsection{Influencing Factors}

1. Overall poor pupil behaviour was a consistent concern for teachers, and that was particularly the case for teachers in early and later professional life phases.

2. In-school support from leaders and other colleagues in school was a key influencing factor in teachers' perceived ability to sustain commitment.

3. Promotions and management and leadership responsibilities outside the classroom (79\% of all teachers) played a key role in teacher workload, worklife management and a sense of effectiveness from year four of experience onwards.

4. The 8-15 phase was a key watershed in determining levels of teachers' long term commitment. In this phase, work-life balance began to emerge as a significant concern.

5. Life events played a positive or negative role in teachers' commitment and this was particularly the case in mid to late professional life phases (16-23 and 2430). For these groups, also, excessive paperwork, policy and heavy workloads were key hindrances to their perceived effectiveness.

6. The socio-economic status (SES) of the school affected teachers' lives and perceptions of effectiveness. Teachers in high SES schools had more positive views of pupil behaviour, those in low SES schools, less positive views; teachers in lower SES schools were more likely to suffer from ill-health than those in higher SES schools.

Analysis of two years value added data shows that the attainment by pupils of $65.5 \%$ and $68.3 \%$ of all the teachers was 'as expected' or 'above' expectations. However, in all professional life phases, pupils of teachers in downward trajectories who were, by definition, less committed and resilient were more likely to perform below 
expectations than pupils of teachers in upward trajectories ${ }^{24}$.

Only around half were above or as expected, compared with two thirds of those with an upward trajectory. Proportionately, nearly twice as many of the downward group had below V.A. results (31\%) compared with the upward group (only 17\%). This trend is consistent over the two year period and statistically significant.

Figure 8.9 shows the relationships between teachers' professional life phase trajectories and pupil attainment (Cohort 1), as illustrated in Table 8.2. Figure 8.10, based on Table 8.3, indicate the relationships for Cohort 2.

Figure 8.9: Teacher Professional Life Phase and Value Added Pupil Attainment

(Cohort) 1

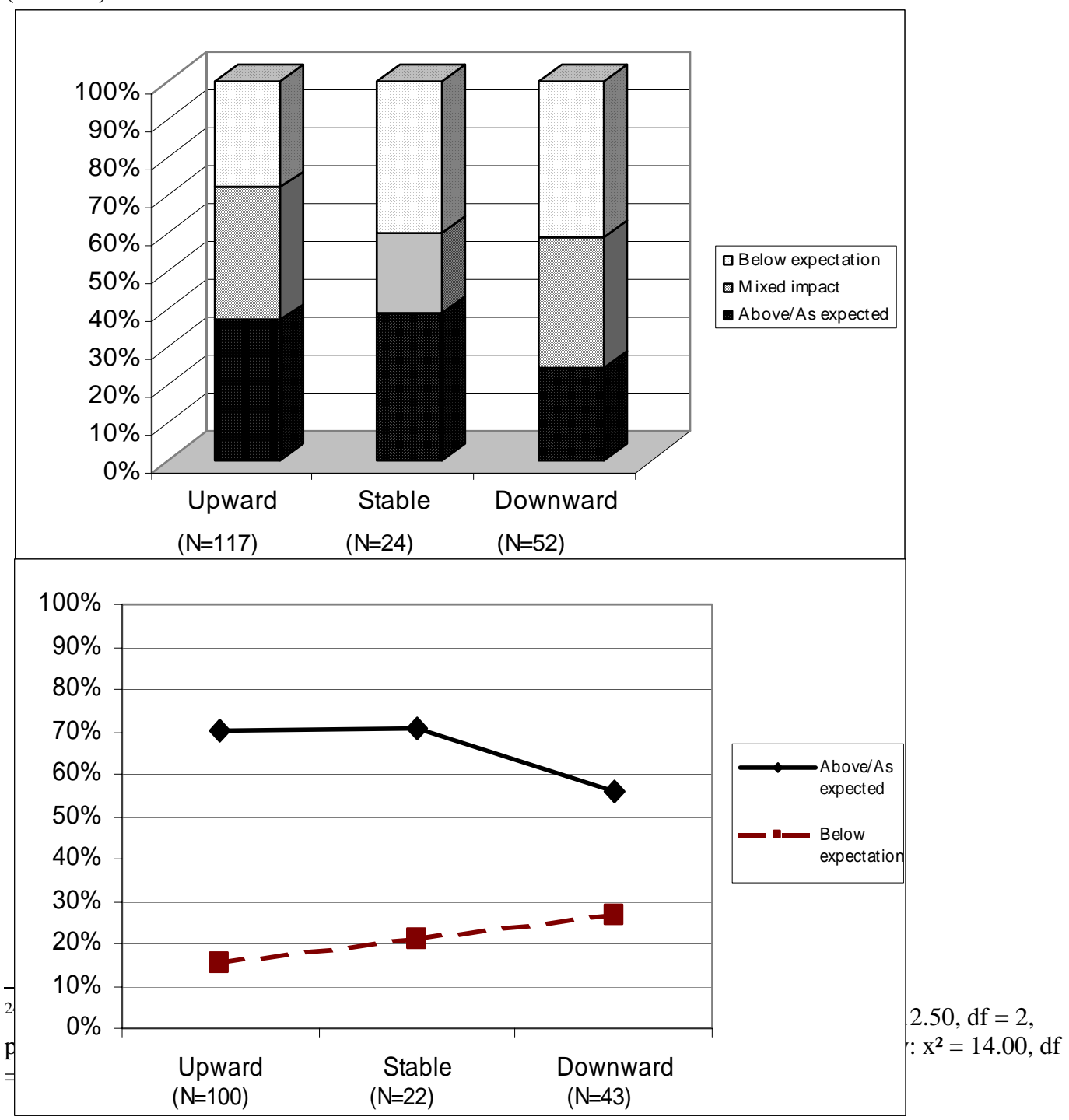


Table 8.2: Crosstabulation of professional life phase trajectories and pupil attainment (Cohort 1)

\begin{tabular}{|l|l|l|l|}
\hline & $\begin{array}{l}\text { Above/ As } \\
\text { Expected }\end{array}$ & Below Expectation & $\begin{array}{l}\text { Mixed Impact } \\
\text { (primary teachers) }\end{array}$ \\
\hline Upward & $82(70 \%)$ & $18(15 \%)$ & $17(15 \%)$ \\
\hline Stable & $17(71 \%)$ & $5(21 \%)$ & $2(8 \%)$ \\
\hline Downward & $29(56 \%)$ & $14(27 \%)$ & $9(17 \%)$ \\
\hline
\end{tabular}

Fig 8.10: Teacher Professional Life Phase and Value Added Pupil Attainment (Cohort 2)

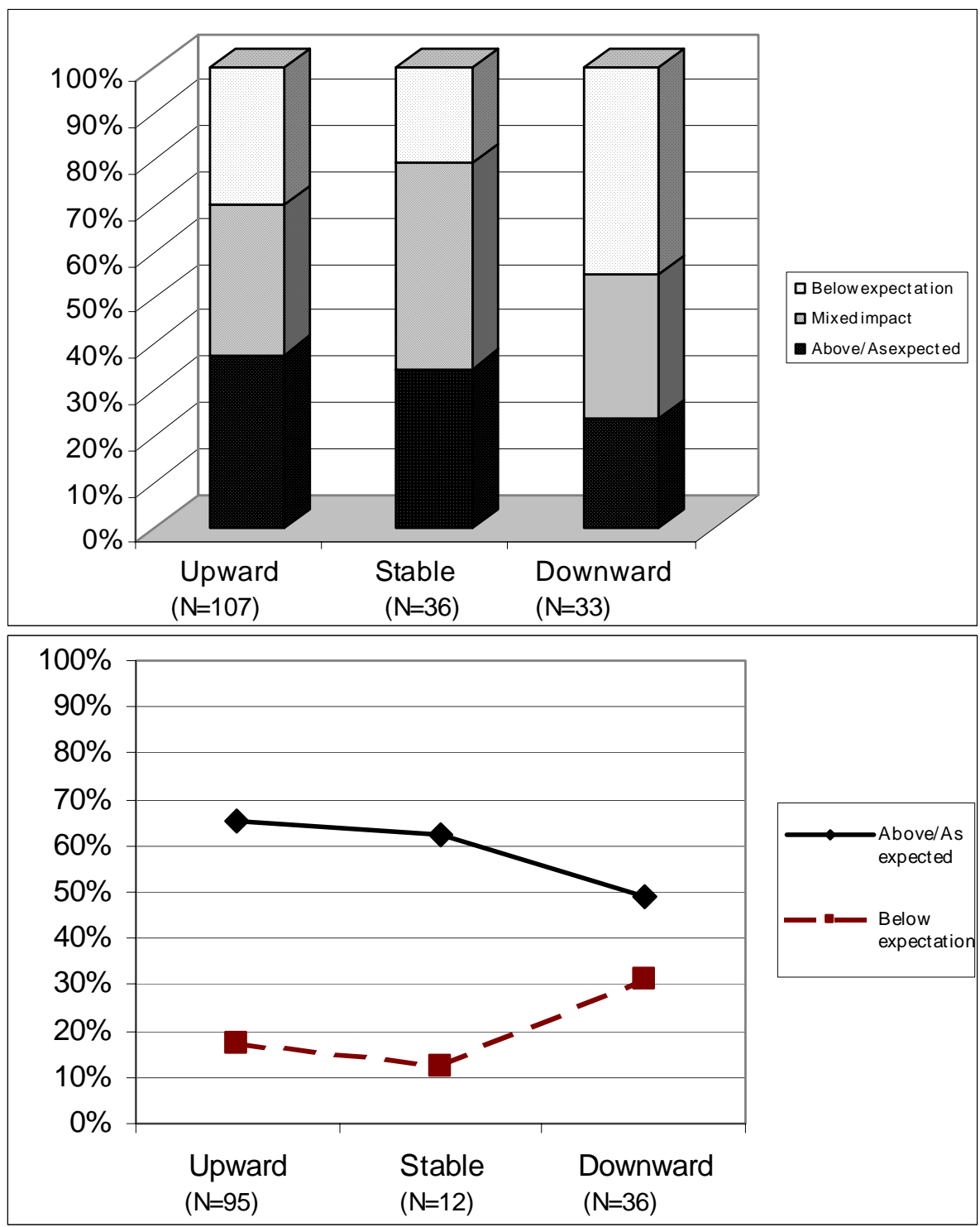


Table 8.3: Crosstabulation of professional life phase trajectories and pupil attainment (Cohort 2)

\begin{tabular}{|l|l|l|l|}
\hline & $\begin{array}{l}\text { Above/ As } \\
\text { Expected }\end{array}$ & Below Expectation & $\begin{array}{l}\text { Mixed Impact } \\
\text { (primary teachers) }\end{array}$ \\
\hline Upward & $75(65 \%)$ & $20(17 \%)$ & $20(17 \%)$ \\
\hline Stable & $10(63 \%)$ & $2(13 \%)$ & $4(25 \%)$ \\
\hline Downward & $22(49 \%)$ & $14(31 \%)$ & $9(20 \%)$ \\
\hline
\end{tabular}

Further analyses, taking into account the analyses on teachers' identities have shown also that these perceptions of commitment and the association between commitment and effectiveness are not confined to teachers in any single professional life phase. Thus, our data challenge notions of linear progression in terms of the growth of effectiveness over a teaching career. In other words, there were teachers within each professional life phase who perceived were themselves to be more and less effective and the value added measures of relative effectiveness were also found not to be associated with particular professional life phases. Thus, the analyses of professional life phases and teacher identities provide challenge of linear 'stage' and 'expertise' development theories i.e. that teachers begin their careers as 'novices' and move through various stages to become 'experts'. They provide explanations for this through investigations of the different positive and negative 'Scenarios' which provide challenges to the stability of teachers' identities and the factors which help or hinder teachers in their management of these. There are, it seems, strong associations between commitment, resilience and effectiveness.

The key issues which arose from this 'cut' of the analysis of variations in the commitment and resilience of teachers across all professional life phases were:

i) Teacher commitment and its effects on pupil attainment vary within and across professional life phases.

ii) The majority $(74 \%)$ of teachers were maintaining their sense of commitment. However, a sizeable minority (26\%) were not. Thus, more than 1 in 4 students were receiving teaching from teachers who were not as effective as they might be. 
iii) Primary school teachers were more committed than Secondary school teachers in each professional life phase and over all phases $(81 \%$ and 65\%). Twice as many Secondary school teachers as Primary teachers were less committed over all phases (35\% and $19 \%)$.

iv) Teachers in downward trajectories, regardless of professional life phase, were less committed and resilient and their pupils were more likely to perform below expectations than pupils of teachers in upward trajectories.

v) Overall, there is a statistically significant association between teachers in different professional life phases who have high levels of commitment and their pupils' attainment.

\subsection{Conclusions: How Teachers Sustain Their Commitment, Resilience And Effectiveness}

Commitment and resilience are multi-faceted and unstable constructs. Their nature is determined by the interaction between the internal assets of the individual and the external environments in which the individual lives and grows. This part of the Report has discussed the initial motivation and sustained commitment (resilience) of teachers, in relation to their effectiveness, using three broad groupings: teachers who had sustained their commitment; teachers who were sustaining their commitment in spite of challenging circumstances; and, those whose commitment had declined. Thus, the manifestations of commitment and resilience vary from person to person and fluctuate over time.

\subsection{Variations in Work Circumstances and Effectiveness}

Teachers' work circumstances vary in positive and negative ways. The evidence from this research demonstrates that, whilst the physical work setting is important, when talking about their effectiveness teachers attach more importance to three other factors: leadership (of the school and department); relationships with colleagues; and relations with and behaviour of pupils.

The quality of the leadership, both at school (and departmental) level, was frequently mentioned by teachers as playing a major role in their sustained commitment and their motivation to remain or leave a school. Eighty-one per cent of primary teachers said that the school leadership had an impact on their teaching, compared to nearly three- 
quarters $(73 \%)$ of secondary teachers. The aspects of leadership which teachers regarded as a positive influence were: the ability to communicate with staff, being approachable, demonstrating a commitment to the school, praising and rewarding staff contribution to the school, feeling supported in decisions, being respected by parents, pupils and staff, and having a visible presence around school. Secondary school teachers also commented upon the mitigating influence of a supportive departmental leadership in the case of poor school level management and support.

The support of colleagues on whom teachers could draw and from whom they could seek advice and discuss issues relating to practice emerged as a theme across both primary and secondary phases, although a higher proportion of primary teachers (59\%) mentioned relationships with colleagues as important to their teaching, compared to secondary teachers (35\%). Teachers in FSM 3 and 4 schools tended to mention the sense of teamwork and common purpose that they shared with other teachers more often (85\%, compared to 73\% in FSM 1 and 2 schools), but regardless of school context, teachers stressed the importance of having someone to talk to when things went wrong and having the time and space to discuss problems and ways of dealing with them.

Where these relationships are positive, then teachers' commitment is enhanced. Where any one of these is negative, then their commitment, and their resilience, are challenged.

\subsection{Variations in Professional Circumstances and Effectiveness}

The majority of teachers in the study had joined the profession because they wanted to 'make a difference' to the learning lives of their pupils. This was seen as central to their identities as teachers. Their professional identities were centred upon this aspiration and most had sustained it either because of or in spite of the impact of external policy imperatives, school-related or personal factors. However, it is clear that teachers either had been or were in the process of being challenged through different Scenarios. Such Scenarios were in part the consequence of school contexts and personal and professional life phases, and in part the result of changes in personal, work or professional circumstances. They varied in complexity. 
Nearly two-thirds (65\%) of secondary and over half $(51 \%)$ of primary teachers identified poor behaviour as an issue that, at times, hindered their teaching. This problem was not more highly reported in challenging schools. In fact the percentage of teachers in challenging schools reporting poor pupil behaviour was lower than teachers in FSM 1 and 2 schools. However, the problem was exacerbated by a number of potential factors which seemed to be more prolific in challenging schools such as a lack of effective and consistent behaviour management and a high pupil mobility/transient pupil population. Teachers across the sample reported the need for effective behaviour management, often linked to strong leadership, as a key element for sustaining commitment. There were also differences relating to professional life phase. $64 \%$ of teachers in the $31+$ professional life phase reported that poor or deteriorating pupil behaviour had an impact on their teaching, compared to $50 \%$ of teachers in the 0-3 professional life phase. Teachers in the 0-3 and 4-7 professional life phases in particular were keen to have a clear point of contact at a senior level to refer problems and felt uncertain and vulnerable when this was not in place. In addition, cases were reported where there was no place for disruptive pupils to be sent away from the classroom, a lack of additional classroom support, and little time invested in helping teachers develop their own capacity and skills to manage difficult behaviour. Thus, the more complex the professional life phase and identity Scenarios, the greater the challenge to teachers' beliefs that they can 'make a difference'.

Teachers' responses to different Scenarios in this research were influenced by a combination of factors relating to the strength of their own values, effects of pupil cohorts and school locations (FSM) and the effects of pupil relationships, pupil behaviour, school leadership and colleagues, external policies, professional life phase and life circumstances. These factors influenced teachers' capacities to be committed and resilient and their ability to enhance and sustain their effectiveness.

\subsection{Variations in Life Circumstances and Effectiveness}

As with other workers, teachers' life circumstances vary in positive and negative ways. Patterns of variations have been identified within and across professional life phases and, the evidence from this research strongly suggests that such variations affect teachers' work lives and perceptions of effectiveness. 
Teaching at its best is an emotional and cognitive endeavour which, unlike other professions, involves face to face interaction with groups of willing and unwilling learners. In such challenging circumstances, maintaining emotional health is vital. Whilst specific variations in life circumstances cannot be predicted, it is important that schools, and school leaders in particular, promote cultures in which positive responses to tensions or crises in teachers' personal lives are able to be made.

The personal support received from colleagues or partners was an important theme for both primary and secondary teachers, although more explicit comments were made by primary teachers in relation to this issue. Teachers often highlighted the support they had from colleagues when faced with personal issues (e.g. health, marriage break-up, caring for parents, children). This support was particularly important at times of personal crisis.

In this research, there is evidence of the use of strategies which had the effect of retaining teachers who otherwise would have left the school or profession, or maintaining their commitment which otherwise would have been lost, and of sustaining their effectiveness.

Drawing upon the VITAE findings on teachers' professional lives and identities, it appears that the interaction between teachers' sense of efficacy, professional/personal identities and their professional and personal contexts in each professional life phase is a sophisticated process and that it contributes strongly to the professional outlook, perceived well-being, resilience and effectiveness trajectories of teachers. The significance of creating positive work conditions, meeting teachers' professional and personal needs and minimising teacher burnout is the key to encouraging teachers' resilience, promoting teacher well-being and positive career trajectories and ultimately, improving the conditions for teachers' effectiveness in relation to pupils' performance.

The agendas relating to leadership, pupils, workload, etc, were important to both primary and secondary teachers' purposes and sense of achievement and clearly went beyond the restricted agenda of the national curriculum and/or national strategies, though more for primary than secondary teachers. A total of 64 primary teachers 
(39\% of all 166 primary teachers) and 30 secondary teachers (21\% of all 143 secondary teachers) indicated that fulfilment of their broader educational agendas was being challenged by what they perceived as the consequences on their work lives of external agendas. Deteriorating pupil behaviour (a consequence of social trends), coupled with the consequences of the 'inclusion' agenda and increasing paperwork demanded by government policy agendas, were the themes most frequently raised.

Increased workload, for teachers in the VITAE project, meant not only longer times spent in working outside the school for the purposes of planning and assessing, it also meant calling upon reserves of emotional energy needed in order to teach in classrooms which contained a broader range of pupils in terms of ability and behaviour; it meant that increased intellectual energy was needed in order to implement new curricula in new ways; and it meant meeting the intellectual and emotional challenges of mediating between the increasingly instrumental focus of the 'performativity' and 'accountability' agendas and their own moral purposes in order to satisfy both. In the end, for most, it was their moral purposes which kept them in teaching, and which enabled them to maintain their motivation, self-efficacy and commitment. Most were able to sustain their commitment despite the professional challenges which tested their resolve, although the group of secondary teachers who felt negatively about these issues were less likely to cope, with only one-third ( $\mathrm{N}=11$, $34 \%$ of 32 ) able to sustain the commitment.

Together, these challenges increased the workloads of all the teachers. Yet simply to identify workloads in general as having a negative effect on moral purposes and effectiveness, as a number of surveys have suggested (e.g. GTCE, 2003) is clearly to underestimate the complexity of work and life contexts which together impact to varying degrees upon teachers, the degree of resilience needed by teachers in all schools, and the factors that may work to strengthen or weaken resilience and identity.

The analysis of teachers in different work contexts found that whilst almost all teachers referred to deteriorating pupil behaviour and the impact of central government initiatives on workload and class composition, it was those in schools in areas of social and economic deprivation who referred more frequently to these, to lack of parental support and to associated problems of demoralisation, failing energy 
and ill health. It is this group of teachers, working in especially challenging circumstances, that may be said to be at greater risk of sooner or later losing their motivation and commitment to their work.

In comparison to other professional, personal and situational factors that influence teachers' work, resilience in teachers is a soft but important key factor that bears significant meaning for teacher effectiveness. It is soft in the sense that it is dynamic and complex in its qualities and characteristics, and heterogeneous in its manifestations in different contexts, at different times and in different people's perceptions. Underlying resilient teachers' effectiveness is their strength and determination to fulfil their original call to teach and to manage and thrive professionally.

Rutter (1985) defines resilience as facing '... stress at a time and in a way that allows self-confidence and social competence to increase through mastery and appropriate responsibility' (cited in Gordon et al., 2000: 1). The need to foster teachers' sense of resilience is twofold: firstly, it is unrealistic to expect students to be resilient if their teachers, who constitute a primary source of their role models, do not demonstrate resilient qualities (Henderson and Milstein, 2003). Secondly, an understanding of teacher resilience in the process of meeting prescribed targets and managing work-life tensions over the course of a career and in different contexts will contribute to the existing knowledge of teacher professional development, commitment and effectiveness. More importantly, it provides a new perspective on teacher quality, effectiveness and retention issues. Research on teacher retention tends to focus on factors affecting teachers' decision to leave the teaching profession. Instead, what is required is a better understanding of the factors that have enabled the majority of teachers to sustain their motivation, commitment and, therefore, effectiveness in the profession. 


\section{PART FIVE \\ CHAPTER NINE: \\ ASSOCIATIONS BETWEEN VARIATIONS IN TEACHERS' \\ WORK, LIVES AND EFFECTIVENESS: \\ SUMMARY OF FINDINGS AND CORE MESSAGES}

\subsection{Introduction}

VITAE is the most comprehensive, large-scale and extensive study of teachers' work and lives ever undertaken. Because it was over real time, using mixed-method approaches over a three year period, it was able to take a multi perspective view of stability and variation among teachers. It investigated their experiences, and the moderating and mediating influences on these in different phases of their professional and personal lives and identities. It also investigated teachers' perceived effectiveness and relative effectiveness as defined by value-added measures of pupil progress and attainment. It was, therefore, able to generate both a more detailed and a more holistic view of teachers' work and lives than has been possible in previous studies. Teachers' perceived and relative effectiveness was found to be moderated by their professional life phases and identities; and mediated by personal, professional and situated factors. Commitment and resilience were found to be key outcomes of the moderating and mediating influences and these were associated with both perceived effectiveness and effectiveness defined by pupil attainment. They varied between primary and secondary teachers within and across each professional life phase and varied also, for a significant number of teachers in secondary schools, according to the level of socioeconomic advantage and disadvantage of the school. We believe that this is the first time that research has found associations between these mediating and moderating factors and levels of pupils' performance in value added attainments in national tests at age 7 (Key Stage 1), 11 (Key Stage 2) and 14 (English and maths, Key Stage 3). 


\subsection{Variations in Effectiveness}

\subsection{Teacher Effectiveness}

Effectiveness is a multi-dimensional concept. This study has found it useful to define effectiveness in two ways:

i) $\quad$ Perceived effectiveness (relational) As defined by teachers themselves, this refers to their abilities to make a difference in pupils' attitudes, motivations, behaviours, measurable attainments and longer term achievements. This may be associated with teachers' accounts of comparisons between their own past and present effectiveness and factors which influence these;

ii) Effectiveness defined by pupil progress and attainment (relative) This refers to the contextual value-added pupil scores in English and maths and involves comparison between measurable attainments of pupils of teachers of similar experience working in schools in similar socio-economic circumstances.

\subsection{Summary Findings}

2.2.1 Teachers vary in their relative and relational effectiveness and such variation is associated with their management of the impact of personal events and circumstances, pupil behaviour, school leadership and culture, workload, changes in external policies or a combination of these within each professional life phase.

2.2.2 Effectiveness does not necessarily grow in relation to time in teaching. Experience does not fully account for teachers' perceived or relative effectiveness.

2.2.3 For teachers in all professional life phases for whom value-added or contextual results were available ( $\mathrm{N}=193$ - cohort $1 ; \mathrm{N}=176$ - cohort 2), most believed that they had become more effective over time but that this had not been an even growth.

2.2.4 In each of the two cohorts, pupils of around two-thirds of teachers over the period of the research attained at or over the level expected $(66 \%$ and $61 \%$ respectively). In a minority of cases, however, progress was significantly 
below that expected given the pupil intake and prior attainment of the class involved. These teachers were spread across each of the professional life phases.

2.2.5 The study of relative effectiveness revealed the existence of significant variance between teachers in terms of pupils' cognitive progress. In Year 6 and 9 this indicated that 15 per cent to 30 per cent of the variance was associated with the teacher, after control for the influence of pupil background and prior attainment. For pupil progress, the teacher's influence was far stronger than that of the pupils' background characteristics such as age, gender, EAL status or low income.

2.2.6 The average ability level of the class, as well as pupil characteristics, was also found to affect pupil progress in Year 9, especially in maths. Pupils in Year 9 made more progress if taught in groups that had a higher average level of attainment and less progress when taught groups with lower average attainment, even taking into account their own prior attainment levels. This result may, at least in part, be mediated by the use of setting by 'ability'. Setting is common at Key Stage 3, especially in maths, and can have differential impacts for pupils.

2.2.7 At the primary level, teachers showed a fair degree of stability in the relative effectiveness in teaching maths and English. There was less stability across years, but a group of broadly more effective teachers could be distinguished from a group of broadly less effective teachers. There was, however, much variation, suggesting that teachers may be more, or less, effective in particular years.

\subsection{Moderating Factors in teachers' work, lives and effectiveness}

\subsection{Teachers Professional Lives and Effectiveness}

Analysis of teachers' professional life phases suggested that there was an important interaction between teachers' work, lives and experiences and their perceived effectiveness. Recognising the impact of such interaction between situational, external (structure), professional and personal influences was of crucial importance in seeking to achieve an holistic understanding of teachers' professional lives. In particular, situated factors - leadership of school and department, staff collegiality, roles and 
responsibilities, and teacher-pupil relationships and behaviour of pupils - were positive and negative contributing influences to teachers' motivation, commitment and resilience, and perceived effectiveness across all professional life phases.

Teachers' professional life phases were by no means static, but dynamic in nature. The interaction between teachers' commitment, resilience and a range of influential factors in their work and personal contexts was a sophisticated and continuous process and impacted differentially on their motivation, commitment and perceived effectiveness within the same and across different phases of their professional lives. Supportive school cultures (leadership and colleagues) were especially important for teachers in early and late professional life phases, though for different reasons. For teachers in the early phases of their career, in-school support promoted their professional growth, whilst for teachers in the later phases of their career, a supportive school culture provided external strengths for them to sustain their commitment in times of change. Heads of departments and key colleagues were key mediating influences on their self-efficacy and morale, especially in the first fifteen years.

Poor leadership, adverse personal events and work-life tensions were key negative influences on teachers' capacities to sustain motivation and commitment in all phases. There were 'generational' factors which applied to variations in teachers' work and lives. For example, adverse personal events in later years of teaching (16-30), when combined with the pressure of additional responsibilities and negative pupil behaviour, policy and school leadership, challenged teachers' resilience more than they challenged those in other years of teaching. This occurred especially among secondary school teachers.

Additional workload, which was a consequence of additional out-of-classroom responsibilities at times when many teachers were still developing their classroom expertise and when teachers in mid and late career were likely to experience work-life tensions, challenged their commitment and perceived effectiveness and - in some cases - physical, emotional and mental health. 
Work-life tensions were a special concern for teachers in the 8-15 and 16-31 professional life experience phases. One in four teachers in the 8-15 phase were beginning to feel detached from their commitment due to heavy workloads which were perceived to act against effectiveness. Half of teachers $(\mathrm{N}=59)$ in the later (16-31 years) phase were struggling with work-life management issues as a result of events in personal lives combined with the weight of additional responsibilities. Many teachers in the project had been given out of classroom management responsibilities at an earlier phase (4-7 years) of their working lives than has been reported in previous studies (e.g. Hilsum and Start, 1974; Huberman, 1993; Maclean, 1992). This is a period in which teachers, whilst consolidating their professional identities in the classroom, have to manage their additional responsibilities. These responsibilities continued, and in some cases intensified or expanded, during the span of their working lives. Heavy workloads began to affect teachers' perceived effectiveness from 4 years of experience onwards, and were associated with a decline in perceived effectiveness of some teachers. This continued to be an issue in each subsequent professional life phase.

Whilst there were a number of common critical influences which affected teachers positively or negatively over the course of their professional lives, there were variations in the impact of these that contributed to teachers' perceived effectiveness as their careers developed. The analysis suggested that although situated factors (e.g. practice settings and pupils), particularly in the form of support or lack of support in the school environment, had the greatest perceived impact on teachers' work in their early professional life phases, the tensions between work and life also played a significant role in different phases of their professional lives. Further, it was the relative intensity of the influences on these that impacted differentially on teachers' work in different phases of their professional lives and which, ultimately, led to significant change in teachers' perceived effectiveness and professional life trajectories. To understand variations in teachers' work and lives as well as their perceived effectiveness, one has to understand variations in the impact of these critical influences on teachers' feelings of being an effective teacher, needs for professional development, and tensions in managing and sustaining a healthy work-life balance over the course of their professional lives. 


\subsection{Summary Findings}

3.2.1 Teachers had similar professional needs and concerns within each of six professional life phases. These related to experience rather than age.

3.2.2 Teachers' professional needs, concerns and the influences upon these varied across their professional work lives.

Table 9.1: Teachers' Professional Life Phases

Professional life phase 0-3 - Commitment: Support and Challenge( $N=26,8 \%$ of 309)

Sub-groups: a) Developing sense of efficacy (60\%); or

b) Reduced sense of efficacy (40\%)

Professional life phase 4-7 - Identity and Efficacy in Classroom (N=75, 24\% of 309)

Sub-groups: a) Sustaining a strong sense of identity, self-efficacy and effectiveness (49\%); or

b) Sustaining identity, efficacy and effectiveness (31\%); or

c) Identity, efficacy and effectiveness at risk (20\%)

Professional life phase 8-15 - Managing Changes in Role and Identity: Growing Tensions and Transitions ( $N=86,28 \%$ of 309$)$

Sub-groups: a) Sustained engagement (76\%); or

b) Detachment/ loss of motivation (24\%)

Professional life phase 16-23 - Work-life Tensions: Challenges to Motivation and Commitment ( $N=46,15 \%$ of 309 )

Sub-groups: a) Further career advancement and good results have led to increased motivation/commitment (52\%); or

b) Sustained motivation, commitment and effectiveness (34\%); or

c) Workload/managing competing tensions/career stagnation have led to decreased motivation, commitment and effectiveness (14\%)

Professional life phase 24-30 - Challenges to Sustaining Motivation (N=52, $17 \%$ of 309)

Sub-groups: a) Sustained a strong sense of motivation and commitment (54\%); or

b) Holding on but losing motivation (46\%)

Professional life phase 31+-Sustaining/Declining Motivation, Ability to Cope with Change, Looking to Retire ( $N=22,7 \%$ of 309)

Sub-groups: a) Maintaining commitment (64\%); or

b) Tired and trapped (36\%)

3.2.3 Within each phase there were more teachers who were on upward trajectories (i.e. whose sense of effectiveness was increasing) than those who were not. 
Teachers in the later phases of their professional lives expressed more negative views of the influence of external policies on their work than those in earlier professional life phases.

\subsection{Teacher Identities and Effectiveness}

The settings in which teaching occurs vary in the complexity and intensity of the emotional demands which they make on teachers to maintain their effectiveness. The state of teachers' emotional identities is a key to their sense of effectiveness. Teachers' identities are also closely associated with their professional and personal values and aspirations. These may be affected by key elements of their personal, professional and work contexts. The research found that variations in teachers' identities occurred in response to their capacities to manage the fluctuations in various Scenarios which exercised positive and/or negative influences upon their sense of stability, commitment and resilience.

Evidence from teachers identified a close association between their sense of positive, stable identity and their self-efficacy and agency - their belief that they could 'make a difference' in the learning and achievement of their pupils. Maintaining a positive sense of identity was also closely related to teachers' sense of commitment, resilient and well-being. Thus, the relative stability/instability of teachers' identities was a key factor in teachers' perceived effectiveness.

Identities themselves comprised three dimensions: the personal, the situated and the professional. These dimensions were stable or unstable, positive or negative, depending upon work and life events and experiences. Teachers' identities within and across all professional life phases were subject to fluctuation. Teachers' capacities to maintain positive (stable or unstable) identities were influenced by their management of the interactions between the strength of their own beliefs and values, the support received from school leaders and colleagues, their relationship with pupils, and support from outside the school. 
Teachers within each professional life phase experienced one (or more) of four different positive and negative Scenarios (described in Table 9.2) which affected the stability of their identities. Each Scenario was defined by the extent to which each of the three dimensions was dominant.

The research found that a total of 73 teachers remained in Scenario 1 (the three dimensions in balance) throughout the project. Likewise, 106 teachers remained in Scenario 2 (one dominant dimension). Twenty-two teachers remained in Scenario 3 (two dominant dimensions), and 16 teachers remained in Scenario 4 (all three dimensions unstable). In contrast, a total of 78 teachers experienced a transition between Scenario groups during the project; that is, they moved from one Scenario group to (at least) one other during the three years. A further 21 teachers experienced a transition within their Scenario i.e. the degree of dominance shifted from one dimension (e.g. professional) to another (e.g. personal). The largest proportion (62\%) of teachers in Scenario 1 taught in schools in relatively privileged contexts (FSM 1/2), whereas the majority of teachers in Scenario 4 (72\%) taught in relatively less privileged contexts (FSM 3/4).

\subsection{Summary Findings}

4.1.1 Teacher identities were formed by three interacting components: the personal, the professional, and the situated.

4.1.2 There was an association between those who were not managing Scenarios well and those whose commitment and resilience were declining, and whose pupils' made poorer progress (relative effectiveness).

4.1.3 The majority of teachers $(67 \%)$ had a positive sense of identity and were managing relatively stable Scenarios $(79 \%)$. However, one in three teachers were not.

4.1.4 There were always fluctuations within and between, but different Scenarios which teachers experienced caused different degrees of fluctuation, from the mild (Scenario 1) to the extreme (Scenario 4). The greater the degree of fluctuation, the more energy was needed for this to be managed, the greater the need for support and the greater the risk to commitment and the capacity to sustain commitment (i.e resilience). 
Table 9.2: Teacher Identity Scenarios

Scenario 1 (35\% of 295, N=102):

Dominant characteristics of group: Are more likely to be in the $4-23$ professional life phases, teach in FSM 1 and 2 schools, and be highly motivated, committed and self-efficacious

Resilient teachers (79\% of 102, N=81): have positive well-being and strong sense of agency

Vulnerable teachers ( $21 \%$ of $102, \mathrm{~N}=21)$ : have negative well-being and mixed sense of agency

Scenario 2: (44\% of 295, N=131)

Dominant characteristics of group: Are more likely to be in the 4-7 or 8-15 professional life phases, teach in FSM 2 schools, be highly motivated, committed and self-efficacious, and have negative well-being

Resilient teachers (65\% of 131, N=85): have a mixed sense of agency

Vulnerable teachers (35\% of 131, N=46): have a weak sense of agency

Scenario 3: (15\% of 295, N=44)

Dominant characteristics of group: Are more likely to be in the 4-7 or 24-30 professional life phases, and have negative well-being

Resilient teachers ( $48 \%$ of $44, \mathrm{~N}=21$ ): tend to be highly motivated, committed and self-efficacious, and have a strong sense of agency

Vulnerable teachers (52\% of $44, \mathrm{~N}=23$ ): are only in the $24-30$ professional life phase, are moderately motivated, committed and self-efficacious, and have a weak sense of agency

Scenario 4: $(6 \%$ of $295, \mathrm{~N}=18)$

Dominant characteristics of group: Are more likely to be in the 8-15 professional life phase, teach in FSM 3 and 4 schools, and have moderate/low self-efficacy

Resilient teachers $(17 \%$ of $18, \mathrm{~N}=3)$ : teach in the secondary phase, are male, and in the 24-30 professional life phase. They are moderately motivated and committed, and have a mixed sense of well-being and agency

Vulnerable teachers $(83 \%$ of $18, \mathrm{~N}=15$ ): are female, have moderate/low motivation, but are highly committed. They have negative well-being and a weak sense of agency

4.1.5 Teacher identities were neither intrinsically positively or negatively stable, nor intrinsically fragmented, but displayed characteristics of stability and/or fragmentation at different times in their professional lives, depending on the dominance of personal, professional and situational factors and their management of these.

4.1.6 Over half (52\%) of the teachers in Scenario 3 and 83 per cent of the teachers in Scenario 4 demonstrated a lack of resilience. 
4.1.7 Teachers in FSM 3 primary and secondary schools were likely to be less resilient than those in FSM 1, 2 and 4 schools; teachers in FSM 4 schools were more likely to be resilient than those in other schools, but were also more likely to experience increased health problems.

4.1.8 The majority of teachers experiencing Scenario 1 (61\%) worked in FSM 1 and 2 schools. The majority of teachers experiencing Scenario 4 worked in FSM 3 and 4 schools (72\%).

4.1.9 Key factors which contributed positively among the $198(67 \%)$ of teachers with a positive sense of agency, resilience and commitment across all Scenarios were:

$\begin{array}{ll}\text { School/department leadership } & 63 \% \\ \text { Supportive colleagues } & 58 \% \\ \text { Family } & 52 \%\end{array}$

4.1.10 Key negative factors among the 97 (33\%) of vulnerable teachers were:

$\begin{array}{ll}\text { Pupil behaviour } & 87 \% \\ \text { Workload } & 70 \%\end{array}$

4.1.11 In all professional life phases there was a statistically significant relationship between teachers who sustained or increased their commitment, and those who maintained positive identities i.e. who were resilient.

\subsection{Mediating Influences on teachers' work, lives and effectiveness}

\subsection{The influence of school context}

Overall, the majority of teachers $(61 \%)$ were sustaining their commitment and a further 12 per cent were sustaining commitment despite working in challenging circumstances. There were differences between primary and secondary school teachers. Primary school teachers were more likely to report positive experiences than their secondary colleagues. They were also Teachers in primary schools were significantly more likely to sustain their commitment and resilience (81\% v 65\%). Yet there were differences between them which related to the socio-economic contexts in which they worked. 
Primary school teachers who responded positively to different Scenarios were more likely to teach in FSM $1 / 2$ schools and more likely to sustain their commitment than those who taught in FSM 3/4 schools. Seventy-three per cent of primary teachers in FSM 1/2 schools sustained their commitment despite heavy workload against 46 per cent of primary teachers in FSM 3/4 schools and in relation to school SES influences, more primary teachers in FSM 3/4 (57\%) experienced more negative professional influences than primary teachers in FSM 1/2 (43\%).

Teachers across the sample reported the need for effective behaviour management, often linked to strong leadership, as a key element for sustaining motivation and commitment. However, 27 per cent of teachers were experiencing a decline in commitment and perceived effectiveness as a result, primarily, of workload and poor pupil behaviour in schools. Whereas most FSM 1 and 2 teachers (78\% primary, $76 \%$ secondary) reported positive pupil behaviour, teachers in FSM 3/4 schools referred more frequently than their colleagues in FSM 1/2 schools to lack of parental support, deteriorating pupil behaviour, failing energy, excessive workload, health problems and demoralisation. In relation to parental support, 11 per cent of FSM 1/2 primary teachers, but 34 per cent of FSM 3/4 primary teachers commented negatively. This was exacerbated by combinations of poor leadership or personal life events. Sixtythree per cent of FSM 1/2 secondary teachers, but only 37 per cent of FSM 3/4 secondary teachers reported positive in-school support. In order to understand, therefore, the complexities of variations in teachers' work and lives and the impact of these on commitment, the relative intensity of these mediating factors has to be acknowledged and understood.

\subsection{Summary Findings}

5.2.1 Teachers who worked in schools in disadvantaged socio-economic circumstances experienced greater challenges to their commitment, resilience and effectiveness. It was the extent to which these challenges were ameliorated by intrinsic and extrinsic support which determined whether teachers were able to maintain their commitment and effectiveness.

5.2.2 School phase exercised a significant influence on teachers' commitment and resilience, particularly in their mid-career professional life phases. 
5.2.3 Teachers in all primary schools were more likely to sustain their commitment and perceived effectiveness than their secondary school colleagues, and this was more likely to be the result of positive relationships with colleagues, school leaders and pupils.

The findings suggest that there are differences in the range and intensity of pupil, parental and government originated challenges which teachers experience according to the relative level of socio-economically deprived contexts in which they work; and that teachers in secondary schools in such contexts experience these more than teachers in primary schools.

\subsection{The Influence of Pupils}

Positive relationships with pupils were central to teachers' perceived effectiveness. They were what gave meaning to their work. However, perceptions of deteriorating pupil behaviour and its impact on teacher commitment were widespread, and were exacerbated by a number of factors such as a lack of effective and consistent behaviour management and a high pupil mobility/transient pupil population. These were more intense and persistent in challenging schools. For example, the data showed that teachers in secondary schools and particularly those in challenging socioeconomic contexts (FSM 3/4) were more likely to experience persistent disruption to teaching and learning by a minority of pupils than those in FSM 3/4 primary schools.

\subsection{Summary Findings}

6.1.1 Positive relationships with pupils were central to teachers' self-efficacy and perceived effectiveness.

6.1.2 Nearly two thirds (65\%) of secondary and over half (51\%) of primary teachers identified poor behaviour as an issue that, at times, impeded their ability to teach well.

6.1.3 Teachers who worked in schools in challenging socio-economic contexts experienced a relatively greater range of negative pupil behaviour influences than those who did not. Seventy-six per cent of FSM 1/2 teachers reported positive pupil behaviour as against 74 per cent of FSM 3/4 teachers who reported pupil behaviour as a negative factor. 
6.1.4 Although the majority of pupils of all ages have positive views of school and their teachers, there is evidence that pupils' views tend to be less positive in Year 9 than in Years 2 and 6. A larger proportion of pupils who were eligible for free school meal were strongly positive about their school and teacher than non-FSM pupils. However there was also a larger proportion of FSM pupils who were strongly negative about their schooling.

6.1.5 There were considerable variations between schools and classes in pupils' attitudes and experiences, indicating important differences in their educational experiences at school. Significant variation between classes was found in pupils' perceptions of particular aspects of teachers' practice and the behaviour of other pupils in the school.

6.1.6 Bullying was reported, particularly in Year 2. A minority of pupils felt unsafe at school. Bullying and concern over safety was more likely to be experienced by disadvantaged pupils (those eligible for FSM). Twenty per cent reported bullying 'all of the time', compared to 12 per cent of non-FSM pupils.

\subsection{School Leaders, Colleagues and Effectiveness}

Two of the most frequently mentioned influences on teachers' work and lives were leadership and relationships with colleagues. Leadership was identified by 85 per cent of the 309 teachers $(\mathrm{N}=262)$ as impacting on their work. Of these $(\mathrm{N}=262), 74$ per cent $(\mathrm{N}=194)$ reported that it had a positive impact on them and their perceived effectiveness (Appendix 4).

The role of colleagues was equally important to teachers' commitment and perceived effectiveness. Of the $276,89 \%$ of teachers reporting on the impact of their colleagues, 87 per cent experienced positive support and 13 per cent a lack of support (Appendix 4). Teachers in FSM 3 and 4 schools tended to mention a sense of team work and common purpose that they shared with other teachers more often (85\%, compared to $73 \%$ in FSM 1/2 schools). 


\subsection{Summary Findings}

7.1.1 The quality of leadership at school and department level and relationships with colleagues and personal support were major factors in teachers' sustained commitment and their motivation to remain in or leave a school.

7.1.2 Those teachers with positive, stable identities were more likely to work in schools with supportive colleagues regardless of socio-economic context. These provided the means to minimize negative Scenarios and fluctuations in identity.

7.1.3 These schools were places where leaders had built structures and cultures where the means of accessing internal and external support were known and valued.

\subsection{Work and Life Interaction (Well-Being) and Effectiveness}

Well-being implies a sense of balance, a capacity to manage pressures in life and work, together with a sense of control. Although, an inevitable part of work and life, there are likely to be times when everyday pressures turn into unhealthy stresses which have adverse emotional, mental and/or physical effects. The balance that teachers have to achieve is between the pressures at work and those in their personal life. The potential impacts on the school are absenteeism, decline in energy, commitment and effectiveness and, ultimately, high staff turnover; and, for the profession, loss of teachers. Teachers' well-being can be positively and negatively affected by a number of issues such as the management of the school, the school ethos, the level of morale amongst staff and the opportunities presented to staff to undertake professional development. The majority of teachers in the project were able to manage the pressures. However, for some teachers $(\mathrm{N}=51,17 \%$ of 309$)$, a combination of pressures were associated with high blood pressure, depression, and chronic fatigue syndrome amongst other health-related problems. Twenty-five per cent of primary and 42 per cent of secondary FSM 1/2 teachers had suffered ill-health against 37 per cent of primary and 63 per cent of secondary teachers in FSM 3/4 schools. There were differences, also, in the incidence of negative stress and ill-health experienced by teachers in different secondary schools. Whereas 21 per cent of teachers in FSM 1/2 schools experienced these, 48 per cent of teachers in FSM 3/4 schools experienced them. 


\subsection{Summary Findings}

8.1.1 Teachers' work and lives interacted and impacted upon one another.

8.1.2 Effective teaching involved both personal and professional investment.

8.1.3 Teachers' well-being and perceived effectiveness at work were affected by life experiences and events.

8.1.4 A sense of personal worth and professional competence was an inherent part of teachers' positive identities and perceived effectiveness.

\subsection{Continuing Professional Development and Effectiveness}

Many teachers had limited experience of CPD. Most tended to see it only as InService Training Programmes (INSET). Whilst there was an overall satisfaction with the current CPD opportunities and the focus, quality and balance of CPD across all six professional life phases, there was less satisfaction with the amount of time teachers had to reflect upon their work and to work with colleagues.

The most frequent reason given for undertaking CPD for teachers across six professional life phases was to enhance classroom knowledge, closely followed by professional/personal development, and then by role effectiveness, external policy and whole school development. The importance of training for role effectiveness grew in importance as careers progress. The importance decreased in the final professional life phase. Teachers in FSM 3/4 schools placed more importance on CPD which focused on personal and professional development than colleagues in FSM 1/2 schools in all phases. Teachers in FSM 3/4 schools were also more concerned with CPD which focused upon pupils' learning in the classroom than their colleagues in FSM 1/2 schools (except for those in the 24-30 phase). The importance of CPD which focused upon personal and professional development grew through the professional life phases, but decreased in the final phase.

\subsection{Summary Findings}

9.1.1 Schools were not perceived to have offered a wide range of CPD experiences.

9.1.2 Most teachers (80\%) were satisfied with their experience of CPD. It had a consistently positive influence on teachers across all professional life phases. 
9.1.3 Teachers (70\%) across all professional life phases felt that heavy workload, a lack of time and financial constraints were important inhibitors in their pursuit of professional development.

9.1.4 Collaborative learning with colleagues within and across schools was rated as a highly important form of CPD.

9.1.5 School phase, gender, school contexts and professional life phases were shown to have significant impacts on teachers' professional development needs and concerns.

9.1.6 Teachers' in all professional life phases associated CPD with building their emotional, health and intellectual capacities.

9.1.7 CPD activities which focused upon role effectiveness were regarded ad important by teachers in middle and later professional life phases, particularly those with 8-15 and 16-23 years of experience in which 76.5 per cent and 91.3 per cent respectively held additional out-of-classroom responsibilities.

\subsection{Commitment, Resilience and Effectiveness}

The majority of teachers $(74 \%, \mathrm{~N}=228)$ across all professional life phases and working contexts were sustaining their commitment and sense of effectiveness; and the majority of these sustained their effectiveness as measured by pupil attainment scores over the period of the research. They were doing so either because of or in spite of personal, professional and work based circumstances. A significant number of teachers, however, $(26 \%, \mathrm{~N}=81)$ were becoming disillusioned with their work or were at risk of doing so. Teachers' commitment and resilience were influenced by their professional life experiences, the influences of the contexts in which they worked and their sense of identity. Pupils of those teachers in each professional life phase who were on an upward trajectory and sustaining their commitment were more likely to attain results at or above the level expected, regardless of school context $(70 \%$ cohort $1 ; 65 \%$ - cohort 2). Pupils of teachers in each professional life phase who were on a downward trajectory and not sustaining their commitment were more likely to attain results below the level expected, regardless of school context (27\% - cohort 1; $31 \%$ - cohort 2). 
In terms of resilience, there was a relatively greater number of teachers who were likely to be less resilient in FSM 3 schools compared to those in other school contexts; there were a relatively greater number of teachers who were likely to be more resilient in FSM 4 schools compared to those in other contexts perhaps because the former, according to their accounts, were more likely to have had a 'calling' to work with this pupil cohort.

The capacities to remain committed and resilient were key factors in establishing and sustaining teachers' effectiveness. However, there were variations between teachers in relation to commitment or resilience across their working lives and in different life and work circumstances. These differences in commitment were moderated by professional life phase and identities and mediated by their capacities to manage the interactions between personal, professional and situated factors. The teachers who were committed spanned a range of experience and school socio-economic contexts. However, there was a relatively greater decline in commitment among 'late' professional life phase primary and secondary school teachers. Additionally, teachers in FSM 3/4 schools were more likely to experience more complex Scenarios with a greater intensity and persistence of challenges to their commitment and resilience than those in FSM 1/2 schools. These challenges were principally concerned with perceived negative pupil behaviour, workload and lack of parental support, and personal and health factors.

\subsection{Summary Findings}

10.1.1 There were statistically significant relationships between teachers who sustained their commitment (i.e. were resilient) in each professional life phase, and the progress and attainment of their pupils.

10.1.2 There was an association between teachers' ability to manage professional life and identity Scenarios successfully and the extent to which they were able to build capacity to sustain their commitment, resilience and effectiveness.

10.1.3 Commitment (motivation, belief, aspiration) was a necessary but insufficient condition for effectiveness. Resilience (the ability of an individual to withstand or recover quickly from difficult conditions) was found to be a necessary condition for sustaining commitment. 
10.1.4 Commitment and resilience influenced and were influenced by professional life phase and identity.

10.1.5 These were mediated positively and negatively by personal, situated and professional influences.

10.1.6 The interaction between teachers' professional and personal contexts in each professional life phase and their capacities to manage the personal, situated and professional influences on these contributed, positively or negatively, to their self-efficacy, well-being, commitment, resilience and effectiveness.

\subsection{Conclusions}

The research has shown that knowledge An understanding of teachers' work, lives, and identities in the process of managing work-life tensions over the course of a career and in different contexts contributes to knowledge of teachers' commitment, resilience and effectiveness. More importantly, it provides a new perspective on teacher retention. Research on teacher retention tends to focus on factors affecting teachers' decisions to leave the teaching profession. Instead, what is required is a better understanding of the moderating and mediating factors which have enabled the majority of teachers to sustain their commitment and effectiveness over the course of their careers.

A strong sense of self-efficacy is an essential component of teacher commitment and resilience. To rebound from setbacks and adversity, teachers need the strength of selfefficacy beliefs; and conversely, their sustained effort and perseverance in the face of difficulty will strengthen their sense of efficacy and result in a stronger sense of resilience. In other words, the development of teachers' self-efficacy interacts with the growth of their resilient qualities. It is by nature a dynamic, developmental process the key characteristic of resilience.

Analysis of teachers' professional life phases, identities, and the influences on them suggested that there was an interaction between these and their ability to sustain commitment and effectiveness. Commitment and resilience for the VITAE teachers were both a product of their histories and socially constructed through their experiences at work. 
Whilst there were a number of factors which affected all teachers, there were noticeable differences observed in the way that these factors impacted upon teachers, in different professional life phases and in different identity Scenarios who were teaching in different school contexts (as defined by FSM). Their capacity to sustain commitment (i.e. resilience) and thus effectiveness, was related to the ways they managed and were supported in managing these.

Teachers' commitment and resilience were moderated by their professional life phases and identities. Commitment and resilience influenced and were influenced, positively or negatively, for the VITAE teachers, by the interaction between their i) beliefs, values, life experiences and events (personal dimension); ii) professional life phases, professional beliefs and values, and external policies (professional dimension); iii) the socio-economic context of their schools, composition of the pupil population, school leadership and colleagues (situated dimension). These three sets of influences contributed positively or negatively to the teachers' capacities to manage the different work and life. Scenarios which sometimes threatened to de-stabilise their positive professional identities, commitment and capacity to be effective, pursue their original call to teacher and sustain commitment in the profession. Most of the teachers in VITAE were continuing to do so when facing adverse circumstances and complex Scenarios. Many, but not all, exercised a strong sense of resilience in managing negative influences and rebounding from adversity.

A strong sense of self-efficacy is an essential component of teacher commitment and resilience. To rebound from setbacks and adversity, teachers need the strength of selfefficacy beliefs; and conversely, their sustained effort and perseverance in the face of difficulty will strengthen their sense of efficacy and result in a stronger sense of resilience. In other words, the development of teachers' self-efficacy interacts with the growth of their resilient qualities. Thus, resilience - the ability of an individual to withstand or recover quickly from difficult conditions - may be said to be a necessary quality for all, and especially for those who experience changing or challenging circumstances. 
This research has shown that teachers' commitment and resilience, underpinned by their sense of vocation, play an essential role in their endeavours to sustain effectiveness throughout their professional lives, in both favourable and unfavourable circumstances. Research on teacher retention tends to focus on factors affecting teachers' decisions to leave the teaching profession. This research has focused on retaining teacher quality. It suggests that what is required is a better understanding of the moderating and mediating factors which enable teachers, not simply to remain in teaching but, more importantly, to sustain their commitment, resilience and, therefore, effectiveness over the whole of their careers.

\subsection{Core Messages}

1. There are significant variations in both teachers' perceived and relative effectiveness across year groups and sectors (Chapter 4, 2.0, p. 62). Teachers' capacities to be effective are influenced by variations in their work, lives and identities and their management of these (Chapter 7, 2.0, p. 153).

2. Teachers' effectiveness is not simply a consequence of age or experience (Chapter 5, 2.0, p. 86).

3. Teachers' professional life phases are core moderating influences on teachers' effectiveness (Chapter 5, 2.0, p. 86).

4. Teachers' capacities to sustain their effectiveness in different phases of their professional lives are affected positively and negatively by their sense of professional identity (Chapter 7, 2.0, p. 153).

5. Teachers' sense of identity is a major contributing factor to teachers' commitment and resilience. It is neither intrinsically stable nor unstable, but is affected positively or negatively by different degrees of tension experienced between their own educational ideals and aspirations, personal life experiences, the leadership and cultures in their schools, pupils' behaviour and relationships and the impact of external policies on their work (Chapter 7, 2.0, p. 153; Chapter 8, 2.0, p. 220).

6. Commitment and resilience are found to be crucial to teachers' abilities to sustain effectiveness (Chapter 8, 2.0, p. 220). 
7. CPD has a consistently positive influence on teachers across all professional life phases, though needs and concerns vary in relation to these (Chapter 6, 2.0, p.123)

8. The extent to which teachers sustain their commitment (i.e. are resilient) is dependent upon their capacities to manage interactions between personal, work and professional factors which mediate their professional lives and identities positively or negatively (Chapter 8, 2.0, p. 220).

9. The quality of leadership, both at school and departmental level, relationships with colleagues and personal support are key influencing factors on teachers' motivation, commitment and quality retention (Chapter 8, 2.0, p.220).

10. Teachers who work in primary schools are more likely to sustain their commitment over a career than secondary teachers (Chapter 8, 2.1, p. 226).

11. Teachers who work in schools in more challenging socio-economic contexts are more likely to experience greater challenges to their health, well-being, and thus resilience, than those who work in relatively more advantaged schools (Chapter 8, 2.3, p. 228).

12. There is a statistically significant association between the levels of pupils' progress and attainment at KS1, 2 and 3 (English and maths) and the extent to which teachers sustain their commitment (Chapter 8, 2.4, p. 231).

Commitment, agency and resilience influence and are influenced, positively or negatively, by the interaction between i) beliefs, values, life experiences and events (personal dimension); ii) professional life phase, professional beliefs and values, external policies (professional dimension); iii) the socio-economic context of the school, composition of the pupil population, school leadership, colleagues (situated dimension). These three influences contribute positively or negatively to teachers' capacities to manage the different work, life and identity Scenarios which sometimes threaten to destabilise their commitment and capacity to be effective.

The study has established the dynamic, emotional nature of professional life phases and identities and the ways in which variations in these and the influences upon them affect teachers' relative and relational effectiveness. If teachers are to manage the tensions they face within and across both, and sustain their commitment, resilience and effectiveness, they and those responsible for their leadership must draw upon and 
be encouraged to build understandings of the cognitive and emotional contexts in which they work in order to increase their capacities to manage these. It is possible to identify patterns which will assist in understanding the complexities of teacher's work lives in particular contexts, provide information related to sustaining the quality of teacher commitment over a the course of teachers' professional lives and inform those concerned with their well being, retention and quality. 


\section{References}

Acker, S. (1999) The Realities of Teachers' Work: Never a dull moment. London: Cassell.

Ancess, J. (1997). Urban Dreamcatchers: Launching and leading new small schools. New York: National Center for Restructuring Education, Schools, and Teaching (NCREST). Teachers College Press, Columbia University.

Andrews, M. (1983) Evaluation: An essential process. Journal of Extension (September-October) pp. 8-13.

Archer, J. (1996) Sex differences in social behaviour: Are the social role and evolutionary explanations compatible? American Psychologist, 51, p 909 - 917

Ashton, P. T. and Webb, R. B. (1986) Making a Difference. Teachers' sense of Efficacy and student achievement. New York: Longman.

Askew, M., Brown, M., Rhodes, V., William, D. and Johnson, D. (1997) Effective Teachers of Numeracy. London: Kings' College, for the Teacher Training Agency.

Ausubel, D. 1968. Educational Psychology : A cognitive view. New York: Hold, Rhinehart and Winston.

Ball, S. J. (1994) Education Reform: A critical and post-structural approach. Buckingham: Open University Press.

Ball, S. J. and Goodson, I. (1985) Teachers' Lives and Careers. Lewes: Falmer Press.

Bandura, A. (1989) Human agency in social cognitive theory. American Psychologist, September, 44/9: 1175-1184.

Barbalet, J. (2002) Introduction: Why emotions are crucial. In Barbalet J. (ed) Emotional Sociology. London: Blackwell Publishing, pp. 1-9.

Barber, B. R. (2001). The 'engaged university' in a disengaged society: Realistic goal or bad joke? Retrieved October 1, 2003, from www.diversityweb.org/Digest/Sm01/engaged.html

Benard, B. (1991) Fostering Resiliency in Kids: Protective Factions in the Family, School and Community. San Francisco: WestEd Regional Educational Laboratory.

Bennett N. and Carre C. (Eds.) (1993), Learning to Teach. Routledge, London

Bernstein, B. (1996) Pedagogy, Symbolic Control and Identity. Theory, Research, Critique. London: Taylor and Francis.

Bolam, R. (1990) Recent developments in England and Wales. In Joyce, B (ed) 
Changing School Cultures through staff development: An international survey. Beckenham: Croom Helen, pp. 147-167.

Borich, G. D. (1996) Effective Teaching Methods (3rd ed) New Jersey: Prentice-Hall.

Bosker, R. and Scheerens, J. (1994) Alternative models of school effectiveness put to the test, in R. J. Bosker, B. P. M. Greemers and J. Scheerens (Eds.) Conceputal and methodological advances in educational effectiveness research (Special Issues). International Journal of Educational Research, Vol. 21, pp.159-180.

Bottery, M. (2005) The Individualization of Consumption: A Trojan Horse in the Destruction of the Public Sector? Educational Management, Administration and Leadership, 33/3: 267-288.

Bowe, R. and Ball, S. (1992) Reforming Education and Changing Schools. London: Routledge.

Boyle, B., Lamprianou, I., and Boyle, T. (2005) A longitudinal study of teacher change: What makes professional development effective? Report of the second year of the study. School Effectiveness and School Improvement, 16/1: 1-27.

Brandt. R. (1996) Powerful Learning. Alexandria, VA: ASCD.

Bransford, J.D., A.L. Brown, R.R. Cocking, eds. 2000. How People Learn: Brain, mind, experience, and school. Nat. Acad. Press; online at http://tinyurl.com/apbgf.

Brennan, M. (1996) Multiple professionalisms for Australian teachers in an important age. New York: American Educational Research Association.

Brophy, J., and Good, T. (1986). Teacher behavior and student achievement. In M. Wittrock (Ed.), Handbook of Research on Teaching (pp. 340-370). NY: Macmillan.

Brown, A. L. and Palinscar, A. S. (1989). Guided cooperative learning and individual knowledge acquisition. In L. B. Resnick (Ed.), Knowing, learning, and instruction: Essays in honor of Robert Glaser (pp. 393-451). Hillsdale, NJ: Erlbaum.

Bryk, A. S., Lee, V. E. and Holland, P. B. (1993) Catholic schools and the common good. Cambridge, MA: Harvard University Press.

Bryman, A. (1988) Quality and Quantity in Social Research. London: Allen and Unwin.

Bush, T. and Middleton, D (2005) Leading and Managing People in Education. London: 101 Productions.

Butt, R. L., and Raymond, D. (1989) Studying the nature and development of teachers' knowledge using collaborative autobiography. International Journal of Educational Research, 13 (4) p.403-419.

Chapman, D. W. (1982) or (1983) A model of the influences on teacher attrition. 
Journal of Teacher Education, 34, 43-49.

Clark, C. M. and Peterson, P. L. (1986) Teachers' Thought Processes. In M. C. Wittrock (Ed) Handbook of Research on Teaching ( ${ }^{\text {rd }}$ ed) pp. 255-296. New York: Macmillan.

Cochran-Smith, M., and Lytle, S. (1999). Relationships of knowledge and practice: Teacher learning in communities. Review of Research in Education.

Cohen, L., Manion, L. and Morrison, K. (2000) Research Methods in Education. London : Routledge Falmer

Creemers, B. (1994) The Effective Classroom. London: Cassell.

Cresswell, J. (2003). Research Design: Qualitative, quantitative and mixed methods approaches. London: Sage.

Day, C. (1999) Developing Teachers: The challenges of lifelong learning. London: Falmer Press.

Day, C. (2004) A Passion for Teaching. London and New York: Routledge Falmer.

Day, C.W., Elliot, B, and Kington, A. (2005). 'Reforms, Standards and Teacher Identity: Challenges of sustaining commitment'. Teaching and Teacher Education, 21, 563-577.

Day, C. and Hadfield, M. (1996) Metaphors for Movement: Accounts of professional development. In Kompf, M., Boak, R. T., Bond, W. R. and Dworek, D. H. (eds.) Changing Research and Practice: Teachers' Professionalism, Identities and Knowledge. London: Falmer Press, pp. 149-166.

Day, C., Harris, A., Hadfield, M., Tolley, H. and Beresford, J. (2000) Leading Schools in Times of Change. Buckingham: Open University Press.

Day, C.W., Kington, A., Stobart, G. and Sammons, P. (2006) 'The Personal and Professional Selves of Teachers: Stable and unstable identities'. British Educational Research Journal.

Day, C. W., Sammons, P., Stobart, G. and Kington, A. (forthcoming) Variations in the Work and Lives of Teachers: Relative and relationship effectiveness. Teachers and Teaching: Theory and Practice.

Day, C., Stobart, G., Sammons, P., Kington, A. and Gu, Q. (in press) Teachers Matter. Buckingham: Open University Press.

De Fraine, B., Van Damme, J. And Onghena, P. (2003) Accountability of Schools and Teachers: What should be taken into account? European Education Research Journal, Vol 1 (3). 
De Jager, B., Creemers, B. P. M. and Reezigt, G. (2002) Constructivism and Direct Instruction: Competing or complementary models? Paper presented at the International Congress of School Effectiveness and Improvement, Copenhagen.

Denzin, N. K. (194) On Understanding Emotion. San Francisco: Jossey-Bass.

Department for Education and Employment (1998) Teachers Meeting the Challenge of Change, London: DfEE.

Department for Education and Skills (1999) Tender No: 4/RP/173/99

Department for Education and Employment (DfEE) (2001) Learning and Teaching: A Strategy for Professional Development. (Ref: DfEE 0071/2001). London: DfEE.

Department for Education and Skills (2003a). Excellence and Enjoyment: A strategy for primary schools. London: DfES

Department for Education and Skills (2003b). National Agreement on Raising Standards and Tackling Workload. London: DfES

Department for Education and Skills (2005) Professional Development for Teachers Early in their Careers: An Evaluation of the Early Professional Development Pilot Scheme. London: DfES.

Desforges, C. (2000) Familiar challenges and new approaches: necessary advances in theory and methods in research on teaching and learning, paper presented at BERA Conference, Cardiff, 2000.

Dinham, S. and Scott, C. (1998). 'A Three Domain Model Of Teacher And School Executive Career Satisfaction', Journal of Educational Administration, 38 (5), 362-378.

Dreyfus, H. L. and Dreyfus, S. E. (1986) Mind Over Machine: the power of human intuition and expertise in the era of the computer, New York, The Free Press.

Duxbury, L. and Higgins, C. (1994) Interference between work and family: A status report on dual-career and dual-earner mothers and fathers. Employee Assistance Quarterly, 9 (3/4), 55-80.

Duxbury, L., Higgins, C., and Lee, C. (1994) Work-family conflict: A comparison by gender, family type, and perceived control. Journal of Family Issues, 15, 449-466.

Dweck, C. S. and Leggett, E. L. (1988). A social-cognitive approach to motivation and personality. Psychological Review, 95, 256-273

Earle, L., Watson, N., Levin, B., Leithwood, K., Fullan, M., and Torrance, n. (2003). Watching and Learning 3. OISE/UT Evaluation of England's National Literacy and Numeracy Strategies, Third and Final Report. Ontario: Ontario Institute for Studies in Education, University of Toronto.

Ebmeier, H. and Nicklaus, J. (1999) The Impact of Peer and Principal Collaborative 
Supervison on Teachers' Trust, Commitment, Desire for Collaboration, and Efficacy. Journal of Curriculum and Supervision, Vol. 14, No. 4, p351-78, Summer 1999.

Elliott, B. and Crosswell, L. (2001) Commitment to Teaching: Australian perspectives on the interplays of the professional and the personal in teachers' lives. Paper presented at the International Symposium on Teacher Commitment at the European Conference on Educational Research, Lille, France.

EPPI-Centre (2005) The Impact of Collaborative CPD on Classroom Teaching and Learning: How do Collaborative and Sustained CPD and Sustained but not Collaborative CPD Affect Teaching and Learning? (June 2005) London: EPPI-Centre, Social Science Research Unit, Institute of Education, University of London.

Evans, R. N. (1992). The state of the union in industrial, technical, and technology teacher education. Journal of Industrial Teacher Education, 29(2), 7-14.

Firestone, W. A. (1996) Images of Teaching and Proposals for Reform : A comparison of ideas from cognitive and organisational research. Educational Administration Quarterly, 32 (2), pp. 209-235.

Firestone, W. A. and Pennell, J. R. (1993) Teacher commitment, working conditions and differential incentive policies. Review of Educational Research, 63: 489-526.

Fischman, W., Schutte, D. A., Solomon, B., and Wu Lam, G. (2001). The development of an Enduring Commitment to Service Work. New Directions for Child and Adolescent Development, 93, 33-44.

Fraser, B. J. (1989) 'Research Syntheses on School and Instructional Effectiveness', in Creemers, B. P. M. and Scheerens, J. (eds) International Journal of Educational Research, 13 (7): 707-719.

Fraser, H., Draper, J. and Taylor, W. (1998) The Quality of Teachers' Professional Lives: Teachers and job satisfaction. Evaluation and Reserach in Education, 12 (2), pp. $61-71$.

Freidus, H. (1989). Gender and the Choice of Teaching as a Second Career. (ERIC Document Reproduction Service No. ED 314 360)

Friedson, E. (2001) Professionalism: The third logic. Cambridge Polity.

Frone, M. R., Yardley, J. K. and Markel, K. S. (1997) Developing and testing an integrative model of the work-family interface. Journal of Vocational Behaviour, 50, 145-167.

Fukuyama, F. (1999) The Great Disruption: Human nature and the reconstitution of social order. London: Profile Books Ltd.

Furlong, J., Furlong, R., Facer, K. and Sutherland, R. (2000). The National Grid for Learning: a curriculum without walls? Cambridge Journal of Education, 30 (1): 91 110. 
Galton, M. and McBeath, J. with Page, C. and Steward, S. (2002) A Life in Teaching? The impact of change on primary teachers' working lives. A report commissioned by the NUT. Cambridge: University of Cambridge, Faculty of Education.

General Teaching Council for England (GTCE) (2003) Teacher survey (London, Guardian/General Teaching Council for England).

Gergen, K. (1987) Toward self as a relationship. In K. Yardley and T. Honness (eds.), Self and Identity: Psychological Perspectives, New York: John Wiley.

Giddens, A. (1986) Constitution of Society. University of California Press.

Giddens, A. (1991) Modernity and Self Identity. Stanford: Stanford University Press.

Gipps, C. and MacGilchrist, B. (1999) 'Primary School Learners', in P. Mortimore (Ed) Pedagogy and its Impact on Learning (46-67). London, Sage Publications

Gipps C, McCallum B and Hargreaves E (2000) What Makes a Good Primary School Teacher?: Expert Classroom Strategies. London: RoutledgeFalmer

Goldstein, L. (1997) Teaching with Love: A feminist approach to early childhood. New York: Peter Lang.

Goodlad, J. (1990) Teachers for our nation's schools. San Francisco: Jossey-Bass.

Goodson, I. (2003) Professional Knowledge, Professional Lives: Studies in Education and Change. Open University Press: Maidenhead and Philadelphia.

Goodson, I. and Hargreaves, A. (eds.) (1996) Teachers' Professional Lives. London: Falmer Press.

Googins, B. (1991) Work/family conflicts: private lives, public responses. New York: Auburn House.

Gordon, K. A. (1995) The self-concept and motivational patterns of resilient African American high school students. Journal of Black Psychology, 21: 239-255.

Gordon, K. A., Longo, M. and Trickett, M. (2000) Fostering resilience in children. The Ohio State University Bulletin 875-99: http:/ohioline.osu.edu/b875

Grant-Vallone, E. J. and Donaldson, S. (2001) Consequences of work-family conflict on employee well-being over time. Work and Stress, Vol. 15, No. 3, July 2001.

Grundy, S. and Robinson, J. (2004) Teacher Professional Development: Themes and trends in the recent Australian experience. In Day. C. and Sachs, J. (eds.) International Handbook on the Continuing Professional Development of Teachers. Maidenhead, England: Open University Press.

Grzywacz, J. and Marks, N. (2000) Family, Work, Work-Family Spillover, and 
Problem Drinking During Midlife. Journal of Marriage and Family, Vol. 62, No. 2, pp. 336-348.

Haigh, G. (1995) To be Handled with Care. Times Educational Supplement, February 10, pp.3-4.

Hallam, S. (2002) Ability Grouping Practices and Consequences, NSIN Research Matters No. 16, Spring 2002, London: National School Improvement Network, Institute of Education University of London.

Hallam, S. and Ireson, J. (1999) Ability Groupings in Schools: Practices and consequences. End of Award Report to the ESRC.

Hammersley, M. (1996) Post Mortem or Post Modern? Some reflections on British sociology of. education, British Journal of Educational Studies, 44, pp.

Hammersley, M. and Atkinson, P. (1983). Ethnography: Principles in practice. London: Tavistock

Hanlon, N. (1988). The role of library research instruction in developing teachers' problem solving skills. Journal of Teacher Education, 39(6), 44

Hargreaves, A. (1993) Individualism and Individuality: Reinterpreting the teacher culture. In J. W. Little and M. W. McLaughlin (eds.) Teachers' Work: Individuals, colleagues, and contexts, pp. 51-76. New York: Teachers College Press.

Hargreaves, A. (1994) Changing Teachers, Changing Times - teachers' work and culture in the postmodern age. London: Cassell.

Hargreaves, A. (1998) The Emotional Practice of Teaching. Teaching and Teacher Education. Vol. 14, No. 8, pp. 835-854.

Hargreaves, A. (1999) Series Editor's Forward, in Acker, S. The Realities of Teachers' Work: never a dull moment, London: Cassell.

Harland, J. and Kinder, K. (1997) Teachers' Continuing Professional Development: Framing a model of outcomes. British Journal of In-service Education, 23/1: 71-84.

Harris, Al., Jamieson, I. and Russ, J. (1996) School Effectiveness and School Improvement: A practical guide. London: Pitman Publishing.

Hay McBer (2000) Research into Teacher Effectiveness: A model of teacher effectiveness.

Hegarty, S. (2000). 'Teaching as a knowledge-based activity' (Special Issue: The Relevance of Educational Research), Oxford Review of Education, 26, 3 and 4, 451 65 .

Helsby, G. (1999) Changing Teachers' Work, Buckingham: Open University Press. 
Henchey, N. (2001) Schools that Make a Difference: Final Report Twelve Canadian Secondary Schools in Low Income Settings, Kelowna, B.C.: Society for the Advancement of Excellence in Education.

Henderson, M. and Milstein, M. (2003) Resiliency in Schools: Making it Happen for Students and Educators. Thousand Oaks, California: Corwin Press.

Higgins, G. O. (1994) Resilient Adults: Overcoming a cruel past. San Francisco: Jossey-Bass.

Hill, P.W. and Rowe, K.J. (1996) Multilevel modeling in school effectiveness research. School Effectiveness and School Improvement, 7 (1): 1-34.

Hill, P.W. and Rowe, K.J. (1998) Modeling student progress in studies of educational effectiveness. School Effectiveness and School Improvement, 9 (3): 310-333.

Hilsum, S. and Start, K. B. (1974) Promotion and Careers in Teaching. Slough: National Foundation for Educational Research.

Hobson A.J. and Malderez, A. (Eds) (2005) 'Becoming a Teacher: Student teachers' motives and preconceptions, and early school-based experiences during initial teacher training (ITT)'. DfES Research Report. http://www.dfes.gov.uk/research/data/uploadfiles/RR673.pdf

Hochschild, A. (1983) The Managed Heart: Commercialisation of Human Feeling. Hoyle, Eric and John, Peter D. (1995) Professional Knowledge and Professional Practice London: Cassell

Huberman, M. (1989) The Professional Life Cycle of Teachers. Teachers College Record, 91, 1, Fall 1989, pp. 31-57.

Huberman, M. (1993) The Lives of Teachers. London: Cassell.

Huberman, M. (1995) Networks That Alter Teaching. Teachers and Teaching: Theory and Practice. Vol. 1, No. 2, pp. 193-221.

Hughes, E. C. (1952) The sociological study of work: an editorial introduction. The American Journal of Sociology, 57: 423-426.

Hustler, D., McNamara, Q., Jarvis, J., Londra, M., Campbell, A. and Howson, J. (2003) Teachers' Perceptions of Continuing Professional Development. London: DfES.

Hutchinson, G.E. and Johnson, B. (1993). Teaching as a Career: Examining high school students' perspectives. Action In Teacher Education, 15: 61-67.

Jackson, P. R., Boostrom, and Hansen, D. (1993) The Moral Life of the Schools. San Francisco: Jossey-Bass.

James, C., Connolly, M., Dunning, G. and Elliot, T. (2005) The Characteristics of High 
Attainment Primary Schools in Disadvantaged Settings, paper submitted to the British Journal of Educational Studies, September 2005.

James-Wilson, S. (2001) The Influence of Ethnocultural Identity on Emotions and Teaching. Paper presented at the Annual Meeting of the American Educational Research Association, New Orleans, April 2000.

Jantzen, J. M. (1981). Why college students choose to teach: A longitudinal study. Journal of Teacher Education, 32, (2), 45-47.

Jeffrey, B. and Woods, P. (1996) Feeling Deprofessionalised. Cambridge Journal of Education. Vol 26, No. 3, pp. 325-343.

Joyce, B. and Showers, B. (1980) Improving In-service Training: The messages of research. Educational Leadership, 37: 379-385.

Kahneman, D, Diener, E. and Schwarz, N. (1999) (Eds) Well-being: the Foundations of Hedonic Psychology. New York: Russell Sage Foundation.

Kelchtermans, G. (1993) Getting the Story, Understanding the Lives: From career stories to teachers' professional development. Teaching and Teacher Education. Vol. 9, No. 5/6, pp. 443-456.

Kelchtermans, G. (1996) Teacher Vulnerability: Understanding its moral and political roots. Cambridge Journal of Education. Vol. 26, No. 3, pp. 307-324.

Kelchtermans, G. (2004) CPD for Professional Renewal: Moving beyond knowledge for practice. In Day, C. and Sachs, J. (eds.) International Handbook on the Continuing Professional Development of Teachers. Maidenhead, England: Open University Press.

Kushman, J. W. (1992) The Organisational Dynamics of Teacher Workplace Commitment: A study of urban elementary and middle schools. Educational Administration Quarterly 28/1: 5-42.

Kyriacou, C. (1986) Effective Teaching in Schools. Cheltenham: Stanley Thomes.

LeCompte, M. D. and Dworkin, A.G. (1991) Giving Up on School: Student dropouts and teacher burnouts. Newbury Park, California: Corwin Press.

Lortie, D. (1975) School Teacher: A sociological study. Chicago: University of Chicago Press.

Louis, K. S. (1998) Effects of teacher quality worklife in secondary schools on commitment and sense of efficacy. School Effectiveness and School Improvement. Vol. 9, No. 1, March, pp. 1-27.

Luthar, S. (1996) Resilience: A construct of value? Paper presented at the $104^{\text {th }}$ Annual Convention of the American Psychological Association, Toronto.

Luthar, S., Cicchetti, D. and Becker, B. (2000) The construct of resilience: a critical 
evaluation and guidelines for future work. Child Development, 71/3: 543-562.

Maclean, R. (1992) Teachers' Careers and Promotional Patterns: A sociological analysis. London: Falmer Press.

MacLure, M. (1993) Arguing for Your Self: Identity as an organising principle in teachers' jobs and lives. British Educational Research Journal. Vol. 19, No. 4, pp. 311322.

Marcel, A. (2004) The sense of agency: Awareness and ownership of action. Clarendon Press.

Masten, A., Best, K. and Garmezy, N. (1990) Resilience and development contributions from the study of children who overcome adversity. Development and Psychopathology, 2: 425-444.

Matthews, P. and Sammons, P. (2004) Improvement Through Inspection: An evaluation of the impact of Ofsted's work. Ofsted: Institute of Education, London.

McAdams, P. (1993) The Stories We Live By: Personal myths and the making of the self. New York: The Guildford Press.

Menter, I, Muschamp, Y., Nicholis, Pl, Ozga, J., with Pollard, A. (1997) Work and Identity in the Primary School. Buckingham: Open University Press.

Mortimore, P. (1993) School Effectiveness and the Management of Effective Learning and Teaching. School Effectiveness and School Improvement, 1993.

Mortimore, P., Sammons, P., Stoll, L., Lewis, D. and Ecob, R. (1988). School Matters: The Junior Years. Somerset: Open Books Publishing Ltd.

Mortimore, P. and Watkins, C. (1999) Understanding Pedagogy and it's Impact on Learning. Paul Chapman Publishing Ltd.

Muijs, D., Harris, A., Chapman, C., Stoll, L. and Russ, J. (2004) Improving Schools in Socio-Economically Disadvantaged Areas: An overview of research. School Effectiveness and School Improvement, Vol 15. No. 2, pp. 149-176.

Muijs, D. and Reynolds, D. (2005) Effective Teaching: Evidence and Practice. London: Sage.

Murname, R. J., Singer, J. D., Willett, J. B., Kemple, J. J. and Olsen, R. J. (1991) Who Will Teach? Cambridge, MA: Harvard University Press.

National Foundation for Educational Research (NFER) (2005) All Together better: An evaluation of the GTC-DfES-LEA Continuing Professional Development Partnership Project. Slough: NFER.

Nias, J. (1981) Commitment and Motivation in Primary School Teachers. Educational Review, 33 (3), pp. 181-190. 
Nias, J. (1989) Primary Teachers Talking: A study of teaching as work. London: Routledge.

Nias, J. (1996) Thinking About Feeling: The emotions in teaching. Cambridge Journal of Education. Vol. 26, No. 3, pp. 293-306.

Nias, J. (1998) Why Teachers Need Their Colleagues: A developmental perspectice. In A. Hargreaves, A. Leiberman, M. Fullan and D. Hopkins (eds) International Handbook of Educational Change. Dordrecht: Kluwer, pp. 1257-1271.

Organisation for Economic Cooperation and Development (2004). Learning for Tomorrow's World; First results from PISA 2003. OECD: France.

Ofsted (1996) Making The Most of Inspection: A guide to inspection for schools and governors. HMSO.

Ofsted (1997) The OFSTED Handbook: Guidance on the Inspection of Nursery Education Provision in the Private, Voluntary and Independent Sectors.

Ofsted (1999) Inspecting Schools: The framework. London: Ofsted Publications.

Osborn, M., Abbot, D., Broadfoot, P., Croll, P. and Pollard, A. (1996) 'Teachers' Professional Perspectives: continuity and change', in Chawla-Duggan, R. and Pole, C.J. (eds) Reshaping Education in the 1990s: Perspectives on Primary Schooling, London: Falmer Press.

Oswald, M., Johnson, B. and Howard, S. (2003) Quantifying and evaluating resiliencepromoting factors - teachers' beliefs and perceived roles. Research in Education, 70: 50-64.

Parsons, C. (1996) Education, Exclusion and Citizenship. London: Routledge.

Parsons, S. and Bynner, J. (1998) Influences on Adult Basic Skills Factors Affecting the Development of Literacy and Numeracy from Birth to 37. London: The Basic Skills Unit.

Pate, R. H., Derdeyn, M. J. and Goodnough, G. E.(1989) Perceptions Held by Academically Talented High School Students of Teaching as Career. The School Counselor, 36, pp. 352-358.

Pavalko, R. M. (1971) Sociology of Occupations and Professions. Hasca, IL: Peacock Publishers.

Pence, A. R. (ed.) (1998) Ecological Research with Children and Families: From concepts to methodology. New York: Teachers' College Press.

Porter, A. C. and Brophy, J. (1988) Synthesis of Research on Good Teaching: Insights from the work of the institute for research on teaching. Educational Leadership, Vol 45 (8), p. 74-85. 
Power, M. (1994) The Audit Explosion. London, Demos.

Powney, J., Wilson, V., Hall, S., Davidson, J., Kisk, S., Edward, S. with Mirza, H. S. (2003) Teachers' Careers: The impact of age, disability, ethnicity, gender and sexual orientation. Research Report 488. The Scottish Council for Research in Education. ISBN 1844781178.

Prick, L. (1986) Career Development and Satisfaction Among Secondary School Teachers. Amsterdam: Vrije Universiteit, Amsterdam.

Prick, L. (1989) Satisfaction and Stress Among Teachers. International Journal of Educational Research, Vol 13, pp. 363-77.

Pulkkinen, M-L. and Aaltonen, J. (2003) Sense of agency in narrative processes of repeateadly convicted drunk drivers. Counselling Psychology Quarterly, Vol. 16, No. 2/June 2003.

Raju, P. Mohan and Srivastava, R. C. (1994) Factors Contributing to Commitment to the Teaching Profession. International Journal of Educational Management, Vol 8 (5), pp. 7-13.

Revell, P. (2005) The Professionals: Better teachers, better schools. Stoke on Trent: Trentham Books.

Reynolds, A. (1995) The Knowledge Base for Beginning Teachers: Education Professionals' expectation versus research findings on learning to teach. Elementary School Journal, Vol 95 (3), pp. 199-221.

Reynolds, D. (2000) The Pupil Progress Project.

Rich, Y. (1993) Stability and Change in Teacher Expertise. Teaching and Teacher Education, 9/2: 137-146.

Richardson, G. E., Neiger, B. L., Jenson, S. and Kumpfer, K. L. (1990) The resiliency model. Health Education, 21/6: 33-39.

Richardson, V. and Placier, P. (2001) Teacher Change. In Richardson, V. (ed) Handboook of Research on Teaching. 4th edn, pp. 905-47. Washington: American Educational Research Association.

Riehl, C. and Sipple, J. W. (1996) Making the most of time taken and talent. Secondary school organisational climates, teaching tasks environments, and teacher commitment. American Educational Research Journal, 33 (4), pp. 873-901.

Ritzer, G. (1972) Man and His Work: Conflict and change. New York: AppletonCentury-Crofts.

Rosenholtz, S. J. (1989) Teachers' Workplace. The social organisation of schools. New York: Longman. 
Ross, S., Smith, L. and Casey, J. (1999) Bridging the Gap: The effects of the Success For All program on elementary school reading achievement as a function of student ethnicity and ability levels. School Effectiveness and School Improvement, 10, 2: 129150.

Rudow, B. (1999) Stress and Burnout in the Teaching Professionl: European studies, issues, and research perspectives. In Vandenberghe and Huberman (eds.) op. cit. pp$38-58$.

Russell, J. (1996) Agency - Its role in mental development. Hove: Erlbaum (UK) Taylor and Francis.

Rutter, M. (1985) Resilience in the face of adversity: protective factors and resistance to psychiatric disorder. British Journal of Psychiatry, 147: 598-611.

Rutter, M., Maughan, B., Mortimer, P. and Ousten, J. (1979) Fifteen-thousand Hours: Secondary schools and their effects on children. Cambridge, MA: Harvard University Press.

Sachs, J. (2003) The Activist Professional. Journal of Educational Change, 1, pp. 7795.

Sammons, P. (1996) Complexities in the Judgement of School Effectiveness. Educational Research and Evaluation, Vol 2, pp. 113-49.

Sammons, P (1998). Applying value added methods to investigate children's attainment and development over four years. Paper presented at the International Congress for School Effectiveness and Improvement. University of Manchester UK January 1998

Sammons, P. (1999) School Effectiveness: Coming of age in the twenty first century. Lisse: Exton, PA: Swets and Zeitlinger Publishers.

Sammons, P., Hillman, J. and Mortimore, P. (1995) Key Characteristics of Effective Schools: A review of school effectiveness research. London, Ofsted.

Sammons, P. and Smees, R. (1998) Measuring Pupil Progress at Key Stage 1: Using baseline assessment to investigate value added. School Leadership and Management, Vol 18 (3), pp. 389-407.

Sammons, P., West, A. and Hind, A. (1997) Accounting for Variations in Pupil Attainment at the end of Key Stage 1. British Educational Research Journal, Vol 23, pp. 489-511.

Scheerens, J. (1992) Effecting Schooling: Research, theory and practice. London: Cassell.

Scheerens, J. (1995) Measuring the Quality of Schools. Washington D.C.: OECD Information and Publications Center. 
Scheerens, J. and Bosker, R. J. (1997) The Foundations of Educational Effectiveness. Oxford: Pergamon.

School Standards and Framework Act (1998). ISBN 0105431982 London: The Stationary Office Ltd.

Selwood, I. and Pilkington, S. (2005) Teacher Workload: Using ICT to release time to teach. Educational Review, Vol 57 (2), pp. 163-174.

Senior Chief Inspector of Schools, Scotland, in Davies, M. and Edwards, G. (2001) Will the Curriculum Caterpillar Ever Learn to Fly?, in Collins, J., Insley, K. and Soler, J. (eds) Developing Pedagogy . London : Paul Chapman.

Serow, R. C. (1993) Why Teach? Altruism and career choice among nontraditional recruits to teaching. Journal of Research and Development in Education, Vol 26 (4), pp. 197-204.

Shulman, L. S. (1986) Those Who Understand: Knowledge growth in teaching. Educational Researcher, Vol 15 (2), p. 4-14.

Sikes, P., Measor, L. and Woods, P. (1985) Teacher Careers: Crises and continuities. London: Falmer Press.

Sleegers, P. and Kelchtermans, G. (1999) Inleiding op het themanummer: professionele identiteit van leraren (Professional Identity of Teachers) Pedagogish Tijdschrift, 24, pp. 369-374.

Smithers, A. and Robinson, P. (2003) Factors Affecting Teachers' Decisions to Leave the Profession. DfES Research Report, RR430.

Snyder, C. and Lopez, S. (2002) Handbook of positive psychology. Oxford: Oxford University Press.

Sockett, H. (1993) The Moral Base for Teacher Professionalism. Columbia University: Teachers College Press.

Stobart, G. and Stoll, L. (2005) The Key Stage 3 Strategy: What kind of reform is this? Cambridge Journal of Education, Vol 35 (2), pp. 225-238.

Stoll, L. and Fink, D. (1996) Changing Our Schools: Linking school effectiveness and school improvement. Buckingham: Open University Press.

Stoll, L., Fink, D. and Earl, L. (2003). It's About Learning (And It's about Time): What's in it for schools? London: Routledge Falmer.

Strand, S. (1997) Pupil Progress during Key Stage 1: A value added analysis of school effects. British Education Research Journal, 23, 471-487.

Strand, S. (1999) Pupil background and baseline assessment results at age 4. Journal of Research in Reading, 22, 14-26. 
Strand, S. (2002) Pupil Mobility, Attainment and Progress During Key Stage 1: A study in cautious interpretation. British Education Research Journal, 28, 63-78.

Stronach, I., Corbin, B., McNamara, O., Stark, S. and Warne, T. (2002) Towards An Uncertain Politics of Professionalism: Teacher and nurse identities in flux. Journal of Educational Policy, Vol. 17, No. 1, pp. 109-138.

Strauss, A. and Corbin, J. (1998) Basics of Qualitative Research, Techniques and Procedures for Developing Grounded Theory. $\left(2^{\text {nd }}\right.$ ed) Thousand Oaks, CA: Sage.

Sturman, L., Lweis, K., Morrison, J., Scott, E., Smith, P., Styles, B., Taggart, G. And Woodthorpe, A. (2005) General Teaching Council Survey of Teachers 2005 Final Report. Slough: National Foundation for Educational Research.

Sugrue, C. (1997) Complexities of Teaching: Child-centred perspectives. London: Falmer Press.

Sukhanandan, L. and Lee, B. (1998) Streaming, Setting and Grouping by Ability: A review of the literature. www.nfer.ac.uk/pubs/streaming $2 / \mathrm{html}$

Sumsion, J. (2002) Becoming, Being and Unbecoming an Early Childhood Educator: A phenomenological case study of teacher attrition. Teaching and Teacher Education. Vol. 18, pp. 869-885.

Sutton, R. S.(2000) The Emotional Experiences of Teachers. Paper presented at the Annual Meeting of the American Educational Research Association, New Orleans, April, 2000.

Tashakkori, A. and Teddlie, C. (1998) Mixed Methodology: Combining qualitative and quantitative approaches. Thousand, CA: Sage.

Tashakkori, A. and Teddlie, C. (2003) (Eds.) Handbook of mixed methods in social and behavioral research. Thousand Oaks, CA: Sage Publications, Inc.

Teddlie, C. (1994) Integrating Classroom and School Data in School Effectiveness Research. In D. Reynolds, et al, Advances in School Effectiveness Research Practice. Oxford: Pergamon.

Teddlie, C. and Stringfield, S. (1993) Schools Make a Difference: Lessons learned from a 10 year study of school effects. New York: Teachers College Press.

Teddlie, C. and Reynolds, D. (2000) Responses to the Criticisms of School Effectiveness Research, contained in Slee, Weiner and Tomlinson (1998) and Thrupp (1999). American Education Research Association, New Orleans.

Thomas, S. and Mortimore, P. (1996) Comparison of value-added models for secondary-school effectiveness. Research Papers in Education, 11 (1): 5-33.

Troman, G. and Woods, P. (2000) Primary Teachers' Stress. London: Routledge. 
Tsui, K. T. and Cheng, Y. C. (1999) School Organisational Health and Teacher Commitment: A contingency study with multi-level analysis. Educational Research and Evaluation, 5 (3), pp. 249-265.

Tyree, A. K. (1996) Conceptualising and measuring commitment to high school teaching. Journal of Educational Research, 89 (5), pp. 295-304.

Van Den Berg, R. (2002) Teacher's meanings regarding educational practice. Review of Educational Research, 72/4: 577-625.

Van der Grift, E. (2006) General and differential effects of constructivist teaching. Keynote presentation at the annual meeting of the International Congress for School Effectiveness and Improvement, Florida, 3-6 January 2006.

Verdis, M. P. (2002) Learning Effects of Print and Digital Geographic Maps. Journal of Research on Technology in Education, Vol 35 (2).

Walberg, H. J. (1986) Synthesis of Research on Teaching. In M. C. Wittrock (Ed) Handbook on Research on Teaching (3rd ed), pp. 214-229.

Walberg, H. J. (1990) Productive Teaching and Instruction: Assessing the knowledge base. Phi Delta Kappan, pp. 470-478.

Walker, C. (1985) Learning English: The south east Asian refugee experience. Topics in Language Disorders, 5, pp. 53-65.

Wang, M. C., Haertel, G. and Walberg, H. J. (1993) Synthesis of research: what helps students learn? Educational Leadership, 51/4: 74-79.

Warr, P. (1987) Work, unemployment, and mental health. Oxford: Oxford University Press.

Warr, P. B. (1999) Well-being and the workplace. In Kahneman, D., Diener, E. and Schwarz, N. (Eds) Well-being: the Foundations of Hedonic Psychology. New York: Russell Sage Foundation.

Wenger, E. (1998) Communities of Practice: Learning, meaning and identity. Cambridge University Press.

Wiener, R.L.; Pritchard, C.; Frauenhoffer, S.M.; and Edmonds, M. Evaluation of a drug-free schools and community program: Integration of qualitative and quasiexperimental methods. Eval Rev 17(5):488-503, 1993.

Weiner, L., Swearingen, J., Pagano, A. and Obi, R. (1993) Choosing Teaching as a Career. Comparing motivations of Harvard and urban college students. Paper presented to the Conference of the Eastern Education Research Association, Clearwater, Florida.

Werner, E. and Smith, R. (1988) Vulnerable but invincible: A longitudinal study of 
resilient children and youth. New York: Adams Bannister and Cox.

Wittrock, M. C. (1986) (Ed) Handbook of Research on Teaching ( $3^{\text {rd }}$ ed). New York: Macmillan.

Wong, R. (1994) Eye on Politics: The Four Ugly Lies About Immigrants. Asian Week (Stamford, Conn.: Ethnic NewsWatch, SoftLine Information Inc., February 11, 1994).

Woods, P. (1978) Negotiating the Demands of Schoolwork. Curriculum Studies, 10, 4, pp. 309-327.

Woods, P (1995) Creative Teachers in Primary Schools. Open University Press.

Woods, P. (1997) Restructuring Schools, Reconstructing Teachers. Open University Press.

Woods, P. (2001) 'Teaching and Learning in the New Millennium', in Sugrue, C. (ed) Developing Teachers and Teaching Practice: International Research Perspectives, London: Falmer Press.

Woods, P. and Jeffrey, B. (1996) Teachable Moments: The art of teaching in primary schools. Buckingham: Open University Press.

Woods, P., Jeffrey, B. and Troman, G. (1997) Restructuring Schools, Reconstructing Teachers. Buckingham: Open University Press.

Wragg, E. C. (1984) Conducting and Analysing Interviews. In Bell, J., Bush, T., Fox, Al. Goodey, J. and Goulding, S. (eds.) Conducting Small-Scale Investigations in Educational Management. London: Harper and Row Publishers, pp 177-179.

Zembylas, M. (2003) Emotions and Teacher Identity: A poststructual perspective. Teachers and Teaching: Theory and Practice. Vol. 9, No. 3, August 2003.

Zimpher, N. (1989). The RATE Project: A profile of teacher education students. Journal of Teacher Education, 40(6), 27-30. 


\section{Appendix One: Summary of working papers}

\section{2}

Day, C., Sammons, P., Kington, A. and Lee, T. (2002). A Critical Review of the Literature on School and Teacher Effectiveness and Teacher's Work and Lives: Towards Relational and Relative Effectiveness

\section{3}

Day, C. (2003). Designing Longitudinal Research on Variations in Teachers' Work. Lives and Effects on Pupils: An Overview. Paper presented at the British Educational Research Association Conference, Edinburgh, September 2003 and the European Educational Research Association Conference, Hamburg, September 2003. http://www.nottingham.ac.uk/education/centres/crtsd/vitae/index.htm

Day, C. (2003). Variations in the Work and Lives of Teachers: A Four Year MultiSite Research Project. Changing Contexts of Teachers' Work. Paper presented at the University of Houston College of Education, December 2003 and at ICET, 2004

Day, C., Stobart, G., Kington, A. and Ellison, L.(2003). Variations in Teachers' Lives, Work and Effectiveness (VITAE): An Overview of the Research Design and Key Factors Emerging from Phase One of the Study. Paper presented at ATEE Annual Conference, Malta, August 2003

Day, C., Stobart, G., Sammons, P. and Kington, A. (2003). Variations in Teachers' Work and Lives and Their Effects on Pupils (VITAE). Paper presented at ICET, 2003 and at ISATT, Norway, 2003

Day, C., Stobart, G., Sammons, P., Kington, A. and Last, J. (2003). Variations in Teachers, Work and Lives and Their Effects on Pupils (VITAE): Methodology Paper

Hadfield, M., Kington, A., Day, C. and Sammons, P. (2003). Combining Qualitative and Quantitative Methods in Multi-Site Longitudinal Research. Paper presented at the British Educational Research Association Conference, Edinburgh, September 2003 and the European Educational Research Association Conference, Hamburg, September 2003 http://www.nottingham.ac.uk/education/centres/crtsd/vitae/index.htm

Sammons, P., Day, C., Kington, A. and Lee, T. (2003). A Critical Review of the Literature on School and Teacher Effectiveness and Teachers' Work and Lives: Towards Relational and Relative Effectiveness. Paper presented at the British Educational Research Association Conference, Edinburgh, September 2003 and the European Educational Research Association Conference, Hamburg, September 2003 http://www.nottingham.ac.uk/education/centres/crtsd/vitae/index.htm

Sammons, P. and Day, C., Kington, A. and Lee, T. (2003). A 4 Year Study of the Variations in Teachers' Work, Lives and their Effects on Pupils. A Critical Review of the Literature on School and Teacher Effectiveness and Teachers' Work and Lives: International Evidence. Paper presented at DfES Conference, London, December 2003

Smees, R., Sammons, P. and Stobart, G. (2003). Progress report on the Value Added 
analysis of the 2002/2003 cognitive assessments

Stobart, G. and Mujtaba, T. (2003). Early Indicators of Key Factors in Teachers' Perceptions of Relational Effectiveness: Initial Survey. Paper presented at the British Educational Research Association Conference, Edinburgh, September 2003 and the European Educational Research Association Conference, Hamburg, September 2003

\section{4}

Day, C., Stobart, G., Sammons, P., Hadfield, M. and Kington, A. (2004). Profiling Variations in Teachers' Work, Lives and Effectiveness: The VITAE Project. Selected Symposium Paper presented at the British Educational Research Association Conference, Manchester, September 2004 and at the European Educational Research Association Conference, Crete, September 2004 http://www.nottingham.ac.uk/education/centres/crtsd/vitae/index.htm

Day, C., Stobart, G., Sammons, P. and Kington, A. (2004). Understanding Variations in the Work and Lives of Teachers: Interim Findings of a 4 Year National Multi-Site Research Project. Paper presented at American Educational Research Association Conference, San Diego, California, April 2004

Smees, R., Sammons, P. and Stobart, G. (2004). Measuring the Impact of teachers on Pupil's Cognitive Progress over Year 6 and Year 9: A Value Added analysis

\section{5}

Day, C., Kington, A., Gu, Q. and Sammons, P. (2005). The Role of Identity in Variations in Teachers' Work, Lives and Effectiveness. Paper presented as part of an ESRC Seminar Series.

Day, C., Sammons, P., Kington, A., Gu, Q., Kidd, H. and Stobart, G. (2005). The Interaction Between professional, Personal and Contextual Influences and Notions of Relative and Relational Effectiveness: Findings from VITAE. Paper presented at the British Educational Research Association Conference, Glanmorgan, Wales, September 2005, the European Educational Research Association Conference, September 2005 and the Australian Association for Research in Education Conference, Australia, November 2005

Day, C., Sammons, P., Stobart, G., Kington, A. and Gu, Q. (2005). Conceptualising the Role of Identity in Variations in Teachers' Work, Lives and Effectiveness. Paper presented at the American Educational Research Association Conference, Montreal, April, 2005

Day, C., Stobart, G., Sammons, P., Hadfield, M. and Kington, A. (2005). Profiling Variations in Teachers' Work, Lives and Effectiveness: The VITAE Project. Paper accepted at ISATT, 2005

Smees, R., Sammons, P. and Stobart, G. (2005). Measuring the Impact of schools on children's attainment at the end of Year 2: a contexualised analysis of cohorts 1 and 2 
Smees, R., Sammons, P. and Stobart, G. (2005). Measuring the Impact of teachers on pupil's cognitive progress over Year 6: Summary of the Value Added analysis of cohort 2 pupils

Smees, R., Sammons, P. and Stobart, G. (2005). Measuring the Impact of teachers on Pupil's Cognitive Progress over Year 9: A summary of the Value Added analysis of COHORT 2 data

\section{6}

Day, C., Kington, A., Stobart, G. and Sammons, P. (forthcoming). The Personal and Professional Selves of the Teachers: Stable and Unstable Identities. British Educational Research Journal

Day, C., Stobart, G., Sammons, P. and Kington, A. (2006). Variations in the Work, Lives of Teachers: Relative and Relational Effectiveness. Teachers and Teaching: Theory and Practice, Vol. 12, No. 2, pp. pp. 169-192, April 2006. 


\section{Appendix Two: Technical report on Value Added analysis of pupil key stage outcomes across three cohorts}

This document summarises the technical aspects of the multilevel analyses of pupil attainment outcomes carried out on the three cohorts of Vitae pupils.

\section{Key Findings}

At each Key Stage national assessment results were used as outcome measures.

In Years 6 and 9 test scores provide more finely differentiated attainment measures but in year 1 only level data are available.

- A contextualised multilevel analysis was used to compare the attainment of Year 2 pupils from different primary schools in the VITAE samples. This approach allows for a fairer comparison of schools' performance levels than assessing raw results alone. A contextualised analysis uses multilevel statistical modelling to compare different schools, after adjusting for the impact of specific pupil and school background characteristics such as gender and FSM status that are out of the control of the school. A contextualised analysis is used when prior attainment is not available. It is not as robust a method as a full Value Added analysis that would utilise prior attainment, but has been proven to be a useful alternative.

- A Value Added multilevel analysis was used to compare the progress over one year school of Year 6 and Year 9 pupils from different classes. The Value Added analysis carried out for the Vitae Year 6 and 9 pupils adjusted for the impact of prior attainment (measured early in the autumn term) and specific pupil and school background characteristics such as gender and FSM status that are out of the control of the school.

- The main purpose of this analysis was to produce an indicator of effectiveness for each school or teacher. This indicated whether the school/teacher was showed higher or lower attainment than would be expected based on the characteristics and, in Year 6 and 9, the prior attainment of children in the school or individual teachers' class/teaching group (Year 6 and 9). By using data from the whole sample the analysis can see whether children from individual schools/classes are attaining better or worse results than all similar children within the whole sample of schools/classes.

- Pupil's Key stage 1, 2 and 3 attainment in English and Mathematics was assessed.

- Before the contextualised/Value Added indicators could be calculated, any pupil and school characteristics that were found to significantly impact on attainment or progress needed to be adjusted for. The pupil characteristics adjusted for varied to some degree from year to year, but also between year groups. There were more 
background characteristics found to significantly predict attainment in the contextualised analysis of Year 2 outcomes than the other two year groups. This is to be expected as prior attainment data was not available (because such drawn results are also related to prior attainment).

- The analysis found that schools/classes differed significantly in the attainment/progress of their children even after making adjustments for a wide range of characteristic pupil intake. The differences between schools were large in educational terms.

\section{Aims}

The multilevel analysis uses an 'educational effectiveness' design to investigate pupils' attainment/progress in three year groups in both English and mathematics to establish the relative 'effectiveness' of different project teachers (Year 6 and 9) in promoting pupils' achievement in these subjects. These analyses were intended to feed into the qualitative strand of the project.

The multilevel analysis for the whole project can be split into two main parts:

i) To identify the amount of variation that exists across schools (or classes) by controlling for student intakes and create an indicator for each school that controls for pupil background characteristics and prior attainment (where available). This measure of effectiveness will indicate how well children from each school have progressed compared to similar children in other schools (or classes).

ii) To assess the impact of teacher's lives and schools characteristics on the outcomes of students. Information taken from the teacher survey, pupil survey and national databases will be utilized. This analysis will investigate whether, once differences in class intake have been accounted for, any particular teacher or school characteristics of pupils' progress or attainment.

\section{Introduction}

This section summarises the Value Added analysis of attainment data across three cohorts and two Key stages (Key stages 2 and 3), as well as a 'contextualised' analysis of Key stage 1 outcomes.

\section{The methodology: Multilevel modelling, Contextualised and Value Added}

To assess the impact of an individual teacher on the academic progress their pupils make over one academic year, it is essential for factors that are beyond the influence of the teacher to be identified. These factors can be seen as the 'dowry' that pupils bring to the classroom, such as gender, socio-economic status and ethnicity, EAL status, age and prior attainment. Because the intake characteristics of different classes can differ widely it is essential that pupil characteristics that can be shown statistically to impact on attainment are adjusted for before we compare classroom attainment. In this way we can compare the potential influence of teachers who are working with very different pupil groups. Multilevel modelling can both identify these factors and produce 'Value Added estimates (residuals) and their confidence limits' that have been adjusted to take them into account. 
The aim of a contextualised analysis is to identify the contribution of particular pupil and school characteristics to children's outcomes (in this case Key stage 1 attainment) when prior attainment is not available. Thus, for example, the impact of family socioeconomic status (using FSM as a quasi indicator of SES), is established while taking into account the influence of pupil gender, ethnicity, EAL status etc. These significant characteristics can then be adjusted for when producing a 'contexualised' indicators (a contextualised score) of a school's effectiveness in promoting attainment levels. This sort of analysis is not as precise as a complex Value Added analysis (which would have prior attainment and pupil/school characteristics), but is a fairer way of comparing schools than raw performance tables of attainment.

The contextualised or Value Added score indicates whether a school or class is performing better or worse than expected based on their pupil/school intake characteristics. To aid interpretation it is important to establish whether differences are statistically significant. For the purpose of the project, the contextualised residuals were categorised into five 'effectiveness' groupings (see Table A2). Schools with contextualised residuals significantly above or below expectation at the $95 \%$ and $68 \%$ confidence limit are identified by calculating confidence intervals for each contextualised residual ${ }^{25}$.

Table A2: Categorisation of contexualised residuals

\begin{tabular}{|l|l|l|l|l|}
\hline $\begin{array}{l}\text { Below (-1.96 se) } \\
\text { expectation } \\
\mathbf{9 5 \%} \\
\text { significance) }\end{array}$ & $\begin{array}{l}\text { Below (-1 se) } \\
\text { expectation } \\
\mathbf{6 8 \%}\end{array}$ & $\begin{array}{l}\text { As expected } \\
\text { significance) }\end{array}$ & $\begin{array}{l}\text { Above (+ 1 se }) \\
\text { expectation } \\
\mathbf{6 8 \%} \\
\text { significance) }\end{array}$ & $\begin{array}{l}\text { Above (+ 1.06 } \\
\text { se) expectation } \\
\mathbf{9 5 \%} \\
\text { significance) }\end{array}$ \\
\hline-- & - & As expected & + & ++ \\
\hline $\begin{array}{l}95 \% \text { chance the } \\
\text { school is } \\
\text { performing } \\
\text { worse than } \\
\text { expected }\end{array}$ & $\begin{array}{l}\text { 68\% chance the } \\
\text { school is } \\
\text { performing } \\
\text { worse than } \\
\text { expected }\end{array}$ & $\begin{array}{l}\text { The school's } \\
\text { performance is } \\
\text { statistically as } \\
\text { expected }\end{array}$ & $\begin{array}{l}\text { 68\% chance the } \\
\text { school is } \\
\text { performing } \\
\text { better than } \\
\text { expected }\end{array}$ & $\begin{array}{l}\text { 95\% chance the } \\
\text { school is } \\
\text { performing } \\
\text { better than } \\
\text { expected }\end{array}$ \\
\hline
\end{tabular}

A statistically significant score is classified as one in which the schools contextualised score differs from zero using a $95 \%$ confidence interval. In real terms, this means there is a $95 \%$ chance that this score is significantly different to zero so should be taken as a true indication that a school has is effective in promoting attainment (i.e. an outlier). In addition to this, contexualised residuals that are significant using a $68 \%$ confidence interval have also been used as an 'indication' of a school's contextualised attainment $^{26}$.

\section{The sample}

Table A3 shows the number of pupils, classes and schools for which sufficient data was available for inclusion in the multilevel analyses. In summary, seven English Local Authorities (LAs) participated in the research.

\footnotetext{
${ }^{25}$ Confidence intervals at the $95 \%$ confidence limit $=$ residual $+/-1.96$ standard error. Confidence intervals at the $68 \%$ confidence limit $=$ residual $+/-1.00$ standard error.

${ }^{26}$ There is a $68 \%$ chance that this score is significantly different to zero.
} 
Because the analysis of Key stage 1 outcomes was a contextualised analysis the data was obtained directly from nationally datasets, so all schools completing the national assessments could be included. New assessment arrangements were being piloted in around $25 \%$ of LEAs in cohort 2 . The schools involved in the pilot were not required to return test/task data. Because of this, some schools did not have enough data to be included in the cohort 2 analysis. Table A4 shows the number of pupils, classes and schools for which sufficient data was available for inclusion in the multilevel analyses.

Table A3: The numbers of pupils, classes and school in the 2003/04 multilevel analysis

\begin{tabular}{|c|c|c|c|c|c|c|}
\hline & \multicolumn{6}{|c|}{ Year 2 (Key stage 1) } \\
\hline & \multicolumn{4}{|c|}{$2002 / 03$} & \multicolumn{2}{|c|}{$2004 / 05$} \\
\hline & \multicolumn{2}{|c|}{ Cohort 1} & \multicolumn{2}{|c|}{ Cohort 2} & \multicolumn{2}{|c|}{ Cohort 3} \\
\hline & Maths & English & Maths & English & Maths & English \\
\hline \multirow[t]{5}{*}{$\begin{array}{l}\text { Number of schools } \\
\text { Number of pupils }\end{array}$} & $\begin{array}{l}67 \\
1955\end{array}$ & $\begin{array}{c}66 \\
1954\end{array}$ & $\begin{array}{l}53 \\
1543\end{array}$ & $\begin{array}{l}52 \\
1536\end{array}$ & $\begin{array}{l}69 \\
2014\end{array}$ & $\begin{array}{l}69 \\
2014\end{array}$ \\
\hline & \multicolumn{6}{|c|}{ Year 6 (Key stage 2) } \\
\hline & \multirow{2}{*}{\multicolumn{2}{|c|}{ Cohort 1}} & \multicolumn{2}{|c|}{ Cohort 2} & \multicolumn{2}{|c|}{ Cohort 3} \\
\hline & & Primary year 6 & \multicolumn{2}{|c|}{ Primary year 6} & \multicolumn{2}{|c|}{ Primary year 6} \\
\hline & Maths & English & Maths & English & Maths & English \\
\hline Number of schools & 59 & 59 & 44 & 44 & 30 & 29 \\
\hline Number of classes & 63 & 63 & 45 & 45 & 30 & 29 \\
\hline \multirow[t]{4}{*}{ Number of pupils } & 1232 & 1235 & 935 & 934 & 612 & 612 \\
\hline & \multicolumn{6}{|c|}{ Year 9 (Key stage 3) } \\
\hline & \multicolumn{2}{|c|}{ Cohort 1} & \multicolumn{2}{|c|}{ Cohort 2} & \multicolumn{2}{|c|}{ Cohort 3} \\
\hline & Maths & English & Maths & English & Maths & English \\
\hline Number of schools & 16 & 17 & 18 & 13 & 17 & 13 \\
\hline Number of classes & 43 & 49 & 43 & 29 & 28 & 19 \\
\hline Number of pupils & 1046 & 1068 & 1066 & 723 & 670 & 436 \\
\hline
\end{tabular}

The sample remained similar across the three cohorts in terms of background characteristics, as can be seen in Tables A3, A4 and A5.

Table A4 Characteristics of the VITAE Year 2 sample

\begin{tabular}{|c|c|c|c|}
\hline & $\begin{array}{l}\text { Cohort 1* } \\
\text { n }(\%)\end{array}$ & $\begin{array}{l}\text { Cohort 2* } \\
\text { n }(\%)\end{array}$ & $\begin{array}{l}\text { Cohort } 3^{*} \\
\text { n }(\%)\end{array}$ \\
\hline Gender: & $\begin{array}{l}1064(51.4 \%) \\
1005(48.6 \%)\end{array}$ & $\begin{array}{c}1088(52.8 \%) \\
971(47.2 \%)\end{array}$ & $\begin{array}{l}1036(50.0 \% \\
1035(50.0 \%)\end{array}$ \\
\hline Ethnicity : & $1393(67.4 \%)$ & $1380(68.9 \%)$ & $1447(69.9 \%)$ \\
\hline English as a Second Language & $310(15.0 \%)$ & $354(17.2 \%)$ & $343(16.6 \%)$ \\
\hline Receiving free school meals & $476(23.0 \%)$ & $488(23.7 \%)$ & $485(23.4 \%)$ \\
\hline $\begin{array}{l}\text { SEN status: Statement in progress } \\
\text { Full statement }\end{array}$ & $\begin{array}{l}430(20.8 \%) \\
38(1.8 \%)\end{array}$ & $\begin{array}{l}423(20.8 \%) \\
42(2.6 \%)\end{array}$ & $\begin{array}{l}402(19.4 \%) \\
41(2.0 \%)\end{array}$ \\
\hline 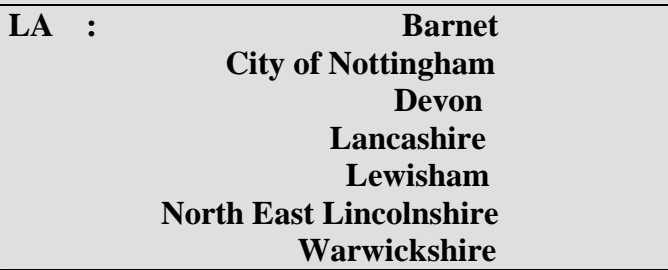 & $\begin{array}{l}264(12.8 \%) \\
147(7.1 \%) \\
335(16.2 \%) \\
552(26.7 \%) \\
409(19.8 \%) \\
78(3.8 \%) \\
282(13.6 \%)\end{array}$ & $\begin{array}{l}270(13.1 \%) \\
148(7.2 \%) \\
358(17.4 \%) \\
605(29.4 \%) \\
412(20.6 \%)^{* *} \\
46(2.2 \%)^{* *} \\
220(10.7 \%)\end{array}$ & $\begin{array}{l}301(14.5 \%) \\
203(9.8 \%) \\
335(16.2 \%) \\
556(26.8 \%) \\
346(16.7 \%) \\
68(3.3 \%) \\
262(12.7 \%)\end{array}$ \\
\hline Total pupil n & 2067 & 1543 & 2071 \\
\hline
\end{tabular}

* based on the full dataset for whom PLASC data was available

**These two LAs did not have test/task data so could not be included in the analysis 
Table A5 Characteristics of the VITAE Year 6 sample

\begin{tabular}{|c|c|c|c|}
\hline & $\begin{array}{l}\text { Cohort } 1 \\
\text { n }(\%)\end{array}$ & $\begin{array}{l}\text { Cohort } 2 \\
\text { n }(\%)\end{array}$ & $\begin{array}{l}\text { Cohort } 3 \\
\text { n }(\%)\end{array}$ \\
\hline Gender: & $\begin{array}{l}716(49.5 \%) \\
731(50.5 \%)\end{array}$ & $\begin{array}{l}558(52.3 \%) \\
509(47.7 \%)\end{array}$ & $\begin{array}{l}331(49.8 \%) \\
333(50.2 \%)\end{array}$ \\
\hline Ethnicity : & $1056(74.3 \%)$ & $704(66.0 \%)$ & $508(73.8 \%)$ \\
\hline English as a Second Language & $188(13.2 \%)$ & $174(17.0 \%)$ & $79(11.9 \%)$ \\
\hline Receiving free school meals & $303(21.3 \%)$ & $199(19.4 \%)$ & $128(19.3 \%)$ \\
\hline $\begin{array}{l}\text { SEN status: Statement in progress } \\
\text { Full statement }\end{array}$ & $\begin{array}{l}328(23.1 \%) \\
23(1.6 \%)\end{array}$ & $\begin{array}{l}236(23.0 \%) \\
25(2.4 \%)\end{array}$ & $\begin{array}{l}126(19.0 \%) \\
13(2.0 \%)\end{array}$ \\
\hline 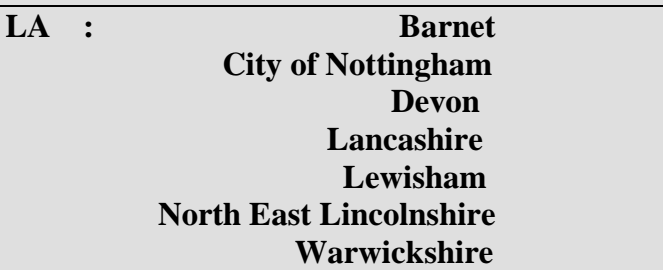 & $\begin{array}{l}113(7.8 \%) \\
89(6.2 \%) \\
207(14.5 \%) \\
447(30.9 \%) \\
264(18.2 \%) \\
84(5.8 \%) \\
243(16.8 \%)\end{array}$ & $\begin{array}{l}191(17.9 \%) \\
35(3.3 \%) \\
152(14.2 \%) \\
307(28.8 \%) \\
207(19.4 \%) \\
14(1.3 \%) \\
161(15.1 \%)\end{array}$ & $\begin{array}{l}91(13.2 \%) \\
36(5.2 \%) \\
95(13.8 \%) \\
302(44.6 \%) \\
57(8.3 \%) \\
42(6.1 \%) \\
60(8.7 \%)\end{array}$ \\
\hline Total pupil n & 1447 & 1067 & 688 \\
\hline
\end{tabular}

* based on the full dataset for whom baseline data was available

Table A6 Characteristics of the VITAE Year 9 Sample

\begin{tabular}{|c|c|c|c|c|c|c|}
\hline & \multicolumn{2}{|l|}{$\begin{array}{l}\text { Cohort } 1 \\
\text { n }(\%)\end{array}$} & \multicolumn{2}{|l|}{$\begin{array}{l}\text { Cohort } 2 \\
\text { n }(\%)\end{array}$} & \multicolumn{2}{|l|}{$\begin{array}{l}\text { Cohort } 3 \\
\text { n }(\%)\end{array}$} \\
\hline & English & Maths & English & Maths & English & Maths \\
\hline $\begin{array}{lr}\text { Gender: } & \text { Male } \\
& \text { Female }\end{array}$ & $\begin{array}{l}637 \\
(55.2 \%) \\
518 \\
(44.8 \%)\end{array}$ & $\begin{array}{l}592 \\
(54.0 \%) \\
505 \\
(46.0 \%)\end{array}$ & $\begin{array}{l}385 \\
(51.4 \%) \\
364 \\
(45.7 \%)\end{array}$ & $\begin{array}{l}604 \\
(54.3 \%) \\
508 \\
(45.7 \%)\end{array}$ & $\begin{array}{l}234 \\
(50.9 \%) \\
226 \\
(49.1 \%)\end{array}$ & $\begin{array}{l}352 \\
(51.2 \%) \\
336 \\
(48.8 \%)\end{array}$ \\
\hline $\begin{aligned} \text { Ethnicity } & \\
& \text { White UK }\end{aligned}$ & $\begin{array}{l}953 \\
(82.5 \%)\end{array}$ & $\begin{array}{l}949 \\
(86.6 \%)\end{array}$ & $\begin{array}{l}606 \\
(81.9 \%)\end{array}$ & $\begin{array}{l}838 \\
(78.6 \%)\end{array}$ & $\begin{array}{l}385 \\
(85.2 \%)\end{array}$ & $\begin{array}{l}564 \\
(82.7 \%)\end{array}$ \\
\hline EAL & $\begin{array}{l}129 \\
(11.3 \%)\end{array}$ & $\begin{array}{l}113 \\
(10.3 \%)\end{array}$ & $97(13.1 \%)$ & $\begin{array}{l}155 \\
(14.1 \%)\end{array}$ & $53(11.7 \%)$ & $73(10.7 \%)$ \\
\hline Entitled to FSM & $\begin{array}{l}176 \\
(15.5 \%)\end{array}$ & $\begin{array}{l}154 \\
(14.1 \%)\end{array}$ & $\begin{array}{l}116 \\
(15.6 \%)\end{array}$ & $\begin{array}{l}165 \\
(15.0 \%)\end{array}$ & $77(17.0 \%)$ & $83(12.2 \%)$ \\
\hline $\begin{array}{l}\text { SEN status: } \\
\text { SEN register } \\
\text { Full statement }\end{array}$ & $\begin{array}{l}127 \\
(11.2 \%) \\
13(1.1 \%) \\
\end{array}$ & $\begin{array}{l}130 \\
(11.9 \%) \\
22(2.0 \%)\end{array}$ & $\begin{array}{l}90(12.1 \%) \\
9(1.2 \%)\end{array}$ & $\begin{array}{l}152 \\
(13.8 \%) \\
18(1.6 \%)\end{array}$ & $\begin{array}{l}58(12.8 \%) \\
10(2.2 \%)\end{array}$ & $\begin{array}{l}99(14.5 \%) \\
11(1.6 \%)\end{array}$ \\
\hline $\begin{array}{rr}\text { LA : } & \text { Barnet } \\
\text { City of Nottingham } & \text { Devon } \\
\text { Lancashire } \\
\text { Lewisham } \\
\text { N.E. Lincolnshire } \\
\text { Warwickshire }\end{array}$ & $\begin{array}{l}66(5.7 \%) \\
80(6.9 \%) \\
189 \\
(16.4 \%) \\
566 \\
(49.0 \%) \\
---- \\
73(6.3 \%) \\
181 \\
(15.7 \%)\end{array}$ & $\begin{array}{l}----- \\
54(4.9 \%) \\
196 \\
(17.9 \%) \\
559 \\
(51.0 \%) \\
---- \\
73(6.7 \%) \\
215 \\
(19.6 \%)\end{array}$ & $\begin{array}{l}45(6.0 \%) \\
80(10.7 \%) \\
64(8.5 \%) \\
423 \\
(56.5 \%) \\
---- \\
57(7.6 \%) \\
80(10.7 \%)\end{array}$ & $\begin{array}{l}118 \\
(10.6 \%) \\
82(7.4 \%) \\
192 \\
(17.3 \%) \\
501 \\
(45.1 \%) \\
37(3.3 \%) \\
46(4.1 \%) \\
136 \\
(12.2 \%) \\
\end{array}$ & $\begin{array}{l}19(4.2 \%) \\
43(9.5 \%) \\
60(13.3 \%) \\
278 \\
(61.5 \%) \\
--- \\
30(6.6 \%) \\
22(4.9 \%)\end{array}$ & $\begin{array}{l}73(10.7 \%) \\
27(4.0 \%) \\
87(12.8 \%) \\
307 \\
(45.0 \%) \\
36(5.3 \%) \\
52(7.6 \%) \\
100 \\
(14.7 \%)\end{array}$ \\
\hline Total pupil n & 1155 & 1097 & 749 & 1112 & 460 & 693 \\
\hline
\end{tabular}

\section{Data collection}

Data from multiple sources was required to run the Value Added and contextualised analyses: 
- Baseline attainment data was collected by the VITAE project team at the beginning of each of three successive $(2002 / 03,2003 / 04,2004 / 05)$ academic years for Year 6 and 9 pupils ${ }^{27}$.

- Outcome data in the form of Key stage 1,2 and 3 attainment was collected from the Department for Education and Skills (DfES) from the end of the academic year.

- Pupil background information such as age within the year group, ethnicity etc was collected from the PLASC dataset, also provided by the DfES.

- Some school level contextual information was also collected from the PLASC dataset such as proportion of the pupils in the school entitled to Free School meals etc.

\section{Main findings}

\section{Key predictors of progress and attainment}

As would be anticipated prior attainment was the strongest predictor of Year 6 and 9 attainment for both English and maths at the end of the academic year. Prior attainment adjusts for differences at the start of the academic year, so adjusting for prior attainment allows for comparisons of the progress made by pupils across the academic year.

Progress for different pupil groups was found to vary, even over the single academic year. Tables A6 and A7 display the child and school factors that were found to significantly relate to progress (after prior attainment had been taken into account for years 6 and 9), and attainment (for Year 2).

\footnotetext{
${ }^{27}$ The assessments sat were part of the NFER-Nelson 'progress 5-14' series (NFER assessments ' progress in English/maths 10' and 'Progress in English/maths 13'). They provide age standardised scores that adjust pupils' performance according to their age, and provide comparisons with a nationally representative sample.
} 
Table A7: Child and school factors significantly related to attainment (Year 2)

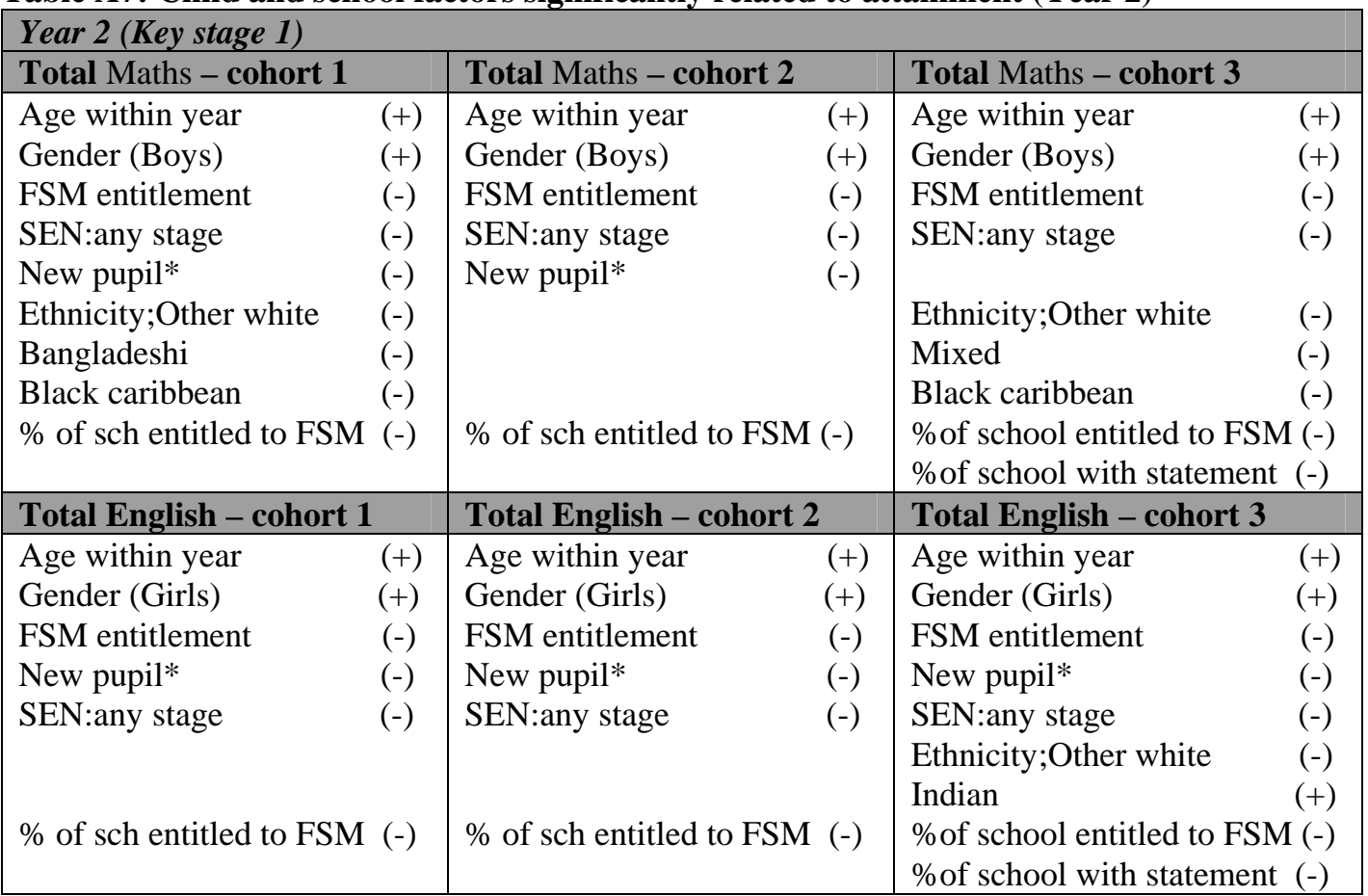

* Joined school in this or previous academic year

Table A8: Child and school factors significantly related to progress (Years 6 and 9)

\begin{tabular}{|c|c|c|c|}
\hline \multicolumn{4}{|l|}{ Year 6 (Key stage 2) } \\
\hline Total Maths - cohort 1 & \multicolumn{2}{|c|}{ Total Maths - cohort 2} & Total Maths - cohort 3 \\
\hline Age within year & FSM entitlement & $(-)$ & Age within year \\
\hline Gender (Boys) & Age within year & $(+)$ & Gender (Boys) \\
\hline Ethnicity: & Gender (Boys) & $(+)$ & \\
\hline Chinese & & & \\
\hline Other & SEN:any stage & $(-)$ & \\
\hline SEN status: In progress & EAL & $(-)$ & \%of school entitled to FSM (-) \\
\hline Total English - cohort 1 & Total English - co & & Total English - cohort 3 \\
\hline FSM entitlement & FSM entitlement & $(-)$ & Age within year \\
\hline Age within year & Age within year & $(+)$ & Gender (Girls) \\
\hline Gender (Girls) & Gender (Girls) & $(+)$ & New pupil* \\
\hline Ethnicity: & & & \\
\hline Mixed & & & \\
\hline SEN:any stage & SEN:any stage & $(-)$ & SEN:any stage \\
\hline \multicolumn{4}{|l|}{ Year 9 (Key stage 3) } \\
\hline Total Maths - cohort 1 & \multicolumn{2}{|c|}{ Total Maths - cohort 2} & Total Maths - cohort 3 \\
\hline FSM entitlement & FSM entitlement & $(-)$ & \\
\hline Age within year & Age within year & $(+)$ & \\
\hline SEN:statement & EAL & $(+)$ & \\
\hline Class ability level & Class ability level & $(+)$ & Class ability level \\
\hline Total English - cohort 1 & \multicolumn{2}{|c|}{ Total English - cohort 2} & Total English - cohort 3 \\
\hline FSM entitlement & FSM entitlement & $(-)$ & SEN: any stage \\
\hline Class ability level & Age & $(+)$ & \\
\hline$\%$ of sch with statement & SEN statement & $(-)$ & \\
\hline & Class ability level & $(+)$ & \\
\hline
\end{tabular}

* Joined school after Year 1 
The impact of setting by ability level

The analyses of baseline data showed evidence of setting by ability level within the Year 9 sample, especially for maths (see Sammons et al 2003 for more details). The analysis team was aware that setting by ability may have an effect on the analysis and the Value Added results. Literature suggests (Sukhanandan and Lee 1998) that higher ability pupils achieve better in high ability sets than in mixed groups. The opposite is true for lower ability pupils, who tend to make less progress in lower ability groups. Value Added analyses on Dutch data have pointed to the impact of ability level of the teaching group, suggesting that who you are taught with can have a larger impact than how you are taught (De Fraine et al 2003).

The Value Added analyses for both cohorts confirmed the impact of the ability level of the class (measured at the beginning of the academic year) ${ }^{28}$ at KS 3 . The findings suggested that the ability group you were placed in had a strong impact on progress, even after the individual prior attainment levels of the pupils had been taken into account. This suggests that being in a higher ability group confers an advantage in the amount of progress made, and being in a lower ability group confers a disadvantage.

The reasons for such effects are not simple. A high ability class may be easier to teach in terms of pupil behaviour, motivation or engagement than a lower ability class, an advantage or disadvantage beyond the control of the teacher. An alternative hypothesis would suggest that the higher skilled teachers are more likely to teach higher ability classes. In this Scenario, adjusting for class ability level would be unfair as it would adjust for teaching ability. For this reason, two separate Value Added scores per subject have been fed back that do and don't take account of class ability level. It is also possible that curriculum coverage varies and teacher expectations in different teaching groups and also that teacher behaviour may vary.

\section{Variations in class and school effectiveness}

Significant differences between individual classes were identified in terms of value added for both outcomes investigated (mathematics and English), reflecting differences in the attainment and progress pupils made across a single academic year (see Tables 8 and 9). The intra-school correlation for these multilevel models show the extent to which individual schools or classes differ in their impact on attainment. The intra-school correlation would be zero if schools did not vary significantly in their impact on progress rates, once pupil background had been taken in account. For example, we can see from Table 8 that the intra-school correlation for the contextualised Year 2 analyses is around $10 \%$ (cohort $1=0.096$, cohort $2=0.104$, cohort $3=0.104$ ) for Writing and $6-9 \%$ for maths (cohort $1=0.073$, cohort $2=0.062$, cohort $3=0.092$ ), which is significantly different to zero. Intra-school correlations of this magnitude are quite large in educational terms.

The size of the class or school effect (measured by the intra-class correlation, see Table A9) and the number of outliers (see Table A11) are higher in this value added analyses than in most previous school effectiveness studies. They range from 0.1050.150 for maths and 0.17-0.29 for English in Year 6. For Year 9 they vary from 0.097-

\footnotetext{
${ }^{28}$ The Year 9 Value Added analysis of cohort 3 showed only a small ability group effect for maths and none for English (although it was close to significance). This maybe due to the much smaller sample size for this cohort.
} 
0.226 for maths and 0.15-0.296 for English. Teacher effectiveness studies generally show that variations in teacher effects on pupil progress over one year are usually larger than school effects over several years common in studies across Key Stages (for example see Sammons et al 2003 for details of KS3 evaluation across one academic year).

Table A9 Intra-school correlations for contextualised Year 2 outcomes

\begin{tabular}{|l|l|l|l|l|l|l|}
\hline \multicolumn{7}{|l|}{ Year 2 (Key stage 1) } \\
\hline & Writing & \multicolumn{2}{l|}{ Maths } \\
\hline & $\begin{array}{l}\text { Cohort } \\
\mathbf{1}\end{array}$ & $\begin{array}{l}\text { Cohort } \\
\mathbf{2}\end{array}$ & $\begin{array}{l}\text { Cohort } \\
\mathbf{3}\end{array}$ & $\begin{array}{l}\text { Cohort } \\
\mathbf{1}\end{array}$ & $\begin{array}{l}\text { Cohort } \\
\mathbf{2}\end{array}$ & $\begin{array}{l}\text { Cohort } \\
\mathbf{3}\end{array}$ \\
\hline $\begin{array}{l}\text { Intra-school correlation } \\
\text { (Explanatory variables added) }\end{array}$ & 0.099 & 0.106 & 0.104 & 0.073 & 0.062 & 0.092 \\
\hline Number of children & 1954 & 1536 & 2014 & 1955 & 1543 & 2014 \\
\hline
\end{tabular}

Table A10 Intra-class correlations for Value Added Year 6 and 9 outcomes

\begin{tabular}{|c|c|c|c|c|c|c|}
\hline & \multicolumn{6}{|c|}{ Year 6 (Key stage 2) } \\
\hline & \multicolumn{3}{|c|}{ English } & \multicolumn{3}{|l|}{ Maths } \\
\hline & $\begin{array}{l}\text { Cohort } \\
1\end{array}$ & $\begin{array}{l}\text { Cohort } \\
2\end{array}$ & $\begin{array}{l}\text { Cohort } \\
3\end{array}$ & $\begin{array}{l}\text { Cohort } \\
1\end{array}$ & $\begin{array}{l}\text { Cohort } \\
2\end{array}$ & $\begin{array}{l}\text { Cohort } \\
3\end{array}$ \\
\hline $\begin{array}{l}\text { Intra-school correlation } \\
\text { (Explanatory variables added) }\end{array}$ & 0.293 & 0.271 & 0.170 & 0.150 & 0.167 & 0.105 \\
\hline \multirow[t]{4}{*}{ Number of children } & 1235 & 934 & 612 & 1232 & 935 & 612 \\
\hline & \multicolumn{6}{|c|}{ Year 9 (Key stage 3$)$} \\
\hline & \multicolumn{3}{|c|}{ English } & \multicolumn{3}{|l|}{ Maths } \\
\hline & $\begin{array}{l}\text { Cohort } \\
1\end{array}$ & $\begin{array}{l}\text { Cohort } \\
2 \\
\end{array}$ & $\begin{array}{l}\text { Cohort } \\
\mathbf{3} \\
\end{array}$ & $\begin{array}{l}\text { Cohort } \\
1\end{array}$ & $\begin{array}{l}\text { Cohort } \\
2 \\
\end{array}$ & $\begin{array}{l}\text { Cohort } \\
\mathbf{3} \\
\end{array}$ \\
\hline $\begin{array}{l}\text { Intra-school correlation } \\
\text { (Explanatory variables added } \\
\text { without class ability) }\end{array}$ & 0.268 & 0.264 & 0.295 & 0.541 & 0.513 & 0.152 \\
\hline $\begin{array}{l}\text { Intra-school correlation } \\
\text { (Explanatory variables added } \\
\text { with class ability) }\end{array}$ & 0.150 & 0.155 & 0.296 & 0.226 & 0.263 & 0.097 \\
\hline Number of children & 1068 & 723 & 436 & 1046 & 1046 & 670 \\
\hline
\end{tabular}

Tables A11 and A12 show the distribution of contextualised and value added scores for the different outcomes. The teachers at the extremes of the table can be considered the outliers $(95 \% \mathrm{cl})$, either achieving far above or below expectation. 
Table A11 Distribution of contextualised results for Year 2 outcomes

\begin{tabular}{|c|c|c|c|c|c|}
\hline & \multicolumn{5}{|c|}{ Year 2 (Key stage 1) } \\
\hline & $\begin{array}{l}\text { Below } \\
\text { expectation } \\
(95 \% \\
\text { significance) }\end{array}$ & $\begin{array}{l}\text { Below } \\
\text { expectation } \\
(68 \% \\
\text { significance })\end{array}$ & As expected & $\begin{array}{l}\text { Above } \\
\text { expectation } \\
(68 \% \\
\text { significance })\end{array}$ & $\begin{array}{l}\text { Above } \\
\text { expectation } \\
(95 \% \\
\text { significance) }\end{array}$ \\
\hline $\begin{array}{l}\text { Cohort 1 } \\
\text { Writing } \\
\text { Maths }\end{array}$ & $\begin{array}{ll}7 & (10.6 \%) \\
6 & (9.1 \%)\end{array}$ & $\begin{array}{ll}14 & (21.2 \%) \\
11 & (16.7 \%)\end{array}$ & $\begin{array}{l}26(39.4 \%) \\
34(56.1 \%)\end{array}$ & $\begin{aligned} 14 & (21.2 \%) \\
4 & (6.1 \%)\end{aligned}$ & $\begin{array}{ll}5 & (7.6 \%) \\
8 & (12.1 \%)\end{array}$ \\
\hline $\begin{array}{l}\text { Cohort 2 } \\
\text { Writing } \\
\text { Maths }\end{array}$ & $\begin{array}{ll}5 & (9.6 \%) \\
4 & (7.7 \%)\end{array}$ & $\begin{array}{ll}7 & (10.5 \%) \\
6 & (11.5 \%)\end{array}$ & $\begin{array}{ll}26 & (50.0 \%) \\
32 & (61.5 \%)\end{array}$ & $\begin{array}{r}10(19.2 \%) \\
7(13.5 \%)\end{array}$ & $\begin{array}{ll}4 & (7.7 \%) \\
3 & (5.8 \%)\end{array}$ \\
\hline $\begin{array}{l}\text { Cohort } 3 \\
\text { Writing } \\
\text { Maths }\end{array}$ & $\begin{array}{ll}9 & (13.0 \%) \\
8 & (11.6 \%) \\
\end{array}$ & $\begin{array}{ll}9 & (13.0 \%) \\
8 & (11.6 \%) \\
\end{array}$ & $\begin{array}{ll}34 & (49.3 \%) \\
37 & (53.6 \%)\end{array}$ & $\begin{array}{ll}11(15.9 \%) \\
12(17.4 \%)\end{array}$ & $\begin{array}{l}6(8.7 \%) \\
4(5.8 \%) \\
\end{array}$ \\
\hline
\end{tabular}


Table A12 Distribution of Value Added results for Year 6 and 9 outcomes

\begin{tabular}{|c|c|c|c|c|c|}
\hline & \multicolumn{5}{|c|}{ Year 6 (Key stage 2) } \\
\hline & $\begin{array}{l}\text { Below } \\
\text { expectation } \\
(95 \% \text { sig. }) \\
\end{array}$ & $\begin{array}{l}\text { Below } \\
\text { expectation } \\
\text { (68\% sig.) }\end{array}$ & As expected & $\begin{array}{l}\text { Above } \\
\text { expectation } \\
\text { (68\% sig.) }\end{array}$ & $\begin{array}{l}\text { Above } \\
\text { expectation } \\
\text { (95\% sig.) }\end{array}$ \\
\hline $\begin{array}{l}\text { Conort I } \\
\text { English }\end{array}$ & $14 \quad(22.2 \%)$ & $(11.1 \%)$ & $(33.3 \%)$ & $7 \quad(11.1 \%)$ & $(22.2 \%)$ \\
\hline Maths & $10 \quad(15.9 \%)$ & $(17.5 \%)$ & $(39.7 \%)$ & $7 \quad(11.1 \%)$ & $(15.9 \%)$ \\
\hline $\begin{array}{l}\text { Cohort } 2 \\
\text { English } \\
\text { Maths } \\
\end{array}$ & $\begin{array}{ll}9 & (20.0 \%) \\
8 & (17.8 \%) \\
\end{array}$ & $\begin{array}{lr}2 & (2.2 \%) \\
5 & (11.1 \%) \\
\end{array}$ & $\begin{array}{ll}25 & (55.6 \%) \\
20 & (44.4 \%) \\
\end{array}$ & $\begin{array}{ll}1 & (2.2 \%) \\
5 & (11.1 \%) \\
\end{array}$ & $\begin{array}{ll}9 & (20.0 \%) \\
7 & (15.6 \%) \\
\end{array}$ \\
\hline \multirow[t]{3}{*}{$\begin{array}{l}\text { Cohort } 3 \\
\text { English } \\
\text { Maths }\end{array}$} & $\begin{array}{lr}4 & (13.8 \%) \\
2 & (6.9 \%)\end{array}$ & $\begin{array}{ll}3 & (10.3 \%) \\
6 & (20.7 \%)\end{array}$ & $\begin{array}{ll}14 & (48.3 \%) \\
14 & (48.3 \%)\end{array}$ & $\begin{array}{ll}3 & (10.3 \%) \\
4 & (13.8 \%)\end{array}$ & $\begin{array}{ll}5 & (17.2 \%) \\
3 & (10.3 \%)\end{array}$ \\
\hline & \multicolumn{5}{|c|}{ Year 9 (Key stage 3$)$} \\
\hline & $\begin{array}{l}\text { Below } \\
\text { expectation } \\
(95 \% \text { sig. }) \\
\end{array}$ & $\begin{array}{l}\text { Below } \\
\text { expectation } \\
(68 \% \text { sig. })\end{array}$ & As expected & $\begin{array}{l}\text { Above } \\
\text { expectation } \\
\text { ( } 68 \% \text { sig. })\end{array}$ & $\begin{array}{l}\text { Above } \\
\text { expectation } \\
\text { (95\% sig.) }\end{array}$ \\
\hline $\begin{array}{l}\text { Cohort } 1 \\
\text { (excluding class } \\
\text { ability) } \\
\text { English } \\
\text { Maths }\end{array}$ & $\begin{array}{l}10(20.4 \%) \\
11(25.0 \%)\end{array}$ & $\begin{array}{r}10(20.4 \%) \\
5(11.4 \%)\end{array}$ & $\begin{array}{c}13(26.5 \%) \\
9(20.5 \%)\end{array}$ & $\begin{array}{l}4(8.2 \%) \\
2(4.5 \%)\end{array}$ & $\begin{array}{c}12(24.5 \%) \\
17(38.6 \%)\end{array}$ \\
\hline $\begin{array}{l}\text { Cohort 1 } \\
\text { (including class } \\
\text { ability) } \\
\text { English } \\
\text { Maths }\end{array}$ & $\begin{array}{l}8(16.3 \%) \\
7(15.3 \%)\end{array}$ & $\begin{array}{l}3(6.1 \%) \\
3(6.8 \%)\end{array}$ & $\begin{array}{l}26(53.1 \%) \\
19(43.2 \%)\end{array}$ & $\begin{array}{l}6(12.2 \%) \\
\quad 5(11.4 \%)\end{array}$ & $\begin{array}{l}6(12.2 \%) \\
\quad 10(22.7 \%)\end{array}$ \\
\hline $\begin{array}{l}\text { Cohort } 2 \\
\text { (excluding class } \\
\text { ability) } \\
\text { English } \\
\text { Maths }\end{array}$ & $\begin{array}{r}7(24.1 \%) \\
13(30.2 \%)\end{array}$ & $\begin{array}{l}3(10.3 \%) \\
7(16.3 \%)\end{array}$ & $\begin{array}{ll}7 & (27.6 \%) \\
7 & (16.3 \%)\end{array}$ & $\begin{array}{l}6(20.7 \%) \\
2(4.7 \%)\end{array}$ & $\begin{array}{l}5(17.2 \%) \\
13(32.6 \%)\end{array}$ \\
\hline $\begin{array}{l}\text { Cohort } 2 \\
\text { (including class } \\
\text { ability) } \\
\text { English } \\
\text { Maths }\end{array}$ & $\begin{array}{l}4(13.8 \%) \\
8(18.6 \%)\end{array}$ & $\begin{array}{l}3(10.3 \%) \\
9(20.9 \%)\end{array}$ & $\begin{array}{l}16(55.2 \%) \\
13(30.2 \%)\end{array}$ & $\begin{array}{l}3(10.3 \%) \\
4(9.3 \%)\end{array}$ & $\begin{array}{l}3(10.3 \%) \\
9(20.9 \%)\end{array}$ \\
\hline $\begin{array}{l}\text { Cohort } 3 \\
\text { (excluding class } \\
\text { ability) } \\
\text { English } \\
\text { Maths }\end{array}$ & $\begin{array}{l}4(21.1 \%) \\
2(7.1 \%)\end{array}$ & $\begin{array}{l}4(21.1 \%) \\
5(17.9 \%)\end{array}$ & $\begin{array}{r}6(31.6 \%) \\
15(53.6 \%)\end{array}$ & $\begin{array}{l}1(5.3 \%) \\
2(7.1 \%)\end{array}$ & $\begin{array}{l}4(21.1 \%) \\
4(14.3 \%)\end{array}$ \\
\hline $\begin{array}{l}\text { Cohort } 3 \\
\text { (including class } \\
\text { ability) } \\
\text { English } \\
\text { Maths }\end{array}$ & $\begin{array}{l}5(26.3 \%) \\
2(7.1 \%)\end{array}$ & $\begin{array}{l}1(5.3 \%) \\
3(10.7 \%)\end{array}$ & $\begin{array}{r}7(36.8 \%) \\
18(64.3 \%)\end{array}$ & $\begin{array}{l}3(15.8 \%) \\
2(7.1 \%)\end{array}$ & $\begin{array}{l}3(15.8 \%) \\
3(10.7 \%)\end{array}$ \\
\hline
\end{tabular}

$$
++\mathrm{p}<0.05 \quad \mathrm{cl}=\text { confidence limit }
$$




\section{Summary}

The contextualized and value added analyses have pointed to the existence of significant variation between schools (Year 2) in pupil attainment (taking account of intake characteristics) and classes (Year 6 and 9) in pupil progress. Class level variation can be interpreted in relation to teacher effectiveness levels and variation is larger than in school effectiveness studies. The average ability level of the class is significant at KS 3 but over and beyond this there remains evidence of differences in teacher effects. The classification of teachers into one of five groups (from significant negative outlier to significant positive outlier) has been incorporated into the teacher profiles and has been treated as an additional feature of the quantitative analysis of variations in teachers lives and work and their effectiveness on pupils. 


\section{Appendix Three: Examples of Transition Teachers (Professional life phase)}

Continuity across professional life phases

0-3 'Developing sense of agency' --- 4-7 'sustained a strong sense of identity'

\section{0-3}

Positive influences:

school leadership, staff collegiality, teacherpupil relationships, CPD, pupil behaviour, personal

(no apparent negative influences)

\section{4-7}

Positive influences:

school leadership, staff collegiality, teacherpupil relationships, $\mathrm{CPD}$, pupil behaviour, personal

(no apparent negative influences)

\section{4-7 'Strong sense of identity' --- 8-15 'Sustained engagement'}

\begin{tabular}{l|l}
\hline 4-7 & $\mathbf{8 - 1 5}$ \\
Positive influences: & Positive influences: \\
Departmental leadership, staff collegiality, & Departmental leadership, staff collegiality, \\
teacher-pupil relationships, personal & teacher-pupil relationships, personal \\
Negative influences: & Negative influences: \\
School leadership, pupil behaviour, & School leadership, pupil behaviour, \\
workload, CPD, policy & workload, CPD, policy \\
\hline
\end{tabular}

8-15 'Sustained engagement' --- 16-23 'Increased motivation and commitment, further professional life advancement'

\begin{tabular}{|l|l}
\hline $\mathbf{8 - 1 5}$ & $\mathbf{1 6 - 2 3}$ \\
Positive influences: & Positive influences: \\
School leadership, CPD & CPD, school leadership, promotion \\
Negative influences: & Negative influences: \\
Personal, lack of work-life balance, policy, & Personal, lack of work-life balance, policy, \\
pupil behaviour & school leadership (Deputy Head) \\
\hline
\end{tabular}

16-23 'Sustained motivation and commitment' --- 24-30 'Increased self-efficacy, motivation and commitment'

\section{6-23}

Positive influences:

School leadership, staff collegiality, CPD, personal

Negative influences:

Pupil behaviour, CPD

\section{4-30}

Positive influences:

School leadership, staff collegiality, CPD, personal, permanent contract

Negative influences:

Pupil behaviour, CPD

\section{4-30 'Holding on but losing motivation' --- 31+ 'Tired and trapped'}

\section{4-30}

Positive influences:

Staff collegiality, teacher-pupil relationships, CPD

Negative influences:

\section{1+}

Positive influences:

Staff collegiality, teacher-pupil relationships, CPD

Negative influences: 
School leadership, pupil behaviour, personal, lack of work-life balance, policy
School leadership, pupil behaviour, personal, lack of work-life balance, policy

\section{Discontinuity across professional life phases}

\section{4-7 'Identity, efficacy and effectiveness as risk' --- 8-15 'Sustained engagement'}

\section{4-7}

Positive influences:

Headteacher support, staff collegiality, teacher-pupil relationships, CPD

\section{Negative influences:}

Pupil behaviour, personal, lack of work-life balance, policy, heavy workload

\section{8-15}

Positive influences:

Headteacher support, staff collegiality, teacher-pupil relationships, CPD, change of year groups and additional responsibility

Negative influences:

Personal, work-life tensions, policy

\section{4-7 'Identity, efficacy and effectiveness as risk' --- 8-15 'Sustained engagement'}

4-7

Positive influences:

School leadership, staff collegiality, teacherpupil relationships, CPD

\section{Negative influences:}

Policy, personal, lack of work-life balance, target-driven culture, pupil behaviour, policy, lack of support from departmental leadership

\section{8-15}

\section{Positive influences:}

School/departmental leadership, staff collegiality, teacher-pupil relationships, CPD, promotion (new job), personal

\section{Negative influences:}

Target-driven culture, pupil behaviour, policy

\section{4-7 'Sustained identity and effectiveness' --- 8-15 'Loss of motivation'}

4-7

Positive influences:

Staff collegiality, teacher-pupil relationships, pupil behaviour, improved work-life balance Negative influences:

School/departmental leadership, personal, CPD

\section{8-15}

Positive influences:

School/departmental leadership, staff collegiality, teacher-pupil relationships, pupil behaviour

\section{Negative influences:}

Internal and external policies and initiatives, personal, lack of work-life balance, CPD 


\section{Career Phase 0-3 (N=26: 9xP, 17xS)}

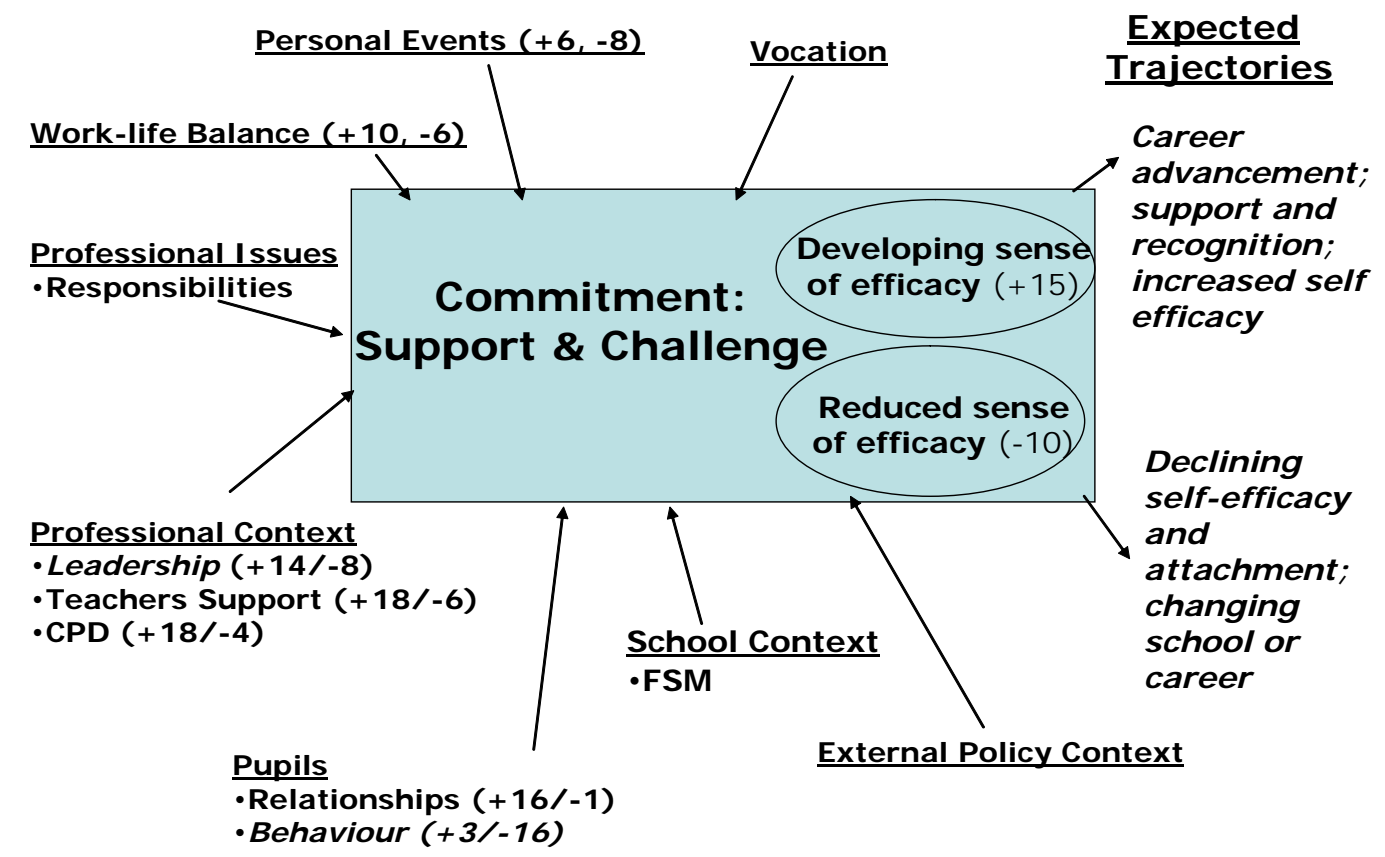

\section{Career Phase 4-7 (N=75: 36xP, 39xS)}

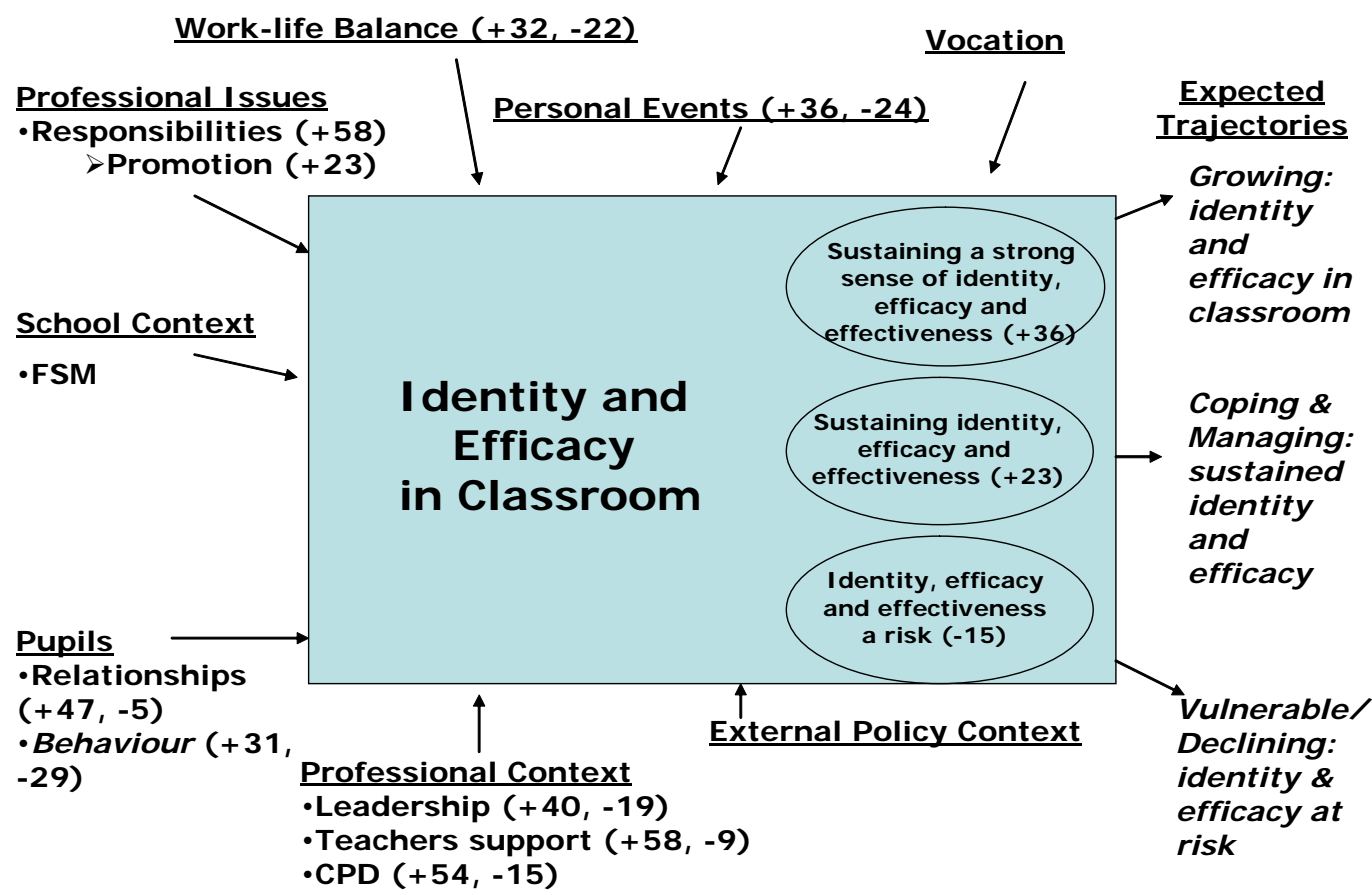




\section{Career Phase 8-15 (N=86: 51xP, 35xS)}

Work-life Balance $(+27,-32)$

-Tensions of time/ stress management

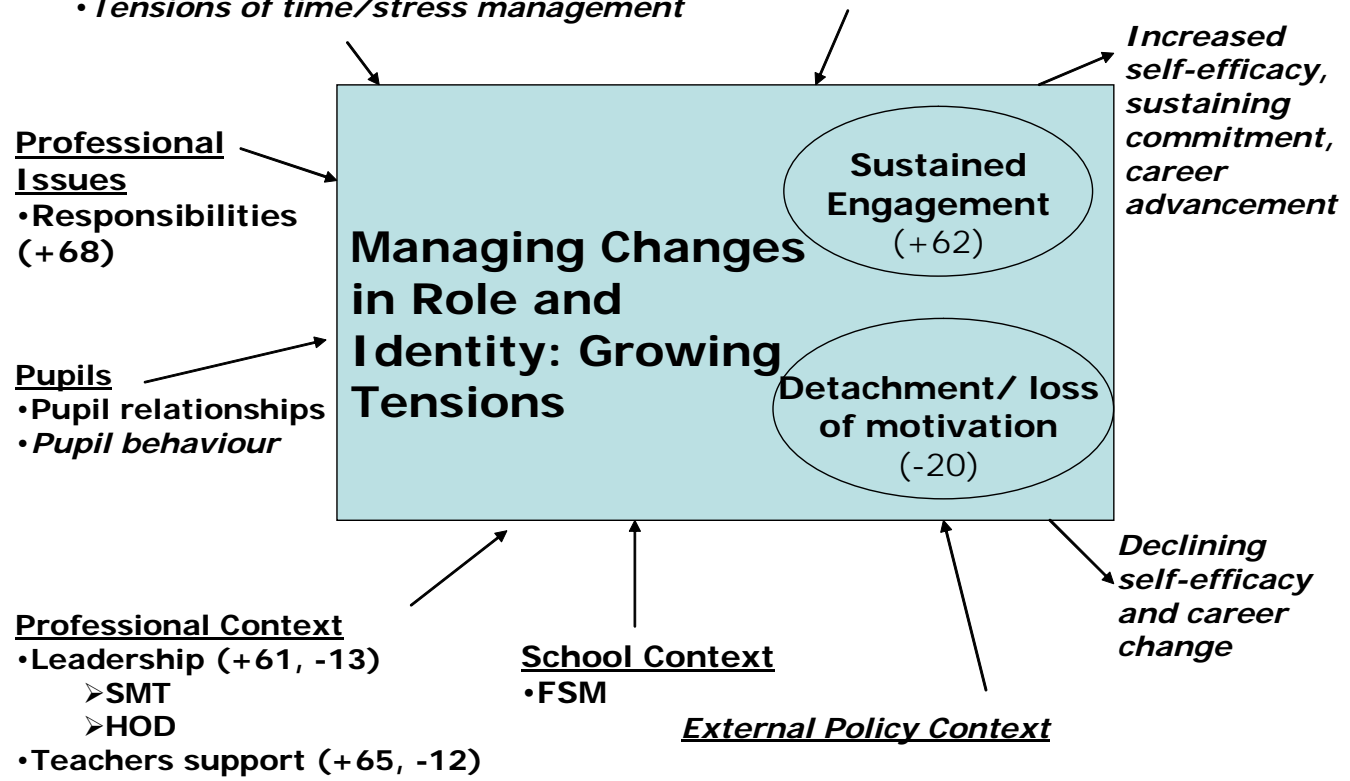

\section{Career Phase 16-23 ( $\mathrm{N}=46: 27 x \mathrm{P}, 19 x \mathrm{~S})$}

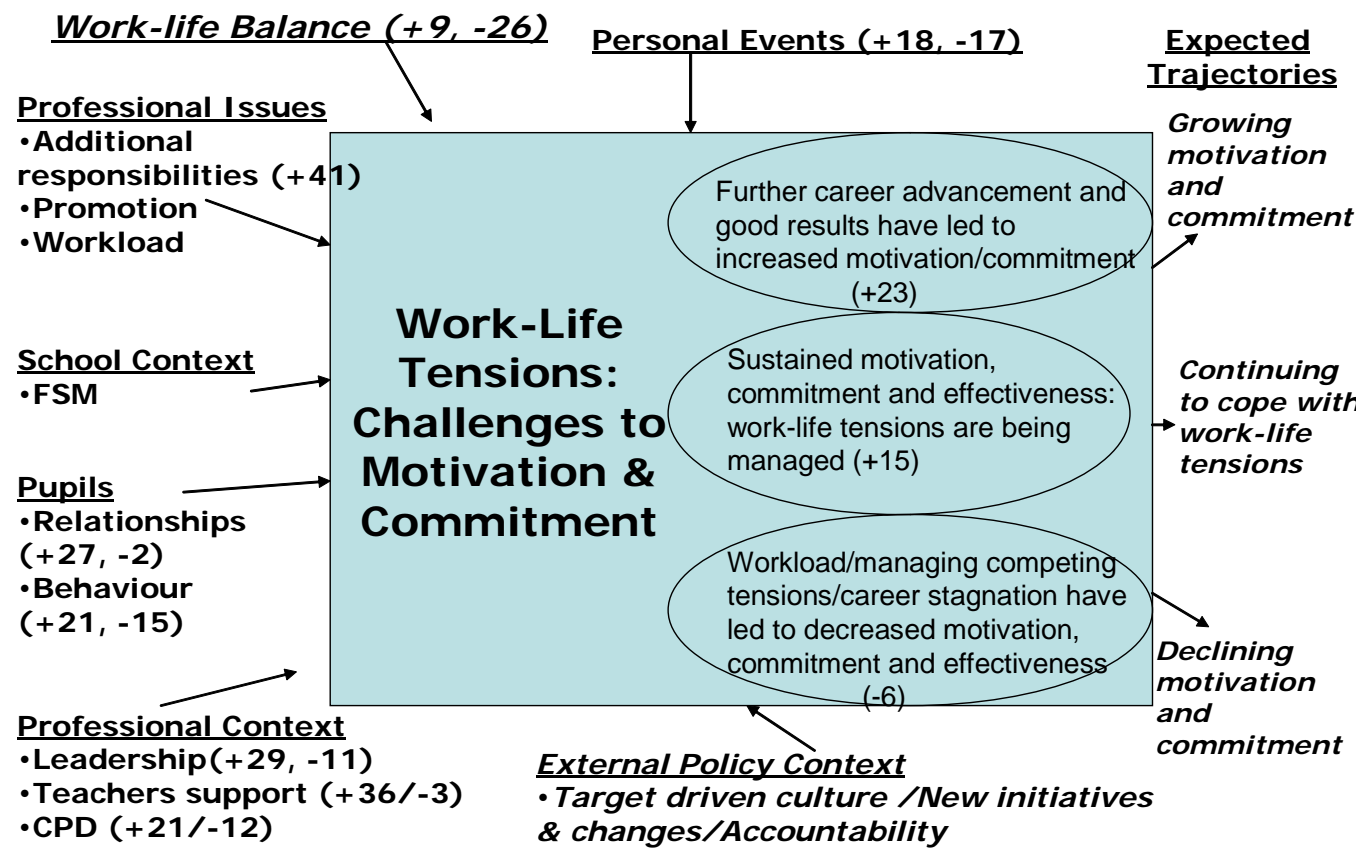




\section{Career Phase 24-30 ( $\mathrm{N}=52: 32 \times \mathrm{P}, 20 \times \mathrm{S})$}

Work-life Balance $(+14 /-22)$

-Tensions of time/ stress management
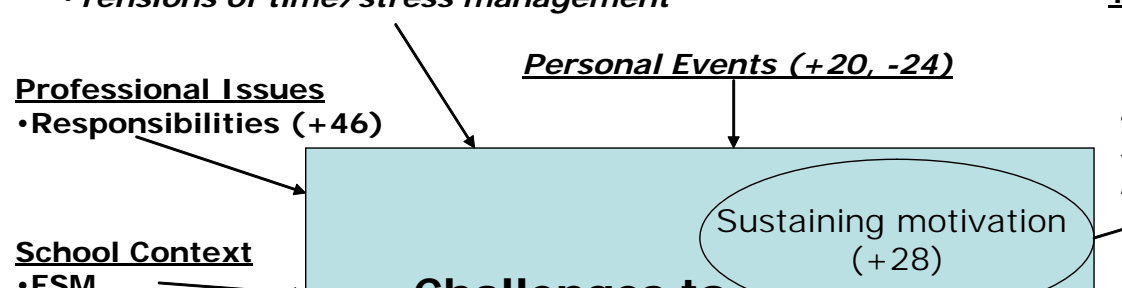

-FSM

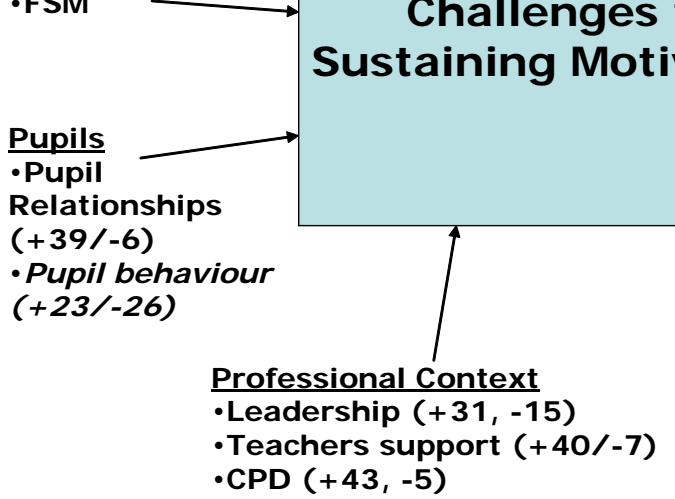
-Accountability

- I nclusion policy

-Targets and initiatives

\section{Expected}

Trajectories

work-life adjustment/ sustaining motivation

\section{Career Phase 31+ (N=22: 11xP, 11xS)}

Work-life Balance $(+6 /-11)$

-Tensions of time/ stress management

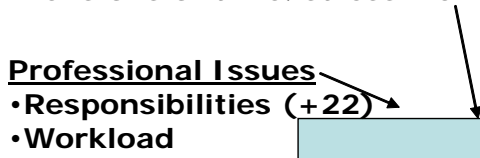

Personal Events $(+13,-6)$

Expected

External Policy Context detachment/ disenchantment

-Workload

School Context -FSM

$\frac{\text { Pupils }}{\text {-Pupil }}$ relationships

$(+15 /-3)$

-Pupil behaviour $(+8 /-10)$ -Leadership $(+19,-2)$ -Teachers support $(+22)$ -CPD (+14, -7)
Trajectories

\section{Strong} agency/ efficacy/ moral purpose/ achievement
Maintaining Commitment $(+14)$ Declining Motivation, Ability to Cope with Change, Looking to Retire

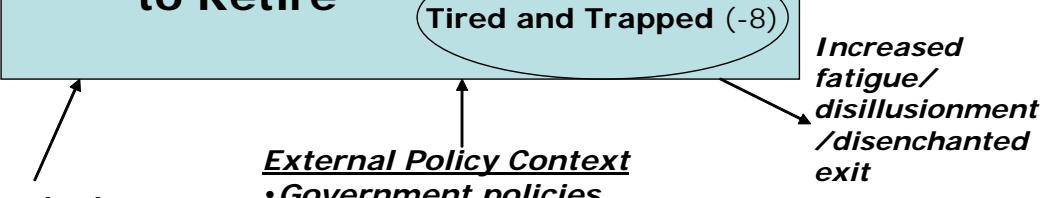

-Government policies

(0/-19)

-Accountability 
Copies of this publication can be obtained from:

\author{
DfES Publications \\ P.O. Box 5050 \\ Sherwood Park \\ Annesley \\ Nottingham \\ NG15 ODJ
}

Tel: 08456022260

Fax: 08456033360

Minicom: 08456055560

Oneline: www.dfespublications.gov.uk

\title{
(c) Crown Copyright 2006
}

Produced by the Department for Education and Skills

ISBN 1844787281

Ref No: RR743

www.dfes.go.uk/research 